\title{
FLOW AND HEAT TRANSFER PHENOMENA IN AERATED VIBRATED BEDS
}

\author{
by \\ ERROL R. A. ECCLES \\ Department of Chemical Engineering \\ McGill University, Montreal
}

A Thesis submitted to the Faculty of Graduate Studies and Research in partial fulfillment of the requirements

for the degree of Doctor of Philosophy

McGill University

Montreal, Canada

April 1990

(C) Errol R. A. Eccles 
In loving memory of my brother, Lincoln Everton George Eccles 


\begin{abstract}
Flow characteristics including resonance phenomena, bubble phenomena, particle circulation and mixing patterns as well as surface-to-bed heat transfer in aerated vibrated beds were studied experimentally. Beds of various model particles were vibrated in the vertical direction with a frequency varying from $0-25 \mathrm{~Hz}$ and halfamplitude from $0-4 \mathrm{~mm}$. Alumina, glass beads and molecular sieve particles of sizes ranging from $6 \mu \mathrm{m}$ to $3600 \mu \mathrm{m}$ were used as the model particles. Air flow rates through holes in the bottom plates varied from 0 to 4 times the minimum fluidizing velocity with one, five or a multiplicity of holes. The resonance phenomenon was characterized by a sudden bed expansion and intense surface agitation; this phenomenon was generally observed only in beds of small particles $\left(d_{p}<250 \mu \mathrm{m}\right)$. Bubble sizes increased while the bubble rise velocities decreased with increasing vibration frequency. An analytical model was developed to predict the resonant frequency assuming that the aerated vibrated bed behaves as a porous piston undergoing reciprocating motion at the applied trequency. Contact heat transfer between an immersed circular cylinder and the vibrated bed was found to be a function of particle circulation which, in turn, depends on the vibration parameters. Particle circulation is maximal at the point at which the bed displayed resonant behaviour. The cylinder-to-bed heat transfer coefficient is also maximal at resonance. A correlation is proposed for the surface-to-bed heat transfer based on these features.
\end{abstract}




\section{RESUME}

Les caracteristiques aérodynamiques d'un lit aéré en vibratıon, comprenant les phénomènes dus a la résonance et aux bulles, la circulation et le mélange des particules, ainsi que le transfert de chaleur entre une surface chauffante et le lit ont été étudiés expérimentalement. Des lits de diverses particules-modeles ont été étudiés en vibration dans la direction verticale à une fréquence variant de $0-25 \mathrm{~Hz}$ et une demi-amplitude de $0-4 \mathrm{~mm}$. De l'alumine, des bılles de verre. et des particules de tamis moléculaires de talle $6 \mu \mathrm{m}$ a $3600 \mu \mathrm{m}$ turent utılisées comme particules-modeles. Le débit d'air passant par des trous dans les plaques sous le lit variait de 0 a 4 fois la vitesse minimale de fluidisation pour un, cinq, ou une multiplicité de trous. Le phénomène de résonance était caractérisé par une expansion soudaine du lit et une agitation intense de la surface; ce phénomene a généralement été observé seulement dans les lits de petites particules $\left(d_{p}<250\right.$ $\mu \mathrm{m})$. La dimension des bulles augmentait pendant que la vélocité de montée des bulles diminuait avec la croisssance de la fréquence de vibration. Un modele analytique est développé pour prédire la fréquence de résonance en supposant que le lit aéré en vibration se comporte comme un piston poreux animé d'un mouvement alternatif a la fréquence appliquée. Le transfert de chaleur par contact entre un cylindre circulaire immergé et le lit en vibration est avéré être tonction de la circulation des particules qui dépend elle-meme des parametres de vibraton. La circulation des particules est maximale au point de resonance dans le lit. Le coefficient de transfert de chaleur du cylindre au lit est aussi maximal a la résonance. Une corrélation pour le transfert de chaleur de la surface au lit basé sur ces caractéristiques est proposée. 


\section{ACKNOWLEDGEMENTS}

The author is indeed indebted to his research advisor, Professor A. S. Mujumdar for his constant supervision and suggestions throughout the work.

The author is grateful to Dr. Karoly Erdesz of Veszprem, Hungary, for his contributions to this work both during his time spent at McGill University and afterwards.

The author wishes to thank the members of the Chemical Engineering Machine Shop particularly Mr. Walter Greenland who did most of the fabrication. The author acknowledges the periodic advice offerred by Professor Weber. Thanks also to other members of the departmental staff who contributed in some way or another to my completing this work. The author also wishes to thank Mr. David Mulligan for his assistance in proofreading this thesis. Thanks to the persons with whom I shared Lab PP 8, particularly Mr. Gouhua Chen, Dr. Bing Huang, Dr. Suna Polat and Dr. Osmen Polat who made life more bearable.

The author is grateful to the Association of Universities and Colleges of Canada for financial support during his stay in Canada. Alcan Aluminium Ltd. provided the alumina for this work and their generosity is thankfully acknowledged.

Finally, it is not very often that one has a wife for a colleague, particularly in such related work. My wife, Teresa, not oriy helped me in my work, but also played a patient, understanding and supporting role even though she had to keep my life in order and complete her masters thesis as well. 
TABLE OF CONTENTS

$\begin{array}{ll}\text { ABSTRACT } & \mathrm{i} \\ \text { RESUME } & \mathrm{ii} \\ \text { ACKNOWLEDGEMENTS } & \mathrm{iii} \\ \text { TABLE OF CONTENTS } & \text { iv } \\ \text { LIST OF TABLES } & \text { viii } \\ \text { LIST OF FIGURES } & \text { ix } \\ \text { NOMENCLATURE } & \text { xvi }\end{array}$

CHAPTER 1. INTRODUCTION 1

CHAPTER 2. REVIEW OF RELATED

$2.1 \quad$ INTRODUCTION 5

2.2 AERODYNAMICS OF VIBRATED BEDS 5

2.2.1 Bed Dynamics 5

2.2.2 Models for Vibrated and Aerated Vibrated Beds 11

2.2.3 Particle Circulation 13

2.2.4 Shape of Surface 15

2.2.5 Resonance Phenomenon 16

2.2.6 Mixing 18

2.2.7 Inter-Particle Effects 18

2.2.8 Wall Effects 19

2.2.9 Bubbles in Gas-Fluidized Beds 20

2.3 HEAT TRANSFER IN VIBRATED BEDS 22

2.3.1 Effect of Vibrational Parameters 22

2.3.2 Effect of Surface Location and Orientation 22

2.3.3 Effect of Particle Size 24

2.3.4 Effect of Particle Circulation and Mixing 24

2.3.5 Effect of Gas Medium 25

2.3.6 Mechanism of Heat Transfer 26

2.4 CLOSURE 28 
CHAPTER 3. EXPERIMENTAL APPARATUS 29 AND PROCEDURE

3.1 EXPERIMENTAL APPARATUS 29

3.1.1 Vibration System $\quad 29$

3.1.2 Air Supply 32

3.1.3 Vessels and Bottom Plates 32

3.1.4 Heat Transfer Probe 36

3.1.5 Auxiliary Equipment 36

$\begin{array}{lll}3.1 .6 \text { Materials } & 39\end{array}$

3.2 EXPERIMENTAL PROCEDURE 39

3.2.1 Resonance Phenomenon 39

3.2.2 Bubble Phenomena 40

3.2.3 Particle Flow and Mixing 44

3.2.4 Heat Transfer 45

CHAPTER 4. $\quad$ RESONANCE PHENOMENA

$\begin{array}{lll}4.1 & \text { INTRODUCTION } & 49\end{array}$

4.2 GENERAL FEATURES 50

4.3 THEORETICAL ANALYSIS 53

4.3.1 Surface Waves in Liquids 53

4.3.2 Surface Waves in Aerated Vibrated Beds 55

4.3.3 Theoretical Model 56

4.4 RESULTS AND DISCUSSION 63

4.4.1 Resonance in Cylindrical Bed 67

4.4.2 Resonance in Rectangular Bed 74

4.4.3 Effect of Particle Size and Type 79

4.4.4 Effect of the Bottom Distributor Plate 80

4.4.5 Effect of Air Flow 80

4.4.6 Bed Pressure Drop and Resonance 82

$\begin{array}{lll}4.5 & \text { CLOSURE } & 83\end{array}$ 
CHAPTER 5. BUBBLE PHENOMENA

$\begin{array}{lll}5.1 & \text { INTRODUCTION } & 84\end{array}$

$\begin{array}{lll}5.2 & \text { RESULTS AND DISCUSSION } & 85\end{array}$

5.2.1 Bubble Formation $\quad 86$

5.2.1 Frequency of Bubble Formation 90

$\begin{array}{lll}\text { 5.2.3 Bubble Size } & 97\end{array}$

5.2.4 Bubhle Rise Velocity 100

5.2.5 Bubble Shape 104

5.2.6 Some General Bubble Characteristics 108

5.2.7 Effect of Immersed Surfaces on Bubbling 108

5.2.8 Bubble Splitting and Coalescence 109

5.2.9 Correlation of Data using Dimensionless Groups 109

5.3 IMPLICATIONS FOR DESIGN 111

$\begin{array}{lll}5.4 \text { CLOSURE } & 112\end{array}$

CHAPTER 6. FLOW CHARACTERISTICS - MIXING 113 AND PARTICLE FLOW PATTERNS

$\begin{array}{lll}6.1 & \text { INTRODUCTION } & 113\end{array}$

6.2 FLOW CHARACTERISTICS IN BEDS WITHOUT 114 INTERNALS

6.2.1 Flow Characteristics for Small-Particle Beds (Alumina) 114

6.2.2 Flow Characteristics for Beds of Glass Beads 118

6.2.3 Flow Characteristics for Mixtures: Beds of 120 Glass Beads and Alumina

6.2.4 Mechanism of Solid Circulation in Small-Particle Beds 121

6.2.5 Flow Characteristics in Non-Aerated Beds 126

6.2.6 Mechanism of Solid Circulation in Non-Aerated 128 Vibrated Beds

6.2.7 Flow Characteristics for Molecular Sieve Particles $\quad 130$

6.2.8 Mechanism of Solid Circulation in Large-Particle Beds 131

6.3 FLOW CHARACTERISTICS OF ALUMINA IN A BED 134 WITH INTERNALS

6.3.1 Effect of a 20-mm Diameter Circular Cylinder 
6.3.2 Effect of a 40-mm Diameter Circular Cylinder 138

6.3.3 Mechanism of Solid Circulation in Beds with Internals 138

6.4 IMPLICATIONS FOR DESIGN $\quad \$ 40$

$\begin{array}{lll}6.5 & \text { CLOSURE } & 141\end{array}$

CHAPTER 7. SURFACE-TO-BED HEAT TRANSFER 143

$\begin{array}{lll}7.1 & 1 & 143\end{array}$

$\begin{array}{lll}7.2 & \text { EXPERIMENTAL RESULTS } & 143\end{array}$

$\begin{array}{lll}\text { 7.2.1 Particle Surface Coverage } & 144\end{array}$

$\begin{array}{lll}\text { 7.2.2 Heat Transfer } & 146\end{array}$

$\begin{array}{lll}7.3 & \text { DATA CORRELATION } & 175\end{array}$

7.3.1 Heat Transfer Mechanism: S̈eneral Features 175

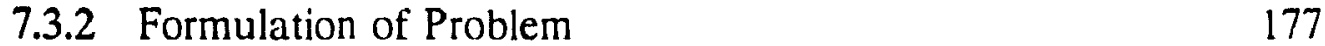

$\begin{array}{ll}\text { 7.3.3 The Fit of the Correlation } & 184\end{array}$

$\begin{array}{ll}\text { 7.3.4 Limitations of the Correlation } & 186\end{array}$

$\begin{array}{lll}7.4 & \text { IMPLICATIONS FOR DESIGN } & 186\end{array}$

$\begin{array}{lll}7.5 & \text { CLOSURE } & 188\end{array}$

CHAPTER 8. CONCLUSIONS AND CONTRIBUTIONS TO KNOWLEDGE

8.1 CONCLUSIONS

8.2 CONTRIBUTIONS TO KNOWLEDGE 191

REFERENCES 193 


\section{LIST OF TABLES}

TABLE

PAGE

Table $3.1 \quad$ Particle thermophysical properties.

Table 3.2 Maximum experimental uncertainty of variables. 48

Table 4.1 Properties of particles used.

Table 7.1 Fractional particle coverage of cylnder surface with air flow through a bottom plate with one central hole.

Taóle 7.2 Maximum heat transfer coefficients in aerated vibrated beds.

Table 7.3 Maximum heat transfer coefficients in vibrated beds in this and other studies. 


\section{LIST OF FIGURES}

FIGURE

PAGE

Figure 2.1 Motion of a vibrated bed and vessel;

$t_{0}$ - vibrational period, $t_{1}$ - instant of bed-vessel separation, $t_{c}$ - instant of bed-vessel collision.

Figure 3.1 Experimental set-up.

Figure 3.2 Vibration mechanism:

a - Drive mechanism (vibrating rods connected to vibrating vessel base); $b$ - Amplitude adjustment (adjusted by changing eccentricity).

Figure 3.3 Single-aperture and perforated bottom plates:

$a$ - for rectangular column, $b$ - for cylindrical column.

Figure 3.4 Rectangular vessel.

Figure 3.5 Cylindrical vessel and its associated

vibrating plate and coupling.

Figure 3.6 Heat transter probe.

Figure 3.7 Equipment set-up for video recordings.

Figure 4.1 The resonating bed: Particle type alumina $-d_{p}=100-\mu \mathrm{m}$,

$\mathrm{H}_{0}=80 \mathrm{~mm}, \mathrm{~A}=2 \mathrm{~mm}, \mathrm{f}=25 \mathrm{~Hz}, \mathrm{U} / \mathrm{U}_{\mathrm{mf}}=0.65$, $\mathrm{W}=20 \mathrm{~mm}$ ).

Figure 4.2 The vibratıng liquid (ethylene glycol) column:

(a) $\mathrm{H}_{0}=300 \mathrm{~mm}, \mathrm{~A}=1.92 \mathrm{~mm}, \mathrm{f}=10.5 \mathrm{~Hz}$;

(b) $\mathrm{H}_{0}=300 \mathrm{~mm}, \mathrm{~A}=1.92 \mathrm{~mm}, \mathrm{f}=15.0 \mathrm{~Hz}$.

Figure 4.3 The aerated vibrated bed system as a porous piston.

Figure 4.4 The vibrating liquid column model for an aerated vibrated bed system.

Figure 4.5 Variation of bed height and pressure drop with trequency in 64 aerated vibrated beds of alumina particles at increasing static bed heights; (a) $\mathrm{H}_{0}=110 \mathrm{~mm}$ and (b) $\mathrm{H}_{11}=149 \mathrm{~mm}$. 
Figure 4.6 Variation of bed height and pressure drop with frequency in 65 aerater vibrated beds of alumina particles at increasing static bed heights; (a) $\mathrm{H}_{0}=261 \mathrm{~mm}$ and (b) $\mathrm{H}_{0}=334 \mathrm{~mm}$.

Figure 4.7 Variation of bed height with frequency in aerated 66 vibrated beds of alumina particles at very large bed heights.

(a) $\mathrm{H}_{0}=665 \mathrm{~mm}$ and (b) $\mathrm{H}_{0}=778 \mathrm{~mm}$.

Figure 4.8 Variation of resonance intensity factor (I) with static bed 68 height $\left(\mathrm{H}_{0}\right)$ for alumina particles in rectarigular column. (a) $d_{p}=0.100 \mathrm{~mm}$ and (b) $d_{p}=0.027 \mathrm{~mm}$.

Figure 4.9 Variation of resonant bed height with resonant trequency 70 for alumina particles $(100 \mu \mathrm{m})$ in the cylindrical bed.

Figure 4.10 Variation of resonant bed height with resonant frequency 71 for alumina particles $(100 \mu \mathrm{m})$ for different $A$ and $U / U_{m r}$ values in the cylindrical bed using the bottom plate with one central hole.

Figure 4.11 Variation of resonance intensity factor (l) with static bed height $\left(\mathrm{H}_{0}\right)$ for alumina particles in cylindrical column.

(a) $\mathrm{A}=1 \mathrm{~mm}$ and (b) $\mathrm{A}=2 \mathrm{~mm}$ (bottom plate with 5 holes).

Figure 4.12 Variation of resonance intensity factor (I) with static bed 73 height $\left(\mathrm{H}_{0}\right)$ for alumina particles in cylindrical column. (a) $A=4 \mathrm{~mm}$ and (b) $A=2 \mathrm{~mm}$.

Figure 4.13 Variation of resonant bed height with resonant frequency 76 for alumina particles $(100 \mu \mathrm{m})$ at different bed thicknesses for constant air flow and constant air flow per unit area in the rectangular bed using a bottom plate with one central hole.

Figure 4.14 Effect of the position of the single hole in the bottom plate on the variation of the resonant bed height with resonant frequency for alumina in the rectangular bed.

Figure 4.15 Effect of the particle size and type on the variation 78 of the resonant bed height with resonant frequency in the rectangular bed. 
Figure 5.1 Bubble formation in aerated vibrated beds with single hole in bottom plate.

(a) $\mathrm{f}=8 \mathrm{~Hz}, \mathrm{~A}=2 \mathrm{~mm}, \mathrm{H}_{0}=164 \mathrm{~mm}, \mathrm{U} / \mathrm{U}_{\mathrm{mi}}=0.65$ :

(b) $\mathrm{f}=15 \mathrm{~Hz}, \mathrm{~A}=2 \mathrm{~mm}, \mathrm{H}_{0}=164 \mathrm{~mm}, \mathrm{U} / \mathrm{U}_{\mathrm{mt}}=0.65$.

Figure 5.2 Bubble formation in aerated vibrated beds:

$\mathrm{U} / \mathrm{U}_{\mathrm{mf}}=0.65, A=2 \mathrm{~mm}$; (a), (b) and (c) single hole in bottom plate, (d) perforated bottom plate.

Figure 5.3 Effect of the excitation frequency on bubble frequency for $100-\mu \mathrm{m}$ alumina particles in a vibrated bed with a single central hole in the bottom plate.

Figure 5.4 Effect of the excitation frequency on bubble frequency for $100-\mu \mathrm{m}$ alumina particles incipiently fluidized in a vibrated bed.

Figure 5.5 Effect of the excitation frequency on bubble frequency for $360-\mu \mathrm{m}$ glass beads in a vibrated vessel with air forced through a single central aperture in the bottom plate.

Figure 5.6 Effect of the excitation frequency on bubble size for $100-\mu \mathrm{m}$ alumina particles in a vibrated vessel with a single central hole in the bottom plate.

Figure 5.7 Effect of the excitation frequency on bubble size for $100-\mu \mathrm{m}$ alumina particles incipiently fluidized in a vibrated bed.

Figure 5.8 Effect of the excitation frequency on bubbble size for $360-\mu \mathrm{m}$ glass beads in a vibrated vessel with air forced through a single central aperture in the bottom plate.

Figure 5.9 Effect of the excitation frequency on bubble rise velocity for $100-\mu \mathrm{m}$ alumina particles in a vibrated vessel with a single central hole in the bottom plate.

Figure 5.10 Effect of the excitation frequency on bubble rise velocity 103 for $100-\mu \mathrm{m}$ alumina particles incipiently fluidized in a vibrated bed.

Figure 5.11 Effect of the excitation frequency on bubble rise velocity for $360-\mu \mathrm{m}$ glass beads in a vibrated vessel with air forced through a single central aperture in the bottom plate. 
Figure 5.12 Bubble shapes in aerated vibrated beds of $100-\mu \mathrm{m}$ alumina 106 particles with a single hole in bottom plate.

$\mathrm{f}=24 \mathrm{~Hz}, \mathrm{~A}=2 \mathrm{~mm}, \mathrm{H}_{0}=112 \mathrm{~mm}, \mathrm{U} / \mathrm{U}_{\mathrm{m} f}=0.65$ :

Figure 6.1 Schematic flow patterns for AVB's of $100-\mu \mathrm{m}$ alumina particles with a single-aperture bottom plate, $\mathrm{U} / \mathrm{U}_{\mathrm{mr}}=0.65$ and $\mathrm{H}_{0}=110 \mathrm{~mm}$.

Figure 6.2 Schematic flow patterns for AVB's of $100-\mu \mathrm{m}$ alumina particles with a single-aperture bottom plate, $\mathrm{U} / \mathrm{U}_{\mathrm{mt}}=0.65$ and $\mathrm{H}_{0}=160 \mathrm{~mm}$.

Figure 6.3 Schematic flow patterns for AVB's of $100-\mu \mathrm{m}$ alumina particles with a single-aperture bottom plate, $\mathrm{U} / \mathrm{U}_{\mathrm{m} \varepsilon}=0.65$ and $\mathrm{H}_{0}=260 \mathrm{~mm}$.

Figure 6.4 Schematic flow patterns for AVB's of $100-\mu \mathrm{m}$ alumina particles at resonance with a single-aperture bottom plate for different $\mathrm{H}_{0}$ values and $\mathrm{U} / \mathrm{U}_{\mathrm{m} t}=0.65$.

Figure 6.5 Schematic flow patterns for AVB's of $360-\mu \mathrm{m}$ glass beads at resonance with a single-aperture bottom plate for different $\mathrm{H}_{0}$ and $\mathrm{U} / \mathrm{U}_{\mathrm{mf}}$ values: (a), (b) $\mathrm{H}_{0}=110 \mathrm{~mm}$ (c) $\mathrm{H}_{0}=200 \mathrm{~mm}$ (d), (e) $\mathrm{H}_{0}=300 \mathrm{~mm}$.

Figure 6.6 Mixing of $100-\mu \mathrm{m}$ alumina particles and $360-\mu \mathrm{m}$ glass beads in an AVB with a single-aperture bottom plate, $\mathrm{U} / \mathrm{U}_{\mathrm{mt}}=0.65$ and $\mathrm{H}_{\mathrm{a}}=150 \mathrm{~mm}$ (50 mm alumina on top of $100 \mathrm{~mm}$ glass beads).

Figure 6.7 Schematic flow patterns for non-aerated vibrated beds of $100-\mu \mathrm{m}$ alumina particles for $\mathrm{H}_{0}=110 \mathrm{~mm}$.

Figure 6.8 Schematic flow patterns for non-aerated vibrated beds of $100-\mu \mathrm{m}$ alumina particles for $\mathrm{H}_{0}=210 \mathrm{~mm}$.

Figure 6.9 Schematic flow patterns for AVB's of 1.4-mm molecular sieve particles with a single-aperture botttom plate, $\mathrm{U} / \mathrm{U}_{\mathrm{mf}}=0.5$ and $\mathrm{H}_{0}=135 \mathrm{~mm}$.

Figure 6.10 Schematic flow patterns for AVB's of 1.4-mm molecular sieve particles with a single-aperture botttom plate, $\mathrm{U} / \mathrm{U}_{\mathrm{mf}}=0.5$ and $\mathrm{H}_{0}=200 \mathrm{~mm}$. 
Figure 6.11 Schematic flow patterns for AVB's of 1.4-mm molecular sieve particles with a perforated botttom plate, (a) $\mathrm{U} / \mathrm{U}_{\mathrm{mt}}=0.6$; (b) $\mathrm{U} / \mathrm{U}_{\mathrm{mt}}=1 ;$ (c) $\mathrm{U} / \mathrm{U}_{\mathrm{mt}}=2$.

Figure 6.12 Schematic flow patterns at resonance for $210-\mathrm{mm}$ high

AVB's of $100-\mu \mathrm{m}$ alumina particles with a $20-\mathrm{mm}$ circular cylinder located $100 \mathrm{~mm}$ from the sides and above the bottom plate with a single aperture,

(a) and (b) $U / U_{m f}=0$ and (c) $U / U_{m f}=0.65$.

Figure 6.13 Schematic flow patterns for 110-mm high AVB's of $100-\mu \mathrm{m}$ alumina particles with a $20-\mathrm{mm}$ circular cylinder located $100 \mathrm{~mm}$ from the sides above a perforated bottom plate with $\mathrm{U} / \mathrm{U}_{\mathrm{m} t}=1$.

Figure 6.14 Schematic flow patterns for 220-mm high AVB's of $100-\mu \mathrm{m}$ alumina particles with a $20-\mathrm{mm}$ circular cylinder located $100 \mathrm{~mm}$ from the sides above a perforated bottom plate with $U / \mathrm{U}_{\mathrm{m} t}=1$. (A solid circle reprepresents the cylinder).

Figure 6.15 Schematic flow patterns for 185-mm high AVB's of $100-\mu \mathrm{m}$ alumina particles with a $40-\mathrm{mm}$ circular cylinder located $100 \mathrm{~mm}$ from the sides above a perforated bottom plate with $\mathrm{U} / \mathrm{U}_{\mathrm{m} t}=1$.

Figure 7.1 Schematic representation of particle surface coverage of heat transfer tube.

Figure 7.2 Schematic time-averaged air gaps around a 20-mm circular 148 cylinder in a bed of $100-\mu \mathrm{m}$ alumina particles as a function of time (each step $=0.0167 \mathrm{~s}$ ):

(a) $\mathrm{H}_{0}=215 \mathrm{~mm}, \mathrm{U} / \mathrm{U}_{\mathrm{m} t}=0, \quad \mathrm{f}=16 \mathrm{~Hz}, \mathrm{~A}=2 \mathrm{~mm}$;

(b) $\mathrm{H}_{0}=215 \mathrm{~mm}, \mathrm{U} / \mathrm{U}_{\mathrm{mf}}=0.65, \mathrm{f}=15 \mathrm{~Hz}, \mathrm{~A}=2 \mathrm{~mm}$.

Figure 7.3 Schematic time averaged air gaps around a 20-mm circular cylinder in a bed of $1.4 \mathrm{~mm}$ molecular sieve particles as a function of time (each step $=0.0167 \mathrm{~s}$ ): $\mathrm{H}_{0}=205 \mathrm{~mm}, \mathrm{U} / \mathrm{U}_{\mathrm{mf}}=0.55, \mathrm{f}=16 \mathrm{~Hz}, \mathrm{~A}=2 \mathrm{~mm}$.

Figure 7.4 Effect of $\mathrm{f}$ on $\mathrm{h}$ for $100-\mu \mathrm{m}$ alumina particles in a vibrated 151 bed with a bottom plate with one hole for different $A$ values.

Figure 7.5 Effeci of $\mathrm{K}$ on $\mathrm{h}$ for $100-\mu \mathrm{m}$ alumina particles in a vibrated 152 bed with a bottom plate with one hole for different $A$ values. 
Figure 7.6 Effect of $\mathrm{F}$ on $\mathrm{Nu}$ for $100-\mu \mathrm{m}$ alumina particles in a vibrated 154 bed with a bottom plate with one hole for different $A$ values.

Figure 7.7 Effect of $\mathrm{K}$ on $\mathrm{Nu}$ for $100-\mu \mathrm{m}$ alumina particles in a vibrated 154 bed with a bottom plate with one hole for different $A$ values.

Figure 7.8 Typical effect of $\mathrm{f}$ on $\mathrm{h}$ for $100-\mu \mathrm{m}$ alumina particles in a 156 vibrated bed with a bottom plate with one hole.

Figure 7.9 Effect of $\mathrm{f}$ on $\mathrm{h}$ for $100-\mu \mathrm{m}$ alumina particles in a vibrated 158 bed with a bottom plate with one hole for different $\mathrm{H}_{0}$ values.

Figure 7.10 Variation of $E$ with $F$ for $100-\mu \mathrm{m}$ alumina particles in 158 a vibrated bed with a bottom plate with one hole for different $\mathrm{H}_{0}$ values.

Figure 7.11 Variation of $\mathrm{h}$ with $\mathrm{f}$ for $100-\mu \mathrm{m}$ alumina particles in 162 a vibrated bed with a bottom plate with one hole at different aeration rates.

Figure 7.12 Variation of $h$ with $\mathrm{f}$ for $100-\mu \mathrm{m}$ alumina particles in a vibrated bed with a bottom plate with one hole at different aeration rates and $\mathrm{H}_{0}$ values.

Figure 7.13 Effect of $f$ on $h$ for $100-\mu \mathrm{m}$ alumina particles in a vibrated bed with a bottom plate with one hole for $\mathrm{H}_{0}=155 \mathrm{~mm}$ and different $\mathrm{U} / \mathrm{U}_{\mathrm{mt}}$ and $A$ values.

Figure 7.14 Effect of $f$ on $h$ for $100-\mu \mathrm{m}$ alumina particles in a vibrated bed with a bottom plate with one hole for different probe locations and $\mathrm{H}_{0}=155 \mathrm{~mm}$.

Figure 7.15 Effect of $\mathrm{f}$ on $\mathrm{h}$ for $100-\mu \mathrm{m}$ alumina particles in a vibrated bed with a bottom plate with one hole for different cylindrical probe sizes and $\mathrm{H}_{0}=155 \mathrm{~mm}$.

Figure 7.16 Effect of $\mathrm{f}$ on $\mathrm{h}$ for particles of different sizes in a vibrated bed with a bottom plate with one hole for $\mathrm{H}_{0}=155 \mathrm{~mm}$.

Figure 7.17 Variation of $E$ with $f$ for particles of different sizes in a vibrated bed with a bottom plate with one hole for $\mathrm{H}_{0}=155 \mathrm{~mm}$. 
Figure 7.18 Effect of $\mathrm{f}$ on $\mathrm{h}$ for 1.4-mm molecular sieve particles in a 168 vibrated bed with a bottom plate with one hole for different A values and $H_{0}=155 \mathrm{~mm}$.

Figure 7.19 Effect of $f$ on $h$ for $100-\mu \mathrm{m}$ alumina particles in vibrated beds at different aeration rates and $\mathrm{H}_{0}=155 \mathrm{~mm}$.

Figure 7.20 Variation of $E$ with $\mathrm{f}$ for $100-\mu \mathrm{m}$ alumina particles in vibrated beds at different aeration rates and $\mathrm{H}_{0}=155 \mathrm{~mm}$.

Figure 7.21 Variation of $\mathrm{h}$ with $\mathrm{K}$ reported by various researchers.

Figure 7.22 Comparison of the variation of $h$ with $\mathrm{K}$ for $1.4-\mathrm{mm}$ molecular sieve particles for this study and previous work.

Figure 7.23 Comparison of the variation of $h$ with $\mathrm{K}$ for small particles for this study and previous work.

Figure 7.24 Comparison of experimental resuits with correlated results for $100-\mu \mathrm{m}$ alumina for different $\mathrm{H}_{0}$ values.

Figure 7.25 Comparison of experimental results with correlated results 185 for $100-\mu \mathrm{m}$ alumina for different $\mathrm{A}$ values.

Figure 7.26 Comparison of experimental results with correlated results 187 for different $d_{p}$ values. 


\section{NOMENCLATURE}

A half-amplitude of vibration, $m$

$A_{w} \quad$ amplitude of surface wave, $m$

$A_{c} \quad$ cylinder surface area, $\mathrm{m}^{2}$

$a_{d} \quad$ sound velocity in dispersed system, $\mathrm{ms}^{-1}$

$\mathrm{a}_{0} \quad$ sound velocity in at resonance, $\mathrm{ms}^{-1}$

b constant of regression equation (Equation 4.24)

$\mathrm{C}_{1} \quad$ constant (Equation 4.16)

$C_{\mathrm{IR}} \quad$ constant $\left(E C_{1}\right.$ dation $\left.4.22-\mathrm{C}_{\mathrm{IR}}=2 \pi(2 \mathrm{~m}-1) / 4\right)$

$C^{\circ}$ amplitude of response to $f(t)$

c damping coefficient of vibrating system, $\mathrm{kgs}$ '

$c_{8}$ heat capacity of air, $\mathrm{Jkg}^{-1} \mathrm{~K}^{1}$

$c_{p}$ heat capacity of particles, $\mathrm{Jkg}^{-1} \mathrm{~K}^{-1}$

$c_{\mathrm{v}}$ heat capacity of air, $\mathrm{Jkg}^{-1} \mathrm{~K}^{-1}$

$\mathrm{c}_{\mathrm{x}} \quad$ damping factor, $\mathrm{kg}$

D diameter of liquid column, mm

$d_{c} \quad$ cylinder diameter, $\mathrm{mm}$

$d_{b} \quad$ bubble size, $\mathrm{mm}$

$d_{h} \quad$ diameter of orifice in bottom plate, $\mathrm{mm}$

$d_{p} \quad$ mean diameter of solid particles, $m$

$d_{1} \quad$ diameter of cylindrical vessel, $m$

F force, $\mathrm{N}$

$F_{0} \quad$ magnitude of force, $\mathrm{N}$

f frequency of vibration, $\mathrm{Hz}$ 


\section{xvii}

$f_{b} \quad$ bubble frequency, $s^{-1}$

$\mathrm{f}_{\mathrm{r}} \quad$ resonant frequency of vibration, $\mathrm{Hz}$

$\mathrm{f}_{0} \quad$ threshold frequency of vibration, $\mathrm{Hz}$

$f(t) \quad$ forcing function

G air flow rate, $\mathrm{m}^{3} \mathrm{~s}^{-1}$

g acceleration due to gravity, $\mathrm{ms}^{-2}$

$\mathrm{H}$ bed height, $\mathrm{m}$

$\mathrm{H}_{0} \quad$ static bed height, m

$\mathrm{H}_{\mathrm{c}} \quad$ compacted bed height, $m$

$\mathrm{H}_{\mathrm{r}} \quad$ resonant bed height, $\mathrm{m}$

$\mathrm{h}$ average surface-to-bed heat transfer coefficient, $\mathrm{Wm}^{2} \mathrm{~K}^{-1}$

$h_{0} \quad$ average surface-to-bed heat transfer coefticient at $f=0 \mathrm{~Hz}, \mathrm{Wm}^{\prime} \mathrm{K}^{\prime}$

$\mathrm{h}_{\max } \quad$ maximum average surface-to-bed heat transfer coefficient, $\mathrm{Wm}^{\prime} \mathrm{K}^{\prime}$

I resonance intensity factor

k "stiffness" of elastic system, $\mathrm{kgs}^{-2}$

$\mathrm{k}_{0} \quad$ "stiffness" of vibratory system at resonance, $\mathrm{kgs}^{-2}$

K coefficient in Ryzhkov and Tolmachov's equation (Equation 4.20)

$k_{c} \quad$ effective non-aerated bed thermal conductivity, $\mathrm{Wm}^{\prime} \mathrm{K}^{1}$

$\mathrm{k}_{\mathrm{e}}{ }^{\circ} \quad$ effective gas-fluidized bed thermal conductivity, $\mathrm{Wm} \mathrm{m}^{\prime} \mathrm{K}$ '

$\mathrm{k}_{\mathrm{g}} \quad$ gas thermal conductivity, $\mathrm{Wm}^{-1} \mathrm{~K}^{1}$

$k_{p} \quad$ particle thermal conductivity, $\mathrm{Wm}^{-1} \mathrm{~K}^{-1}$

$l_{0} \quad$ initial length of gas cushion, $\mathrm{m}$

m vibrated mass, $\mathrm{kg}$

m constant in Ryzhkov and Tolmachov's equation (Equation 4.19)

M amplification factor 
$\mathrm{N}$ constant (Equation 7.5)

n number of orifices in bottom plate

$\mathrm{P}$ pressure, $\mathrm{Pa}$

Q heat transfer rate, $\mathrm{W}$

$\mathrm{R}$ gas constant

$\mathrm{S}$ cross-sectional area of tube, $\mathrm{m}^{2}$

s height of air gap, mm

$\mathrm{T}$ temperature, $\mathrm{K}$

$\mathrm{T}$, heater surface temperature, $\mathrm{K}$

$\mathrm{T}_{\mathrm{b}} \quad$ bed temperature, $\mathrm{K}$

$t$ time, $s$

$t_{c} \quad$ instant of bed collision, $s$

$\mathrm{t}_{0} \quad$ vibrational period, $\mathrm{s}$

$t$ instant of bed separation, $s$

$\mathrm{U}$ overall superficial gas velocity, $\mathrm{ms}^{-1}$

$\mathrm{U}_{\mathrm{br}} \quad$ bubble rise velocity, $\mathrm{ms}^{\prime}$

$\mathrm{U}_{\mathrm{m} t} \quad$ superficial minimum fluidization velocity, $\mathrm{ms}^{-1}$

$\mathrm{V}$ volume, $\mathrm{m}^{3}$

W bed thickness, mm

w particle surface coverage factor

$x_{1} \quad$ any variable

y displacement, $\mathrm{m}$

$y(t) \quad$ bed response to $f(t)$

$\mathrm{Al}_{2} \mathrm{O}_{3}$ Alumina

GB Glass beads 
MS molecular sieve

VB vibrated bed

AVB aerated vibrated bed

VB's aerated and non-aerated vibrated beds

VFB vibrated fluidized beds

\section{Greek letters}

$\alpha_{p} \quad$ particle thermal diffusivity, $\mathrm{m}^{2} \mathrm{~s}^{-1}$

$\gamma \quad$ adiabatic exponent

$\in$ porosity

$\epsilon_{\mathrm{r}} \quad$ porosity at resonance

$\theta \quad$ particle coverage, degrees

$\mu \quad$ viscosity of air, $\mathrm{kgm}^{1} \mathrm{~s}^{-1}$

$\rho_{b} \quad$ bed density, $\mathrm{kgm}^{-3}$

$\rho_{B} \quad$ gas density, $\mathrm{kgm}^{.3}$

$\rho_{1} \quad$ liquid density, $\mathrm{kgm}^{3}$

$\rho_{\mathrm{p}} \quad$ particle density, $\mathrm{kgm}^{-3}$

$\phi \quad$ phase angle, rad

$\phi \quad$ air gap coverage, degrees

$\phi_{s} \quad$ particle volume equivalent shape factor

$\omega \quad$ angular frequency $(2 \pi \mathrm{t}), \mathrm{s}^{1}$

$\omega_{r} \quad$ resonant angular frequency, $s^{\prime}$

$\omega_{0} \quad$ eigen-value angular frequency, $s^{-1}$

$\omega_{\max }$ maximum angular frequency, $\mathrm{s}^{-1}$

$\triangle \mathrm{P} \quad$ pressure drop, $\mathrm{Pa}$ 
$\Delta \mathrm{T} \quad$ temperature difference, $\mathrm{K}$

Dimensionless groups

E heat transfer enhancement factor $=\frac{h}{h_{0}}$

$\mathrm{E}_{\max }$ maximum heat transfer enhancement factor $=\frac{\underline{h}_{\max }}{\mathrm{h}_{0}}$

F frequency factor

$=\frac{\mathrm{f}}{\mathrm{f}_{\mathrm{r}}}$

$\mathrm{Fo}_{m} \quad$ modified Fourier number

$=\underline{d}_{p} \underline{i}$

$\mathrm{Ga}$ Galileo number

$=\frac{\rho_{g}\left(\rho_{\mu}-\rho_{g}\right) g d_{p-}^{3}}{\mu_{s}^{2}}$

I resonance intensity factor

$=A_{\text {w }}$

$2 \mathrm{~A}$

K vibration parameter

$=\frac{A \omega^{2}}{g}$

$\mathrm{K}_{\mathrm{cr}} \quad$ critical vibration parameter

$\mathrm{Nu}$ Nusselt number

$$
=\frac{\mathrm{hd}}{\mathrm{k}_{\mathrm{e}}}
$$

$\mathrm{Nu}_{\mathrm{m}} \quad$ modified Nusselt number

$$
=\frac{h d_{p}}{\hat{k}_{p}}
$$

Pr Prandtl number

$$
=\underline{\mathrm{c}}_{\mathrm{g}} \underline{\underline{\mathrm{k}}}
$$

Re Reynold's number

$$
=\underset{\mu}{\rho_{R} \bigcup_{p} \underline{U}}
$$




\section{CHAPTER 1. INTRODUCTION}

Despite their importance as gas-solid contactors, conventional gas-fluidized beds suffer from several major disadvantages such as bypassing of gas in bubbles (Davidson and Harrison (1963), Kunii and Levenspiel (1984)), channelling (Davidson and Harrison (1963)), inability to fluidize relatively large, polydisperse, sticky or agglomerating materials (Zenz (1983)), particle attrition (Kunii and Levenspiel (1984)), etc. The disadvantages have prompied the search for other gas-solid contactors to overcome these shortcomings. Application of mechanical vibration is one of the more successful techniques that have found industrial applications.

Gupta and Mujumdar (1980) and Mujumdar (1983) have listed the processing advantages of mechanically vibrated beds which include, uniform residence time distribution regardless of particle size, ability to handle beds of polydisperse particles, operability at low aeration rates and hence lower pressure drops, gentle handling of products, ability to handle sticky and agglomerating particles, and heat and mass transfer rates comparable to those of gas-fluidized beds even at much lower gas flow rates.

Mujumdar and Erdesz (1988) have reported on the widespread use of vibrated beds in the food industry. The major operation conducted in vibrated beds is the drying of solids (Mujumdar (1983) and (Mujumdar and Erdesz (1988)). Additionally, Mujumdar and Erdesz (1988) list other major operations involving use of vibrated beds which include heating, cooling, coating, granulation, etc., of particulate solids. Considerable potential exists for their use as chemical reactors (Mujumdar (1984) and 
Thomas and Squires (1989)).

Vibrated beds can be classified according to their operational regimes (Chlenov and Mikhailov (1972), Pakowski et al. (1984), Erdesz and Mujumdar (1987) and Thomas (1988)), The vibrational parameter, $\mathrm{K}$, is commonly defined as:

$$
\mathrm{K}=\frac{\mathrm{A} \omega^{2}}{\mathrm{~g}}=\frac{\text { Maximum vibratory acceleration }}{\text { Acceleration due to gravity }} .
$$

Many classification schemes are based on $\mathrm{K}$ and the minimum fluidization velocity, $U_{m \ell}($ Chlenov and Mikhailov (1972) and Pakowski et al. (1984)). In this thesis, the term vibrated bed (VB) refers to a non-aerated vibrated bed while one with aeration irrespective of the air flow rate or its distribution, is reterred to as an aerated vibrated bed (AVB). However, the term vibrated beds (VB's) will be used to refer collectively to all beds that are vibrated with or without aeration. The term vibrofluidization refers to the vibration-induced mobility of the particles. Additionally, in this thesis, gas-fluidized beds (or simply fluldized beds) refer to beds fluidized by aeration only i.e. without the application of vibration.

Despite their widespread use, the design of VB's still remains an art. Earlier work in VB's at McGill University had focussed on studies of large particles in shallow beds. Various designs and operating parameters need to be identified to find new operating regimes of VB's of small particles. Bubble phenomena in VB's have not been studied to date although, on the basis of visual observations with beds of large particles, Gupta and Mujumdar (1980) suggested that vibration impedes bubble 
coalescence. Particle flow and mixing in VB's of small particles under certain operating conditions have not been studied heretofore although they are important in governing contact heat transfer rates. Additionally, it is necessary to investigate the use of deeper vibrated beds of particles as they allow greater process throughput per unit area of cross-section.

This study examines the flow characteristics including the resonance phenomenon, bubble phenomena, particle circulation and mixing as well as contact heat transfer characteristics of small particles in relatively deep VB's.

The objectives of this work are:

1. To study the resonance phenomenon in vibrated beds of small particles $\left(d_{p}<250 \mu m\right)$

2. To study experimentally the influence of vibration on the frequency of bubble formation, bubble rise velocity and bubble size;

3. To characterize overall particle flow patterns and mixing in vibrated beds;

4. To study surface-to-bed heat transfer from horizontal circular cylinders immersed in vibrated beds with reference to the flow characteristics.

This thesis is divided into eight chapters. A brief review of the relevant literature is presented in Chapter 2. Chapter 3 describes the experimental apparatus and procedure while Chapter 4 presents experimental results and discusses the resonance 
phenomenon. The effect of vibration on the frequency of bubble formation, bubble rise velocity and bubble size is examined in Chapter 5 while particle flow patterns and mixing are discussed in Chapter 6. Chapter 7 discusses surface-to-bed heat transfer from a horizontal circular cylinder. Finally, Chapter 8 summarizes the conciusions of this work and the contributions to knowledge. 


\section{CHAPTER 2. REVIEW OF RELATED \\ LITERATURE}

\section{$2.1 \quad$ INTRODUCTION}

As Erdesz and Mujumdar (1987) have noted, vibrating systems comprise an exciting and an excited system; the excited system is that to which vibration is imparted. For the theory of vibration and vibratory systems, the interested reader is referred to the books of Myklestad (1956), Vernon (1967), Meirovitch (1975), and Newland (1984). This review will be concerned only with a specific excited system i.e. aerated and nonaerated vibrated beds of particles.

Erdesz and Mujumdar (1988) have compiled extensive bibliographies on all variants of vibrated beds of particles. Comprehensive reviews of the state of the art are presented by Pakowski et al. (1984), Sprung (1987) and Thomas (1988). This chapter

presents a brief review of recent literature on the main theme of this thesis, namely, aerodynamics and heat transfer characteristics of aerated vibrated beds. It is also worth noting at the onset that this study is primarily concerned with the special behaviour of beds of small particles $\left(d_{p}<250 \mu \mathrm{m}\right)$.

\subsection{AERODYNAMICS OF VIBRATED BEDS}

\subsubsection{Bed Dynamics}

\section{Pressure Oscillations}

In his work with beds of $130-$ and $290-\mu \mathrm{m}$ glass ballotini and $290-\mu \mathrm{m}$ sand particles, Kröll $(1954,1955)$ measured instantaneous pressure differentials between the floor of a non-aerated vibrating vessel containing particles and the free surface of the bed. 
He used vibrational frequencies of $23.3,50$ and $100 \mathrm{~Hz}$ and amplitudes of 3.72 and $1.42 \mathrm{~mm}$ in beds less than $160 \mathrm{~nm}$ high and obtained a cyclic variation of the pressure differential with respect to the vibrational cycle of the vessel. In absolute values, his maximum positive pressure differential was in all cases higher than the negative value.

Later, Chlenov and Mikhailov (1972) conducted similar experiments for a vibrated bed of quartz sand and reported time-averaged pressure differentials measured by a remote differential manometer connected to the bed by a narrow tube. However, unlike Kröll (1954), they consistently found negative floor pressures indicating net suction over the whole vibrational cycle; the effect increased with increasing values of the vibrational parameters. Chlenov and Mikhailov (1965) found the pressure differential to be a function of the vibrational conditions, bed dimensions, bed permeability, particle size distribution, particle moisture content and inter-particle forces. Like Chlenov and Mikhailov (1972), Bukareva et al. (1974) measured negative floor pressures. Moreover, they found that for identical vibrational conditions, the absolute value of the negative pressure increases with the bed height and particle density and decreases with an increase in the particle size or bed permeability.

Yamazaki et al. (1974) also observed pressure oscillations in aerated vibrated beds. They explained that for the particle sizes used $\left(d_{p}=114,210\right.$ and $\left.296 \mu \mathrm{m}\right)$, there were no pressure fluctuations for $\mathrm{K}<1$. However, for $\mathrm{K}>1$, they measured periodic pressure fluctuations and explained that these were caused by a pulsated gas flow which occurred in the bed due to its motion relative to the supporting perforated 
plate.

Arguing that Kröll's $(1954,1955)$ pressure data were not reliable and citing problems with the experimental techniques of Chlenov and Mikhailov, Gutman (1976a) used a high frequency $(15 \mathrm{kHz})$ pressure transducer and a small air volume between the transducer and the measuring point in vibrated beds. He reported that the frequency response of the pressure transducer and the air volume between the transducer and the measuring point both affected the results. His average pressure differentials were always positive. Contrary to the results of Chlenov and Mikhailov (1972), Gutman's measured maximum positive pressure differentials were greater than the absolute maximum negative pressure differentials in $40-\mathrm{mm}$ deep beds of $90-135-\mu \mathrm{m}$ ballotini. For large particles ( $385-495-\mu \mathrm{m}$ and $675-935-\mu \mathrm{m})$ in deep beds, Gutman (1976a) found that the amplitude of the pressure fluctuations tended to a limiting value with increasing bed height. Furthermore, for $90-135-\mu \mathrm{m}$ particles, the variation of pressure fluctuations with bed height is independent of bed diameter. Gutman's maximum pressure differential increased with vibrational acceleration and decreased with particle size.

\section{Air Gaps}

In his pioneering work, Bachmann (1940) found that vibrated beds behaved as a single mass when the bed heights were greater than six particle diameters. Furthermore, he found that layers of large particles $\left(d_{p}>400 \mu \mathrm{m}\right)$ would leave the floor of the vessel at the instant the gravitational deceleration of the particles was surpassed by that of the vibrating vessel. The particles move under the force of gravity until they collide with the vessel later in the vibrational cycle. They then 
follow the vessel trajectory until a new "lift-off" occurs. An air gap would then form between the bottom of the particulate layer and the floor of the vessel during vibration. This is shown in Figure 2.1. Bachmann treated the movement of the rigid bed as a single particle moving under the action of gravity after leaving the floor of the vessel with an initial velocity corresponding to that of the vessel velocity at lift-off.

Kröll (1955) recognized the importance of floor pressures on bed dynamics and reported oscillatory gas movement through the bed induced by pressure fluctuations. This exerted an additional drag force on the particles reducing both the size of the air gap formed and the time of flight. The effect was more noticeable with decrease in particle size. He incorporated this air drag force into Bachmann's description assuming that the gas behaved as an incompressible fluid.

As if to indicate a difference in behaviour between large- and small-particle beds, Bukareva et al. (1974) attributed the dependence of the mean pressure on bed permeability as being responsible for smaller air gaps in beds of lower permeability. Gutman (1976a) also found that the size of the air gaps was larger in beds of larger particles. Like Kröll (1955), he found that the instant of bed lift-off comes later in the cycle and the size of the air gap reduces with decreasing particle size. However, for beds of small particles $\left(d_{p}<200 \mu \mathrm{m}\right)$ vibrated at a frequency of $25 \mathrm{~Hz}$ and amplitudes varying up to $3 \mathrm{~mm}$, Thomas et al. (1986) noted that the bed cannot be observed to lift off the vessel base at any point during the cycle. 


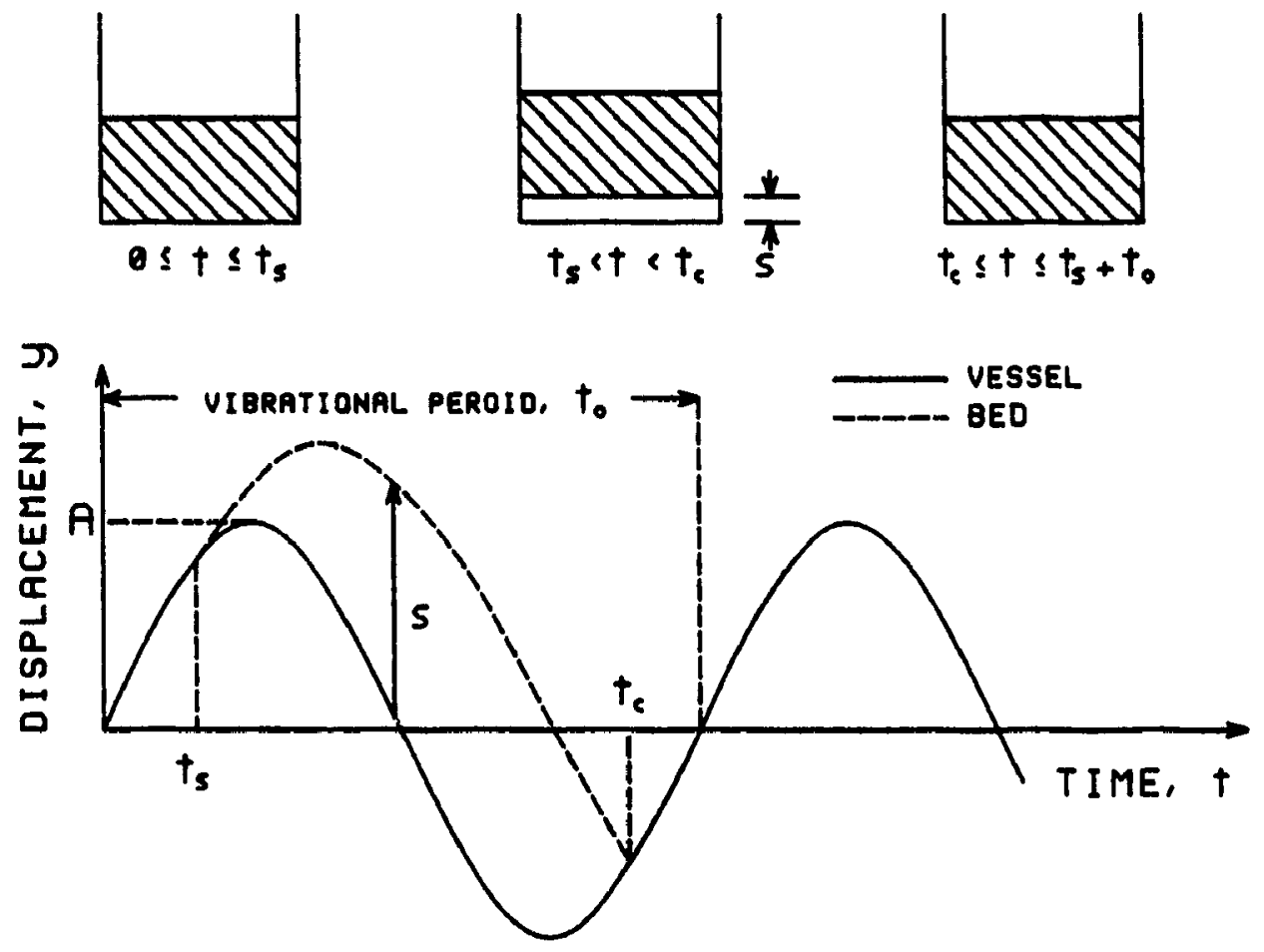

Figure 2.1 Motion of a vibrated bed and vessel; $t_{0}$ - vibrational period, $t_{3}$ - instant of bed-vessel separation, $t_{c}$ - instant of bed-vessel collision. 


\section{Bed Porosity}

Kröll (1955) found that the average porosity of a vibrated bed of particles was dependent on the vibrational conditions and particle properties. Not surprisingly, he found that for a bed of $130-\mu \mathrm{m}$ sea sand, the bed first underwent a reduction in porosity as vibrational amplitude was increased followed by a continual expansion. For identical amplitudes the bed expansion was greater for higher vibrational frequencies. For a vibrated bed of $210-355-\mu \mathrm{m}$ quartz sand and a bed height of 40 $\mathrm{mm}$, Chlenov and Mikhailov (1965) found that for $\mathrm{K}<1$, the bed was compacted and for $\mathrm{K}>1$ the bed was expanded. On the other hand, for fine particles, particularly for cohesive ones, Ur'ev (1978) and Thomas et al. (1987a) found that the critical value of $\mathrm{K}$ below which the bed compacts is much greater than 1 . Additionally, Kröll (1955) found that for $30-\mu \mathrm{m}$ Lycopodium powder vibrated at 30 $\mathrm{Hz}$, bed compaction extended over a wide range of amplitudes. Again, this implies that there is a difference in the dynamic behaviour of small-particle beds as compared to beds of larger particles.

Gutman (1976a) measured instantaneous porosities over the height of a vibrated bed of $90-135-\mu \mathrm{m}$ glass ballotini using a capacitance method. He found that for a bed vibrated at a frequency of $20 \mathrm{~Hz}$ and an amplitude of $1.56 \mathrm{~mm}(\mathrm{~K}=2.5)$, bed expansion occurred during the flight period and the bed compacted when the bed and the vessel were in contact. Earlier, Kröll (1955) found that compaction occurred during that part of the vibrational cycle over which no air gap existed. As the bed depth increased, smaller air gaps were formed indicating reduced air suction. Kröll (1955) found increasing compressibility effects as the bed thickness and vibrational frequency and bed height were increased and the particle size decreased. Beds of 
coarse particles showed a much reduced susceptibility to expansion by vibration.

Kröll (1955) related the porosity variations he observed in vibrated beds to the pressure oscillations at the floor of the vessel and the drag force exerted on the solids by the corresponding induced air currents. He compared vibrated beds to gasfluidized beds and suggested that fluidization and bed expansion occurred when the instantaneous pressure difference between the floor and the top surface overcomes the bed weight per unit area of cross-section. In shallow beds of small particles, the growth of the air gaps with stronger vibrational conditions was related to high gas flow rates which would cause greater bed expansion.

\subsubsection{Models of Vibrated and Aerated Vibrated Beds}

Several attempts have been made in the literature to model vibrated bed dynamics using simplified models. The following is a brief summary of several of these and the basic assumptions made.

Kroll $(1954,1955)$ assumed that the air within the vibrated bed may be treated as an incompressible fluid. He used Darcy's law and the equation of motion for the flight period to obtain an equation describing the size of the air gap formed below the bed. His relation predicts that the size of the air gap is independent of bed height.

The simplest model was proposed by Takahashi et al. (1968). They proposed a single-particle model for a vibrated bed. However, its validity is dubious as it neglects the effect of air drag on the bed. Yet, they obtained rough agreement between calculated and experimental results. 
Gray and Rhodes (1972) attempted to model vibrated beds as a viscoelastic mass. However, their model is not very practical due to the several hard-to-evaluate unknown factors that need to be introduced.

Ryzhkov and Baskakov (1974) included the effect of wall friction and neglected drag force in their force balance for a vibrated bed. They expressed wall friction as a function of semi-empirical parameters.

In their work with aerated vibrated beds, Yamazaki et al. (1974) assumed a constant bed voidage and adiabatic gas expansion in their model. In their efforts to derive an expression for the pressure fluctuations and pulsated gas flow that they observed, they considered a simple piston model for the motion of the bed.

Gutman $(1974$, 1976a) treated the gas as a compressible fluid and assumed isothermal compression. He extended Kröll's model by expanding the time average air gap pressure into a Fourier series to obtain the size of the air gap. Like Kröll $(1954,1955)$, he omitted wall friction.

Buevich and Galontsev (1978), in their expanding bed model for a vibrated bed, assumed that the bed expanded during flight and compressed at rest. They neglected all other forms of resistance except air drag. They developed equations of motion for the top of the bed, the bottom of the bed and the bed's centre of gravity. Their model predicted the so-called "pumping effect". This is an additional component of gas velocity resulting from periodic changes in bed volume. 
Erdesz and Halasz (1984) modelled the aerated vibrated bed as a piston of varying gas permeability undergoing sinusoidal motion in a cylinder closed at one end. They neglected a number of factors including wall friction but were able to show that fluctuations of negative and positive pressures could occur below the bed and were also able to give an explanation for the occurrence of the "pumping effect".

More recently, Erdesz and Mujumdar (1989) modified the model of Erdesz and Halasz (1984) on the basis of results of Thomas et al. (1987b). They assumed periodic fluctuations of gas permeability in the bed and found that bed permeability, porosity fluctuations and amplitude of vibration had the greatest effect on the bed behaviour.

\subsubsection{Particle Circulation}

For vibrated beds, Gutman (1974) reported that for particle sizes below $100 \mu \mathrm{m}$, the lowest value of $K$ at which the bed becomes mobile, i.e. the critical value of $K, K_{r r}$, is greater than unity. As the particle size decreases below $100 \mu \mathrm{m}, \mathrm{K}_{\mathrm{cr}}$ becomes progressively larger. In fact, Thomas et al. (1987a) reported $\mathrm{K}_{\mathrm{cr}}$ values of 5 for 20 105- $\mu \mathrm{m}$ fine-ground white flour. Earlier, Gutman (1974), hypothesized that pressure differences existing between horizontal locations in the bed was the cause of particle circulation. The bed compacts for $\mathrm{K}<\mathrm{K}_{\mathrm{r}}$ and particle circulation ceases.

For beds of $100-1000-\mu \mathrm{m}$ particles in cylindrical vessels up to $100 \mathrm{~mm}$ in diameter, Kröll (1955) observed particle circulatory patterns with particles moving up the centre of the bed of particles and down the sides near the walls. Similar flow patterns were observed by Kapustin et al. (1980). Thomas (1988) obtained particle circulation rates 
in the range $2-8 \mathrm{mms}^{-1}$. Additionally, Kröll (1955) found that for a fixed amplitude, the particle circulation rate increased with frequency.

Other studies seem to indicate that the above-mentioned circulatory patterns are restricted to large-particle beds. Ryzhkov et al. (1976) and Pavlichenko et al. (1984) observed varying types of sloping bed surfaces for fine particles and horizontal surfaces for large particles. Ryzhkov et al. (1976) cited particle accumulation at one side of the vessel as being caused by a horizontal gas velocity generated in addition to a vertical velocity component thus producing a closed loop circulation of particles. As later observed by Thomas et al. (1986), these particles flow downwarts in the shallowest part of the bed and upward in the deepest part with flow on the surface being down the slope. Flow within the bed is in opposite direction.

Muchowski (1980) and Kapustin et al. (1980) reported that overall particle circulation was not present in beds of particles with diameters less than $100 \mu \mathrm{m}$. Kapustin et al. (1980) worked with beds $10-100 \mathrm{~mm}$ high vibrated at a frequency of $10-40 \mathrm{~Hz}$ and $K$ values between 2 and 4.5 and suggested that mixing was caused entirely by the passage of bubbles through the bed. The bubbles were created by the pumping action of the sand bed. However, Muchowski (1980) theorized that during the initial period of bed flight when the bed is moving upwards relative to the vessel, the frictional forces exerted by the vessel wall tend to slow down the lift of particle layers adjacent to the walls inducing a relative downward motion of these layers.

On the other hand, perhaps Chlenov and Mikhailov (1965) had a more correct understanding of particle circulation in vibrated beds of small particles. They 
considered the gas flows generated by pressure differentials responsible for inducing spouting at the bed surface as well as particle circulation and mixing in the bed. They reported that the intensity of these processes increased with increasing values of the pressure differentials. In addition, they found that under vacuum, spouting disappeared and particle motion was reduced to vertical oscillations. Chlenov and Mikhailov (1972) explained that the average negative pressure below the bed induced a flow of gas downwards at the walls where the porosity is the highest. This gis downflow drags particles along the wall towards the bottom of the bed. Particles move up the middle to maintain continuity.

\subsubsection{Shape of Surface}

The shape of the surface is intimately related to particle circulation in the beds and depends on the particle size. For beds of large particles, the shape of the surface is nearly horizontal (Ryzhkov et al. (1976)). For particles smaller than $100 \mu \mathrm{m}$, Kröll (1955), Buevich et al. (1979) and Thomas (1988) found that the surface of the bed was not horizontal but the solids piled up one side of the containing vessel and gas channelling was observed. Also observed was an expanded zone of particles at the surface. Thomas (1988) explained that when the bed pules to one side. particle circulation is determined by the shape of the bed surface.

The shapes of the top surfaces in vibrated beds for coarse dry particles have also been noted by Pakowski et al. (1984). Contrary to other reports, they state that the piling up of particles to one side is more common in lagge-particle beds. Nevertheless, they found that the shapes of the surface became horizontal with increasing gas flow rate indicating a strong effect of air flow rate on particle 
circulation.

Sprung et al. (1986) also observed that vibrated beds do not always have a level surface but particles pile up at different locations in the vessel. They explained that air is first pumped downwards as the bed attempts to lift off and later upwards as the vessel floor and bed are pushed together. This has a noticeable effect on small particles due to their reduced permeability to gas flow.

Buevich et al. (1979) worked with vibrated beds of $80-\mu \mathrm{m}$ corundum particles. They cited the instabilities created by small perturbations in the floor pressure of the bed to explain the non-level nature of the free surface of vibrated beds of small particles and the associated circulatory patterns. Bed surface non-uniformities disappeared when larger particles were used. This again indicates a difference in large- and smallparticle beds. Their analyses accounted for perturbations of mean floor pressures which were obtained by averaging the instantaneous values over the period of time the bed stayed in flight and the effect in deforming an initially horizontal surface.

\subsubsection{Resonance Phenomenon}

The frequency of forced vibration depends only on that of the impressed torce. The amplitude, however, depends both on the magnitude of the fluctuating force and the ratio of its frequency to the natural frequency of the system (Myklestad (1956)). When this ratio becomes equal to unity, the amplitude of vibration becomes very large (Myklestad (1956)). This condition is called resonance. The principal resonance will occur when the fundamental frequency coincides with the natural frequency (Vernon (1967)). 
Akiyama et al. (1986) stated that a vibrated bed exhibits a resonance frequency at which a peak pressure is observed. Their theoretical model, however, failed to predict the resonance phenomenon. In their attempt to achieve optimal heights of aerated vibrated beds, Ryzhkov and Tolmachov (1983) studied the change of pressure which occurred in the beds of $120-\mu \mathrm{m}$ corundum particles as a function of bed height and observed the resonance phenomenon in vibrated beds. This phenomenon refers only to beds of particles and its associated fluid and not to the vibrating structure. The beds were vibrated at frequencies of $7-70 \mathrm{~Hz}$ and an amplitude of $2.73 \mathrm{~mm}$. The changes of pressure were similar to the presure differentials observed by Kröll (1954, 1955), Chlenov and Mikhallov (1972) and Gutman (1974). Ryzhkov and Tolmachov (1983) found that in aerated vibrated beds, on increasing the frequency of vibration, a stage is reached when the bed expands and extensive "boiling" on the surface and mixing inside the bed occur. They considered the mechanism of elastic wave propagation in vibrated beds and calculated resonant bed heights. They believed that the resonant condition was appropriate for intensive hydrodynamical conditions and that it is characterised by the appearance of extremal changes in known parameters which are typical of the vibrofluidized state. Ryzhkov and Putric (1987) observed that resonance effects result in augmented heat/mass transter.

Resonance phenomenon is directly related to the shape of the bed surface. Eccles et al. (1989) defined the resonant condition as one at which the bed expands rapidly to its peak bed height (i.e. highest porosity) and developed intense surface waves like those observed by Hashimoto and Sudo (1985) and De Martin, Paquette and Spınelli (1988) for vibrating liquid columns. 


\subsection{6 $\quad$ Mixing}

Mixing is related to particle circulation and pressure oscillations. For beds deeper than $200 \mathrm{~mm}$, Tamarin and Kalt'man (1971) found that the intensity of mixing decreases as compared to shallower beds. For shallow beds, mixing is more dependent on and increases rapidly with $\mathrm{K}$. However, they did not report whether frequency or amplitude had a more pronounced effect. Additionally, Suzuki et al. (1980) found that in aerated vibrated beds, the mixing rate of particles decreased for $\mathrm{U}>\mathrm{U}_{\mathrm{m} \bullet}$ Arai et al. (1974) and Kavetskii et al. (1975) have attempted to correlate mixing with amplitude and frequency in vibrated beds. However, their correlation is of little value outside the range they used as the intensity of mixing will depend on particle size and bed design.

\subsubsection{Inter-Particle Effects}

Malhotra et al. (1984) compared the flow patterns of dry and sticky particles and concluded that even at moderately high vibrational accelerations, $\mathrm{K}-3.5$, there was no particle circulation within a bed of sticky particles.

Yoshida and Kousaka (1969) and Zaitsev et al. (1976) found that vibration overcomes the inter-particle forces of attraction leading to fluidization of particles that could not be fluidized otherwise. In addition, Zaitsev et al. (1976) found that wet and sticky particles may be mobilized by superimposed vibrations when gas flow alone was not enough. They attributed the effects of vibration to the overcoming of binding forces between the particles preventing them from agglomerating.

In their studies of the transition to vibrofluidization for ultra-fine $\left(2-3-\mu \mathrm{m} \mathrm{SiO}{ }_{2}\right.$ and 
0.7- $\mu \mathrm{m} \mathrm{CaCO})_{3}$ powders, Vinogradov et al. (1980) hypothesized that the forces required to separate cohesive powders must be large enough to overcome adhesive bonds that exist for such fine particles. They recommended the use of the parameter $A^{2} \omega^{3}$ instead of $K$ to characterize the transition to vibrofluidization.

\subsubsection{Wall Effects}

Experiments were performed by Gray and Rhodes (1972) at frequencies as high as $400 \mathrm{~Hz}$ and at low pressures to eliminate air drag forces. They identified the presence of wall frictional forces in vibrated beds. Furthermore, they found that when the air drag forces were absent, wall friction decreased both the maximum throw height and the period of time the bed remained in flight.

For large particles, Gutman (1974) found that an increase in vessel diameter caused a significant increase in floor pressure. However, for small particles, he found that the maximum negative gauge pressure was not appreciably affected by vessel size. This indicates that with small particles a different process is taking place.

Ryzhkov and Baskakov (1974) measured the normal stress exerted by a bed of 1.32 $\mathrm{mm}$ particles on the wall of the vessel over the vibrational cycle for a vibrated bed. They observed that the stress was larger near the bottom of the cycle when the bed was in contact with the floor of the vessel. They concluded that the bottom wall stress would retard lift-off and additional wall frictional forces would result not only in the same effect but also retard relative movement between the bed and the wall once this stress no longer existed. They recognized the difference between large- and small-particle beds and suggested that in the former, the air drag force was small 
compared to wall friction especially when the beds were deep.

Akiyama et al. (1986) measured the coefficient of wall friction in beds of both dry and wet particles. They found that wall frictional forces decreased by almost one order of magnitude when $K>2$.

\subsubsection{Bubbles in Gas-Fluidized Beds}

Jackson (1963) and Murray (1965) have shown that uniform flow in gas-fluidized beds is unstable and that bubbles are a consequence of this instability. They considered bubbles as voids or holes that set up a pattern of flow in an otherwise uniform field. This in turn brings about a pattern of forces on the particles that causes them to move in such a way as to perpetuate the voids, resulting in their upwards motion. The frequency of bubble formation is slightly dependent on the orifice size, bed height, mean air flow and the size and nature of the solids (Kunii and Levenspiel (1984)).

The average bubble size increases with height due to coalescence. The mechanism of coalescence has been described by Rowe (1971). Additionally, Davidson and Harrison (1963) describe coalescence as taking place when one bubble moves into the wake of another.

Bubbles divide by splitting which causes changes in their shape. The upper boundary commonly develops pointed cusps which frequently grow rapidly into long fingers or knives (Rowe (1971)). The knives mainly originate at the forward stagnation point and run around the edge. When they grow fast relative to the lateral movement, they 
result in bubble division as daughter bubbles are sliced off. It is not known whether the application of vibration would promote bubble splitting.

Bubbles in gas-fluidized beds rise by particles flowing around them like a true fluid in streamline motion (Rowe (1971)). The consequence of this is an uplifting of solids around the bubbles' vertical axis and sinking elsewhere. Bubbles rise at rates which increase with size. The wake associated with a bubble sheds particles along the bubble path and at the surface as the bubble erupts (Rowe (1971)). In aerated vibrated beds it is not known to what extent bubble wake is responsible for particle motion.

As described by Davidson and Harrison (1963) in their two-phase theory of gasfluidization, gas in excess of that required for fluidization passes through the bed in the form of bubbles. When the bubbles are small and hence slow-moving, gas flows in through the bottom and out through the roof of the bubbles. When the bubbles are large and hence fast-moving, the bubble rise velocity exceeds $U_{m}$ and gas flows into the bottom, out at the top and back in through the base. As Davidson and Harrison (1963) explained, this means that there exists a spherical surface concentric with the spherical bubbles where the radial component of fluid velocity vanishes i.e. a bubble cloud is set up. This recirculation leads to significant gas bypassing and limits the effectiveness of gas-fluidized beds. Kunii and Levenspiel (1984) explained that the two-phase theory shows that bubbles process about three time, the amount of gas processed by the emulsion phase in a given time interval.

No quantitative results have been reported on bubbles in aerated vibrated beds. 
Gupta and Mujumdar (1980) have suggested that vibration impedes bubble coalescence at least in shallow beds of coarse particles. This would lead to smaller bubbles and hence more controlled mixing and decreased gas bypassing.

\subsection{HEAT TRANSFER IN VIBRATED BEDS}

\subsubsection{Effect of Vibrational Parameters}

The dependence of the horizontal surface-to-bed heat transfer coefficient on vibrational parameters typically displays an S-shaped curve (Zabrodskii et al. (1968), Bukareva et al. (1969), Malhotra and Mujumdar (1987), etc.). At a fixed vibrational amplitude, Zabrodskii et al. (1968) found that the heat transfer coefficient increases with increasing frequency, passes through a maximum and then decreases. Moreover, in their work with $75-\mathrm{mm}$ high beds of $46-\mu \mathrm{m}$ corundum particles vibrated at a frequency of $16 \mathrm{~Hz}$ and amplitudes up to $12 \mathrm{~mm}$, Kal'tman and Tamarin (1969) found that for a given frequency the heat transfer coefficient increased with amplitude. In fact, at an amplitude of $1.5 \mathrm{~mm}$ the value of the heat transfer coefficient was $100 \mathrm{Wm}^{-2} \mathrm{~K}^{-1}$ while it was about $1000 \mathrm{Wm}^{-2} \mathrm{~K}^{-1}$ at an amplitude of 6 mm. Later, Muchowski (1980) studied the heat transfer from the vessel base in a bed of $500-\mu \mathrm{m}$ glass beads and found the heat transfer coefficient to increase from a packed bed value at $\mathrm{K}=1$ to a limiting value at $\mathrm{K}=3$.

\subsubsection{Effect of Surface Location and Orientation}

Bukareva et al. (1969) measured heat transfer coefficients for flat vertical and horizontal surfaces immersed in vibrated beds of quartz sand at frequencies up to 100 $\mathrm{Hz}$ and $\mathrm{K}<10$. They found that for $280-350-\mu \mathrm{m}$ quartz sand, the heat transfer coefficients for the vertical surface were higher than those for horizontal surfaces. 
The difference was later attributed to the formation of air gaps between a horizontal surface and the bed during the flight period of the bed (Mujumdar and Pakowski (1984) and Malhotra and Mujumdar (1987)). No air gaps are formed with vertical flat surfaces i.e. there is better contact between the bed and the surface. In fact, unlike the monotonic increase in the heat transfer coefficient for vertical surfaces, a maximum in the heat transfer coefficient is obtained for horizontal surfaces (Bukareva et al. (1969) and Mujumdar and Pakowski (1984)). This was ascribed to the size and extent of the air gaps formed which offset improvements in particle circulation brought on by increasing vibrational intensity.

Malhotra and Mujumdar (1987) reported that inumersed horizontal tubes rigidly mounted in a vibrated bed not only allow more heat transfer area to be packed in but also permits the use of deeper beds due to the vibratory energy imparted by the tubes. Ryhzkov et al. (1976) and Zabrodskii et al. (1968) found that heaters placed closer to the vibrating distributor give higher heat transfer coefficients due to attenuation of vibration with bed height. Astonishingly, only a small amount of work has been devoted to surface-to-bed heat transfer for externally suspended cylinders immersed in vibrated beds. In fact, those of Kwamya (1984) and Lozada (1985) are the only ones known to the author. They reported a $15 \%$ fall in heat transfer rate due to attenuation of bed motion. This type of design is important in that the heat transfer surface(s) may be easily removed for repairs or replacement without affecting the rest of the equipment. Also, the heat transfer tubes are not subject to stresses due to motion. 


\subsubsection{Effect of Particle Size}

Thomas (1988) has compiled data on heat transfer coefficients obtained from various studies on vibrated beds. While he did not correlate the data from his compilation, he was able to show that there is a decrease in the heat transfer coefficient with increasing particle size. Furthermore, Ryzhkov et al. (1976) and Gutman (1974) reported a continuous decrease in heat transfer coefficients with increasing particle size. On the other hand, Zabrodskii et al. (1968) reported a maximum in heat transfer coefficient for a particle size of $30 \mu \mathrm{m}$ while Kal'tman and Tamarin (1969) reported that the maximum occurred around $70 \mu \mathrm{m}$.

\subsubsection{Effect of Particle Circulation and Mixing}

That the high heat transfer rates in gas-fluidized beds is due to the rapid increase in particle motion and circulatory rates with increasing gas flow have been explained by Botterill (1975). Heat transfer rates from a surface immersed in vibrated beds are several times greater $(9-19$ times) than those in stationary packed beds (Bretszanjder et al. (1963)). In fact, Zabrodskii et al. (1968), Yamazaki et al. (1974) and Mujumdar (1983) have reported that they are also greater than those in gasfluidized beds.

Ryzhkov et al. (1976) measured surface-to-bed heat transfer coefficients for a vertical heating surface in beds $100-500 \mathrm{~mm}$ deep and emphasized the great significance of particle circulation on heat transfer rates. They observed that for a $150-\mathrm{mm}$ deep bed of $120-\mu \mathrm{m}$ corundum particles vibrated at $\mathrm{K}$ values ranging from 1.2 to 1.4 particle motion was more intense at an elevation of $130 \mathrm{~mm}$ than $30 \mathrm{~mm}$ from the bottom plate. Additionally, they found that the heat transfer coefficient was about 
$570 \mathrm{Wm}^{-2} \mathrm{~K}^{-1}$ at the higher elevation and $100 \mathrm{Wm}^{-2} \mathrm{~K}^{-1}$ at $30 \mathrm{~mm}$ above the bottom plate. On increasing the vibrational acceleration, particle mixing was equally intensive everywhere in the bed and hence almost identical heat transfer coefficients were obtained over the entire bed height.

Kossenko et al. (1975) studied both local and overall heat transfer coefficients for a row of 38-mm tubes immersed in a 160-mm deep bed of aluminium oxide particles. Thomas (1988) explained that the heat transfer coefficients are affected by this arrangement because the presence of the immmersed heat transfer surfaces alters the particle flow patterns in the vicinity of the heat transfer surface.

In his work on heat transfer in a continuous conveying trough, Ringer (1980) found that for small residence times, heat transfer coefficients were very dependent on particle size. As the residence times increased, the dependence got weaker, being almost the same for $200-, 630-$ and $2050-\mu \mathrm{m}$ glass particles at very large residence times.

\subsubsection{Effect of Gas Medium}

Muchowski and Mannchen (1980) measured heat transfer coefficients from the bottom of a vessel for 0.1 and $1 \mathrm{~mm}$ glass beads at atmospheric pressure and under vacuum (at a pressure of $13 \mathrm{kPa}$ ). They found that for the $1-\mathrm{mm}$ particles, the value of the heat transfer coefficients was about 10 times higher at the higher pressure. For the smaller $0.1-\mathrm{mm}$ particles the heat transfer coefficients were ajout 20 times higher at the higher pressure. In fact, the heat transfer coefficients for both particle sizes were about the same at the lower pressure. This again indicates a difference 
in behaviour of small- and large-particle beds and the importance of the gas medium in the former.

Mujumdar (1983) reported that the effect of vibration on heat transfer decreases with increasing air flow rate and falls asymptotically around the minimum fluidization value. Additionally, at fixed vibratory conditions, Yamazaki et al. (1974) found that the heat transfer coefficient improved with increasing air flow and then stabilized.

As is the case for heat transfer in gas-fluidized bed (Botterill (1975)), the thermal conductivity of the gas medium has a great effect on heat transfer in vibrated beds. Moreover, Gutman (1976b) believes that the major influence of vibration is upon the conductive heat transfer across the gas sub-layer which separates the surface of the heater from the granular material.

\subsubsection{Mechanism of Heat Transfer}

Mickley et al. $(1949,1955)$ were among the first to appreciate the implications of the unsteady state nature of the heat transfer process in beds of mobile particles. Mickley and Fairbanks (1955) considered the process of heat transfer between a gasfluidized bed and an immersed surface as one in which unsteady state heat conduction occurs by packets of particles coming into contact with the heat transfer surface resulting in heat transfer. The residence time of a packet at the surface is terminated when it is replaced by other packets of particles under the action of bubble-induced particle circulation inside the bed. In fact, Botterill and Williams (1963) reported that heat transfer to a particle in a gas-fluidized bed is primarily in the region around the contact points of a particle with the surface and is hence 
proportional to the number of contact points.

Kal'tman and Tamarin (1969) used a "packet" model similar to that used by Mickley and Fairbanks (1955) for vibrated beds. They observed small-scale fast circulation loops in the vicinity of the heater surface and suggested that the contact time of the particles with the heater surface was the controlling factor in surface-to-bed heat transfer.

Bukareva et al. (1969) alluded to the differences in the mechanism of heat transfer in gas-fluidized bed systems and that of vibrated beds. Additionally, Gutman (1976b) argued that though the heat transfer coefficient observed in gas-fluidized beds and vibrated beds are similar in magnitude, the mechanism of heat transfer does not appear to be the same. Using the Levenspiel and Walton (1954) model for a fluidized bed as the basis for his model for the scouring of the gas sub-layer, Gutman (1976b) modified the film model for non-aerated beds. Gutman's treatment may be more amenable to large-particle beds.

Perhaps Muchowski (1980) and Ringer and Mujumdar $(1982,1984)$ had the correct understanding of surface-to-bed heat transfer in small-particle beds. Assuming that bed mixing governed the heat transfer rate, Ringer and Mujumdar $(1982,1984)$ presented a calculation model on the basis of bed mixing in gas-fluidized beds, time of flight of the bed, the time period of oscillations and the bed pressure drop. Much like the case in gas-fluidized beds, Muchowski (1980) attributed the effect of vibration on surface-to-bed heat transfer coefficient as being due to the transport of heat outside the heater zone by circulation of solids. Particle mobility is thus the most 
important factor affecting the heat transfer process.

\section{$2.4 \quad$ CLOSURE}

Small-particle beds differ from large-particle beds. Pressure oscillations are present in vibrated beds. Moreover, pressures may fluctuate from one negative value to another, from negative to positive values or from positive to positive values. With a decrease in particle size in small-particle beds pressures get increasingly negative. Air gaps are formed in vibrated beds but the size of these air gaps decrease with decreasing particle size and may not be present at all. The dependence of the mean pressure on bed permeability has been attributed as being responsible for smaller air gaps in beds of lower permeability. Particle circulation is apparently due to the presence of differential pressures in the bed and affects the shape of the surface of the bed. Unlike the case for large-particle beds, application of vibration to beds of small particles apparently has an indirect effect on pressure oscillations, air gaps, and bed porosity. For small particles, inter-particle effects are more predominant and drag forces large compared to wall friction. Quantitative results on bubbles in vibrated beds is still lacking. Surface-to-bed heat transfer seems to occur by different mechanisms in large- as compared to small-particle vibrated beds. For the latter, particle circulation may be the dominant process. 


\section{CHAPTER 3. EXPERIMENTAL APPARATUS AND PROCEDURE}

\subsection{EXPERIMENTAL APPARATUS}

The overall experimental set-up is shown in Figure 3.1. The set-up consisted of different parts which are described separately in this chapter.

\subsubsection{Vibration System}

Vibration was imparted sinusoidally in the vertical plane by means of an eccentric mechanism which converted the rotary motion of the electric motor to vertical sinusoidal motion of a vibrating plate. This plate was supported on springs. Figure 3.2a shows the drive mechanism. The vibration generator provided frequencies up to $25 \mathrm{~Hz}$ and half-amplitudes up to $4 \mathrm{~mm}$.

The amplitude of vibration was controlled by adjusting screws labelled A (Figure $3.2 b)$. These screws of equal lengths were designed to set the desired $A$ value. They were secured by adjusting screws labelled $B$. To change the amplitude, screws $B$ then $\mathrm{C}$ were loosened. Screws $\mathrm{A}$ were taken out and a new set of $\mathrm{A}$ screws are put in to obtain the required amplitude. Screws $B$ and then $C$ were tightened.

The frequency of the vibration was varied by controlling the speed of the $745 \mathrm{~W} D C$ motor. The motor was in turn controlled by a Silicon Controlled Rectifier (SCR) variable speed RATIOTROL drive manufactured by Boston Gears. Measurement of frequency was made using a frequency counter. 


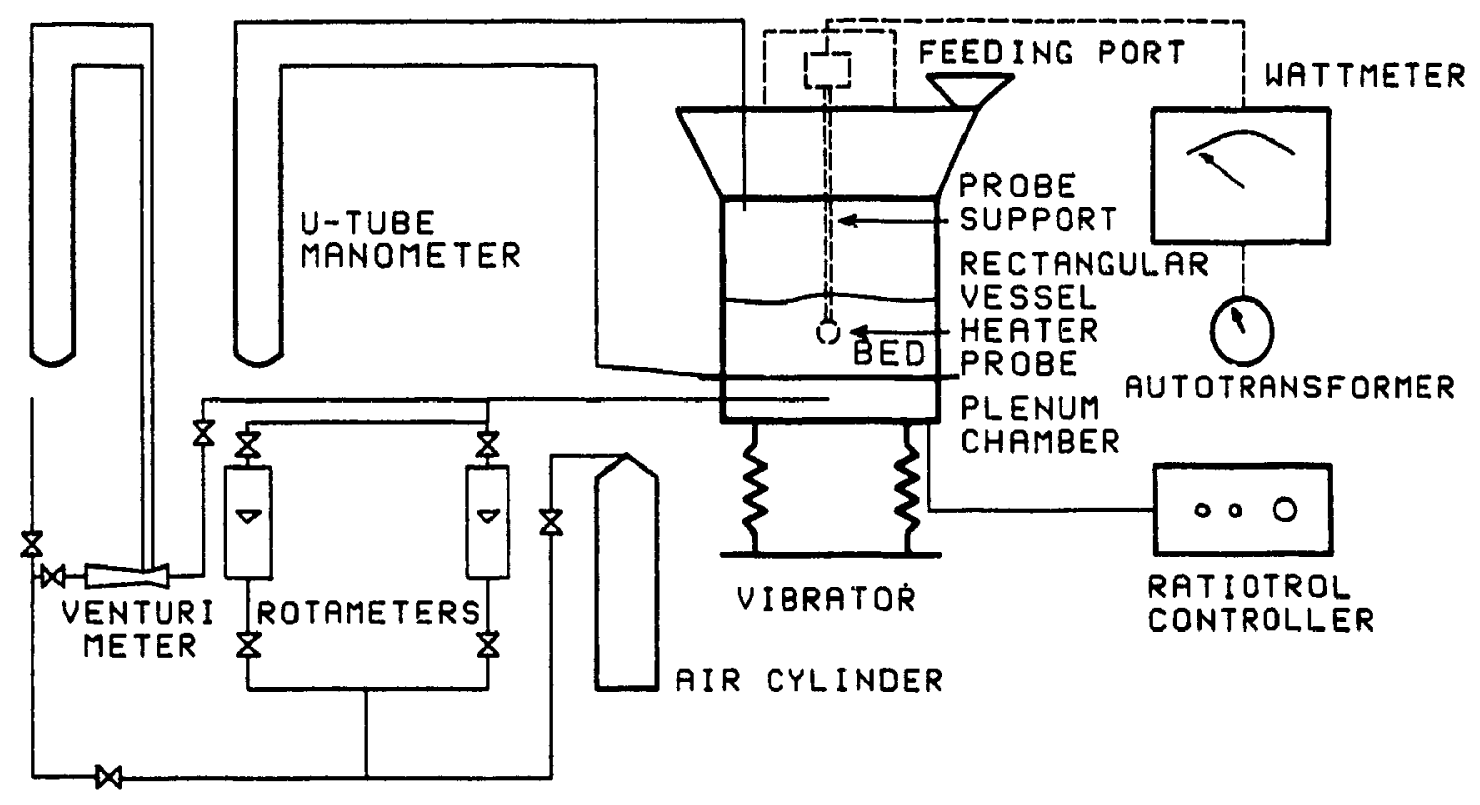

Figure 3.1 Experimental set-up. 


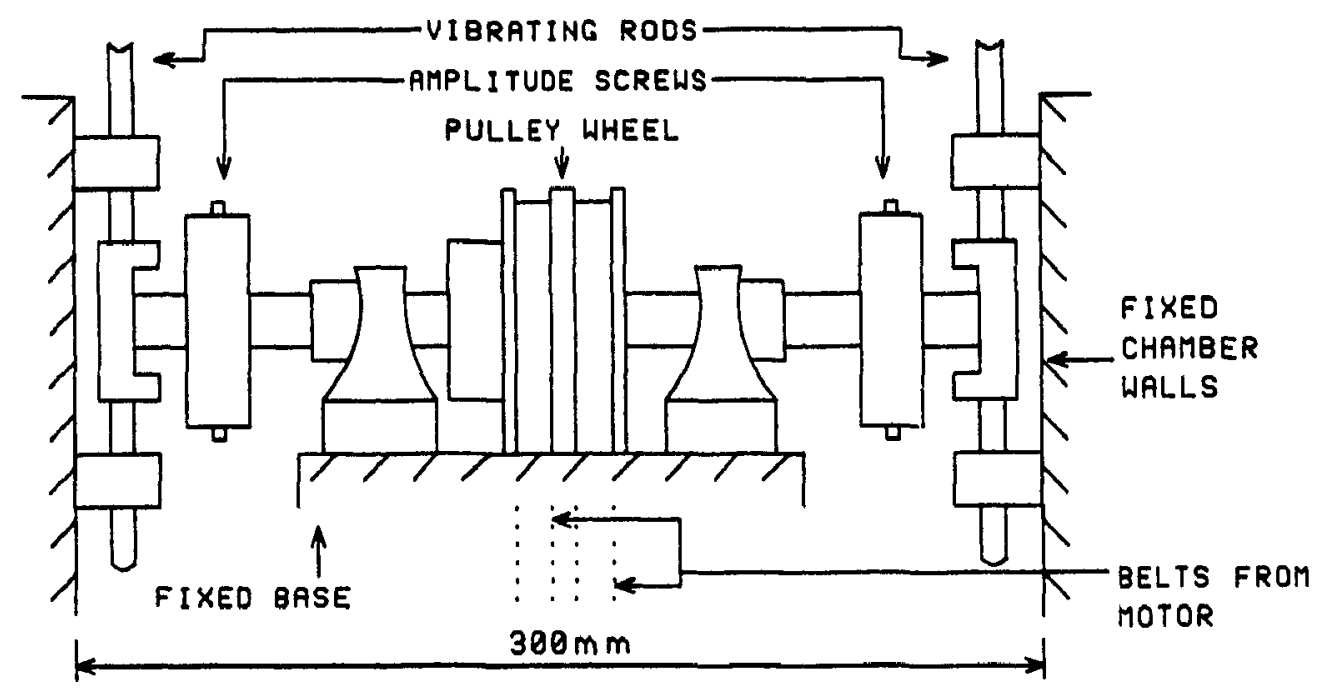

(a)

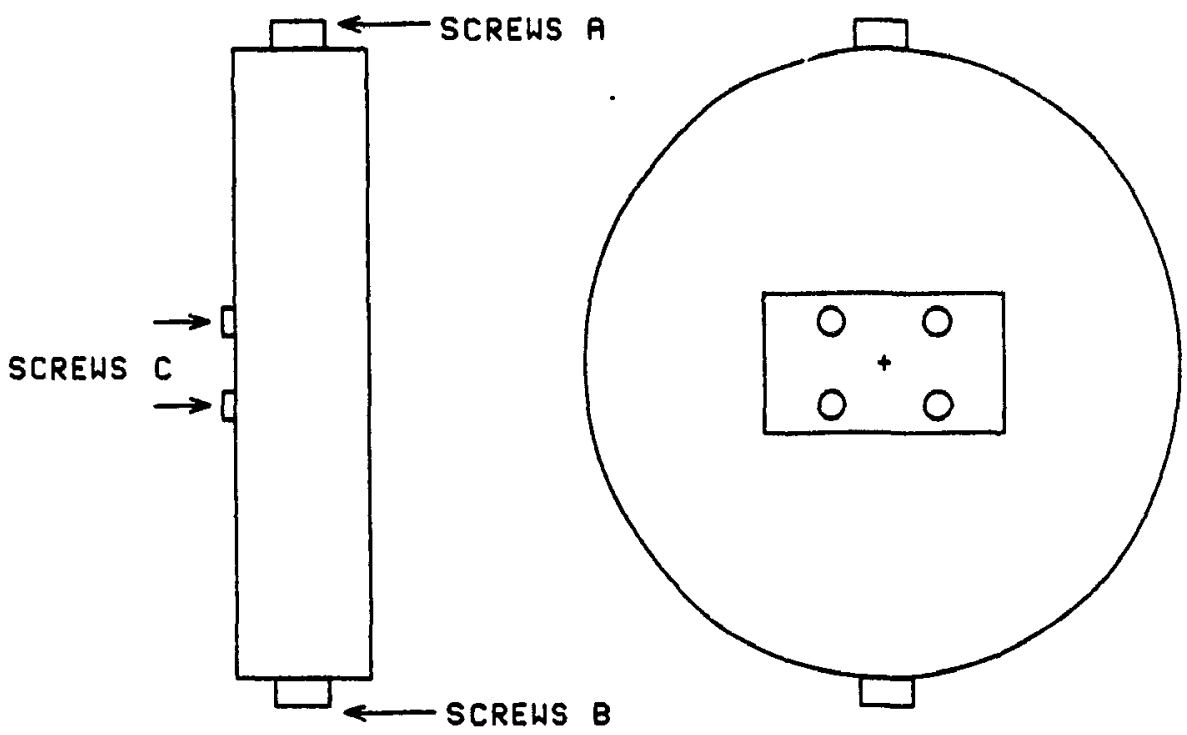

(b)

Figure 3.2 Vibration mechanısm: a - Drive mechanism (vibrating rods connected to vibrating vessel base); $b$ - Amplitude adjustment (adjusted by changing eccentricity). 


\subsubsection{Air Supply}

Air supplied by a compressed air line, was throttled through a pressure regulator. Air was led through a flexible tubing and passed selectively through one of the two rotameters. While one rotameter had a flow capacity of $2.2 \times 10^{-4} \mathrm{~m}^{3} \mathrm{~s}^{1}$ of air, the other was rated at $12.5 \times 10^{-4} \mathrm{~m}^{3} \mathrm{~s}^{-1}$ of air. Both rotameters were fitted with valves at their outlets. Alternatively, air could be led through a valve to a venturimeter when higher air flow rates were required; the pressure drop across the venturimeter was measured by a U-tube manometer. Air passing through the flowmeters was then fed to the operating vessel. Air could also be supplied to the single orifice in the vessel from an air cylinder fitted with a pressure/flow regulator. This air flow was measured by a rotametsr.

\subsubsection{Vessels and Bottom Plates}

Two clear-wall vessels were used in the study. One vessel was rectangular while the other was cylindrical. Both vessels were fitted with pressure taps located flush with the bottom plate and connected to a manometer for measurement of the bed pressure drop and with \%ertical scales for the measurement of bed height.

The vessels could be fitted with several different bottom plates made of aluminium and plexiglas: these include plates with multiple $2-\mathrm{mm}$ holes on a square pitch with $19 \%$ or $6 \%$ open area, plates with five equally spaced holes $2 \mathrm{~mm}$ in diameter and $20 \mathrm{~mm}$ apart, and plates with a single $2-\mathrm{mm}$ hole (open area $=0.04 \%$ for $20-\mathrm{mm}$ thick rectangular bed). These are shown in Figure 3.3. Additionally, for the rectangular vessel, one of the bottom plates could be fitted with different pieces to permit the use of slots or holes of different sizes and locations. The plexiglas plates 
were fitted to the rectangular bed only. All the bottom plates for the rectangular vessel are so fitted that the upper surface can be easily viewed from the front of the vessel. All the holes were covered with a 100 mesh steel screen to prevent leakage of particles into the bottom plenum chamber.

As shown in Figure 3.4, the rectangular vessel was $500 \mathrm{~mm}$ high and had a crosssection of $200 \mathrm{~mm} \times 20-60 \mathrm{~mm}$ i.e. the bed thickness could be varied up to $60 \mathrm{~mm}$. Once the bed thickness was chosen, the moving parts were clamped together using polyethylene strips between them to effect proper sealing. The whole column was vibrated by rigidly connecting it to the vibrating plate.

The cylindrical bed consisted of a $102-\mathrm{mm}$ diameter glass tube and was $840 \mathrm{~mm}$ high. This apparatus was designed to allow vibration to be imparted to the vibrating plate alone (Figure 3.5). The vibrating plate housed the bottom plate which sat on an O-ring. Two vibrating pieces, one above and one below the distributor, allowed only the plate to be vibrated without vibrating the upper and lower parts of the apparatus. The glass tube was rigidly connected to the frame which supports the vibratory mechanism through an aluminium connecting piece. The vibrating piece above the distributor was connected to this connecting piece by way of a flexible tubing. The bottom piece was fitted to the plenum chamber. These pieces were greased and sealed using O-rings.

Both vessels were fitted with expanded top pieces to prevent particle entrainment and to minimize dusting. These expanded pieces were made of aluminium and were covered with a fabric. The top opening for the piece for the rectangular column was 


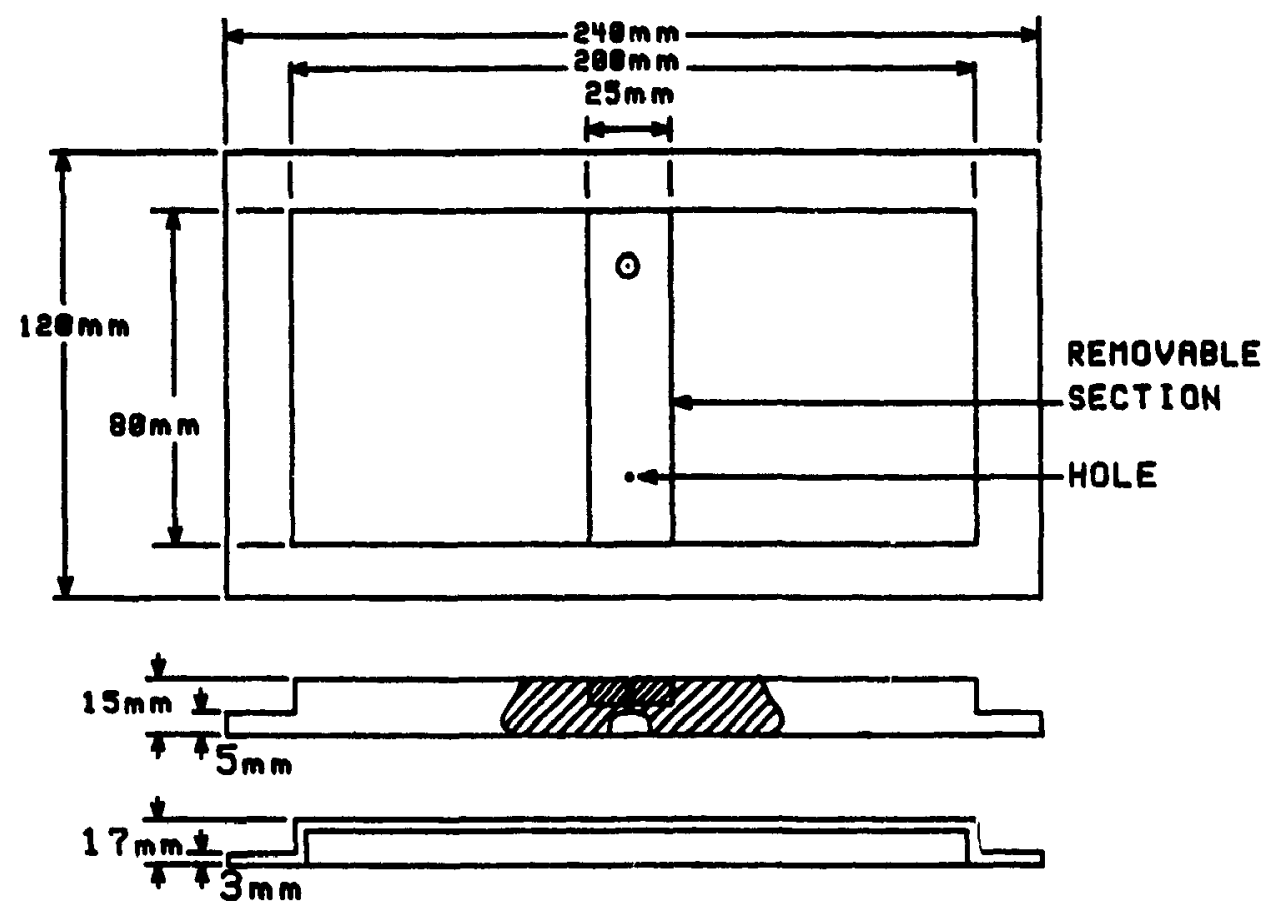

(a)

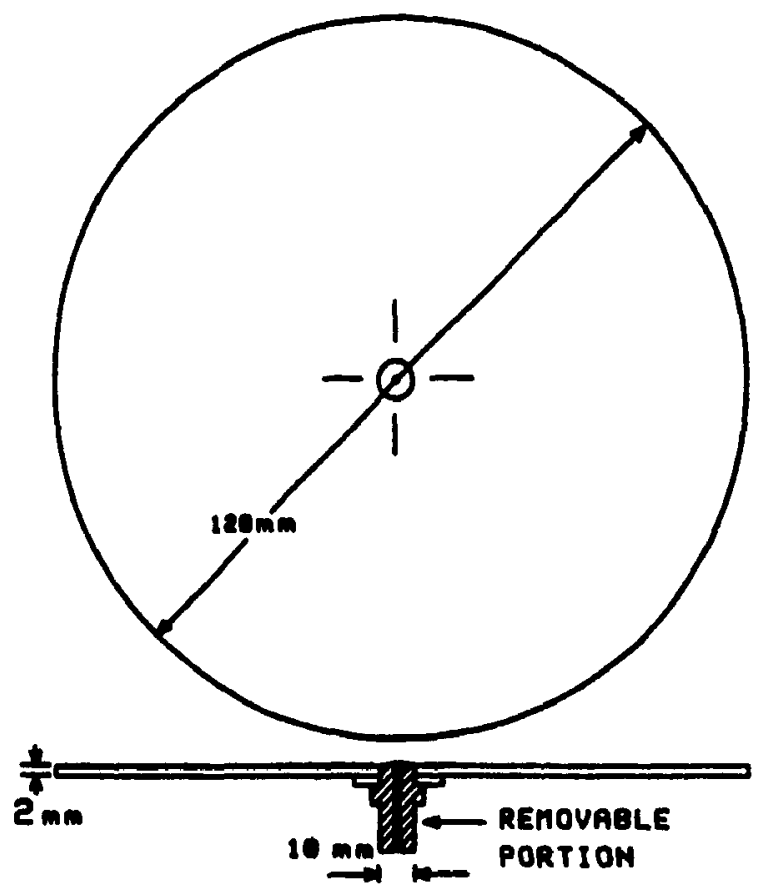

(b)

Figure 3.3 Single-aperture and perforated bottom plates: a - rectangular column, b - cylindrical column. 


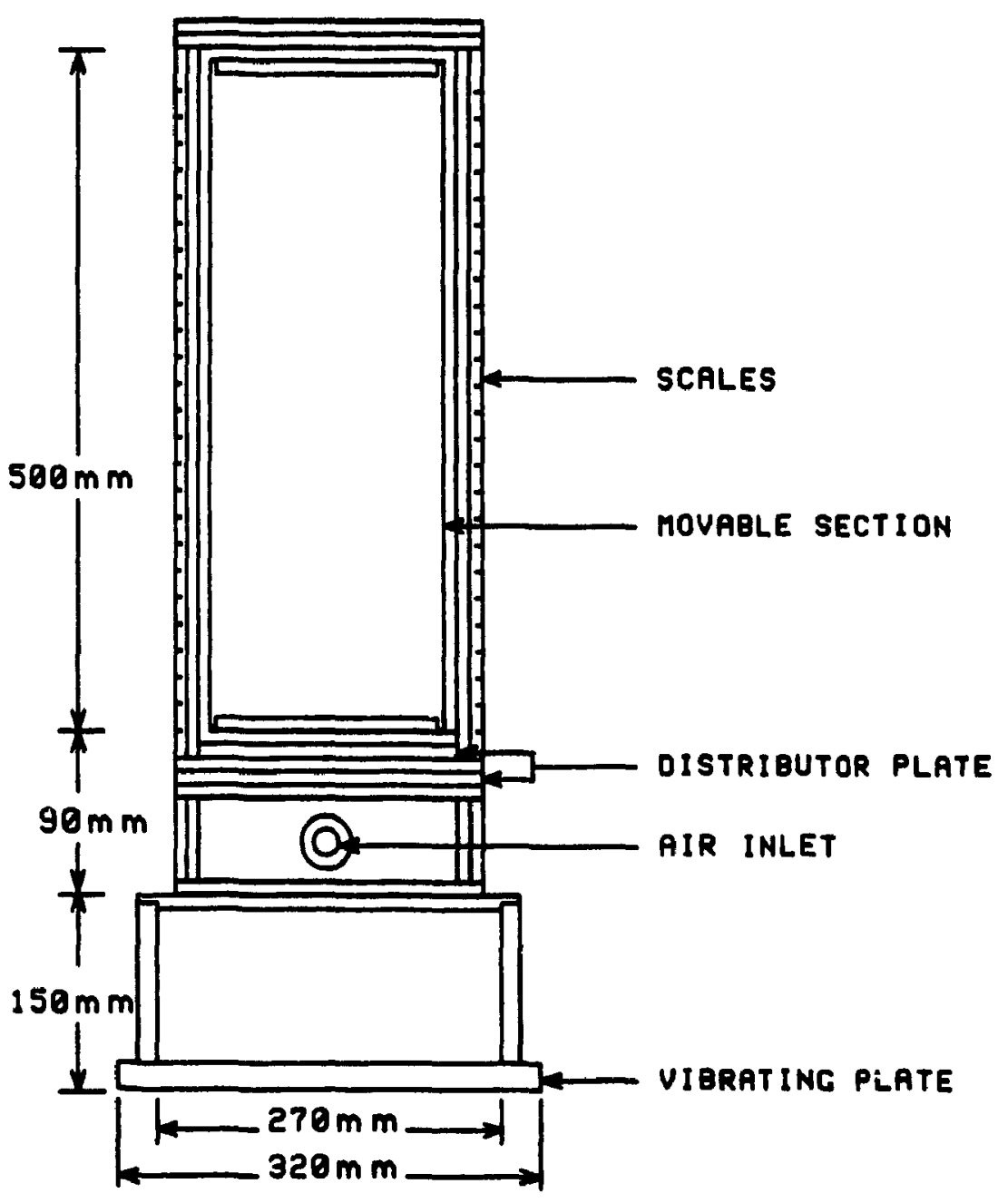

Figure 3.4 Rectangular vessel. 
$250 \mathrm{~mm} \times 250 \mathrm{~mm}$ while that for the cylindrical column was $300 \mathrm{~mm}$ in diameter.

\subsubsection{Heat Transfer Probe}

Two cylindrical heat transfer probes, one $20 \mathrm{~mm}$ and one $40 \mathrm{~mm}$ in diameter were used in the heat transfer study. The basic design is shown schematically in Figure 3.6. Essentially, the probe consisted of a 51-mm long copper tube that housed a cartridge heater of the same length. The $20-\mathrm{mm}$ diameter probe contained a $60 \mathrm{~W}$ cartridge heater, $3.1 \mathrm{~mm}$ in diameter, while the $40-\mathrm{mm}$ diameter probe housed a $250 \mathrm{~W}$ heater, $15.77 \mathrm{~mm}$ in diameter. The heaters had an unheated length of $6 \mathrm{~mm}$ at each end and were soldered into the tubes to provide good thermal contact with the tubes. Each tube was fitted with seven type $\mathrm{T}$ (copper-constantan), 30-gauge $(0.25 \mathrm{~mm})$ thermocouples located around the periphery of the cylindrical probe to measure surface temperatures. Here, the beads were soldered in place and the soldered spots sanded down to provide a smooth external heat transfer surface.

The ends of the tube were insulated with $12.5 \mathrm{~mm}$ long Teflon rods. Stainless steel tubes ( $2 \mathrm{~mm}$ in diameter) were screwed into the Teflon ends to support the probe. The thermocouple wires and the heater leads passed out through the probe supports which were led out of the vessel to be attached to an externally rigidly mounted base.

\subsubsection{Auxiliary Equipment}

Particle size and distribution were measured using a Sonic Sifter, a Sedigraph 5000D Particle Size Analyzer and a micrometer. Particle shape was determined using a microscope fitted with a camera. Particle mass was measured using precision balances. Still pictures of the vibrated bed were taken with a 35-mm SLR camera 


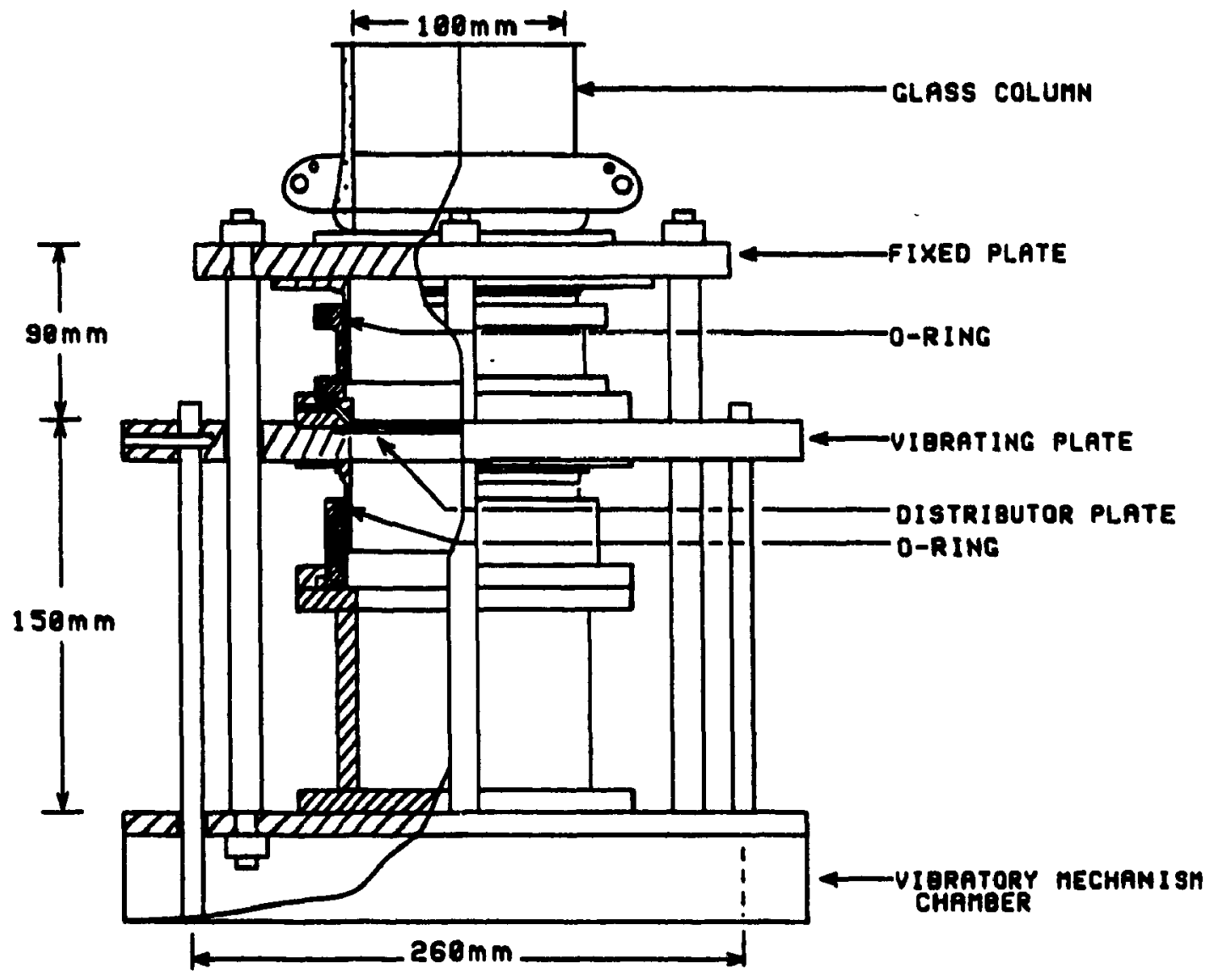

Figure 3.5 Cylindrical vessel and its associated vibrating plate and coupling. 


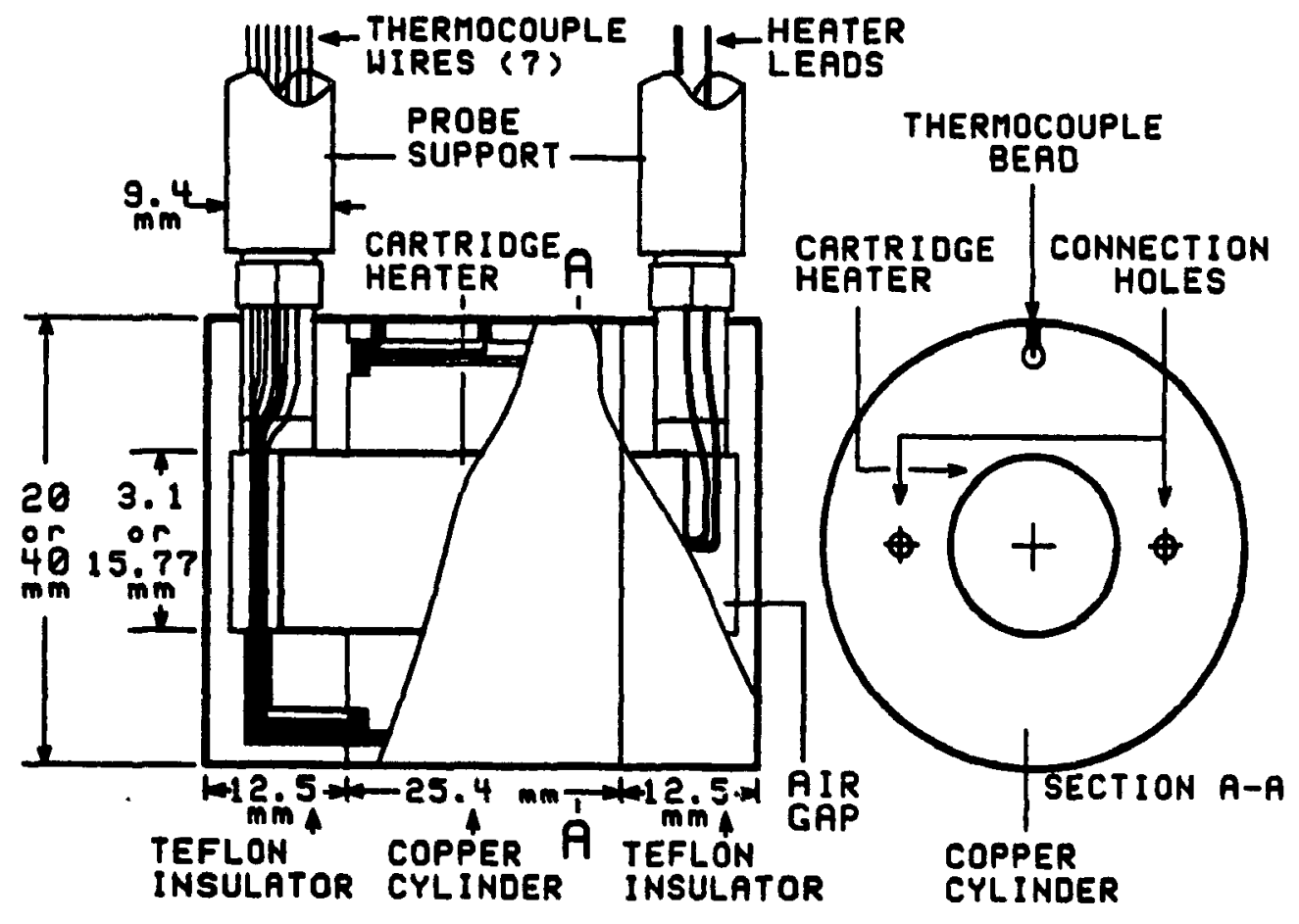

Figure 3.6 Heat transfer probe. 
(Pentax SF1). Temperatures were measured using Omega TT-T-30 and TT-T-24 (0.51 mm) copper-constantan thermocouples. Temperature output was monitored with an Omega $6180 \mathrm{~A}$ electronic digital thermocouple meter using a multi-scan thermocouple selector switch. The meter had a response recording rate of 2.5 readings per second and a response time to the accuracy of less than 3 seconds. The resolution and repeatability were within $0.1{ }^{\circ} \mathrm{C}$ with a maximum error of $\pm 0.4 \%$ (including reference junction and conformity errors). A calibrated $\mathrm{AC} / \mathrm{DC}$ type single-phase wattmeter (Yokogawa Electric Works, Tokyo, Japan) having an accuracy of $\pm 0.5 \%$ was used to measure the power input to the heater probe.

\subsubsection{Materials}

Only dry particles were used. Table 3.1 lists of the model particles used and their thermophysical properties. The particles used covered the whole spectrum of Geldart's (1973) classification. The minimum fluidization velocities were determined experimentally from $\Delta P$ versus $U$ curves in the absence of vibration. Specific heat capacities and thermal conductivities of the particles were obtained from Perry et al. (1984) and the supplier. Particle and bulk densities for alumina particles and glass beads were determined using fluid displacernent methods while those for molecular sieve particles were obtained from the supplier.

\subsection{EXPERIMENTAL PROCEDURE}

\subsubsection{Resonance Phenomenon}

In a typical experiment, particles were weighed and poured into the vessel to obtain a particular bed height. The bed was loose rather than compact and this height is referred to as the static bed height, $H_{0}$. For a given material (see Table 3.1) and a 
given set of static bed heights, $\mathrm{H}_{0}$ bed thicknesses, W, amplitudes of vibration, $\mathrm{A}$, and air flow rates, $U / U_{m}$, the frequency of vibration, $f$ was varied discretely from 0 to 25 $\mathrm{Hz}$. The bed and the particle motion, particularly in the vicinity of the top surface, were observed and recorded using a video recorder (General Electric VHS model number 1C VA 125). The bed height, $H$, and pressure drop across it, $\triangle P$ were measured and recorded over the entire range of frequencies $(0-25 \mathrm{~Hz})$.

The resonant frequency $f_{r}$, is defined as the frequency at which the bed surface is most intensely agitated and the bed height is maximal. Values of $f_{r}$ were obtained for different $\mathrm{H}_{0}$ values until either the phenomenon disappeared at the frequencies that could be applied or the total vessel space was used up. It was also repeated for different operating conditions. Most of these experiments were conducted with a single 2-mm orifice in the centre of the bottom plate for inlet air. The bulk of the experiments were conducted using a bed of $100-\mu \mathrm{m}$ alumina hut other particles were used as well.

\subsubsection{Bubble Phenomena}

Bubble phenomena studies were conducted in the rectangular column for ease of visualization (Figure 3.7). The bed was made nominally two-dimensional by using, for the most part, a bed thickness of $20 \mathrm{~mm}$. A bed thickness of $10 \mathrm{~mm}$ was also used to verify the two-dimensionality assumption for the $20-\mathrm{mm}$ bed.

\section{Bubble Generation and Formation}

With the desired bottom plate in place, air was continually introduced through the rotameter of lower capacity through the central hole or slot in the bottom plate. For 
Table 3.1 Particle thermo-physical properties.

\begin{tabular}{|c|c|c|c|}
\hline Particle & Alumina & Molecular Sieve & Glass Beads \\
\hline Size $(\mu \mathrm{m})$ & $\begin{array}{l}6(\mathrm{C}) \\
27(\mathrm{~A}) \\
100(\mathrm{~B}) \\
180(\mathrm{~B}) \\
925(\mathrm{D})\end{array}$ & $\begin{array}{l}1400 \text { (D) } \\
2200 \text { (D) } \\
3600 \text { (D) }\end{array}$ & $\begin{array}{l}105(\mathrm{~A}) \\
215(\mathrm{~B}) \\
360(\mathrm{~B}) \\
945(\mathrm{D})\end{array}$ \\
\hline Shape & Irregular & Spherical & Spherical \\
\hline Sphericity & 0.67 & 1 & 1 \\
\hline $\begin{array}{l}\text { Particle density } \\
\left(\mathrm{kgm}^{-3}\right)\end{array}$ & 3840 & 1250 & 2480 \\
\hline $\begin{array}{l}\text { Bulk density } \\
\left(\mathrm{kgm}^{\cdot 3}\right)\end{array}$ & $\begin{array}{l}815 \\
1650\end{array}$ & $\begin{array}{l}750 \\
641 \\
641\end{array}$ & $\begin{array}{l}1430 \\
1390 \\
1560 \\
1445\end{array}$ \\
\hline $\mathrm{U}_{\mathrm{mt}}\left(\mathrm{ms}^{-1}\right)$ & $\begin{array}{l}-. . \\
\cdots . . \\
0.0135 \\
0.0720 \\
0.4028\end{array}$ & 0.528 & $\begin{array}{l}0.0198 \\
0.0375 \\
0.1123 \\
0.5709\end{array}$ \\
\hline $\begin{array}{l}\text { Specific heat } \\
\left(\mathrm{Jkg}^{\left.-1 \mathrm{~K}^{-1}\right)}\right.\end{array}$ & 784 & 962 & 753 \\
\hline $\begin{array}{l}\text { Thermal } \\
\text { conductivity } \\
\left(\mathrm{Wm}^{-1} \mathrm{~K}^{-1}\right)\end{array}$ & 36 & 0.589 & 0.864 \\
\hline
\end{tabular}

Letters in brackets signify Geldart's type. 


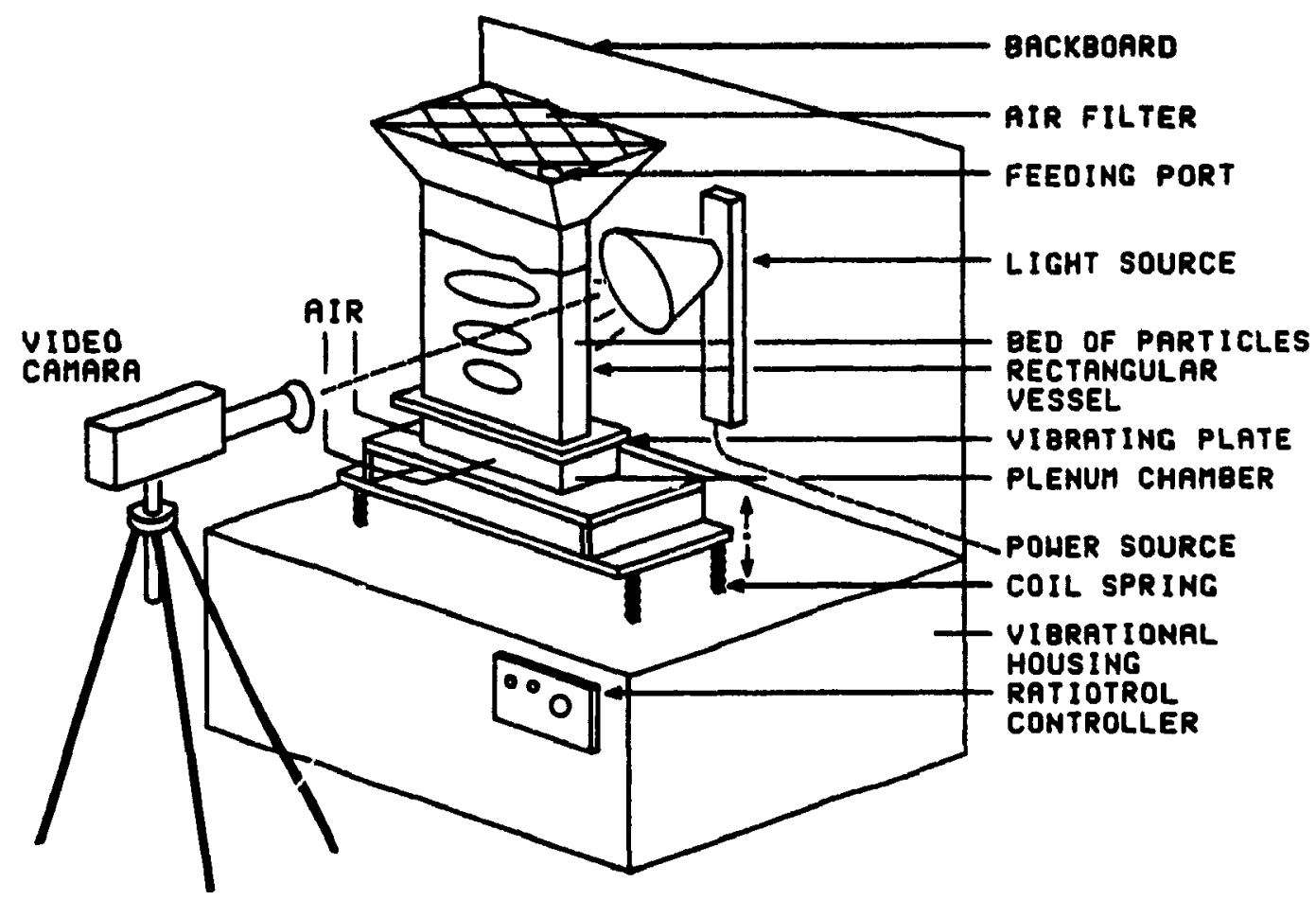

Figure 3.7 Equipment set-up for video recordings. 
bubble formation studies, a bottom plate with a 1-mm slot stretching across the whole thickness of the bed was used. Air was fed into the plenum chamber whence it flowed through the slot into the bed. Since the surface of the bottom plate was easily visible fror 1 the front of the vessel, bubble formation over the slot could be easily observed.

\section{Bubble Frequency, Rise Velocity and Size}

The bed was illuminated from the rear and the behaviour of the bed, including bubble rise and growth, was recorded on a video recorder at a speed of 30 frames per second. The bubble frequency was obtained directly using a VCR (Panasonic Model $4700-\mathrm{K}$ ) by counting the number of frames (30 frames $=60$ still pictures per second) used for six consecutive bubbles to pass a given plane (lowest bed height at which they appeared) and by converting it into the number of bubbles per second. Three such measurements were made and an average taken.

The bubble rise velocity was obtained by determining the time taken by a given bubble to travel vertically from one specific plane to another $(\mathrm{H}=40-100 \mathrm{~mm})$. This region was chosen as the bubbles were best visible at such locattions and negligible coalescence was observed. The transit time was obtained by counting frames. The velocity was then calculated by dividing the distance traversed by the time taken.

Bubble sizes were also measured at both locations from the stills made of the VCR recording. Simultareous observations of bubble shape were made. The projected area was taken as depicting an elliptical void spanning the bed thickness. The void 
was taken as a bubble and the projected area calculated. The diameter of a circle of equivalent area was defined as the bubble diamcter (size). The video camara shown in: Figure 3.7 was replaced by the still camara when still pictures were required.

\subsubsection{Particle Flow and Mixing}

Particle flow and mixing studies were conducted with the same equipment as used for the bubble phenomena studies. For any particular material whose particle circulation patterns in the bed and mixing were to be observed, a small sample was sprayed with black enamel paint. These coloured particles were used as tracer particles. To prevent agglomeration and to ensure uniform paint coverage, the particles were agitated while being sprayed. Measured sizes of tracer particles were found to be only marginally greater than the un-sprayed particles (eg. $104 \mu \mathrm{m}$ for a $100-\mu \mathrm{m}$ particle). This meant that only a thin coat of paint was deposited on the surfaces of the particles and that the physical properties of the sprayed particles were not different from those of the original particles.

For any particular run, the particles are fed into the vessel in alternate horizontal layers of painted and unpainted particles. The bed is then subjected to the required conditions of aeration and vibration and the resulting motion observed as the black particles stand out against the white alumina particles, the light brown molecular sieve or the essentially pale green glass bead particles. The experimental set-up is shown in Figure 3.7. Experiments were carried out at different bed heights with and without aeration and with and without vibration. Different aeration rates and distributor plates were used as well as different vibrational frequencies and 
amplitudes.

Some experiments were conducted with a cylindrical plexiglas piece fixed horizontally to the front and rear walls of the vessel to simulate the presence of a cylindrical heat transfer probe. The piece was either 20 or $40 \mathrm{~mm}$ in d'ameter and was placed 100 $\mathrm{mm}$ above the bottom plate and $100 \mathrm{~mm}$ from either side.

The motion of the particles was recorded on a video recorder. The recorded motion was analyzed on a VCR at different playback speeds so that the particle motion and mixing patterns could be properly identified. Mixing times were estimated using the VCR's experimentally calibrated internal counter system.

\subsubsection{Heat Transfer}

\section{Particle Surface Coverage}

The experimental set-up for the heat transfer experinıents is shown in Figure 3.2. Particle surface coverage experiments were conducted in the $20-\mathrm{mm}$ thick rectingular vessel. The test cylinders used were securely fixed to the front and rear walls of the vessel unlike in the case of the heat transfer experiments where they werr: externally suspended. This was done to permit visual observati on of the air gaps and hence estimation of surface coverage by the particles. A surface coverage factor w, was defined as: 
Heat Transfer Coefficients

All heat transfer coefficient data were obtained in the rectangular vessel at a bed thickness of $60 \mathrm{~mm}$. The heat tran fer probe was fixed in the bed with its centre 100 $\mathrm{mm}$ from the sides and bottom of the vessel. Additionally, it was so fixed that the a clearance of $5 \mathrm{~mm}$ existed between the probe and the front and rear walls of the vessel. The heater probe leads were connected to the main supply via a wattmeter and an auto-transformer. The wattmeter was pre-calibrated using a digital multimeter. The thermociouples were all connected to the thermocouple switch which was in turn connected to a thermocouple thermometer. Two movable thermocouples suspended from the top of the vessel were immersed at two different locations in the bed.to measure the bed temperature $\left(\mathrm{T}_{\mathrm{b}}\right)$ or distribution thereot in the bed. The bed was well-mixed at most frequencies and hence the difference in temperature read by the therrnocouples $(0.5 \mathrm{~K})$ was negligible.

Particles were added to the vibrated bed and the heater switched on so that heater surface temperatures $\left(\mathrm{T}_{\mathrm{s}}\right)$ between $318-333 \mathrm{~K}\left(45-60^{\circ} \mathrm{C}\right)$ could be maintained. Bed temperatures were $298-313 \mathrm{~K}\left(25 \cdot 40^{\circ} \mathrm{C}\right)$ so that a temperature difference $\Delta \mathrm{T}$ of about $20 \mathrm{~K}$ could be maintained. The heater surface temperature was measured using all seven thermocouples and the average value used as the mean surtace temperature. The temperature differences varied within $\pm 0.1 \mathrm{~K}$ of each other. The temperatures at the ends of the heater probe were the same as that of the surface centre $( \pm 0.01 \mathrm{~K})$ indicating that heat losses from the ends were negligible.

Steady-state was assumed to have been reached when the variation in wall temperature was less than $0.1 \mathrm{~K}$ in 3 minutes. The overall heat transfer coefficient 
was calculated using the equation:

$$
\mathrm{h}=\frac{\mathrm{Q}}{\mathrm{A}_{\mathrm{c}} \Delta \mathrm{T}} \quad 3.2
$$

where $A_{c}$ is the surface area of the heat transfer probe given by $\pi \mathrm{dL}$ and

$$
\Delta T=T_{s}-T_{b} .
$$

\subsection{EXPERIMENTAL UNCERTAINTY ANALYSIS}

Estimated maximum errors may be expressed by the root mean squared error as outlined by Kline and McClintock (1953), Bragg (1974) and Barry (1978) amony others,

$$
\delta f-\left(\sum_{i=1}^{n}\left(\frac{\partial f}{\partial x_{i}} \delta x_{i}\right)^{2}\right)^{1 / 2}
$$

The estimated maximum experimental errors are tabulated in Table 3.2. Accuracy ratings for the instruments were obtained from their technical specifications. Note that cylinder-to-bed heat transfer coefficients are reproducible $10 \pm 7 \%$. 
Table 3.2 Maximum experimental uncertainty of variables.

\begin{tabular}{|ll|}
\hline VARIABLE & MAXIMUM EXPERIMENTAL \\
& UNCERTAINTY \\
\hline Amplitude of vibration, $A$ & $\pm 0.05 \mathrm{~mm}$ \\
Frequency of vibration, $\mathrm{f}$ & $\pm 0.1 \mathrm{~Hz}$ \\
Mass of bed, $\mathrm{m}$ & $\pm 0.0005 \mathrm{~kg}$ \\
Bed height, $\mathrm{H}$ & $\pm 3 \mathrm{~mm}$ \\
Bed thickness, $\mathrm{W}$ & $\pm 0.5 \mathrm{~mm}$ \\
Particle size, $\mathrm{d}_{\mathrm{p}}$ & $\pm 1 \%$ \\
Particle density, $\rho_{\mathrm{p}}$ & $\pm 2.7 \%$ \\
Pressure drop, $\Delta \mathrm{P}$ & $\pm 9.8 \mathrm{~Pa}$ \\
Air flow rate, $\mathrm{U} / \mathrm{U}_{\mathrm{m}}$ & \pm 0.02 \\
Bubble rise velocity, $\mathrm{U}_{\mathrm{br}}$ & $\pm 15 \mathrm{mms}{ }^{1}$ \\
Bubble size, $\mathrm{d}_{\mathrm{b}}$ & $\pm 3 \mathrm{~mm}$ \\
Temperature, $\mathrm{T}$ & $\pm 0.05 \mathrm{~K}$ \\
Particle surface coverage, $\mathrm{w}$ & \pm 0.06 \\
Temperature difference, $\Delta \mathrm{T}$ & $\pm 0.07 \mathrm{~K}(0.5 \%)$ \\
Area of heat transfer surface, $\mathrm{m}^{2}$ & $\pm 7.44 \times 10^{\circ} \mathrm{m}^{2}$ \\
Heat input, $\mathrm{Q}$ & $\pm 0.1 \mathrm{~W}$ \\
Heat transfer coefficient, $\mathrm{h}$ & $\pm 22 \mathrm{Wm}{ }^{2} \mathrm{~K}^{\prime}$ \\
& \\
\hline
\end{tabular}




\section{CHAPTER 4. RESONANCE PHENOMENA}

\section{$4.1 \quad$ INTRODUCTION}

To evaluate potential applications for aerated vibrated beds as novel heat exchangers and chemical reactors, it is necessary to obtain basic knowledge about the operating characteristics and aerodynamics of relatively deep vibrated beds of small particles. This chapter is aimed at providing some insight into a physical phenomenon which has not been reported prior to this study, but whose existence has nevertheless been predicted on the basis of a simple mathematical model of a vibrating two-phase system by Ryzhkov et al. $(1983,1987)$.

The resonant condition is defined in this work as one at which the bed expands rapidly to its peak bed height (i.e. highest porosity) and develops intense surtace waves not found under other operating conditions. In some cases, the waves become unstable and degenerate into a number of small fountains or spouts erupting randomly on an oscillating bed surface.

This chapter discusses the resonance phenomenon and presents experimental datil relating the resonant bed height and resonant frequency in a rectangular and a cylindrical vessel. Most of the study was conducted using the rectangular vessel. Alumina particles and glass beads which were A, B and C types according to Geldart's (1973) classification were used for most of the experiments. However, glass beads, alumina and molecular sieve particles which were Geldart D type particles were also used. Also, an expression is derived relating the resonant frequency to the resonant bed height. Unless otherwise stated, the bottom plate used was one with 
the single 2 -mm hole (open area $=0.08 \%$ for the 20 -mm thick bed).

\subsection{GENERAL FEATURES}

It is noteworthy that resonance, as defined here, occurred almost exclusively with beds of small particles i.e. particles belonging to Geldart's groups A, B or C, but not group $\mathrm{D}$ as shown in Table 4.1. It was noted that resonance does not occur when the bed is initially compact, i.e. it occurs only when the bed is initially loose. In all cases, at low static bed heights $\left(\mathrm{H}_{0}<100 \mathrm{~mm}\right.$ for $100-\mu \mathrm{m}$ alumina, and $\mathrm{H}_{0}<50 \mathrm{~mm}$ for the other particles) "jetting" in the bed above the orifice in the bottom was observed. For $100-\mu \mathrm{m}$ alumina and a static bed height $>100 \mathrm{~mm}$, "jetting" changed to bubbling. Some degree of bubbling was generally present when resonance occurred. The resonant condition is manifested by resonant surface waves of large amplitudes $\left(A_{w}\right)$ compared to the forcing half-amplitude (A); these appear in the form of numerous "fingers" of particles emerging at the top surface of the bed (Figure 4.1). The particles inside the bed were well agitated although to a much lower extent than those at the surface. This phenomenon will be further discussed in Section 4.4. Generally, resonance was first observed coincidentally at the highest frequency used (25 Hz in this case) at a corresponding static bed height of $100 \mathrm{~mm}$. The motion of particles at the top of the bed was always vigorous at the resonant point and there was extensive local mixing there with particular circulation in the axial direction. Also, this was particularly pronounced at lower bed heights $\left(\mathrm{H}_{3}<260 \mathrm{~mm}\right)$. The intensity of particle motion at the surface of the bed decreased with increasing bed height as will be discussed in Section 4.4. Air and fine partivles were blown out through the top of the vessel in a pulsating manner during resonance. 
Table 4.1 Properties of particles used.

\begin{tabular}{|lllll|}
\hline Material & $\begin{array}{l}\text { Particle } \\
\text { size } \\
(\mathrm{mm})\end{array}$ & $\begin{array}{l}\text { Particle } \\
\text { density } \\
\mathrm{kg} \mathrm{m}^{-3}\end{array}$ & $\begin{array}{l}\text { Geldart's } \\
\text { classification }\end{array}$ & $\begin{array}{l}\text { Resonance } \\
\text { observed? }\end{array}$ \\
\hline Alumina & 0.006 & 3840. & $\mathrm{C}$ & yes \\
Alumina & 0.027 & 3840 & $\mathrm{~A}$ & yes \\
Alumina & 0.100 & 3840 & $\mathrm{~B}$ & yes \\
Alumina & 0.180 & 3840 & $\mathrm{~B}$ & no \\
Alumina & 0.925 & 3840 & $\mathrm{D}$ & no \\
Glass beads & 0.105 & 2475 & $\mathrm{~A}$ & yes \\
Glass beads & 0.215 & 2475 & $\mathrm{~B}$ & yes \\
Glass beads & 0.360 & 2475 & $\mathrm{~B}$ & no \\
Glass beads & 0.945 & 2490 & $\mathrm{D}$ & no \\
Molecular sieve & 1.400 & 1250 & $\mathrm{D}$ & no \\
Molecular sieve 2.200 & 1250 & $\mathrm{D}$ & no \\
Molecular sieve 3.610 & 1250 & $\mathrm{D}$ & no \\
& & & & \\
\hline
\end{tabular}



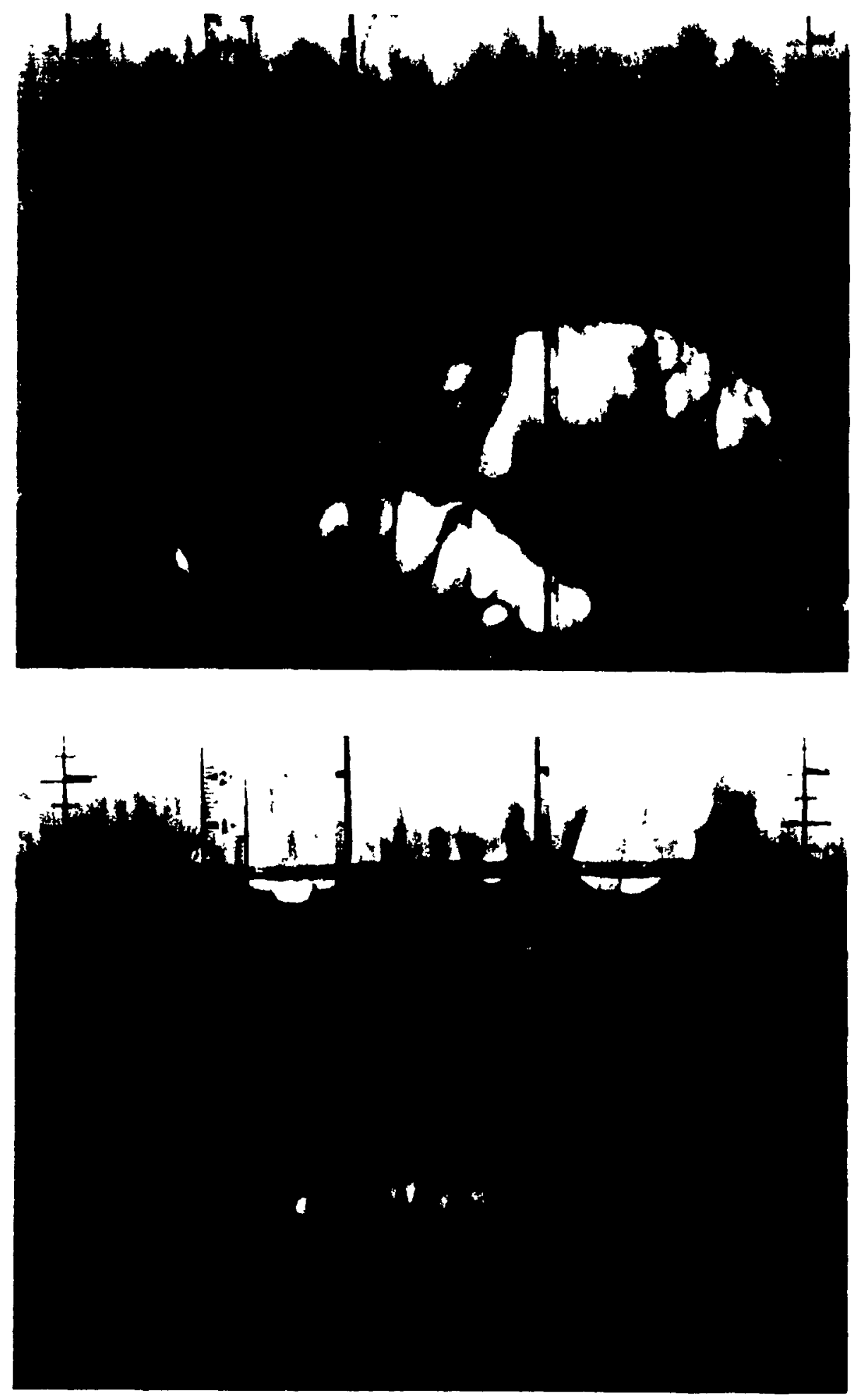

Figure 4.1 The resonating bed: Particle type - alumina $\left(d_{p}=100-\mu \mathrm{m}\right)$, $\mathrm{H}_{\mathrm{n}}=80 \mathrm{~mm}, \mathrm{~A}=2 \mathrm{~mm}, \mathrm{f}=25 \mathrm{~Hz}, \mathrm{U} / \mathrm{U}_{\mathrm{mt}}=0.65, \mathrm{~W}=20 \mathrm{~mm}$. 


\subsection{THEORETICAL ANALYSIS}

\subsubsection{Surface Waves in Liquids}

When the excitation acceleration of a container filled with a liquid is increased slowly from zero to a certain frequency $f_{o}$, a stable pattern of standing waves (surface waves) of small amplitude develops on the free surface (Hashimoto and Sudo (1984)). Further, Ockendon and Ockendon (1973) reported that small-amplitude forced horizontal or vertical oscillation of a container of liquid with a free surface may give rise to motions in the liquid on a scale much larger than the forcing amplitude. They defined resonant oscillations as the response to forced harmonic oscillations whose amplitude is of a larger order of magnitude than the forcing amplitude.

Hashimoto and Sudo (1988) studied free surface standing waves in a partially filled tank vibrated vertically and the influence of air drawn into the liquid. In this work also, free surface standing waves have been observed in vibrating liquid columns (See Figure 4.2). Liquids of varying viscosities and surface tensions were used and harmonic waves were obtained in a range of frequencies. The wavelengths of the waves decreased with increase in trequency. The amplitude of these waves was highest at the lower frequencies.

Sudo and Hashimoto (1988) reported that the variation of the amplitude of the free surface motion showed trends similar to the pressure variation. The surface waves damp slowly compared to the instantaneous damping of the pressure waves. Sudo and Hashimoto (1988) explained that when the excitation frequency exceeds a certain threshold value, air bubbles are trapped in the liquid and hence its vold fraction increases. This increase in void fraction increases the compressibility of the vibration 
(a)

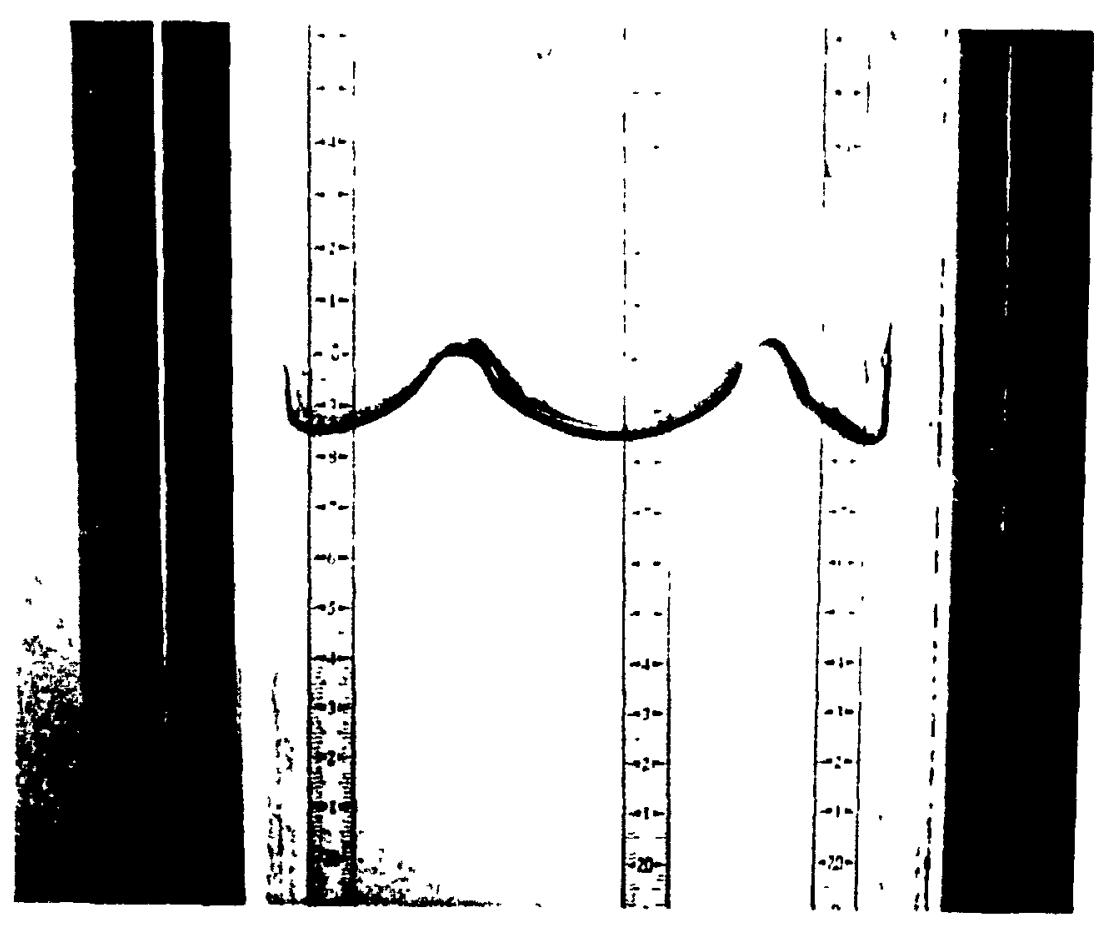

(b)

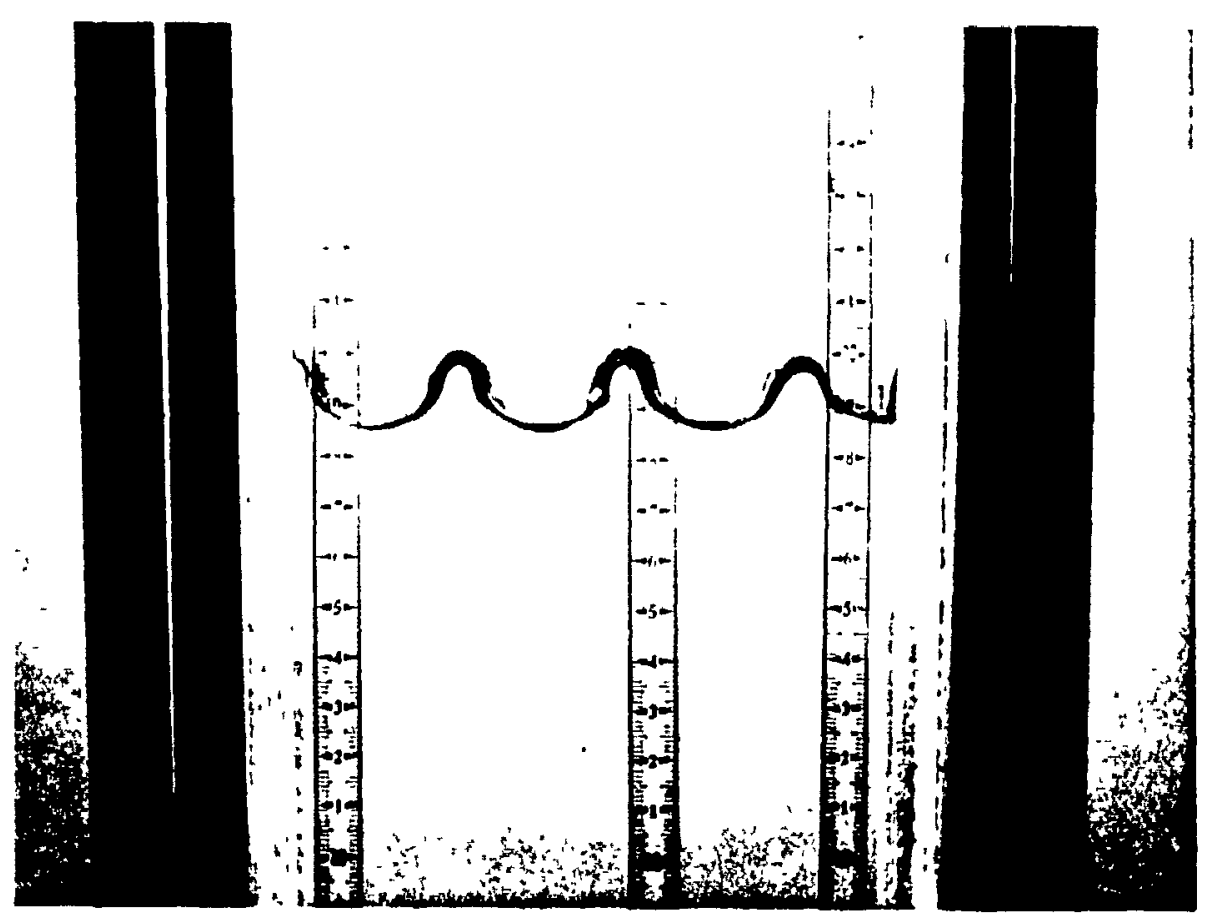

Figure 4.2 The vibrating liquid (ethylene glycol) column:
(a) $\mathrm{H}_{0}=300 \mathrm{~mm}, \mathrm{~A}=1.92 \mathrm{~mm}, \mathrm{f}=10.5 \mathrm{~Hz}$;

(b) $\mathrm{H}_{\mathrm{u}}=300 \mathrm{~mm}, \mathrm{~A}=1.92 \mathrm{~mm}, \mathrm{f}=15.0 \mathrm{~Hz}$. 
system and the pressure amplitude in the liquid increases. This in turn promotes the growth of bubbles and the void fraction continues to increase. This additive effect brings about a state in which the vibration of the system approaches exponentially its resonance with time.

In investigating the propagation of waves in a bubbly liquid, Miksis and Ting (1986) derived a system of non-linear equations which were independent of viscosity. In a later investigation, Miksis and Ting (1987) studied the effect of viscosity on wave propagation in a bubbly liquid. They derived equations which implied that while compression waves will smooth out, it was possible for expansion waves to steepen. Not all expansion waves will steepen, however. The damping term caused by viscosity will make it dependent on the initial shape of the waves. They found that viscosity attenuates the waves. Ursell (1952) observed that either or both non-linear and dissipative effects must be important in determining the actual forced response for the "resonant" conditions.

\subsubsection{Surface Waves in Aerated Vibrated Beds}

According to the results of Yamazaki et al. (1974), there are pressure fluctuations (pressure waves) created in the bed due to its motion relative to its supporting platte. Kröll (1955) hypothesized that porosity variations in vibrated beds are related to) pressure fluctuations. In fact, the cylindrical bed in particular was significantly "loose" at the resonant point. This behaviour was even more pronounced at greater bed heights. This would imply that the structure of the bed is such that air is "trapped" in pockets therein; air is being pulled into the bed from outside and hence a considerable degree of elasticity is imparted to the bed. It is postulated that the 
particles and interstitial gas together behave in a way similar to a liquid column. The propagation of the pressure waves in the bed then gives rise to the observed surface waves. Solutions derived for surface waves in liquids described by Bessel functions (Dodge et al. (1965)) may in some cases be applicable to aerated vibrated beds if their rheological characteristics could be defined and measured. This, however, was beyond the scope of this work.

\subsubsection{Theoretical Model}

In modelling the system, it is expected that a compressible bed model best represents the aerated vibrated bed at resonance. A vibrated bed of particles through which air is flowing vertically upwards may be modelled as a reciprocating porous piston through which gas is pumped. In such a system, a gas cushion can form under the bed imparting a degree of elasticity to the system (Figure 4.3).

The differential equation of motion for this system is (Newland (1984)):

$$
m \ddot{y}+c y+k y=m A \omega^{2} \sin (\omega t+\phi)
$$

where $\mathrm{y}$ is the displacement

$\mathbf{c}$ is the damping coefficient

$\mathbf{k}$ is the "stiffness" of the system

$\mathrm{m}$ is the mass of the system

and $\phi$ is the phase angle.

The eigen-frequency for a single-mass vibrated system is given by:

$$
\omega_{0}=\sqrt{k_{0} / m} \text {. }
$$




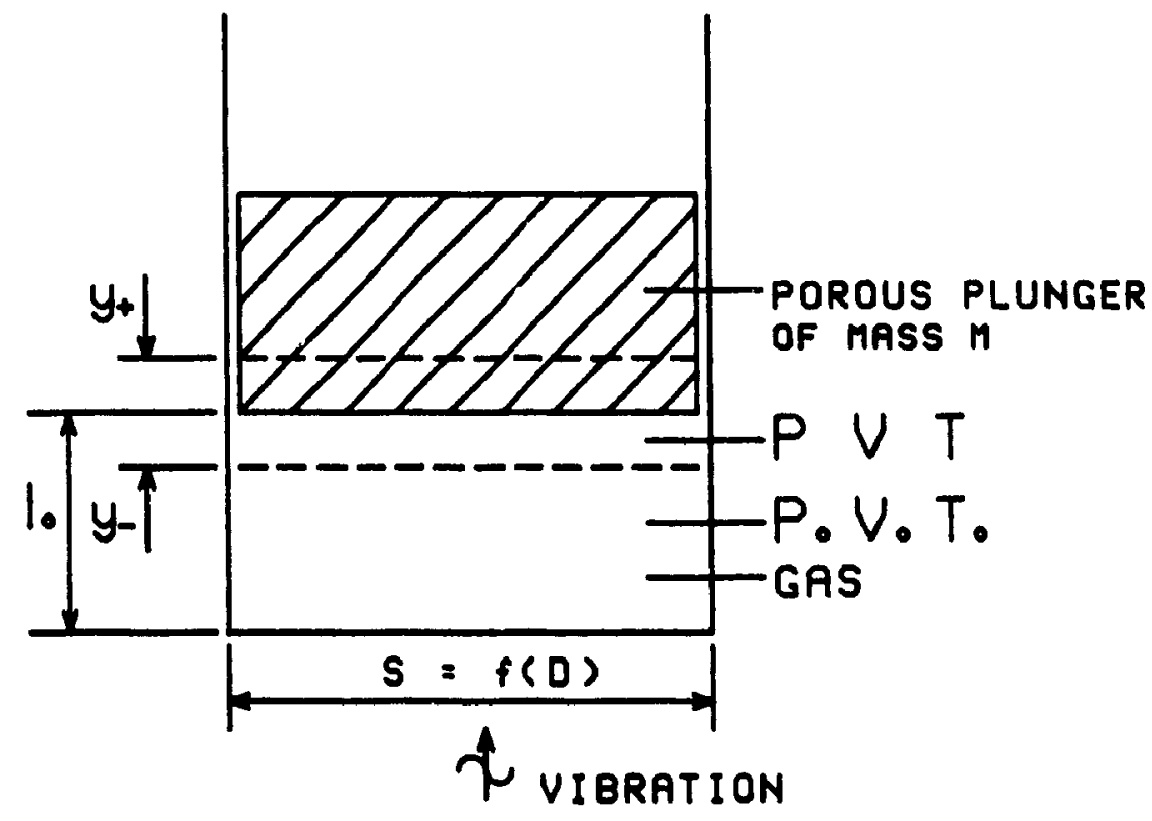

Figure 4.3 The aerated vibrated bed system as a porous piston. 
Resonance occurs when the frequency of excitation equals the eigen-frequency of the vibrated system i.e. $\omega_{\mathrm{r}}=\omega_{\mathrm{o}}$ at resonance. A simple vibrating system consisting of a closed tube partly filled with a liquid and partly with a gas (Figure 4.4) may be used to determine the "stiffness" of the aerated vibrated bed. Using the general gas law for an adiabatic system, one obtains:

$$
\mathrm{P}_{0} \mathrm{~V}_{0}^{7}-\mathrm{PV^{ \gamma }}=\text { constant. }
$$

Upou differentiation,

$$
\frac{d P}{d V}=-\gamma \frac{P}{V}
$$

The "stiffness" of the system is defined as

$$
k=d F / d y
$$

with

$$
d F= \pm S d P
$$

and

$$
d y- \pm d v / s \text {. }
$$

Inserting Equations (4.3), (4.4), (4.6) and (4.7) into Equation (4.5), gives

$$
k=\gamma S^{2} P_{0} V_{0}^{\gamma} / V^{(\gamma+1)}
$$




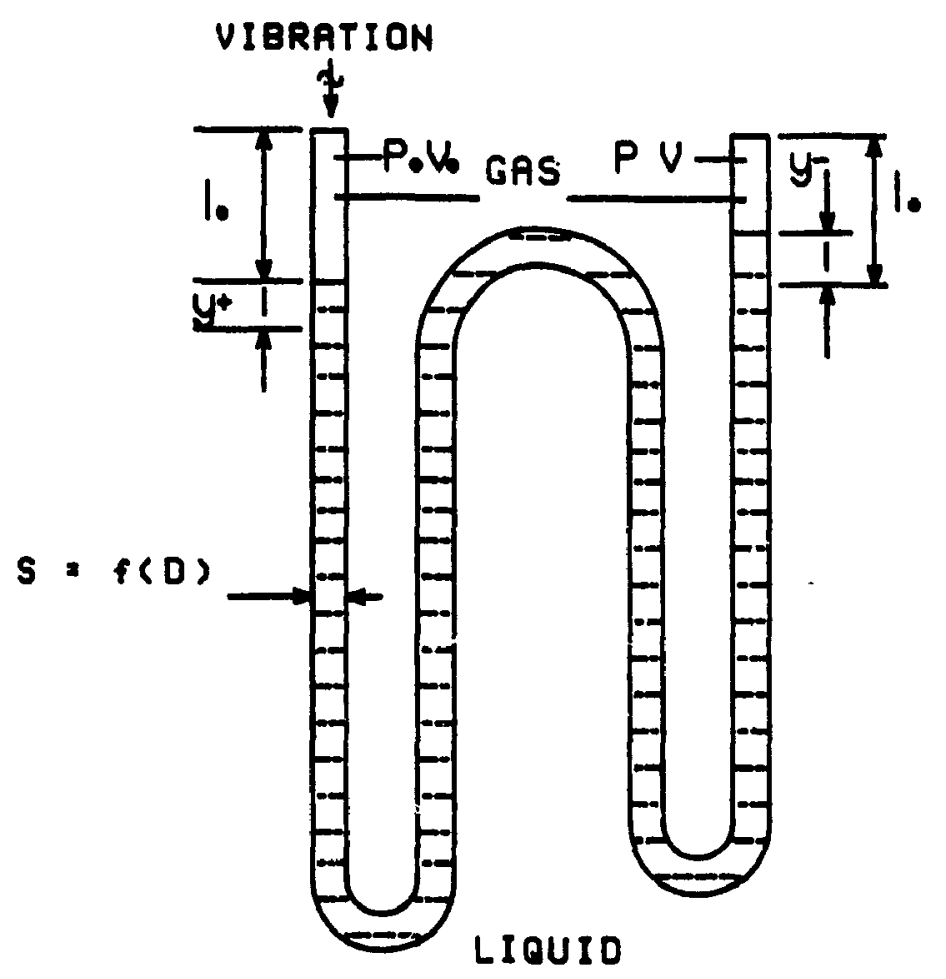

Figure 4.4 The vibrating liquid column model for an aerated vibrated bed system. 
From Figure 4.4

$$
v_{0}-1_{0} s
$$

and,

$$
V=\left(1_{0}-y\right) S \text {. }
$$

Using Equations (4.8), (4.9) and (4.10), one obtains

$$
k=\gamma S \frac{P_{0}}{1_{0}}\left(1-y / 1_{0}\right)^{-(\gamma+1)} .
$$

The amplitude of oscillation may be considered small in comparison to the geometric parameters of the vibrating system $\left(y / h_{0} \rightarrow 0\right)$. Then since $P_{n}=\rho_{g} R T$, one may write

$$
\mathrm{k}_{0}=\gamma \mathrm{S} \rho_{\mathrm{B}} \mathrm{RT} / \mathbf{l}_{0}
$$

The eigen-frequency of the vibrating system is then obtained using Equations (4.12) and (4.2) as:

$$
\omega_{0}=\sqrt{\frac{\gamma S}{l_{0}} \frac{\rho_{8} R T}{m}} .
$$

The mass of the bed in terms of resonant conditions is:

$$
m-S H_{r} \rho_{p}\left(1-\epsilon_{r}\right)
$$

where

$H_{r}$ is the resonant bed height, and

$\epsilon_{\mathrm{r}}$ is the resonant bed porosity.

Since $(\gamma \mathrm{RT})^{1 / 2}$ is the velocity of sound in a gas, substitution of equation (4.14) into 
equation (4.13) at $\omega_{\mathrm{r}}=\omega_{\mathrm{v}}$ and letting

$\mathrm{H}_{\mathrm{r}} \simeq l_{\mathrm{n}}$, gives

$$
\omega_{r}-\frac{1}{H_{r}} \sqrt{\frac{\gamma R T \rho_{g}}{\left(1-\epsilon_{r}\right) \rho_{p}}} .
$$

- By analogy, for a dispersed system one may write

$$
\omega_{0}-c_{1} \frac{1}{H_{0}} a_{d}
$$

where

$a_{d}$ is the velocity of sound in the dispersed system.

All unknown effects of the vibrated dispersed system are lumped in the parameter $C_{1}$. These include the effects of:

- particle size

- amplitude of vibration

- gas flow through the bed

- variation in bed permeability

- wall friction and other damping effects

- gas distributor design.

The velocity of sound in a gas-liquid dispersed system can be expressed as (Wallis (1969)):

$$
a_{d}=\sqrt{\frac{\gamma \operatorname{RT} \rho_{B}}{\epsilon_{\rho_{B}}^{2}+\epsilon(1-\epsilon) \rho_{1}}} .
$$


Since $\rho_{g}$ is small compared to $\rho_{p}, \epsilon^{2} \rho_{g}$ may be neglected. Hence substituting Equation (4.17) into Equation (4.16) for a gas-solid dispersed system gives:

$$
\omega_{r}=C_{1} \frac{1}{H_{r}} \sqrt{\frac{\gamma R T \rho_{g}}{\epsilon_{r}\left(1-\epsilon_{r}\right) \rho_{p}}} .
$$

Comparing equations (4.15) and (4.18), the unknown effects in the dispersed system are accounted for by the constant $C_{1}$. Equations (4.18) and (4.15) are similar to those derived by Ryzhkov and Tolmachov (1983), viz.

$$
\omega_{r}=\frac{2 \pi(2 m-1)}{4} \frac{a_{0}}{H_{r}}
$$

where $a_{0}$ is the velocity of sound expressed as

$$
a_{0}^{2}-\frac{P}{\epsilon \rho_{b}}\left(1+\frac{P \epsilon}{\rho_{b} C_{v} T_{0}}\right)-\frac{K P}{\epsilon \rho_{b}} .
$$

Here $\mathrm{K}$ is a proportionality factor.

Now

$$
\rho_{b}=(1-\epsilon) \rho_{p} \text {. }
$$

Using $\mathrm{P}=\rho_{\mathrm{B}} \mathrm{RT}$ and Equation (4.21) in Equation (4.20), and substituting the resulting equation into Equation (4.19) gives:

$$
\omega_{r}=C_{1 R} \frac{1}{H_{r}} \sqrt{\frac{K R T \rho_{g}}{\epsilon_{r}\left(1-\epsilon_{r}\right) \rho_{p}}} .
$$


This equation is similar to Equation (4.18) which may be rewritten as

$$
\ln H_{r}-\ln b-\ln f_{r}
$$

where

$$
b=\frac{C_{1}}{2 \pi} \sqrt{\frac{\gamma \operatorname{RT} \rho_{g}}{\Xi_{x}\left(1-\epsilon_{x}\right) \rho_{p}}} .
$$

In a more general form this equation becomes

$$
\ln H_{r}-\ln b-a \ln f_{r} \text {. }
$$

\subsection{RESULTS AND DISCUSSION}

Akiyama and Naito (1987) have listed the five factors characterizing the behaviour of a vibrated beds as the particle properties, bed depth, frequency, vibratory acceleration and scale factor. These factors are examined in this study.

For $100-\mu \mathrm{m}$ alumina, typical sets of data for the resonant condition in the rectangular bed are shown in Figures 4.5 and 4.6. They represent plots of the observed bed heights $(\mathrm{H})$ and pressure drops $(\triangle \mathrm{P})$ against the frequency of vibration $(\mathrm{t})$ for a given starting bed height $\left(\mathrm{H}_{11}\right)$. The resonant point defines the resonant condition and is determined as the frequency $\left(f_{r}\right)$ where the bed herght $\left(\mathrm{H}_{r}\right)$ is maximal. Addationally, for the cylindrical vessel, resonance disappeared at a bed height of about $500 \mathrm{~mm}$ but reappeared vigorously at higher bed heights, allowing resonance to be observed at hed heights exceeding $800 \mathrm{~mm}$ (See Figure 4.7). This implies that the resonant condition is harmonic in nature. However, this could not be tested due to the limited 


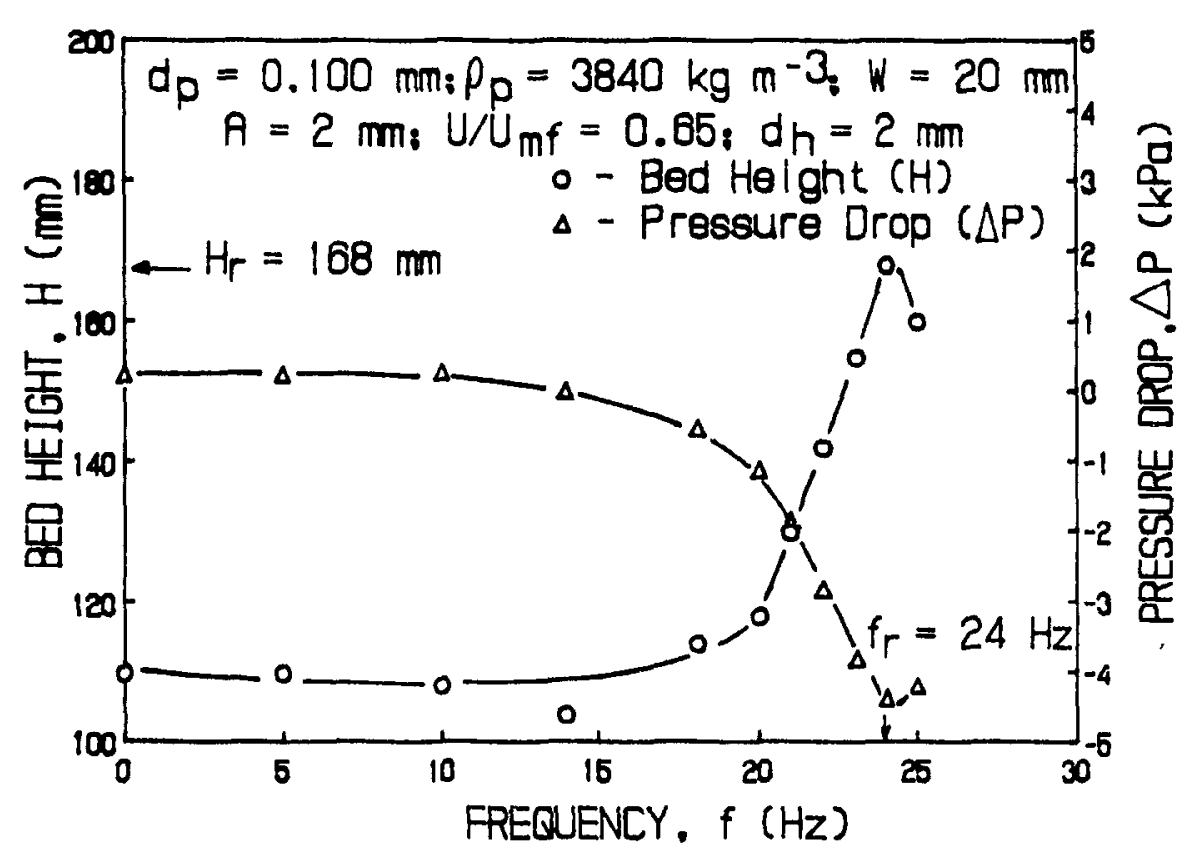

(a)

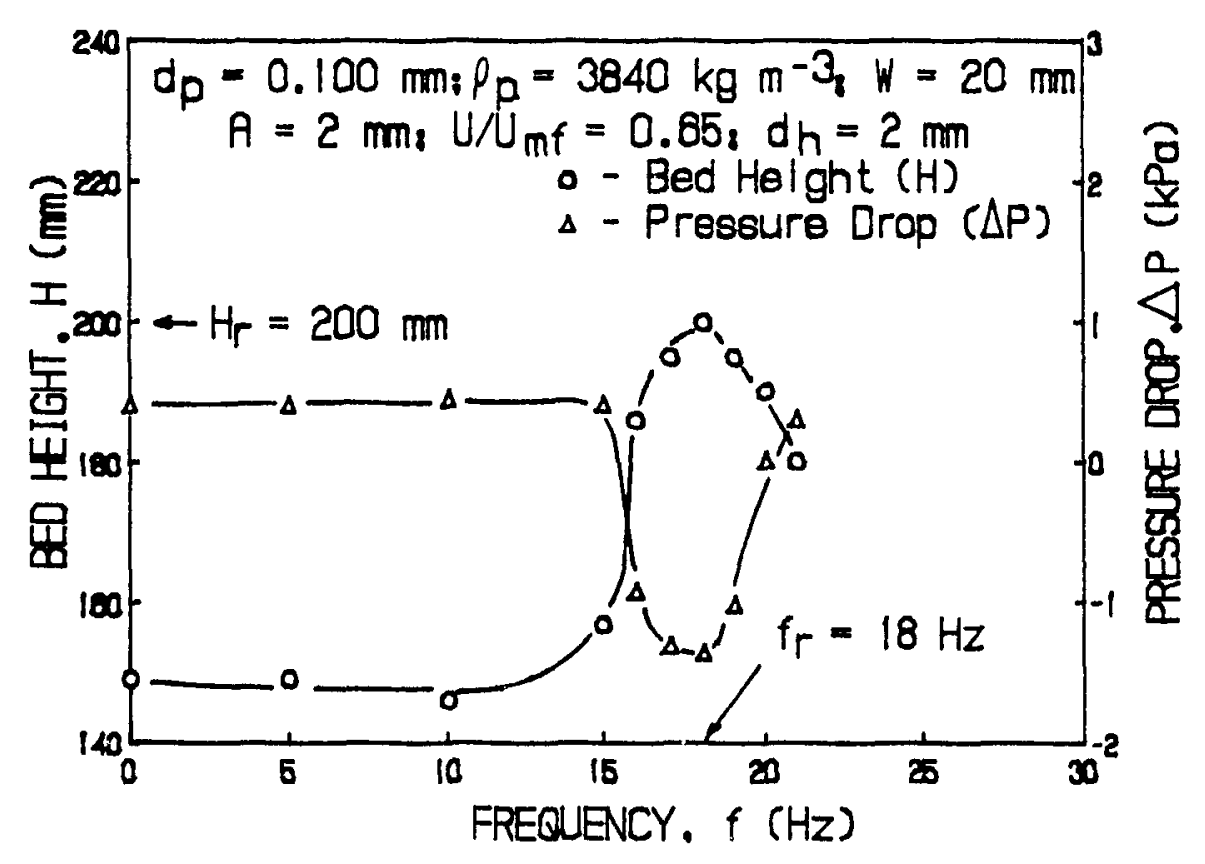

Figure 4.5 Variation of bed height and pressure drop with frequency in aerated vibrated beds of alumina particles at increasing static bed heights; (a) $\mathrm{H}_{\mathrm{n}}=110$ and (b) $\mathrm{H}_{\mathrm{u}}=149 \mathrm{~mm}$. 
(a)
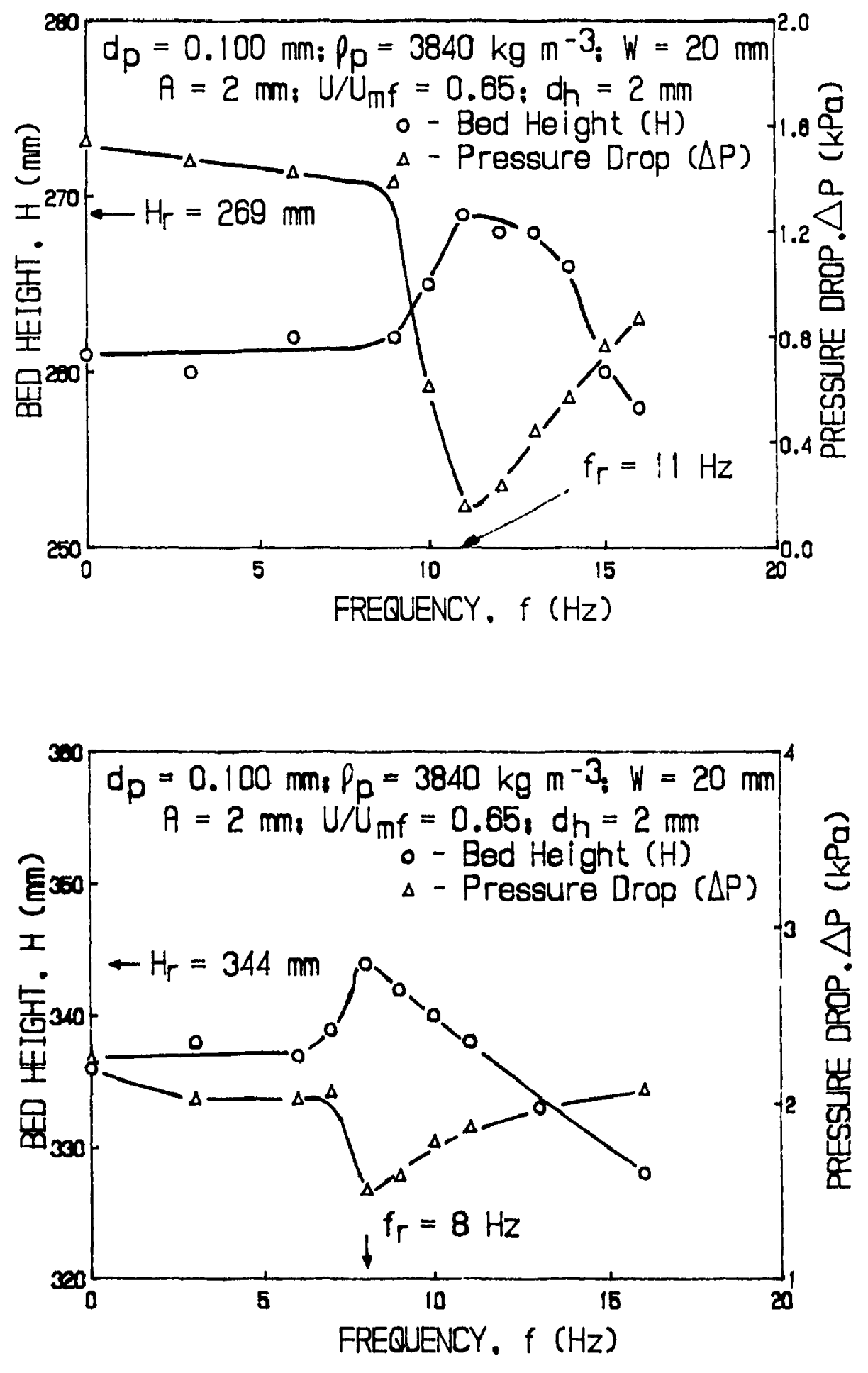

Figure 4.6 Variation of bed height and pressure drop with frequency in aerated vibrated beds of alumina particles at increasing static bed heights. (a) $\mathrm{H}_{0}=261$ and (b) $\mathrm{H}_{0}=334 \mathrm{~mm}$. 


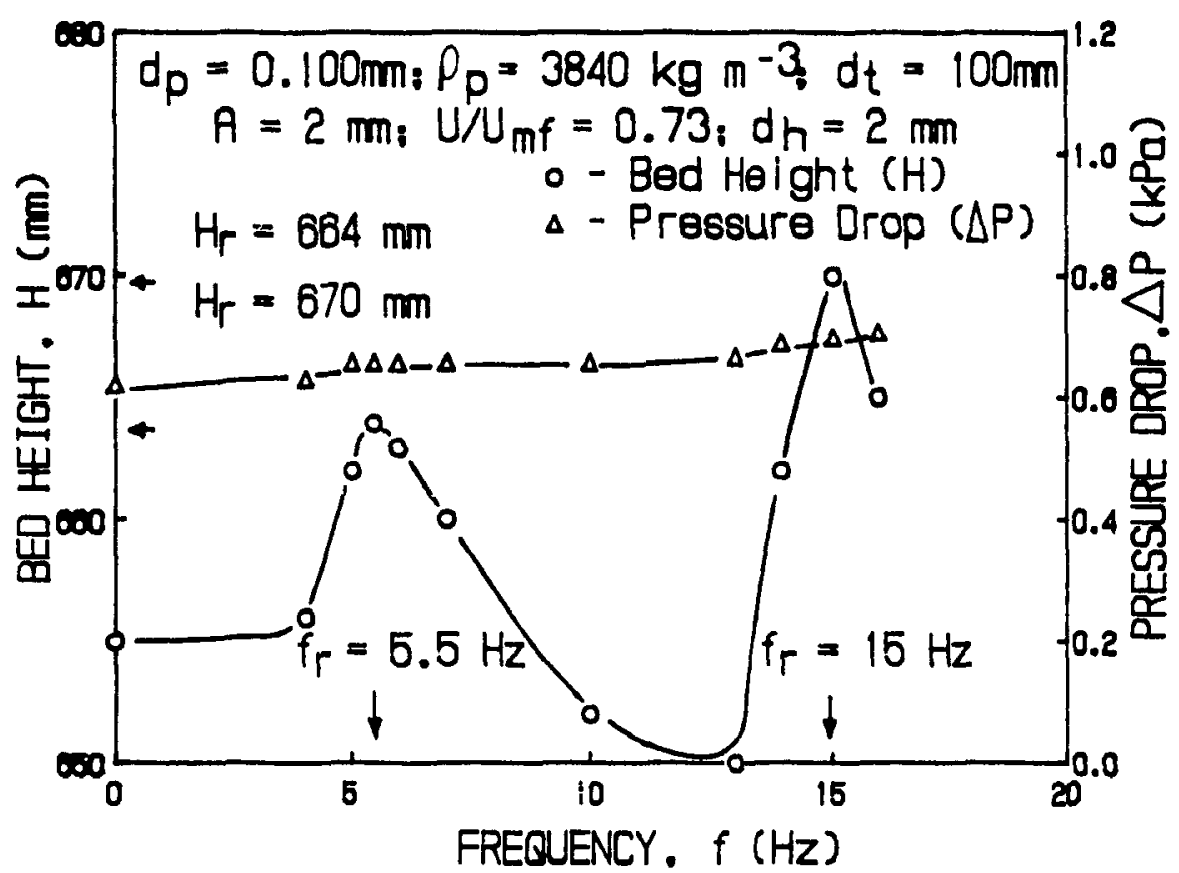

(a)

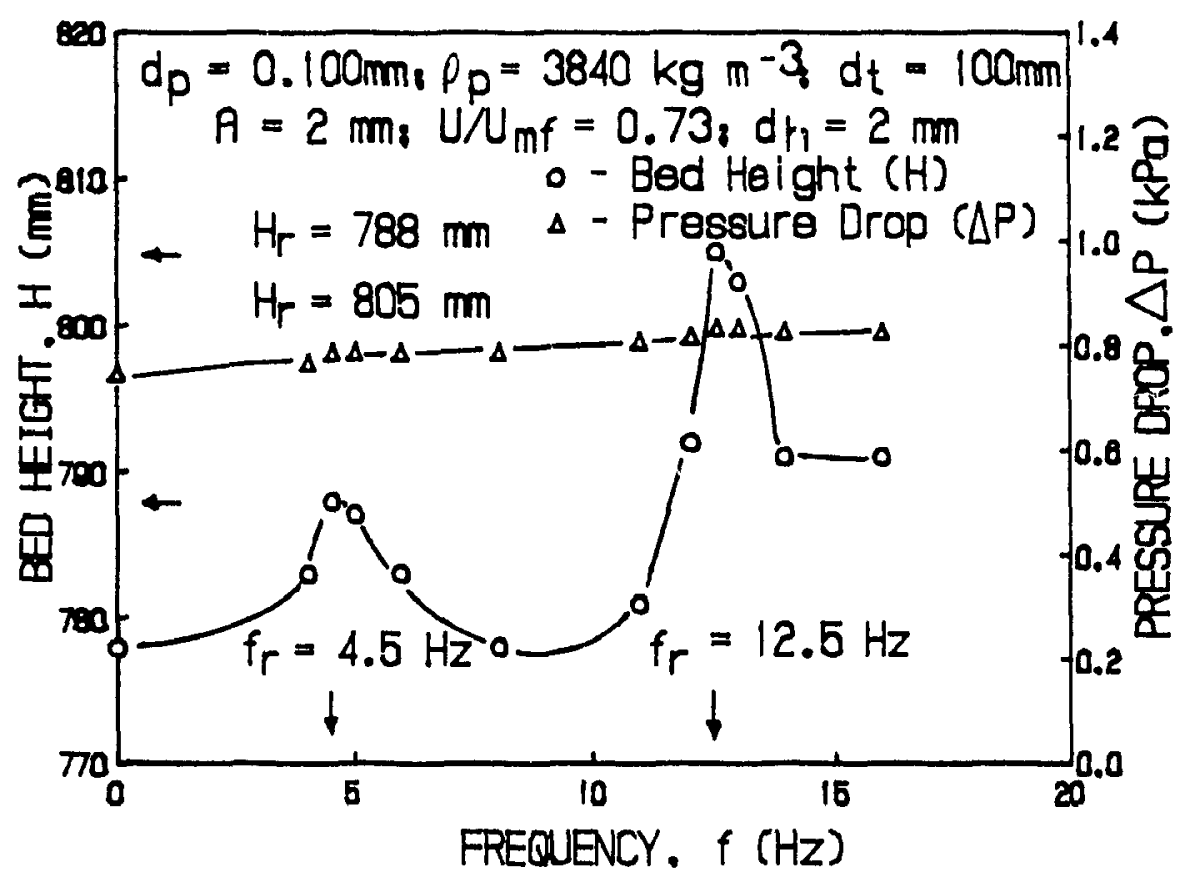

Figure 4.7 Variation of bed height with frequency in aerated vibrated beds of alumina particles at very large bed heights:

(a) $\mathrm{H}_{0}=665$ and (b) $\mathrm{H}_{0}=778 \mathrm{~mm}$. 
frequency range of the vibrating system used.

Resonance was not always characterized by a single maximum bed height at a particular frequency. Sometimes, it occurred over a very short range of frequencies (short plateau with a frequency range of about $2 \cdot 3 \mathrm{~Hz}$ ). Ursell (1952) argued that theory predicts only the frequency at which the amplitude is finite while in a real tluid there is a resonant peak of finite width and height. It is not surprising that resonance was normally but not always noted by a sharp peak in the aerated vibrated bed system.

A resonance intensity factor is detined here to quantify the intensity of surface agitation:

$$
I-\frac{A_{w}}{2 A} \text {. }
$$

$A_{a}$ may be approximated by:

$$
A_{w}-H_{r}-H_{c}
$$

The intensity decreased with increasing $H_{0}$ values, varying from approximately 14.5 at $\mathrm{H}_{n}=110 \mathrm{~mm}$ to 3 at $\mathrm{H}_{0}=212 \mathrm{~mm}$ for the $20-\mathrm{mm}$ thick bed of $100-\mu \mathrm{m}$ alumina as shown in Figure 4.8.

\subsubsection{Resonance in the Cylindrical Bed}

$H_{r}$ and $f_{r}$ values may be obtained from results as depicted in Figures 4.5, 4.6 and 4.7. For $100-\mu \mathrm{m}$ alumina, when $\ln \mathrm{H}_{r}$ is plotted against $\ln \mathrm{f}_{r}$ the experimental results produced straight lines with negative slopes, -a. For a half-amplitude of vibration of 
(a)

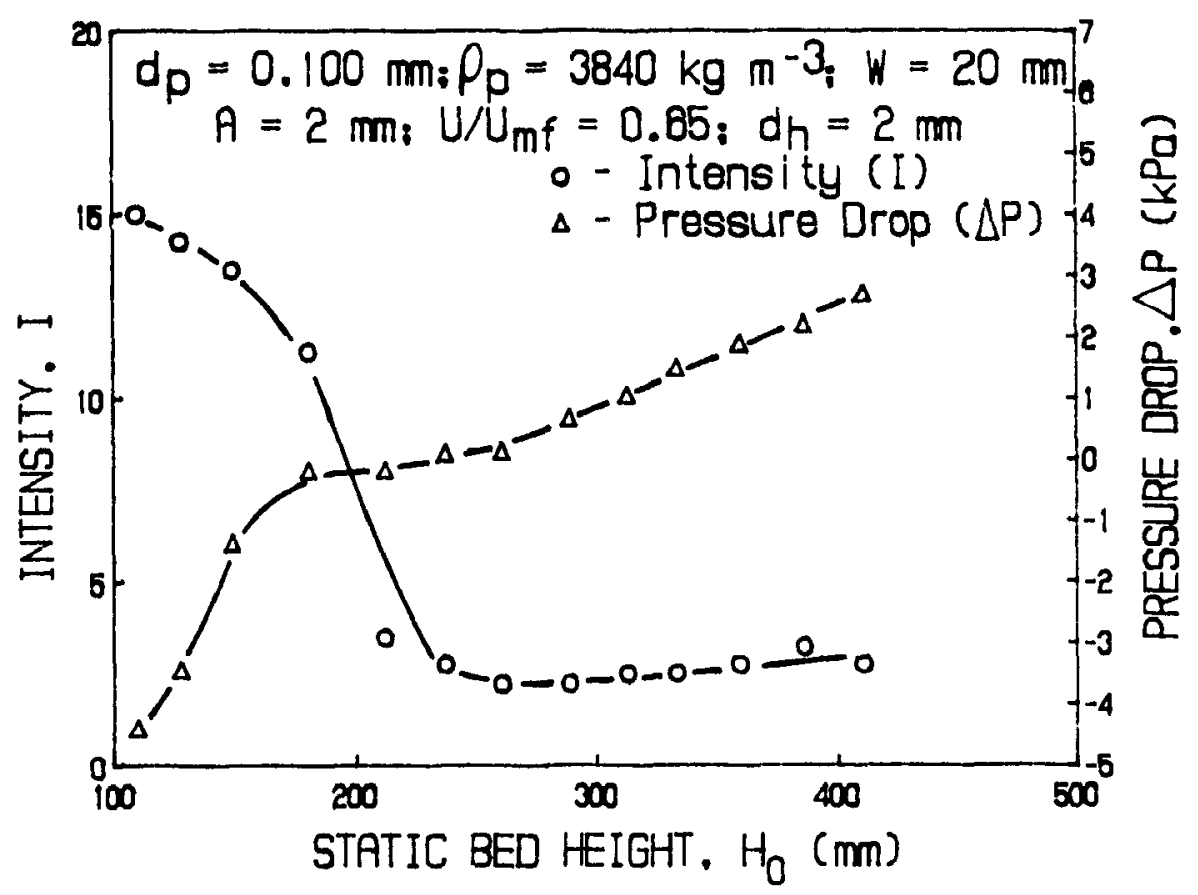

(b)

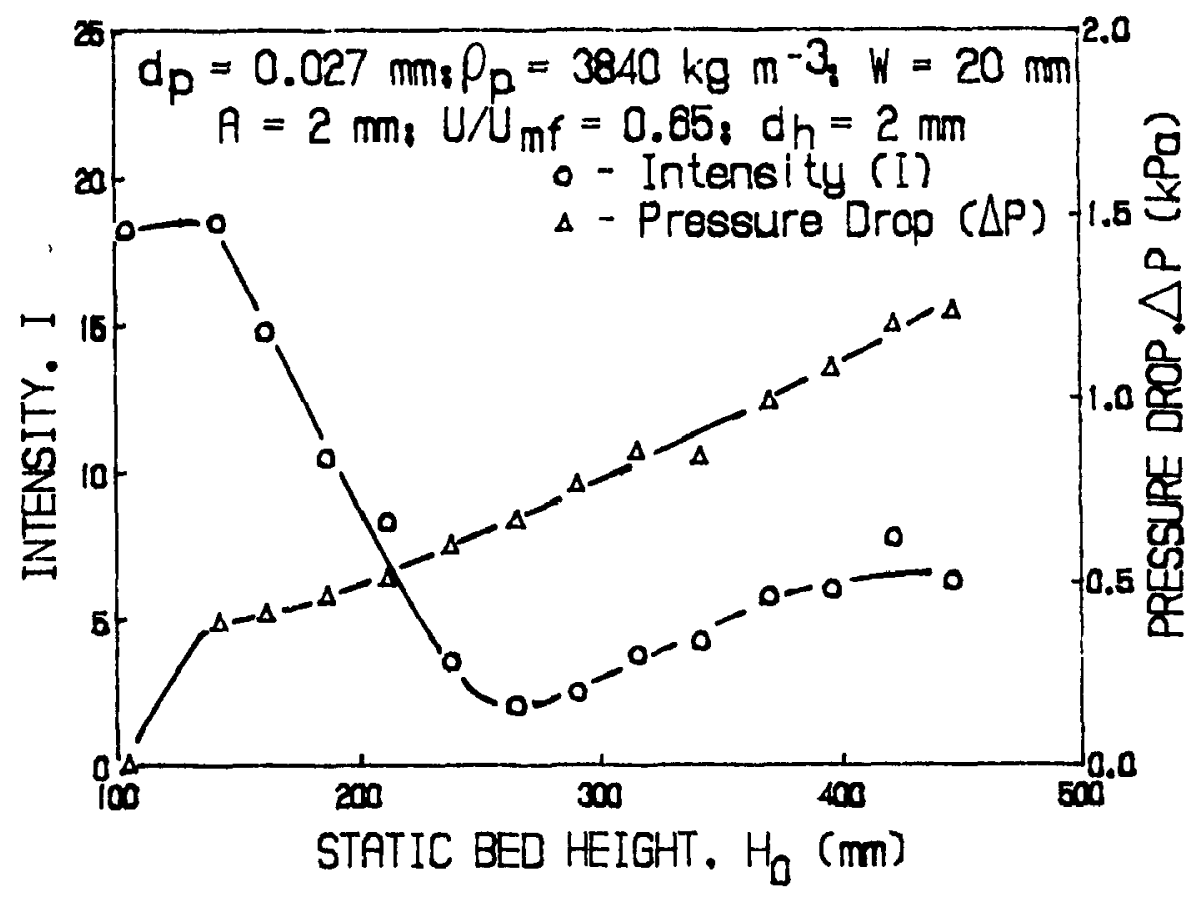

Figure 4.8 Variation of resonance intensity factor (I) with static bed height $\left(\mathrm{H}_{n}\right)$ for alumina particles in rectangular column:

(a) $\mathrm{d}_{\mathrm{p}}=0.100 \mathrm{~mm}$ and (b) $\mathrm{d}_{\mathrm{p}}=0.027 \mathrm{~mm}$. 
$\mathrm{A}=2 \mathrm{~mm}$, an air flow rate of $\mathrm{U} / \mathrm{U}_{\mathrm{mf}}=0.33$ through a single orifice in the bottom plate, Figure 4.9 shows two sets of results for the variation of the resonant bed height $\left(\mathrm{H}_{\mathrm{r}}\right)$ with resonant frequency $\left(\mathrm{f}_{\mathrm{r}}\right)$. Least square analyses were used to draw these and other lines in this chapter. The figure shows that the results are reproducible. The slope of the line in this figure is -1.05 , i.e. $-a=1$. The dependence of $f_{r}$ on $H_{r}$ can then be expressed by Equation 4.23. These results are in accordance with those of Hashimoto and Sudo (1987) who reported that the greater the height of a vibrating liquid column the smaller the threshold input frequency for the onset of resonance.

With $\mathrm{A}=2 \mathrm{~mm}$ and $\mathrm{U} / \mathrm{U}_{\mathrm{mt}}=0.33$, the bottom plate was changed to one with five holes. The results for this and for that with a single hole under the same conditions are shown in Figure 4.9. The amplitude of the surface waves produced at the resonant point was not as great with the five-hole distributor as with the single-hole one (Figure 4.11b). This is probably due to reduced entrapment of air and it shows that the system is closer to the critical \% of open area.

Other experiments with $\mathrm{A}=1$ and $4 \mathrm{~mm}$ with all other parameters remaining the same, were conducted producing results shown in Figure 4.10. The "fingers" of particles at the resonant condition for $A=4 \mathrm{~mm}$ were more extended than those for $\mathrm{A}=1 \mathrm{~mm}$ or $2 \mathrm{~mm}$ as shown in Figures 4.12a, 4.11a, and 4.1 $\mathrm{b}$. These "fingers" represent the amplitude of the surface waves. In addition, $f_{r}$ decreases with an increase in A. A similar result was obtained by Hashimoto and Sudo (1988) for a vibrating liqurd column i.e. $\mathrm{f}_{\mathrm{r}}$ decreases with an increase in $A$. With $A=2 \mathrm{~mm}$, $\mathrm{U} / \mathrm{U}_{\mathrm{m}}$ was increased to 0.73 and the result under this conditoon of air flow is shown in Figure 4.10. 


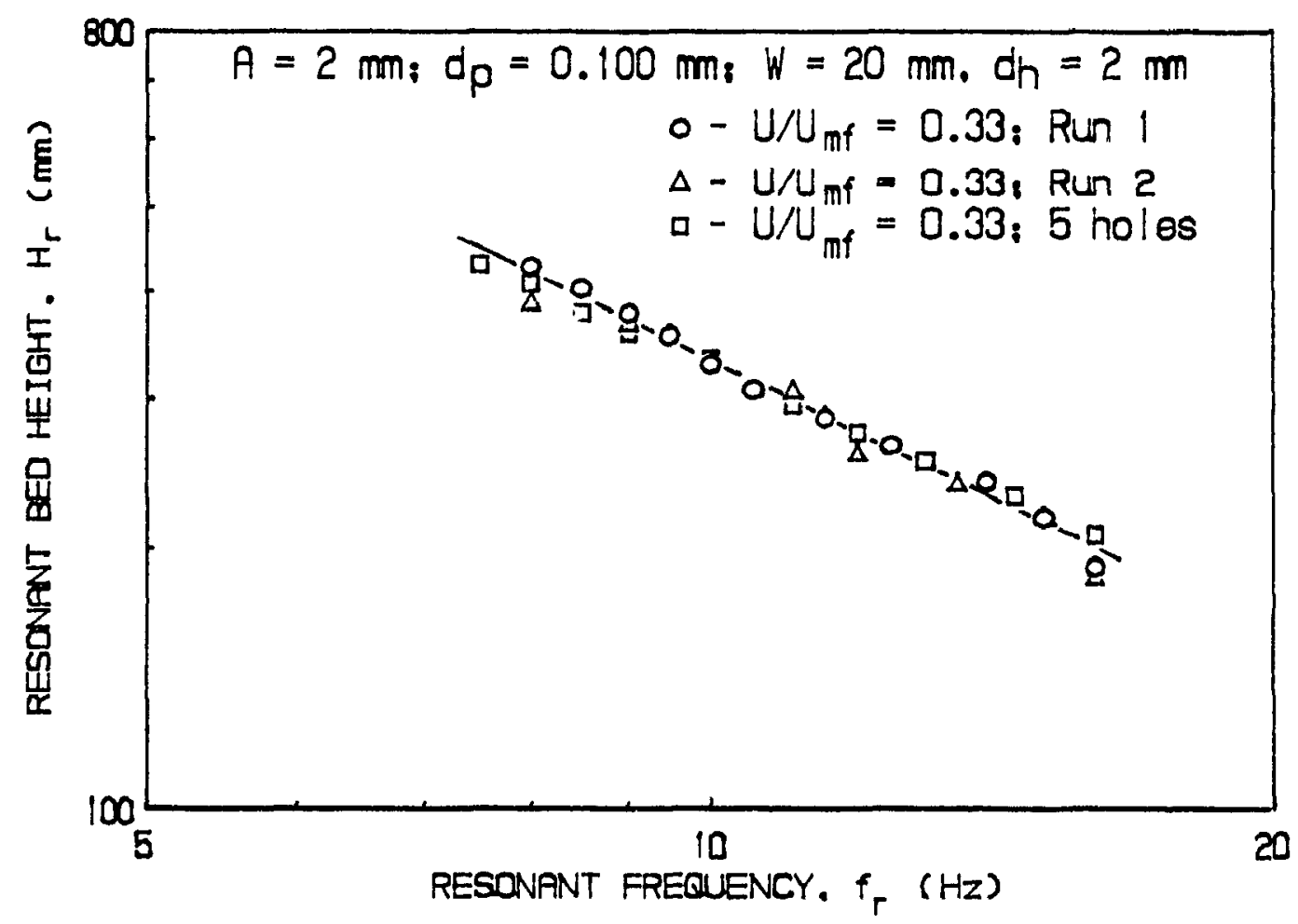

Figure 4.9 Variation of resonant bed height with resonant frequency for alumina particles $(100 \mu \mathrm{m})$ in the cylindrical bed. 


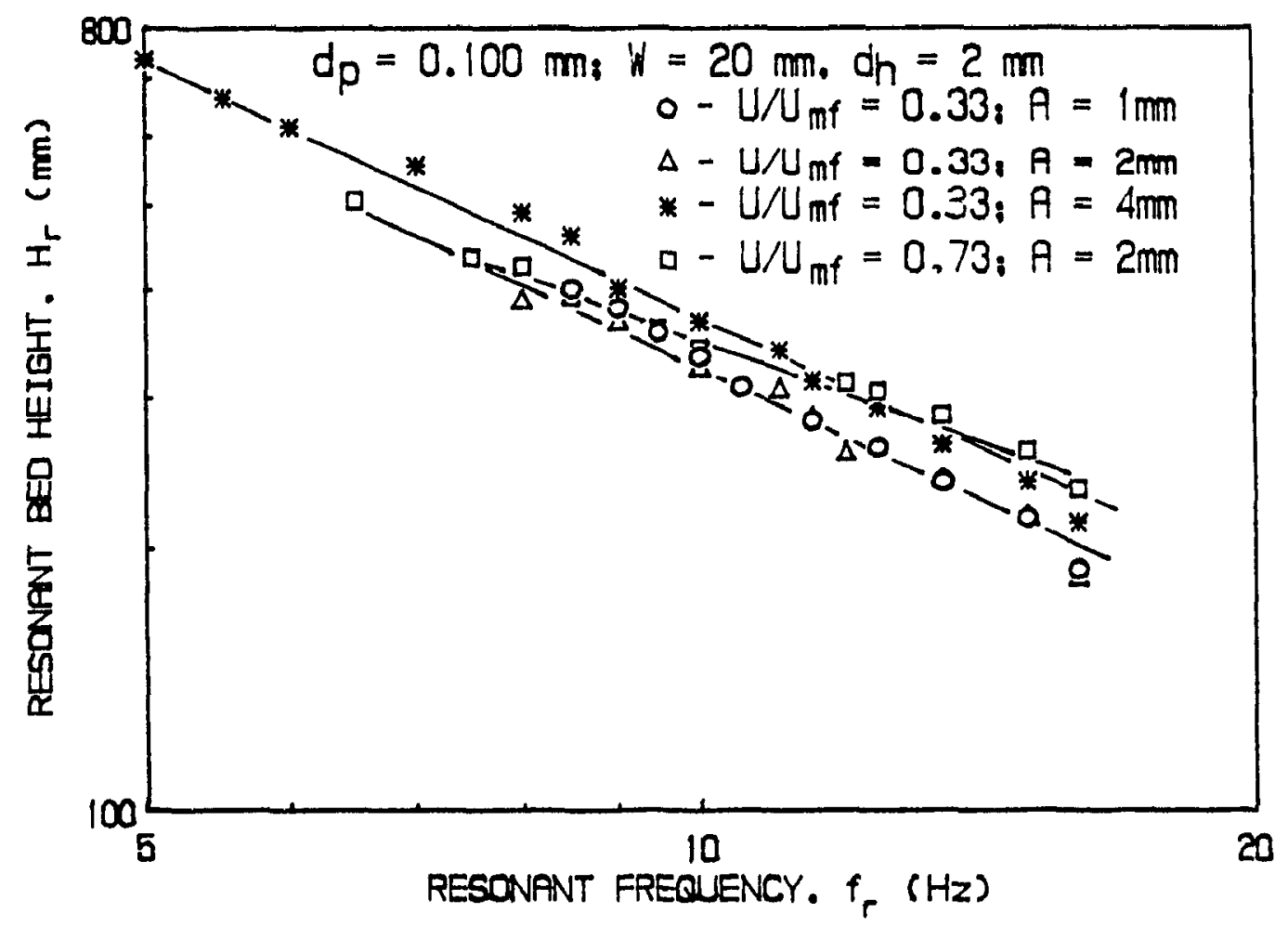

Figure 4.10 Variation of resonant bed height with resonant frequency for alumina particles $(100 \mu \mathrm{m})$ for different $A$. and $U / U_{m t}$ values in the cylindrical bed using a bottom plate with one central hole. 
(a)

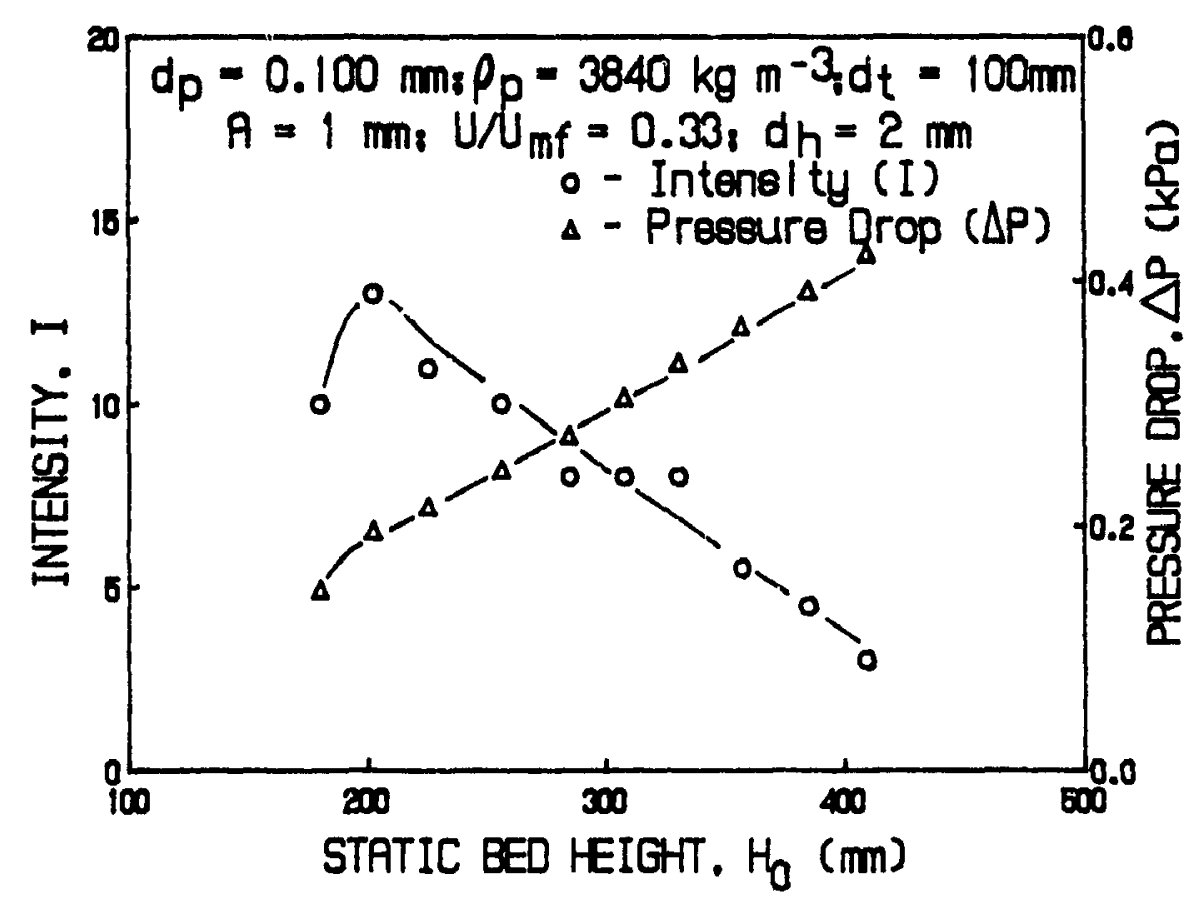

(b)

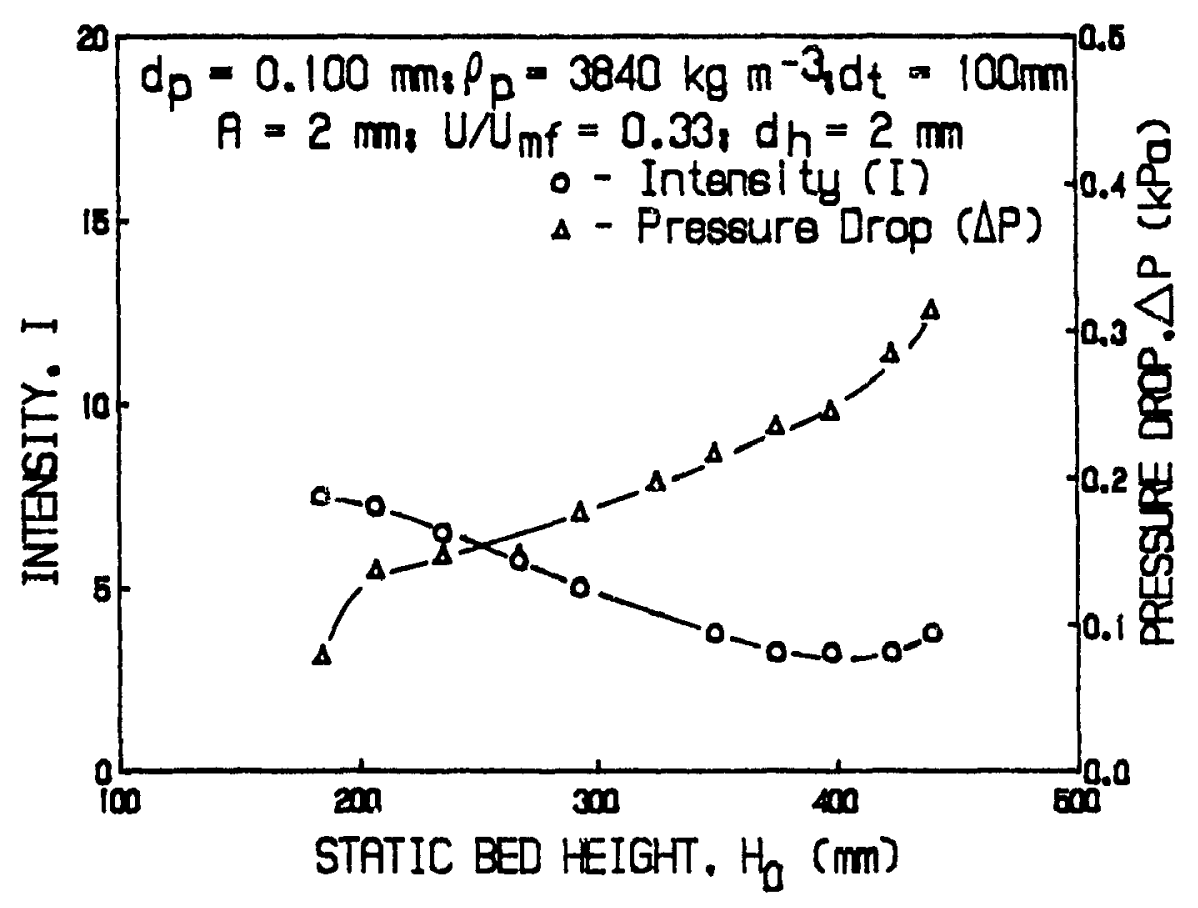

Figure 4.11 Variation of resonance intensity factor (I) with static bed height $\left(\mathrm{H}_{n}\right)$ for alumina particles in cylindrical column:

(a) $\mathrm{A}=1$ and (b) $\mathrm{A}=2$ (bottom plate with 5 holes). 


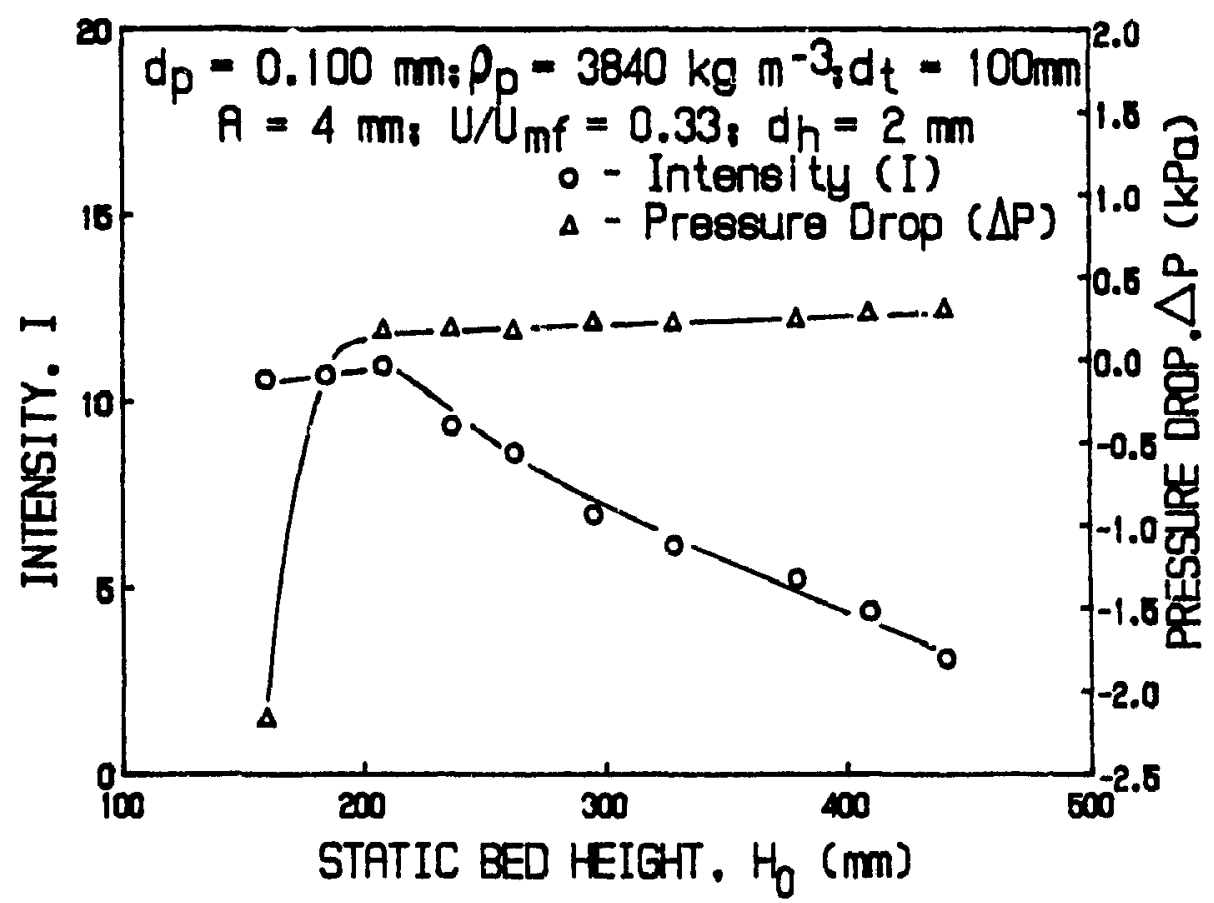

(a)

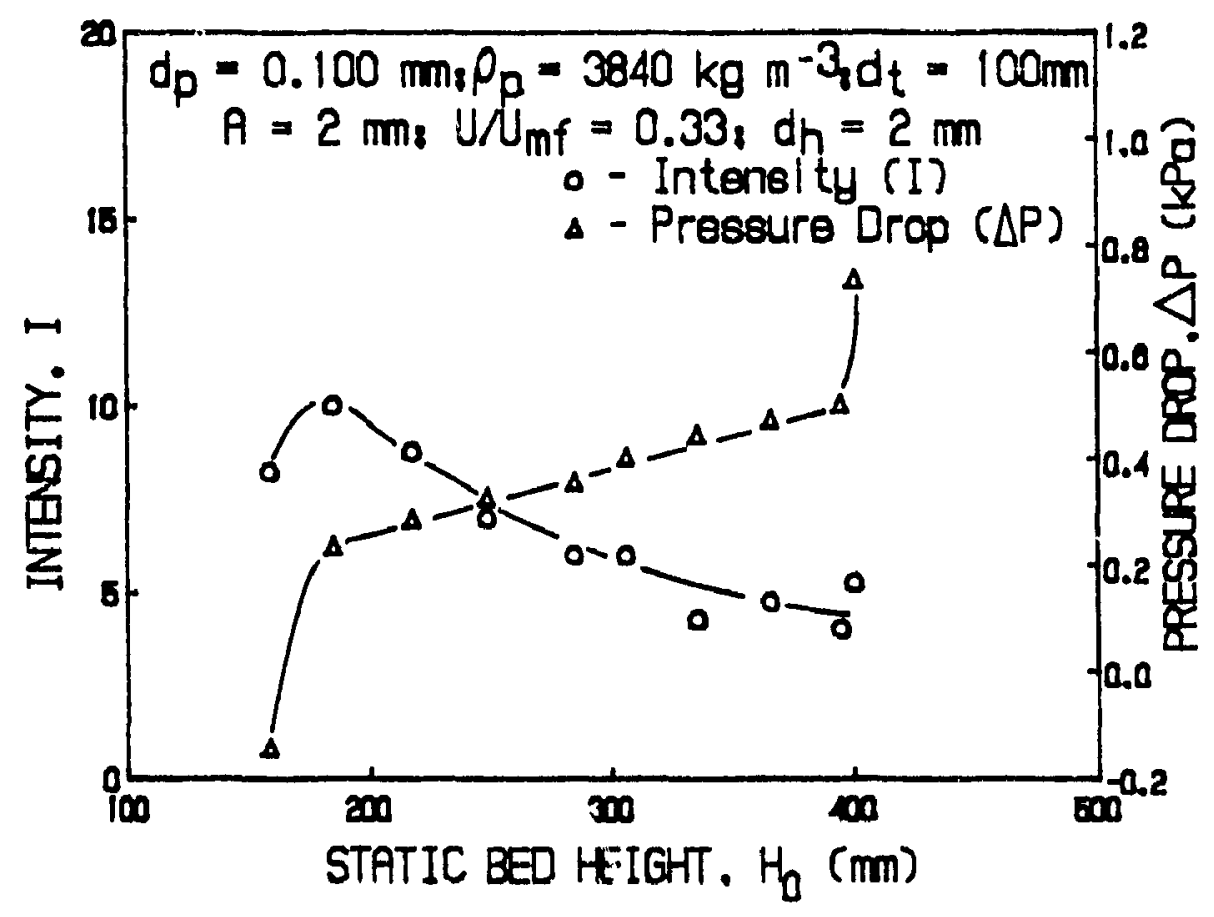

Figure 4.12 Variation of resonance intensity factor (I) with static bed height $\left(\mathrm{H}_{n}\right)$ for alumina particles in cylindrical column:

(a) $A=4$ and (b) $A=2$. 
The data for $A=2 \mathrm{~mm}$ and $\mathrm{U} / \mathrm{U}_{\mathrm{mr}}=0.33$ in Figure 4.10 and the dattit in Figute 4.9 yield the same straight line. Both are for $\ln \mathrm{H}_{r}$ plotted against $\ln \mathrm{f}_{r}$. This indicites that the resonant frequency varies inversely with the corresponding tesonimt bed height as expected from Equation 4.23. However, for an amplitude of $4 \mathrm{~mm}$, the slope of the in $H_{r}$ vs $\ln f_{r}$ plot is -0.78 . When $U / U_{m c}$ was increased from 0.33 to 0.73 . the slope of the line was equal to the others mentioned earlier (unchanged at $a=-1$ ), but the value of the constant $b$ is larger (4640 compared to 3910). These results indicate that the resonance phenomenon in the system (cylindrical bed) is not very sensitive to air flow rate or its distribution. An increase in the air flow rate seems to serve only to increase the bed height at a particular frequency without any other discernible effect. The amplitude of vibration of $4 \mathrm{~mm}$ appears to intluence the phenomenon by affecting the wall frotion, decreasing damping within the bed and by altering the gas flow through the bed possibly via the "pumping" effect.

\subsubsection{Resonance in the Rectangular Bed}

The mechanism leading to resonance seems to be the same in the rectingular bed as it is in the cylindrical one. This is not surprising as Garrett (1970) hats explained that when the wave-maker is submerged, the excitation depends only on the acceleration of the mean free surface and the problem resembles that of one where the whole vessel containing the fluid is vibrated. However, whule the mechanism of resonance seems to be the same in both beds, other unknown eftects ate manifested in the rectangular bed. Bed behaviour may not be appropriately described by Equation 4.23 since $-\mathrm{a}=1$ and must then be described by Equation 4.25 instead. Figure 4.13 shows the results for $\mathrm{A}=2 \mathrm{~mm}$ and a single hole in the centre of the bottom plate for experiments carried out at varyıng bed thıcknesses, keeping $U / U_{m !}$ 
constant at 0.65 . Bed thicknesses of $40 \mathrm{~mm}$ and greater appear to have negligible effect on the variation of the resonant bed height with the corresponding resonant frequency. The value of the slope of $\ln \mathrm{H}_{r} v s \ln f_{r}$ plots in these cases is -0.76 . The value of the slope for the $20-\mathrm{mm}$ bed is the same but the value of the constant $\mathrm{b}$ is lower (1535 compared to 2190 ). This may be attributed to greater wall and damping effects in this case. As indicated in Figure 4.13, experiments were conducted under the same conditions as those previously described except that the air flow rate per unit cross-sectional area was kept constant. Under these conditions the value of the slope is $\mathrm{a}=-0.66$ for the $40-\mathrm{mm}$ bed and $\mathrm{a}=-1.23$ for the $60-\mathrm{mm}$ bed. This may be ascribed to reduced damping effects at higher air flows for the $60-\mathrm{mm}$ bed.

For $\mathrm{U} / \mathrm{U}_{\mathrm{mt}}=0.65, \mathrm{~W}=40 \mathrm{~mm}$ and $\mathrm{A}=2 \mathrm{~mm}$, Figure 4.14 shows the result of the effect of the hole location on the variation of $\ln \mathrm{H}_{\mathrm{r}}$ with $\ln \mathrm{f}_{\mathrm{r}}$. The value of the slope for all the lines in this figure is a $=-0.76$. When off-centre, the hole was $10 \mathrm{~mm}$ from one side and $30 \mathrm{~mm}$ from the other side of the vessel. The orifice posttion has negligible effect on the results i.e. air distribution is not critical to the onset of resonance. This conclusion was supported by several other experiments.

Data for other particles such as very fine alumina $(6 \mu \mathrm{m})$, fine alumina $(27 \mu \mathrm{m})$, glass beads $(100$ and $215 \mu \mathrm{m})$ as well as $100-\mu \mathrm{m}$ alumina are shown in Figure 4.15. The 6- $\mu \mathrm{m}$ alumina beds were supported on a perforated bottom plate with $A=2 \mathrm{~mm}$ and $\mathrm{U} / \mathrm{U}_{\mathrm{m}}=0.65$ for $100 \mu \mathrm{m}$ alumina. Fine alumina $(27 \mu \mathrm{m})$ displayed behaviour similar to $(100 \mu \mathrm{m})$ alumina; the slope was $\mathrm{a}=-0.71$ in these cases. The behaviour of the other particles in Figure 4.15 may be described by Equation 4.23 since $\mathrm{a}=-1$. However, the constant $b$ for the alumina was lower (2680 compared to 3310). 


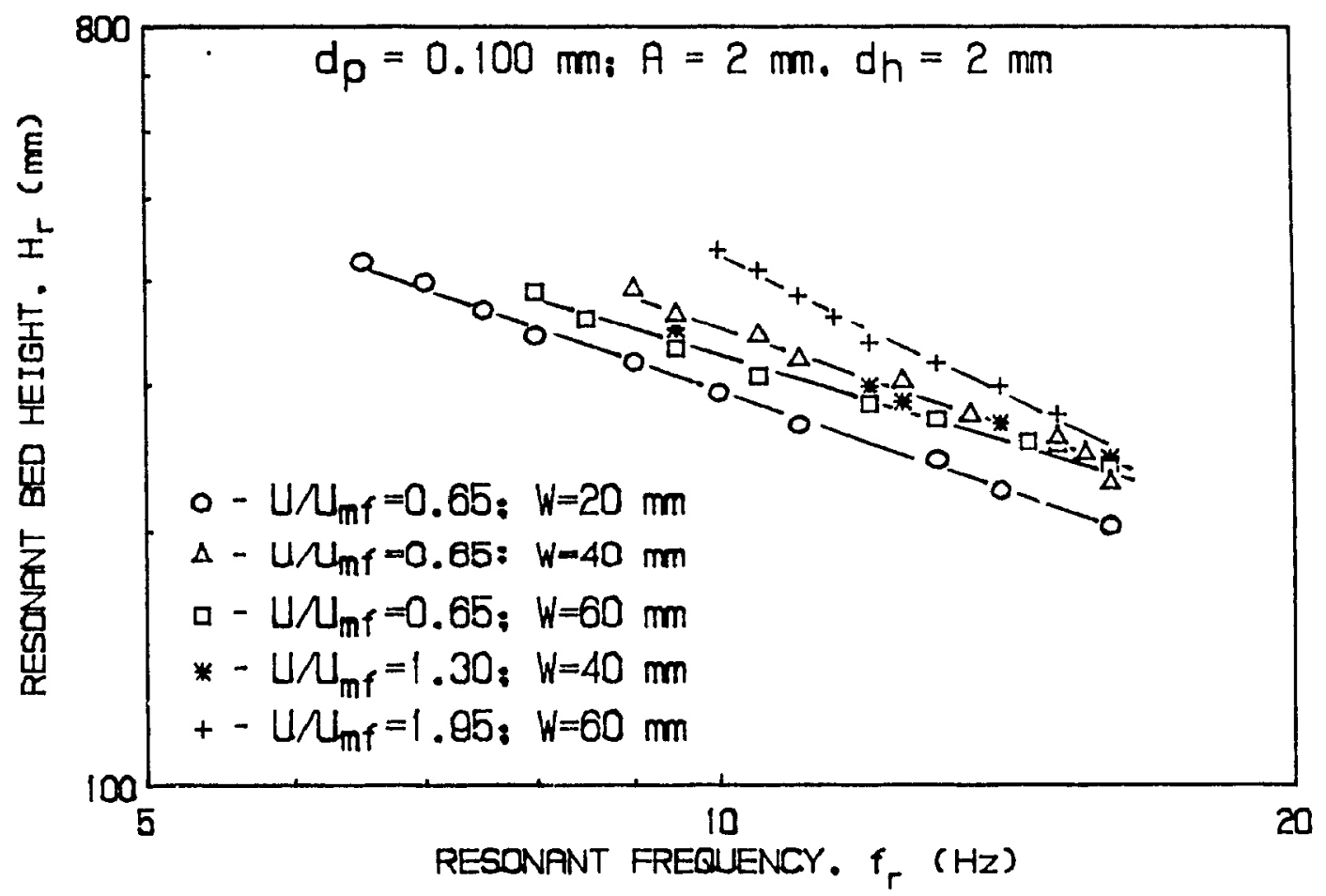

Figure 4.13 Variation of resonant bed height with resonant frequency for alumına particles $(100 \mu \mathrm{m})$ at different bed thicknesses for constant aur flow and constant air flow per unit area in the rectangular bed using a bottom plate with one central hole. 


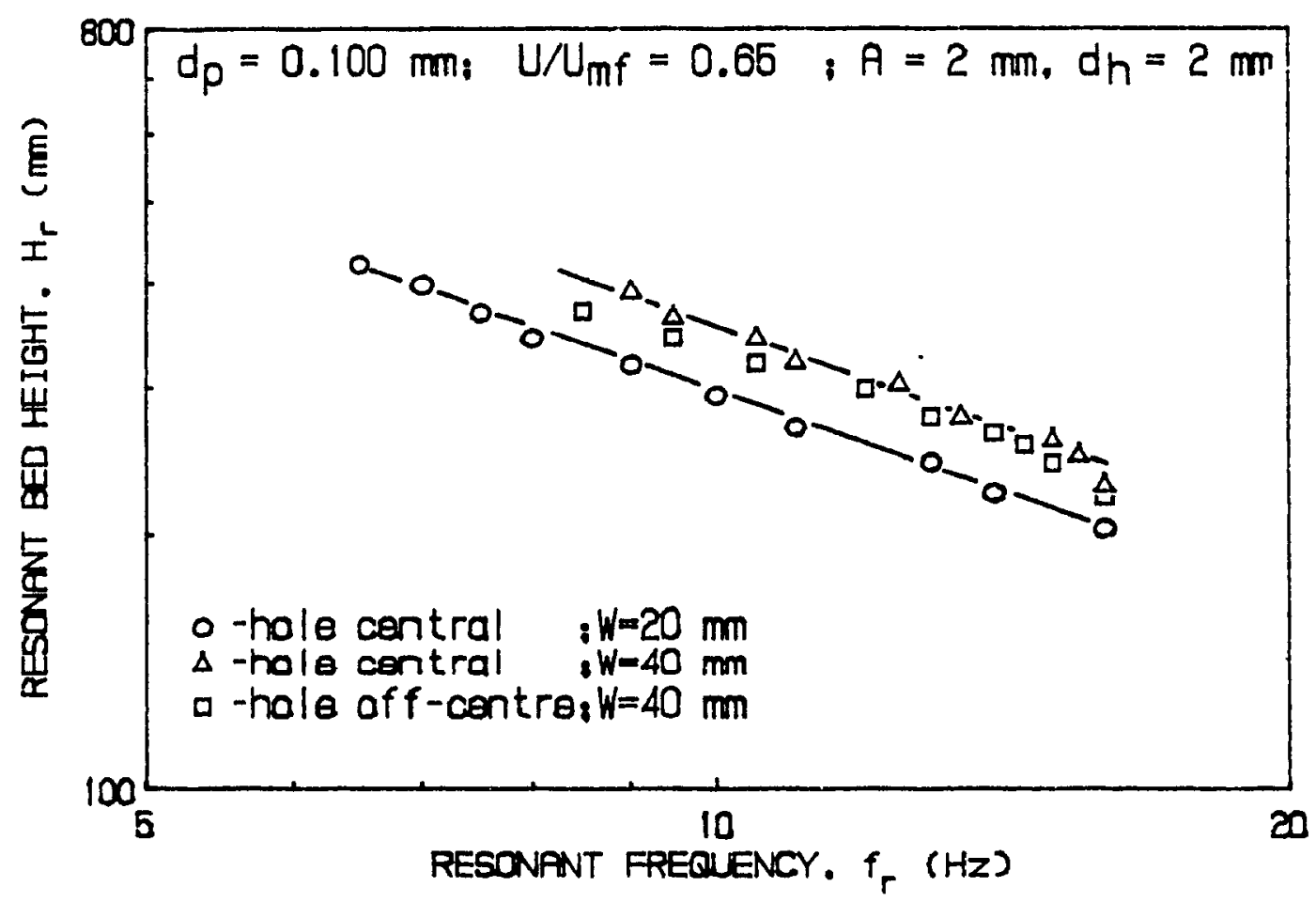

Figure 4.14 Effect of the position of the single hole in the bottom plate on the variation of the resonant bed height with resonant frequency for alumina in the rectangular bed. 


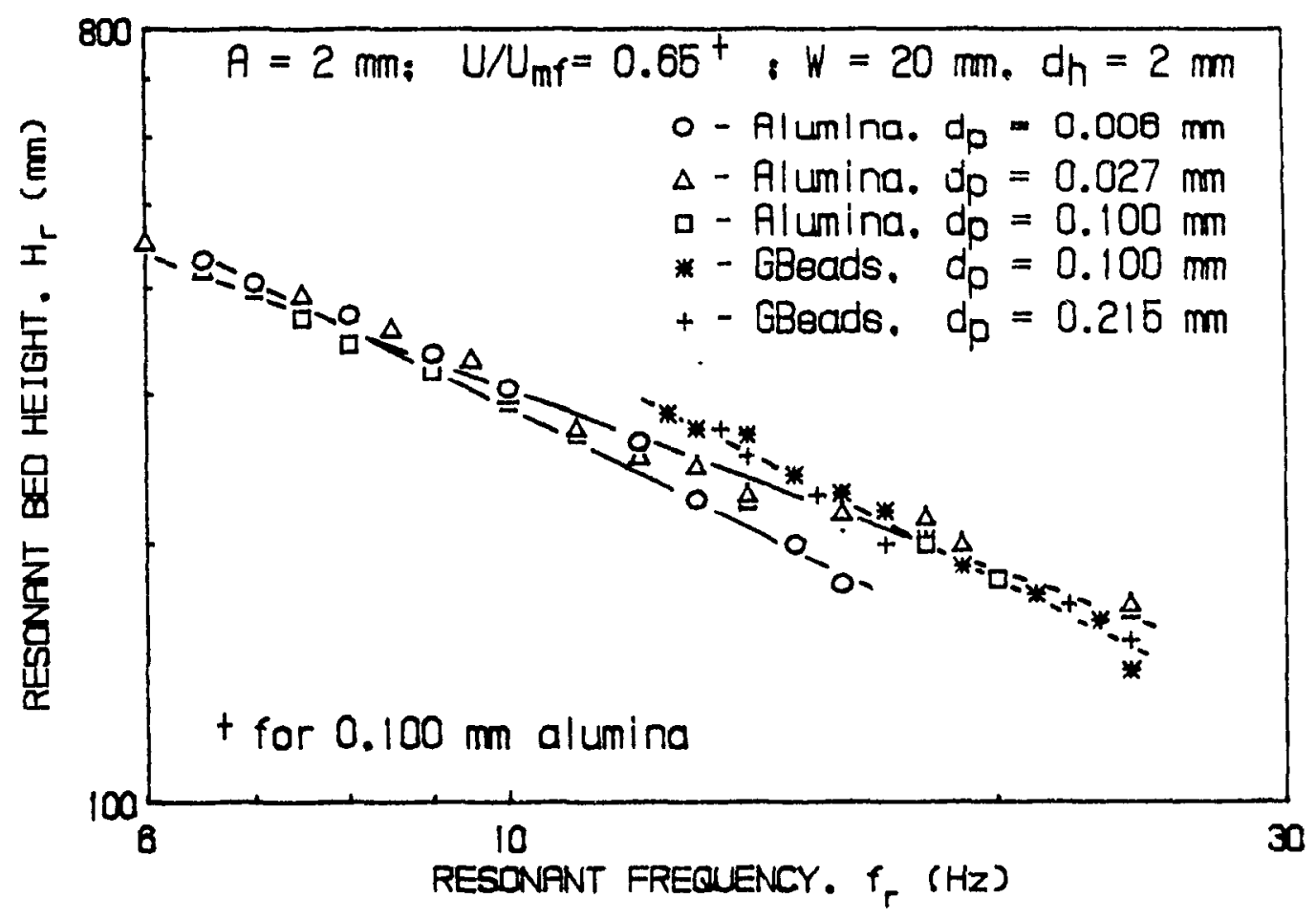

Figure 4.15 Effect of the particle size and type on the variation of the resonant bed height with resonant frequency in the rectangular bed. 


\subsubsection{Effect of Particle Size and Type}

Resonance took place with beds of very fine alumina $(6 \mu \mathrm{m})$ as well as $27-$ and 100 $\mu \mathrm{m}$ alumina particles and $105-$ and $215-\mu \mathrm{m}$ glass beads but not with the other particles used. As stated in Section 4.2, this study shows that resonance takes place almost exclusively in beds of small particles $\left(\mathcal{A}_{\mathrm{p}}<250 \mu \mathrm{m}\right.$ as seen in Table 4.1). Smaller particles not only increase the resistance to percolation of air through the bed, but they also help trap some air in the bed possibly in the form of pockets which act as disturbances in porosity distribution. The trapping of air in the bed possibly gives rise to some degree of compressibility and allow the growth of pressure oscillations. The implications of this were discussed in Section 4.3. Since larger particles cannot trap as much air in the form of pockets as smaller ones, the bed compressiblity is reduced and the resonant condition is not discernible.

Beds of $180-\mu \mathrm{m}$ alumina showed no discernible resunant effects. However, when a mixture of 1:2 mass ratio of $100-\mu \mathrm{m}$ and $180-\mu \mathrm{m}$ alumina is subjected to aeration and vibration, a resonant condition results. This is apparently due to the presence of smaller particles filling the spaces between the larger ones resulting in increased resistance to the passage of air and increased compressibility of the bed. It is noteworthy that the particles were always intimately mixed and no segregation resulted.

While heds of glass beads exhibited behaviour that may be described by Equation 4.23 at low-to-medium bed heights $(70-260 \mathrm{~mm})$, the resonant frequency did not change with bed height beyond this point. This anomalous behaviour could not be explained. 


\subsubsection{Effect of the Bottom Distributor Plate}

For $100-\mu \mathrm{m}$ alumina, the resonant condition is not observed when the bottom plate is perforated (open area of $6 \%$ or $19 \%$ ). This is apparently because in thes cilse nus air is trapped within the bed and hence its conipressibılity is reduced. The reduced vigour in the resonant condition when a bottom plate with tive holes $(0.2 \%$ open area) is used, instead of that with just one hole $(0.08 \%$ for the $2(1)-\mathrm{mm}$ lhich rectangular bed and $0.04 \%$ for the cylindrical bed), appears to be due to reduced trapping of air in the former case. There then seems to be a critical percentige of open area (between 0.2 and $6 \%$ ) beyond which resonance does not occur. The tact that the position of the hole in the bottom plate does not affect the conditon is presumably due to similar trapping of the air irrespective of the postton of the bottom hole.

The resonant condition was observed for the very tine alumına $(6 \mu \mathrm{m})$ partucles when the perforated plate with $19 \%$ open area was used. However, when there wils inly a single central hole in the bottom plate, no resonance wals observed. Since the vibration frequency was increased from $0 \mathrm{~Hz}$. for these small particles, the bed was compacted to form a plug at the lower frequencies. This resulted in particles blocking the air entrance to the vessel thereby preventing air from being trapped in the bed in the form of pockets. At higher trequencies, the bed could not be looseneci by vibration. With the perforated plate the bed remained loose.

\subsubsection{Effect of Air Flow}

Air presence in sufficient quantities is necessary to give the bed a degree of compressiblity. At lower aeration rates the magnitude of the air thow ritte has little 
effect on the resonant condition. The resonant condition is present even when very low air flows are used. Yet, there must be a minimum air flow rate for resonance to he maintained; the lower limit of air flow could not be measured; it is well below $\mathrm{U} / \mathrm{U}_{\mathrm{m} !}=0.30$. If air is allowed to be "pumped" niturally into the vibrating bed, a resonant condition is achieved at the resonant frequency corresponding to that bed hejght, as long as the openings at the top and bottom of the vessel are not closed. Alr is sucked in through the bottom orifice due to the reciprocating piston-like action of the bed. Air is pulled in through the top of the vessel due to the negative pressure gradients across the bed. Alr is torced out due to the positive pressure gradient at the inlet to the forced ar flow. This means that when the resonant condition is intense (I $>3$ ), air is pulled into the bed even from the top opening and pumped back out perıodically. High aeration rates tend to degenerate the resonant condition. Presumably, air does not get an opportunity to be trapped in the bed in this case and pressure fluctuations do not build up.

For a "loose" bed in the absence of air flow, air is freely pulled through the vibrating bottom plate to sustain resonance. It appears that unless air is supplied contınually, alr must be "trapped" in the bed to produce the resonant condition. The fact that the bed can sustain itself at resonance with no forced gas flow, suggests that gas flows within the bed were generated by these pressure pulsatıo: ; discussed in Section 4.3.2.

Further, if the air flow to a resonating bed is suddenly cut off, the bed continues to resonate. However, if for the same bed, the air flow is cut off and the vibration frequency reduced below the resonant frequency, the resonant condition disappears and the bed is compacted. Increasing the frequency back to its original value does 
not restore resonance.

\subsubsection{Bed Pressure Drop and Resonance}

Bed pressure drops increased with decreasing frequency and with increasing bed height at lower bed heights $\left(\mathrm{H}_{1}<260 \mathrm{~mm}\right)$, but remanned essentlally constant an higher bed heights i.e. almost independent of bed height and frequency (Figures 4.5. 4.6, 4.7 and 4.8). At low-to-medium bed heights $\left(H_{n}=70-260 \mathrm{~mm}\right)$. negillace pressure drops across the bed were generally observed. It is worth noting thit thu is the same range of bed height where the resonant behaviour is vigorous. The pressure drop data are in accordance with those obtanned by Chlenov and Mikhanlow (1972). The absolute value of the negative pressure drop increised with decreising particle size but it did not increase with bed depth. In tact, the higlest atbolute values of negative pressures $(-4.4 \mathrm{kPa})$ were obtanned at the hallowest hed heights used $\left(\mathrm{H}_{10}=70-100 \mathrm{~mm}\right.$ ) which corresponded to the highest trequencies (about 25 $\mathrm{Hz}$ ). The observations agree with those of Bukareval et al. (1974). Whale negiltase pressure drops were not observed in the cylindrical hed with the non-vibrating vessel in some cases, they were always observed at low-to-medium hed heghts $\left(\mathrm{H}_{1}=70\right.$. $260 \mathrm{~mm}$ ) with the rectangular aerated vibrated bed for which the dsubutor platle vibrates with the vessel. Negative pressure drops were never obtinned for this yinfem for the very fine $(6 \mu \mathrm{m})$ particles. In fact, the particles tenderl to stuck wgether allowing air to pass between these loose agglomerates. 


\subsection{CLOSURE}

A resonant condition occurs in aerated vibrated beds of small particles. This condition does not occur in beds of large particles $\left(d_{p}>250 \mu \mathrm{m}\right)$. The resonant trequency is defined as that at which the bed expands rapidly to its peak bed height (i.e. highest porosity) and develop intense surface waves like those observed in oscillating liquad columns. The surface waves are considered to be the result of the propagation of pressure oscillations created in the bed. The propagation of the pressure waves is eftected through the trapping of air in pockets in the bed thereby impartıng a degree of compressibılity to the bed. This compressibility allows the propagation and amplification of pressure waves which lead to resonance. In the cylindricil bed the dependence of frequency un bed height can be described by Equation 4.23 based on a simplified model of the aerated vibrated bed as a single-mass vibrating system. In the rectangular bed, the prenomenon may be described by Equation 4.25 developed on the same basis. Air flow rate has only a weak eftect (a slight amplifying effect with increasing air flow) on the resonant treyuency while air distribution has no measurable effect. High aeration rates degenerate resonance. Higher halt-amplitudes of vibration (around $4 \mathrm{~mm}$ ) have an implifying effect on the resonant condition i.e. the resonance intensity factor increases with increasing $A$. Furthermore, the resonant frequency decreases with increasing half-implitude of vibration i.e. resonance occurs at lower frequencies. Bed thicknesses have very strong effects on the resonance phenomenon in rectangular ilerated vibrated beds. 


\section{CHAPTER 5. BUBBLE PHENOMENA}

\section{$5.1 \quad$ INTRODUCTION}

The growth of bubbles and their distribution withn the bed are impostant phenomena in view of their influence on the efficiency of gas-solud contactung which in turn governs the heat/mass transfer operations and chemical reactions in alerated beds of particles. Smaller bubbles result in more uniform mixing and better heat/mass transfer. Empirical correlations for the calculation of bubble characteristics (bubble size, veloctty and frequency) exist only for conventional tluidized beds (Davidson anci Harrison (1963), Gelperın et al. (1967), Kunii and Levenspiel (1984) and Cheremissinoff and Cheremissinoff (1984)).

In aerated vibrated beds, bubble formation may occur due to the inherent "pumping" effect, i.e. forced infiltration of the gas as a result of intensive plug-type moton of the bed and the periodic porosity fluctuations. In this study, the focus is on a comparative analysis of bubble characteristics in conventional gas-fludized beds and aerated vibrated beds and the implications for the design of vibrated beds for drying and chemical reactions.

In this thesis, air flow rates are reported as $U / U_{m f}$ irrespective of the design of the bottom plate. For example, for an incipiently gas-fluidized bed (in the absence of vibration), $\mathrm{U} / \mathrm{U}_{\mathrm{m}}=1$. Air flow through a perforated bottom p'ate is based on the cross-sectional area of the bed. Air flow through the single orifice in the bottom plate is also based on the area of cross-section of the bed. In this thesis, the different methods of aeration are generally specified. However, if the type of bottom plate 
Is not specified, it may be correctly assumed that reference is being made to the sngle-orifice bottom plate.

\subsection{RESULTS AND DISCUSSION}

Unless otherwise stated all experiments were conducted in the rectangular bed 2()$\mathrm{mm}$ thick fitted with a bottom plate with one central 2-mm hole. Most of the experiments were conducted using $100-\mu \mathrm{m}$ alumina particles. Bubble formation. frequency of tormation, size, rise velocity and shape were studied. Bubble formation was studied with air introduced through a $2-\mathrm{mm}$ wide central slot in the bottom plate spanning the whole thickriess of the bed. Bubble size and rise velocity were measured concurrently with the butible frequency using procedures described in Chapter 3. Bubble rise velocity was measured by determining the time taken by a given bubble to rise between two vertically spaced planes separated by a known distance $(\mathrm{H}=40-100 \mathrm{~nm})$. This region was chosen as the bubbles were best visible at such locations and negligible coalescence was observed. The bubble size is represented by the bubble diameter and was measured at both planes and the average of the two measurements is reported here as the bubble dameter. The projected area of a bubble in the two-dimensional bed was calculated by assuming that the bubble cross-seciion was either circular or eiliptical. The diameter of an equivalent circle was defined as the bubble diameter (size). Bubble frequency is the number of bubbles initially appearing at the lowest elevation in the bed per unit tıme. 


\subsubsection{Bubble Formation}

Figure 5.1a shows a still f:cture of a bubble being formed in a vibrated bed of alumina particles $\left(d_{p}=100 \mu \mathrm{m}\right)$ for $\mathrm{f}=8 \mathrm{~Hz}, \mathrm{~A}=2 \mathrm{~mm}, \mathrm{H}_{0}=164 \mathrm{~mm}$ and $\mathrm{U} / \mathrm{U}_{\mathrm{m}}=0.65$. The bubble appears in the form of a jet-like vold which is elongated in the vertical direction. It should also be noted that the bubble forms at the surface of the bottom plate. Figure 5.1b shows a bubble being formed for the same conditions except that $f$ was increased to $15 \mathrm{~Hz}$. The resonant frecpuency tor $H_{10}=164 \mathrm{~mm}$ is just greater than $15 \mathrm{~Hz}$. The bubble is tlattened against the bottom plate for $\hat{f}=15 \mathrm{~Hz}$. Figure 5.2 shows schematic diagrams of bubbles being formed under the two conditions depicted in the still pictures of Figure 5.1 as well as (wo) other operatıng conditions. Note that while the bubbles are relatively tlattened at $\mathrm{f}=15 \mathrm{~Hz}$, they have a spherical cap for $\mathrm{f}=24 \mathrm{~Hz}$. It may be concluded that bubbles had relatively tlat bottoms as they are formed at the resonant frequency but more elongated at non-resonant frequencies which are not influenced by the resonant condition. The formation process appears to be similar for all frequencies of vibration.

The bed of alumina particles $\left(d_{p}=100 \mu \mathrm{m}\right)$ was aerated at $U_{m}$ through a pertorated bottom plate. Additionally, air was bubbled through a central hole in the bottom plate at a rate of $U / U_{m}=2.9$. Figure $5.2 \mathrm{~d}$ shows a bubble being formed for $\mathrm{H}_{0}=112 \mathrm{~mm}, \mathrm{~A}=2 \mathrm{~mm}$ and $\mathrm{f}=24 \mathrm{~Hz}$. The same jetting process is seen. However, it must be recalled from Chapter 4 that beds supported on hottom plates with such large percentage $(6 \%)$ open area do not exhibit resonant behaviour. Had the open area been small, $\mathrm{f}=24 \mathrm{~Hz}$ would have ieen the resonant trequency. 


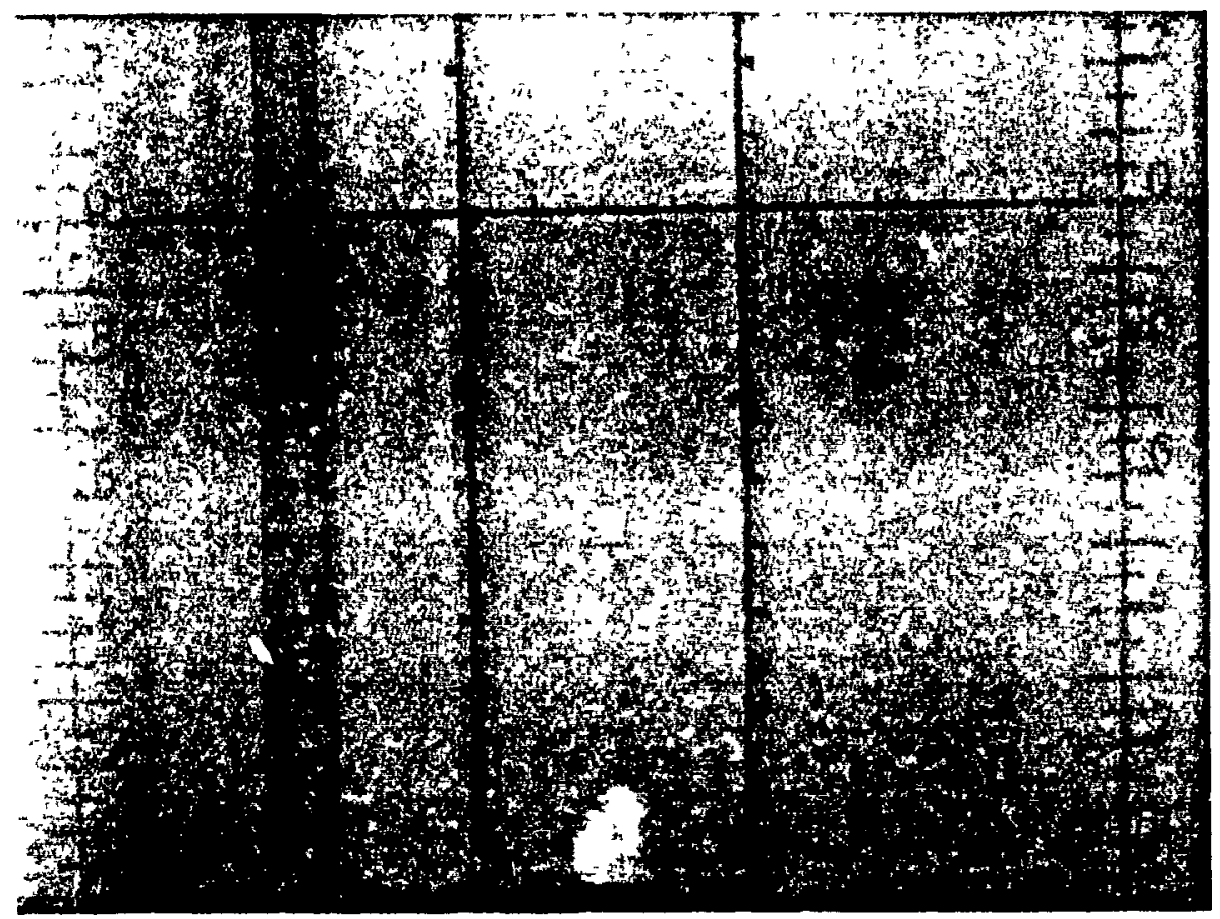

(b)

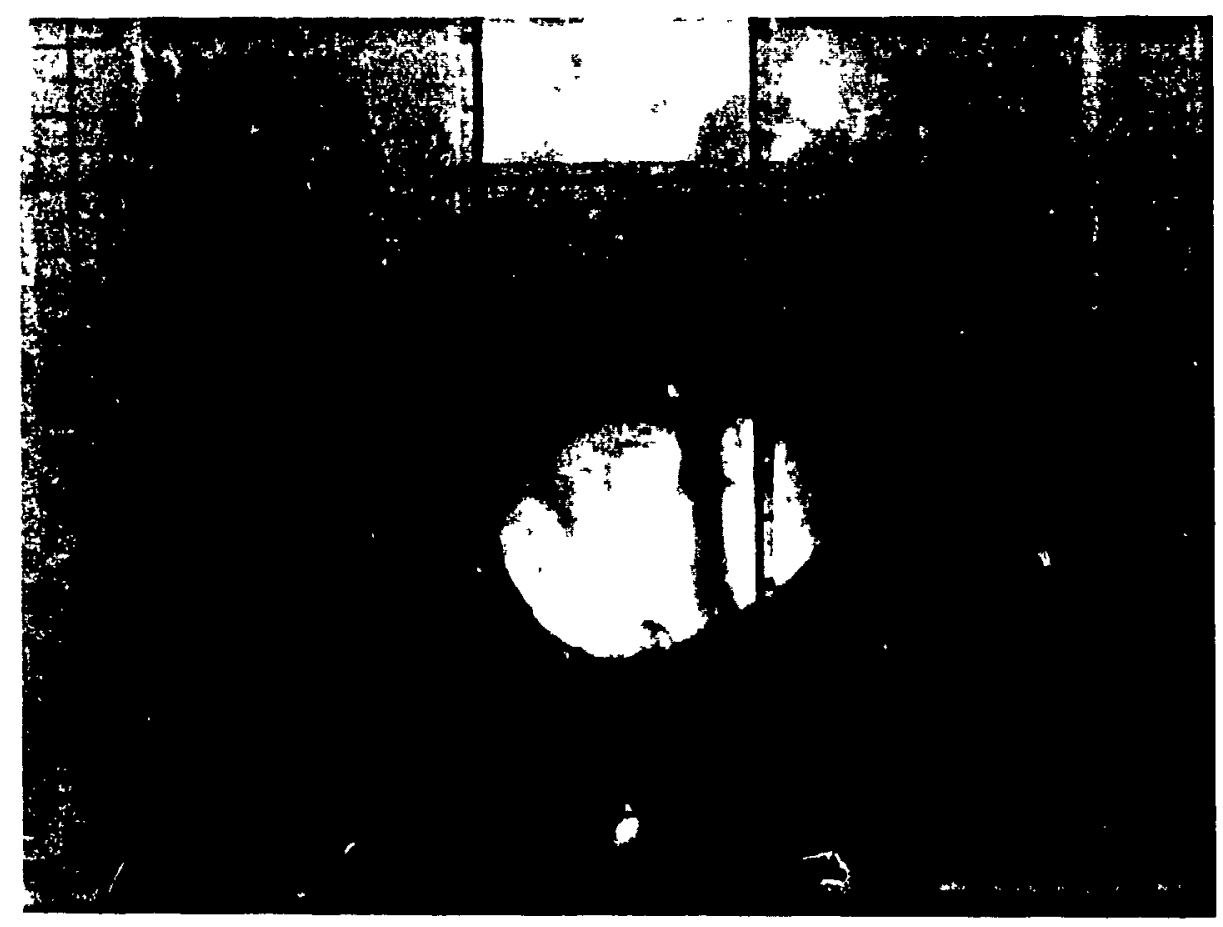

Figure 5.1 Bubble formation in aerated vibrated beds with single hole in bottom plate.

(a) $\mathrm{f}=8 \mathrm{~Hz}, \mathrm{~A}=2 \mathrm{~mm}, \mathrm{H}_{0}=164 \mathrm{~mm}, \mathrm{U} / \mathrm{U}_{\mathrm{mf}}=0.65$ :

(b) $\mathrm{f}=15 \mathrm{~Hz}, \mathrm{~A}=2 \mathrm{~mm}, \mathrm{H}_{0}=164 \mathrm{~mm}, \mathrm{U} / \mathrm{U}_{\mathrm{m} f}=0.65$. 


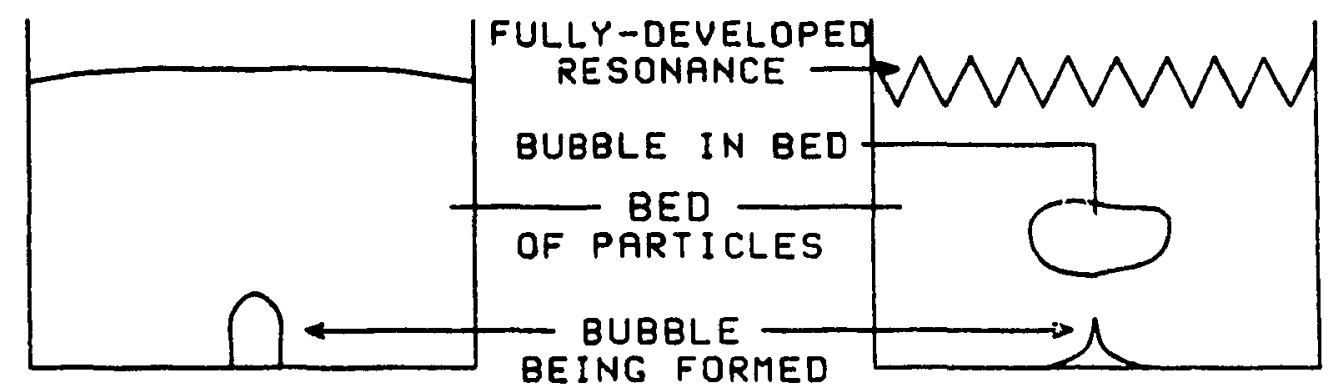

(a) $f=8 \mathrm{~Hz}_{2}, H_{O}=164 \mathrm{~mm}$

(b) $f=15 \mathrm{~Hz}_{2}, H_{O}=164 \mathrm{~mm}$

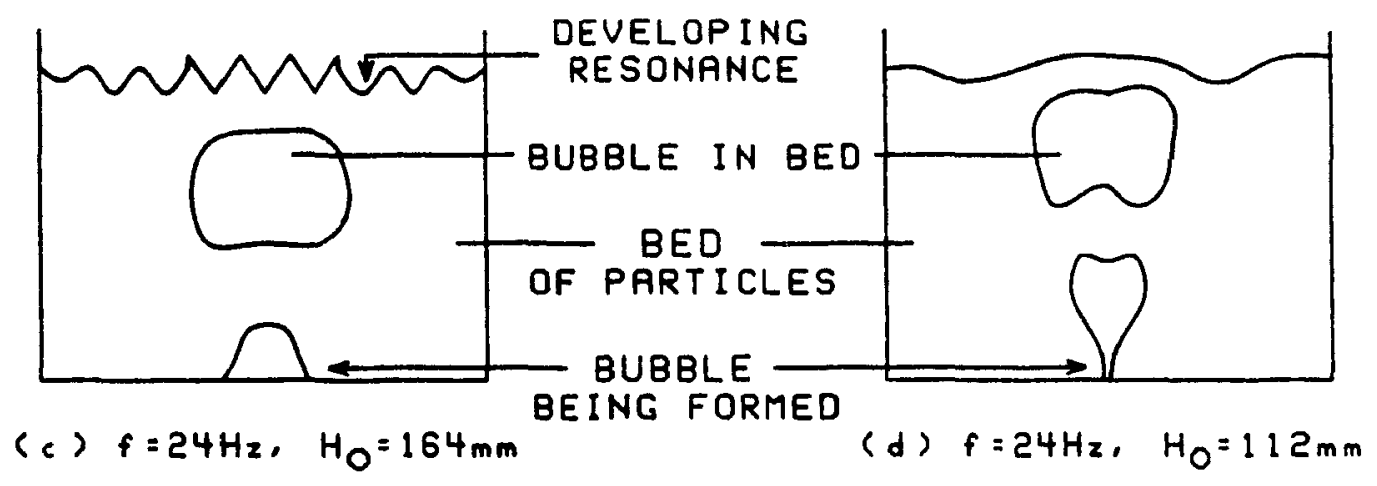

Figure 5.2 Bubble formation in aerated vibrated beds: $\mathrm{U} / \mathrm{U}_{\mathrm{mt}}=0.65, \mathrm{~A}=2 \mathrm{~mm}$; (a), (b) and (c) single hole in bottom plate, (d) perforated bottom plate. 
In aerated vibrated beds, it is believed that oscillations act as nuclei for bubble formation as proposed by Hiby (1967) for fluidized beds. He proposed that oscillation about the ten lowest layers within a bed acts as the triggering mechanism for the formation of bubbles. Furthermore, he found that particles in very shallow beds exhibited periodic vertical oscillations and attributed this to pressure oscillations. For greater bed heights, these pressure oscillations continued but the surface motion became increasingly random. He believed that the disruption of joint oscillation about the lowest particle layers created cavities which acted as nuclei for bubbles. Hiby (1967) theoretically predicted and detected pressure fluctuations in shallow beds and demonstrated periodic bubble formation.

Impressed vibration results in the stabilization of bubbles. This was predicted by Molerus (1967). It is believed that the pressure oscillations (discussed in the preceding chapter) and its disruption by gas inflow is the cause of bubble formation in aerated vibrated beds. This materializes as an initial jet as also seen in gasfluidized beds (Zhang et al. (1987)). However, unlike fluddized beds where the width of the jets increases after leaving the orifice and decreases towards the trailing end, the width of the jets in vibrated beds depends on the excitation frequency. Wallis (1962) suggested that bubbles were shock waves which occur when the rise velocity of the continuity waves exceed the propagation velocity of the dynamic waves in the bed. The periodicity of bubble formation suggests an oscillatory source of bubble formation. 


\subsubsection{Frequency of Bubble Formation}

Figure 5.3 shows the effect of vibration frequency, $f$ on the frequency of bubble formation, $\mathrm{f}_{\mathrm{b}}$ for $100-\mu \mathrm{m}$ alumina. For $\mathrm{U} / \mathrm{U}_{\mathrm{mt}}=2.9, \mathrm{H}_{11}=210 \mathrm{~mm}$ and $\mathrm{A}=+\mathrm{mm}$. $f_{b}$ fell sharply at $11 \mathrm{~Hz}$, fell further at $12 \mathrm{~Hz}$ and increased marginally at higher frequencies. The bubble frequency dropped from a value of $2.74 \mathrm{~s}^{1}$ in the absence of vibration to a value of $0.95 \mathrm{~s}^{\prime}$ at $\mathrm{f}=12 \mathrm{~Hz}$. This compares with a value of about $4 \mathrm{~s}^{1}$ given by Kunii et al. (1967) for fluidized beds of similar particles. The ressonimt frequency for $\mathrm{H}_{0}=210 \mathrm{~mm}$ is $12 \mathrm{~Hz}$. This then implies that vibration frequency hias a strong effect on the bubble frequency which is at its lowest at the resonant point. The variation of $f_{b}$ with $f$ shows opposite trends to the variation of $H$ with $f$ described in Chapter 4.

For $\mathrm{H}_{0}=200 \mathrm{~mm}, \mathrm{U} / \mathrm{U}_{\mathrm{mf}}=2.9$ and $\mathrm{A}=2 \mathrm{~mm}$, the variation of $\mathrm{f}_{\mathrm{i}}$ with $\mathrm{f}$ wals sumilir. However, the change in $f_{n}$ was not as pronounced as for the calse with $H_{n}=210 \mathrm{~mm}$ and the higher amplitude $\mathrm{A}=4 \mathrm{~mm}$. Yet, $\mathrm{f}_{\mathrm{b}}$ decreased with increasing $f$ reachung a minimum at $f=14 \mathrm{~Hz}$. The resonant frequency for this ciase was at $\mathrm{t}_{\mathrm{r}}=1 \mathrm{H} \mathrm{Hz}$. Hence, as for the case with $\mathrm{H}_{0}=200 \mathrm{~mm}$ and $\mathrm{A}=4 \mathrm{~mm}$, the bubble frequency is a minimum at the resonant point. On the other hand, the bubble frequency at $t_{r}$ in this case was $3.16 \mathrm{~s}^{-1}$ i.e. greater than $0.95 \mathrm{~s}^{\prime}$. This implies that the effect of $t$ on $\mathrm{t}_{\text {n }}$ is not as pronounced as at higher amplitudes.

For $\mathrm{H}_{0}=120 \mathrm{~mm}, \mathrm{U} / \mathrm{U}_{\mathrm{mt}}=2.9, \mathrm{~A}=2 \mathrm{~mm}$ and $\mathrm{f}<10 \mathrm{~Hz}, \mathrm{f}_{\mathrm{b}}$ remanned essentially constant i.e. independent of $\mathrm{f}$. However, for $\mathrm{f}>10 \mathrm{~Hz}, \mathrm{f}_{\mathrm{h}}$ decreased monotomially with $f$ up to the highest frequency used, which in this case was $24 \mathrm{~Hz}$. The resomant frequency for $\mathrm{H}_{\mathfrak{v}}=120 \mathrm{~mm}$ is $\mathrm{f}_{\mathrm{r}}=24 \mathrm{~Hz}$. Based on the afore-mentoned results it 
is plausible that $f_{b}$ increases with $f$ for $f>24 \mathrm{~Hz}$. This however, could not be verified due to apparatus limitations.

Figure 5.3 also shows variàtion of $\mathrm{f}_{\mathrm{b}}$ with $\mathrm{f}$ for $\mathrm{H}_{0}=210 \mathrm{~mm}, \mathrm{~A}=4 \mathrm{~mm}$ and $\mathrm{U} / \mathrm{U}_{\mathrm{m}}=0.65$. However, for $\mathrm{f}<11 \mathrm{~Hz}$ well-defined bubbles could not be identified. The bubbles were either too small or not well-developed. Hence no data are reported for $f<11 \mathrm{~Hz}$. For $f>11 \mathrm{~Hz}$, the variation of $f_{b}$ with $f$ was similar to that for $U / U_{m t}=2.9$ i.e. $f_{b}$ decreased with $f$ to a minimum at $f=f_{r}=12 \mathrm{~Hz}$ and increased thereafter. Within the parameter range studied, aeration rates have negligible effect on the frequency of bubble formation in aerated vibrated beds. This contrasts with the results of Harrison and Leung (1961) for fluidized beds. They found that the trequency of bubble formation at an orifice in fluidized beds depended primarily, though slightly, on the gas flow rate to the orifice. Yet, high aeration rates degenerate resonant behaviour and would then be expected to affect the trequency of bubble formation as the effects of aeration would predominate.

For $\mathrm{H}_{\mathrm{n}}=215 \mathrm{~mm}, \mathrm{U} / \mathrm{U}_{\mathrm{mr}}=2.9$ and $\mathrm{A}=2 \mathrm{~mm}$ there was no significant change of $f_{b}$ with $f$. This is quite unlike the other cases indicating that there may be a maximum $H_{n}$ and a minimum $A$ for there to be a marked effect of $f_{b}$ with $f$. Similar effects will be seen for the effect of $f$ on $d_{b}$ and $U_{b r}$ in Sections 5.2.3 and 5.2.4 respectively. A relative decrease in the effect of $f$ on $f_{b}$ had been seen even for $H_{0}=200 \mathrm{~mm}$ and $A=2 \mathrm{~mm}$. For $H_{0}=277 \mathrm{~mm}$ and $U / U_{\mathrm{mf}}=0.65$ reliable bubble frequency data could not be determined for the same reason mentioned above and are hence not reported. 
Bubble frequency variation with vibration frequency for 100- $\mu$ m alumina in inciplently fluidized beds (i.e. $U / U_{m}=1$ ) vibrated at $A=2 \mathrm{~mm}$ and $H_{n}=130 \mathrm{~mm}$ at various frequencies are shown in Figure 5.4. Bubble air is as before forced in through a central hole in the bottom plate. The flow rates of this air were $U / U_{m}=0.65$ and 2.1. These can be compared to data at $\mathrm{H}_{0}=120 \mathrm{~mm}$ shown in Figure 5.3. From these results it is concluded that $f_{b}$ does not depend significantly on $f$. This implies that the effects of aeration supersede the effects of vibration on bubbling in vibrited fluidized beds. Previous studies have shown that the influence of vibration generally diminishes with an increase in the rate of aeration (e.g. Gupta (1979). Paıkowskı and Mujumdar (1982) Malhotra and Mujumdar (1985)), etc. The results here ale in accordance with those of previous works. It will be seen in Sections 5.2.3 and 5.24 that the same conclusions are obtained tor bubble size and rise velocity.

Harrison and Leung (1961) found that the frequency of bubble formatton att an orifice in a gas-fluidized bed was largely independent of the overall bed height. As the above-mentioned results have shown, this is not the case in atrated vibrited beds.

'Results showing the effect of vibration frequency on bubble frequency for heds of glass beads $360 \mu \mathrm{m}$ in diameter vibrated at $\mathrm{A}=2 \mathrm{~mm}$ are shown in Figure 5.5. With $\mathrm{H}_{0}=125 \mathrm{~mm}$ and $\mathrm{U} / \mathrm{U}_{\mathrm{mf}}=0.6$, similar difficulties in obtaining data as mentioned above were experienced for $\mathrm{f}<7 \mathrm{~Hz}$. For all cases using a bottom plitte with the single central hole, $f_{b}$ decreases with an increase of $f$. For $H_{n}=125$ mm and $\mathrm{U} / \mathrm{U}_{\mathrm{m} f}=0.6, \mathrm{f}_{\mathrm{o}}$ fell trom $3.4 \mathrm{~s}^{\prime}$ at $\mathrm{f}=7 \mathrm{~Hz}$ to a minımum of about $1.4 \mathrm{~s}^{\prime}$ at $\mathrm{f}=18 \mathrm{~Hz}$ and remained constant thereafter. It may he recalled trom Chapter 4 that beds of $360-\mu \mathrm{m}$ glass beads do not exhibit discernible resonant behaviour. Vibratuon 


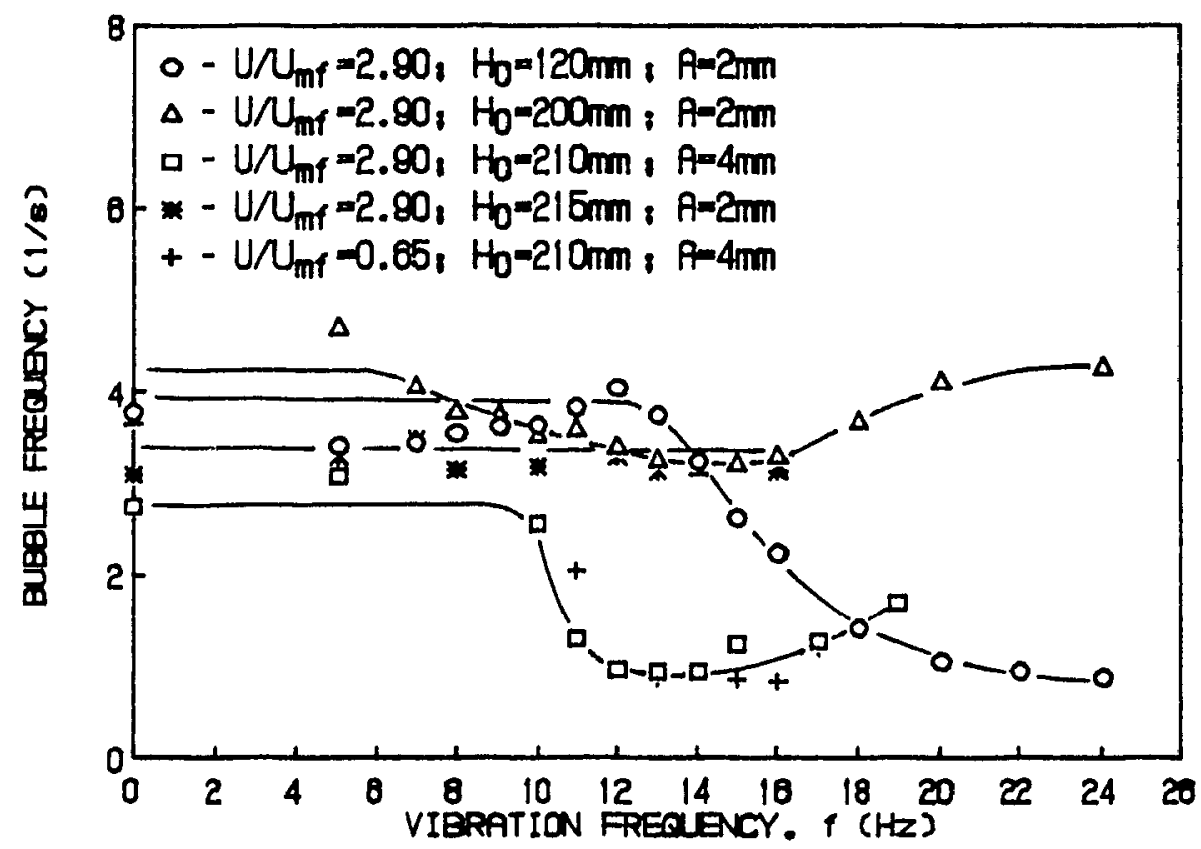

Figure 5.3 Effect of the excitation frequency on bubble frequency for 100- $\mu \mathrm{m}$ alumina par ,cles in a vibrated vessel with a single central hole in the bottom plate.

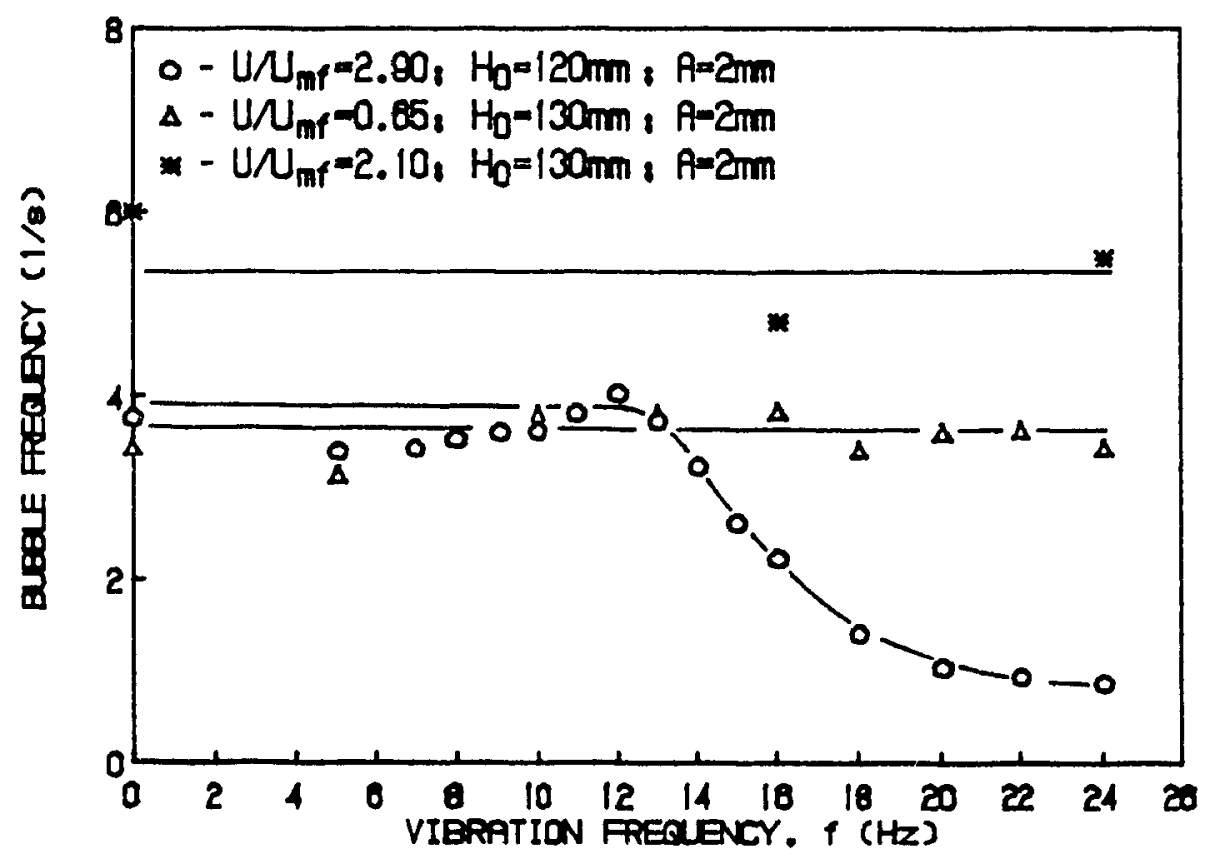

Figure 5.4 Effect of the excitation frequency on bubble frequency for $100-\mu \mathrm{m}$ alumına partıcles incipiently fluidized in a vibrated bed. 
frequency has a significant effect on particulate beds operated in the minner described above but not to the same extent as for beds of particles that exhibit resonant behaviour operated in the same manner. The absence of a minimum in the variation of $f_{b}$ with $f$ is then expected.

Beds of the same particles may be supported on a perforated plate under minimum gas-fluidizing conditions. As shown in Figure 5.5, when additional air is forced up a central hole in the supporting plate $f_{b}$ increases albeit slightly with increasing t. The bubble frequency is $5.6 \mathrm{~s}^{\prime}$ in the absence of vibration and $7.4 \mathrm{~s}^{\prime}$ at $\mathrm{f}=24 \mathrm{~Hz}$ Vibration frequency tends to increase $f_{b}$ in vibrated fluidized beds of particles that do not exhibit resonant behaviour due to the type of particles and the nature of the supporting plate. It may be recalled that $f$ has negligible effect on $f_{b}$ for vibrated fluidized beds of particles that would exhibit resonant behaviour when a bottom plate with a low $\%$ of open area is used. It seens that vibrated fluidized beds of particles limit the effect of $f$ on $f_{b}$.

Harrison and Leung (1961) also found that the frequency of bubble formation alt an orifice in fluidized beds depended promarly, though slightly, on the flundizıng conditions and the nature of the particles. What they considered as fluidizing conditions may be considered in this study as bed dynamics and is thus a functon of the vibratory conditions. Vibration frequency at higher amplitudes had the most pronounced effect on the frequency of bubble formation. This is believed to be due to pressure oscillations creating nuclei for bubbles tormed in the bed and hence an indirect consequence of vibration. The frequency of bubble formation decreases all and close $t$, the resonant point due to the vacuum created below the bed as will be 


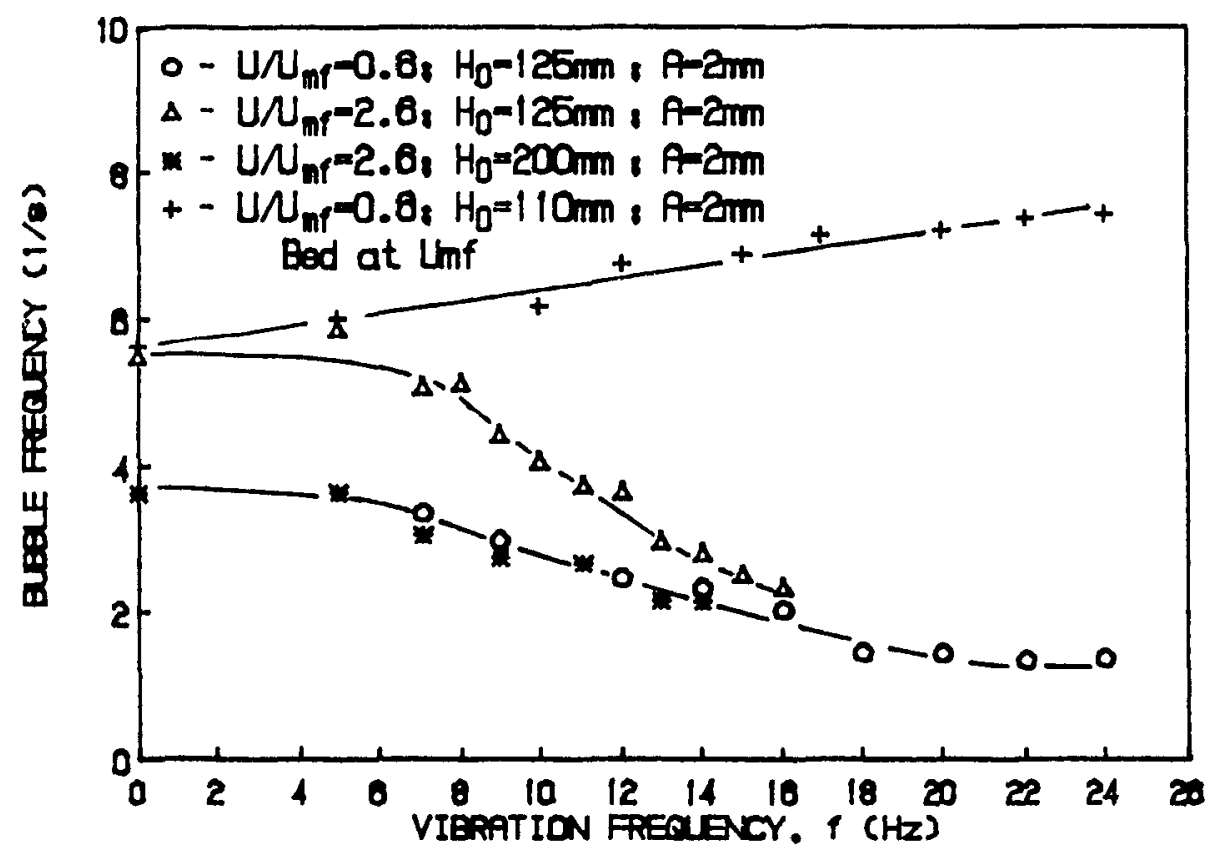

Figure 5.5 Effect of the excitation frequency on bubble frequency for $360-\mu \mathrm{m}$ glass beads in a vibrated vessel with air forced through a single central aperture in the bottom plate. 
further discussed in Sections 5.2.3 and 5.2.4.

The change of bubble frequency with excitation frequency would suggest that impressed oscillations affect the bubble formation process. This should be more pronounced in small-particle beds such as $100-\mu \mathrm{m}$ alumına where cavities are morr easily formed. In fact, vibrated beds of $27-\mu \mathrm{m}$ aluminum particles exhibıted similar behaviour. It is more difficult to form cavities in large-particle beds and this may explain the reduced effect of excitation frequency on bubble frequency in the bed of $360-\mu \mathrm{m}$ glass beads. Not unexpectedly then, the effects were even less pronounced in aerated vibrated beds of $945-\mu \mathrm{m}$ glass beads and $1.4-\mathrm{mm}$ molecular sleve partucles. Interestingly, the limited comparative studies done in beds of $1.4-\mu \mathrm{m}$ molecular steve particles confirmed the previous observation of Gupta and Mujumdar (1980). In fict. bubbles generally disappear before they reach the top of these large-particle beds

For a two-dimensional tluidized bed, Zhang et. al (1987) used a basic torce balince to equate the bunyant forces of a cylindrical bubble to that required to initially accelerate the emulsion phase around the bubbles to arrive at the frequency of bubbie formation. In aerated vibrated beds, the effect of vibration must be taken into account in the force balance. Nguyen and Leung (1972) measures bubble frequency and area in a two-dimensional tluidized bed and reported that at $\mathrm{U} / \mathrm{U}_{\mathrm{m} t}=1.5$ approximately $50 \%$ of the entering gas had leaked into the emulsion phase. Similar experiments were not conducted in this study but it is belteved that there is an appreciable leakage of gas into the emulsion phase though to a lesser degree than in the case for fluidized beds. 


\subsubsection{Bubble size}

Bubble size $\left(\mathrm{d}_{\mathrm{b}}\right)$ data corresponding to $\mathrm{f}_{\mathrm{b}}$ data in Figure 5.3 (i.e. for $100-\mu \mathrm{m}$ alumina particles) are shown in Figure 5.6. No coalescence was observed in the region studied. The variation of $d_{b}$ with $f$ exhibits opposite trends to the variation of $f_{b}$ with $f$.

For $H_{n}=210 \mathrm{~mm}, \mathrm{U} / \mathrm{U}_{\mathrm{m}}=2.9$ and $\mathrm{A}=4 \mathrm{~mm}, \mathrm{~d}_{\mathrm{b}}$ remains independent of $\mathrm{f}$ for $\mathrm{f}<10 \mathrm{~Hz}$, increases sharply at the resonant frequency $(12 \mathrm{~Hz})$ and further to a maximum of $72 \mathrm{~mm}$ at $f=15 \mathrm{~Hz}$. It then decreases to a value of $44 \mathrm{~mm}$ at $17 \mathrm{~Hz}$ (close to the onginal value of $35 \mathrm{~mm}$ ) and remained constant thereafter. This means that the maximum size of the bubble is over $100 \%$ greater than the original value.

It is noteworthy that while resonance is represented by a single point, the near resonant region exhibits behaviour similar to that at resonance but to a lower degree as seen in Chapter 4 . While $\mathrm{f}=12 \mathrm{~Hz}$ is not the frequency at which the bubble size was maximal, the relative difterence in bubble size at the resonant point and the point of maximum $d_{b}$ was mınimal. It may be concluded that bubble size is maximal at the resonant point. Additionally, bubble sizes were largest throughout the resonance-affected region $(f=11-16 \mathrm{~Hz})$.

Figure 5.6 also shows $d_{n}$ variation as a function of $f$ for $H_{n}=210 \mathrm{~mm} . A=4 \mathrm{~mm}$ and $\mathrm{U} / \mathrm{U}_{\mathrm{m}}=0.65$. Contrary to the result for $\mathrm{f}_{\mathrm{b}}, \mathrm{d}_{\mathrm{b}}$ increased markedly at $f=t_{r}$. The bubble size increased by $215 \%$ for $U / U_{m}=0.65$ from $d_{b}=21 \mathrm{~mm}$ at $\mathrm{f}=10 \mathrm{~Hz}$ to $d_{h}=66 \mathrm{~mm}$ at $\mathrm{f}=14 \mathrm{~Hz}$. For $\mathrm{U} / \mathrm{U}_{\mathrm{mf}}=2.90$, the percent increase was not as great. Although the final bubble size was about the same in both cases, the initial bubble size was greater to accommodate the increased air flow. There scems to be a 
maximum bubble size at a particular elevation just like there seems to be a particular minimum $f_{b}$ and it occurs at the resonant point.

Similar growth processes to those described by Kunii et al. (1967) for gas-fluidized beds occur in aerated vibrated beds with perforated bottom plates. A large number of small bubbles are formed above the distributor. They coalesce and grow as they rise in the bed. As in gas-fluidization (Kunil et al. (1967)), it is believed that the coalescence rate is extremely rapid close to the distributor. Figure 5.7 shows the effect of excitation trequency on bubble size for 100$)-\mu \mathrm{m}$ alumina for an incipiently fluidized beds vibrated at $A=2 \mathrm{~mm}$. For $\mathrm{f}<16 \mathrm{~Hz}$. well-defined bubble sizes could not be obtained for the run with $\mathrm{U} / \mathrm{U}_{\mathrm{mf}}=2.1$. From the results of Figure 5.7 it is concluded that, like $f_{b}, d_{b}$ does not change signiticantly with $t$. This supports the results of previous investigators and agan indicates that the elfects of aleration supersede the etfects of vibration on bubbling in aerated vibrated beds.

Results showing the effect of $f$ on $d_{b}$ for $360-\mu \mathrm{m}$ glass beads vitsated at $A=2 \mathrm{~mm}$ are presented in Figure 5.8. For the experiments with the bed at $U_{m}$ and aldditional air bubbled through a hole in the centre of the supporting plate, $d_{b}$ shows no change with f. However, other experiments for a vibrated bed with anr forced only through one hole in the bottom plate showed trends opposite to those for $t_{h}$ data depicted in Figure 5.5. As shown, $d_{h}$ increased with $\mathrm{f}$ for $\mathrm{f}>7 \mathrm{~Hz}$. Agan, this is expected as air tlow has to be conserved as only some of the excess air will percolate from the bubbles into the bed.

The bubble size increases at and close to the resonant point due to the pressure 


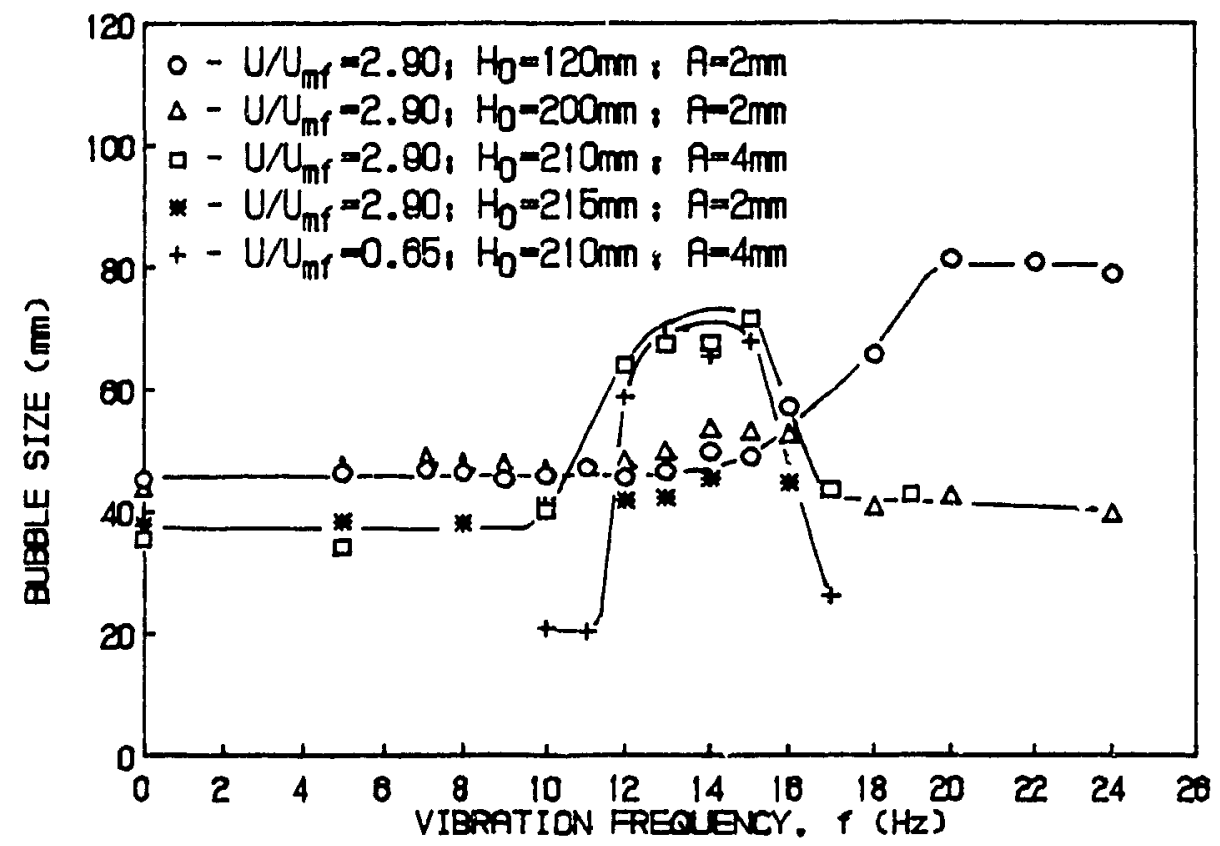

Figure 5.6 Effect of the excitation frequency on bubble size for $100(-\mu \mathrm{m}$ alumına particles in a vibrated vessel with a single central hole in the bottom plate.

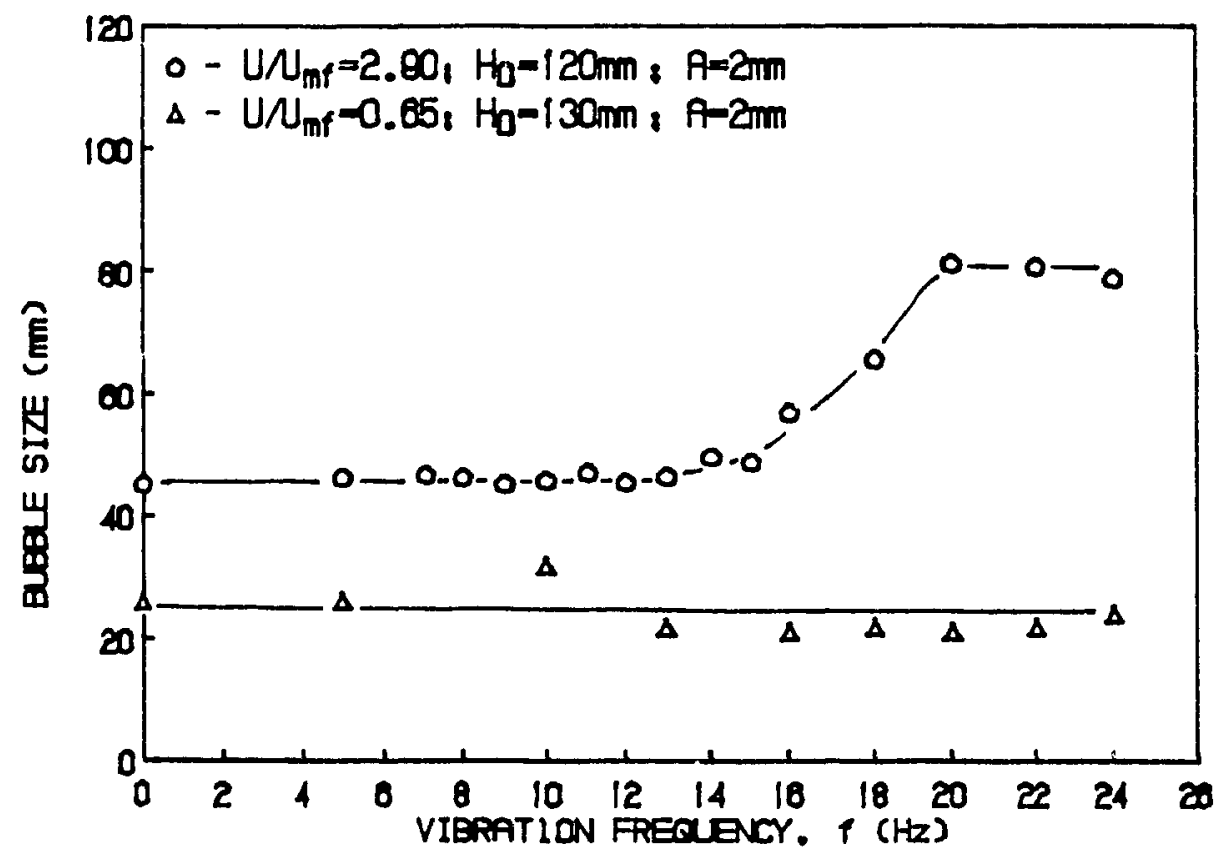

Figure 5.7 Effect of the excitation frequency on bubble size for $100-\mu \mathrm{m}$ alumina particles incipiently tluidized in a vibrated bed. 
waves. These pressure changes do not occur to any appreciable degree in langeparticle beds and in beds aerated through a perforated plate and hence such mat ked bubble growth does not appear in these beds.

\subsubsection{Bubble Rise Velocity}

Figure 5.9 presents bubble rise velocity $\left(\mathrm{U}_{b r}\right)$ data corresponding to the bubble frequency and bubble size data depicted in Figures 5.3 and 5.6. As shown, $U_{\mathrm{br}}$ dependency on $\mathrm{f}$ is similar to that of $\mathrm{f}_{\mathrm{b}}$. For $\mathrm{H}_{0}=210 \mathrm{~mm}, \mathrm{U} / \mathrm{U}_{\mathrm{m}}=2.9$ and $A=4 \mathrm{~mm}, U_{b r}$, like $f_{b}$, fell sharply with increasing $f$ at $f=11 \mathrm{~Hz}$ reaching a minimum at $12 \mathrm{~Hz}$ before increasing at higher vibration frequencies. The munimum value is $66 \mathrm{mms}^{-1}$ which is $52 \%$ below the value of $140 \mathrm{mms}^{1}$ obtaned in the absence of vibration. For gas-fluidized beds the buhble rise velocity is given by (Kunii and Levenspiel (1984)) as:

$$
U_{b r}=c_{1} g^{1 / 2} d_{b}^{1 / 2}
$$

5.1

where $c_{1}$ is 0.711 for a three-dimensional bubble and approximately $75 \%$ of this value for a two-dimensional bubble. A bubble with $d_{b}=35 \mathrm{~mm}$ would then rise at a rate of $313 \mathrm{mms}^{-1}$ in a fluidized bed i.e. much larger than the value of $140 \mathrm{mms}$ ' measured here. An even greater difference exists for the aerated vibrated bed operated at the resonant point; for a $67 \mathrm{~mm}$ bubble, it is $66 \mathrm{mms}^{\text {' }}$ compared to 434 $\mathrm{mms}^{-1}$ in a gas-fluidized bed. It is noteworthy that, as is the case for $\mathrm{I}_{\mathrm{h}}, \mathrm{U}_{\mathrm{hr}}$ decreases with increasing $f$ to a minımum at the resonance point s.e. at $\mathrm{t}=\mathrm{I}_{\mathrm{t}}=12 \mathrm{~Hz}$. Thıs behaviour is expected since if negligible leakage of air out of the bubble is assumed, its size must increase to match the reduced bubble rise velocity if the air flow through the bubble is held constant as in these experiments. 


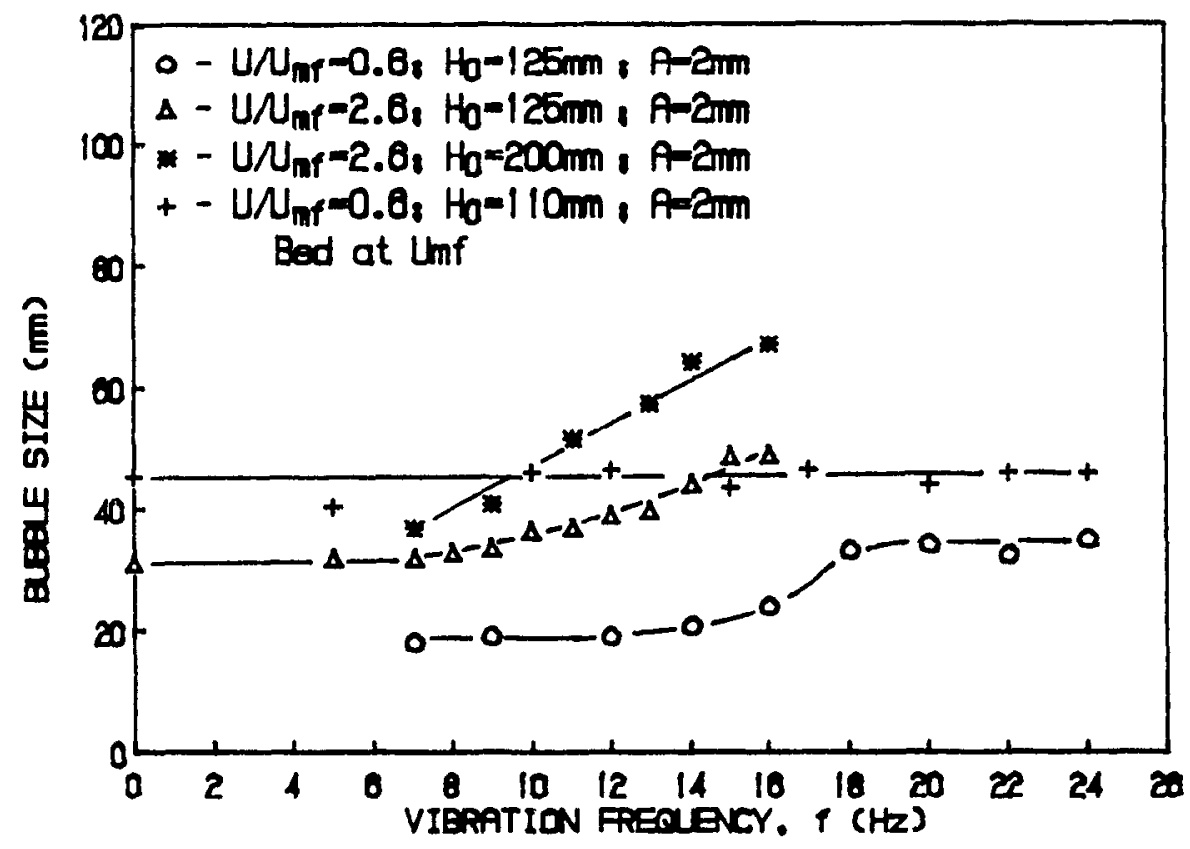

Figure 5.8 Effect of the excitation frequency on bubbble size for $360-\mu \mathrm{m}$ glass beads in a vibrated vessel with air forced through a single central aperture in the bottom plate. 
Like the case for $\mathrm{f}_{\mathrm{b}}$, for $\mathrm{H}_{0}=200 \mathrm{~mm}, \mathrm{U} / \mathrm{U}_{\mathrm{mt}}=2.9$ and $\mathrm{A}=2 \mathrm{~mm}, \mathrm{U}_{\mathrm{tr}}$ decrealses only marginally with $f$ to reach a minimum at $f=f_{r}=14 \mathrm{~Hz}$ i.e. the minimum is al the resonant point. These results indicate that the effect of vibration on bubble rise velocity was insignificant at the $\mathrm{H}_{0}$ and $A$ values used.

Also shown in Figure 5.9 is variation of $\mathrm{U}_{\mathrm{br}}$ with $\mathrm{f}$ for $\mathrm{H}_{0}=210 \mathrm{~mm}, \mathrm{~A}=4 \mathrm{~mm}$ and $\mathrm{U} / \mathrm{U}_{\mathrm{m}}=0.65$. Again, the dependency of $U_{b r}$ on $\mathrm{f}$ is similar to that for $f_{1 .}$. For $f>11 \mathrm{~Hz}$, the variation of $\mathrm{U}_{\mathrm{br}}$ with $f$ was similar to that for the higher flow latte of $\mathrm{U} / \mathrm{U}_{\mathrm{mf}}=2.9$ i.e. $\mathrm{U}_{\mathrm{br}}$ decreased with $\mathrm{f}$ to a minımum at $\mathrm{f}=\mathrm{f}_{\mathrm{r}}=12 \mathrm{~Hz}$ and increilsed thereafter.

Bubble rise velocity variation wit' 1 vibration frequency results corresponding to the bubble frequency results shown in Figure 5.4 are depicted in Figure 5.10. The bed was at minimum fluidizing conditions and it was difficult to record datti tom $\mathrm{H}_{\mathrm{n}}=130 \mathrm{~mm}$ and $\mathrm{U} / \mathrm{U}_{\mathrm{mt}}=2.1$ for $\mathrm{f}<16 \mathrm{~Hz}$ and hence no data are reported. Again, like $f_{b}, U_{b r}$ does not change significantly with $f$ leading to similar conclusions as stated above and are again in accordance with the conclusions of previous works (Gupta (1979), Pakowski and Mujumdar (1982) and Malhotra and Mujumdar (1985)).

Figure 5.11 shows results of the effect of vibration frequency on bubble rise velocily for beds of $360-\mu \mathrm{m}$ glass beads vibrated at $A=2 \mathrm{~mm}$. As in the case for $t_{n}$, when a bottom plate with a single central hole was used, $U_{b r}$ decreased with increising 1 . For $\mathrm{H}_{0}=125 \mathrm{~mm}$ and $\mathrm{U} / \mathrm{U}_{\mathrm{ml}}=0.6, \mathrm{U}_{\mathrm{br}}$ decreased with increasing $\mathrm{f}$ from a value of $20 \mathrm{mms}^{-1}$ at $\mathrm{f}=7 \mathrm{~Hz}$ to a minimum of $6 \mathrm{mms}^{1}$ at $\mathrm{f}=18 \mathrm{~Hz}$ and remained constint at that value. 


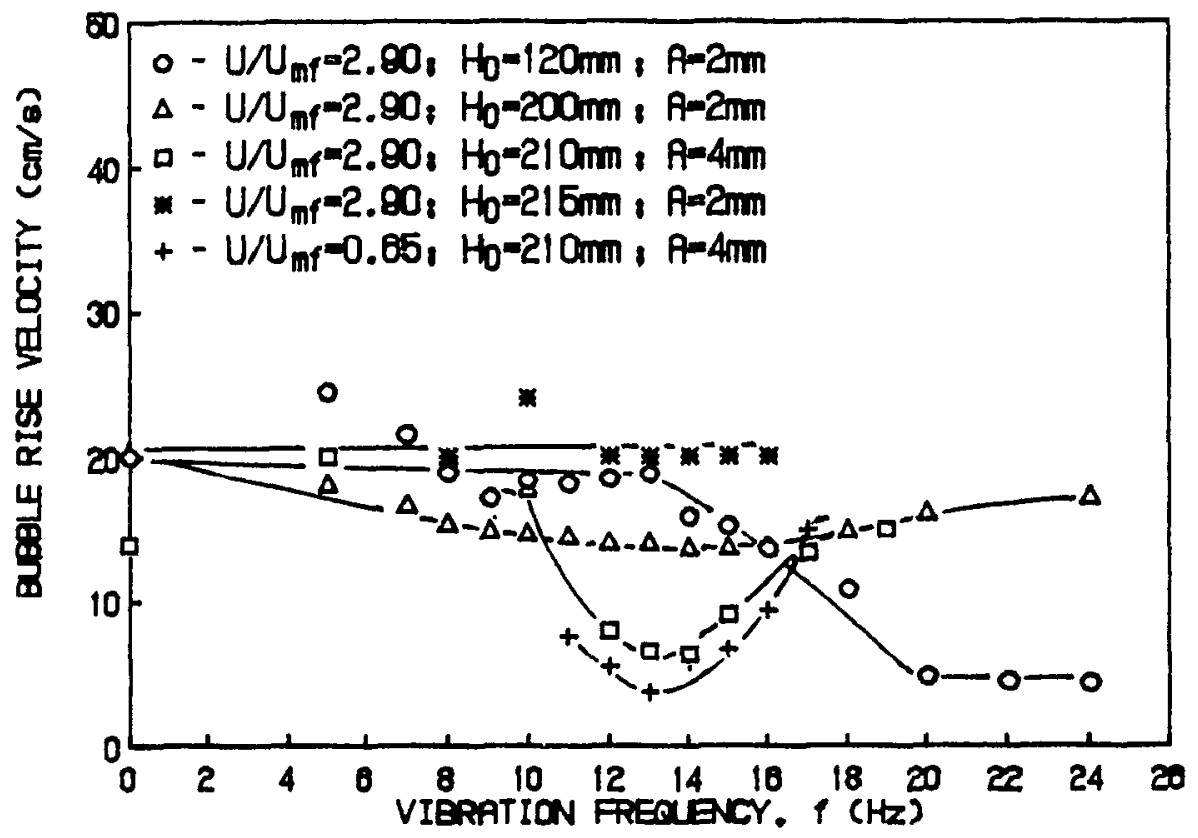

Figure 5.9 Effect of the excitation frequency on bubble rise velocity for $100-\mu \mathrm{m}$ alumina particles in a vibrated vessel with a single central hole in the bottom plate.

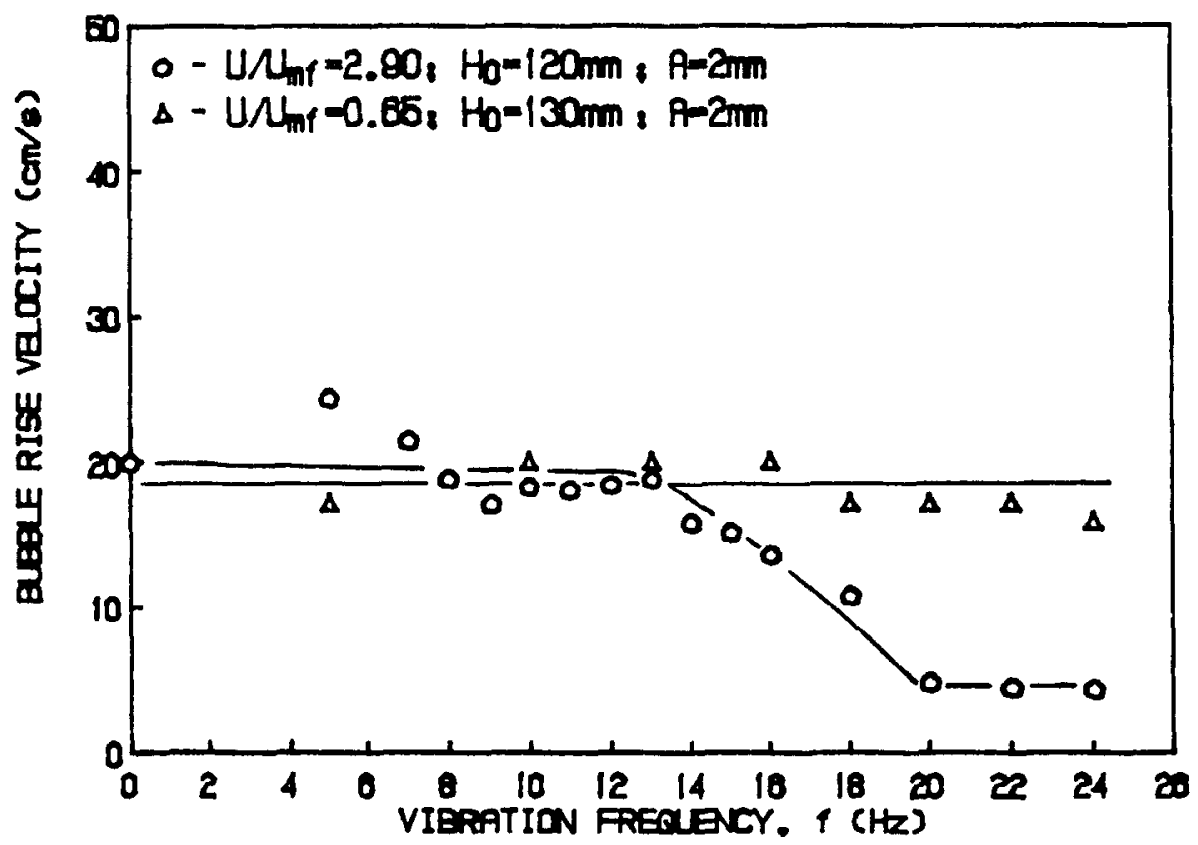

Figure 5.10 Effect of the excitation frequency on bubble rise velocity for $100-\mu \mathrm{m}$ alumina particles incipiently fluidized in a vibrated bed. 
For the vibrated fluidized bed, $U_{b r}$ increased only marginally with $f$. Explanattons similar to those given before for $f_{b}$ are applicable to $U_{b r}$ l.e. increase in vibratton frequency results in increase in $U_{b r}$ in vibrated fluidized beds that do not displity resonant behaviour.

Bubble rise velocity decreases at, and close to, the resonant point for the same reison the bubble size increases and the bubble frequency decreases i.e. due to the vacuum created below the bed. This creates a reduction in pressure head and hence the driving force pushing the bubbles upwards is reduced. Because of the bubbles' slowe movement up through the bed, they spend a longer time close to the bottom plate accumulating more air and increasing size and hence the observed trequency of formation decreases. These pressure changes do not occur to any signticint degree in large-particle beds and in beds aerated through a perforated plate and hence such marked changes in bubble rise velocity do not occur in these beds.

\subsubsection{Bubble shape}

For $100-\mu \mathrm{m}$ alumina particles at low air flow rates e.g. $\mathrm{U} / \mathrm{U}_{\mathrm{mr}}=0.65$ and alt $\mathrm{low}$ frequencies $\left(\mathrm{f}<<\mathrm{f}_{\mathrm{r}}\right.$ ), bubbles generally have a circular cross-section throughout the bed. For a bed exhibiting resonant behaviour, the bubbles were elongated in the horizontal direction, particularly at higher A values i.e. they were highly flattened. Figure 5.12 shows a bubble for $f=f_{r}=24 \mathrm{~Hz}, A=2 \mathrm{~mm}, H_{v}=112 \mathrm{~mm}$ and $\mathrm{U} / \mathrm{U}_{\mathrm{mf}}=0.65$. Past the frequency at which the bubble size returned close to its preresonant size, the bubble cross-section assumed a circular shape again. Resonance thus causes enlargement and flattening of bubbles. Some other bubble shapes observed in the present study are shown in Figures 5.1 and 5.2. 


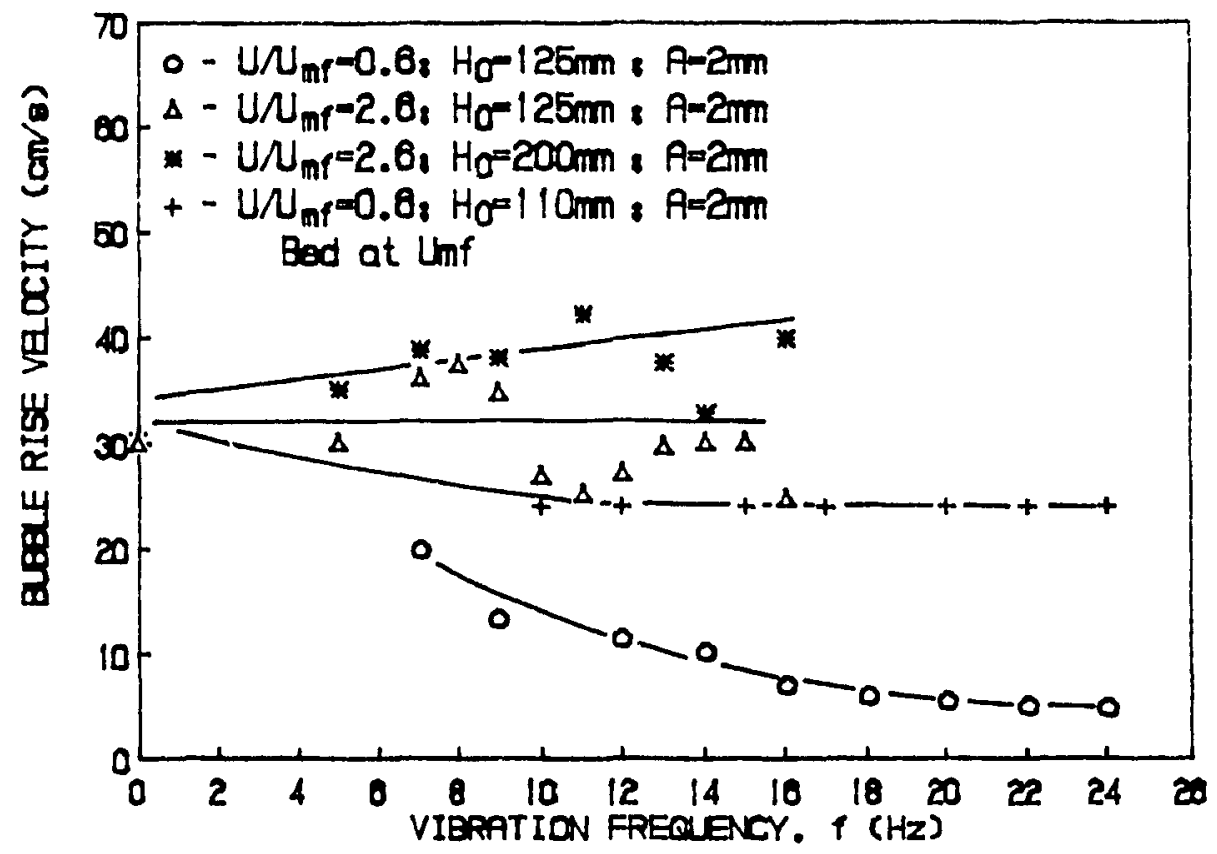

Figure 5.11 Effect of the excitation frequency on bubble rise velocity for $360-\mu \mathrm{m}$ glass beads in a vibrated vessel with air forced through a single central aperture in the bottom plate. 


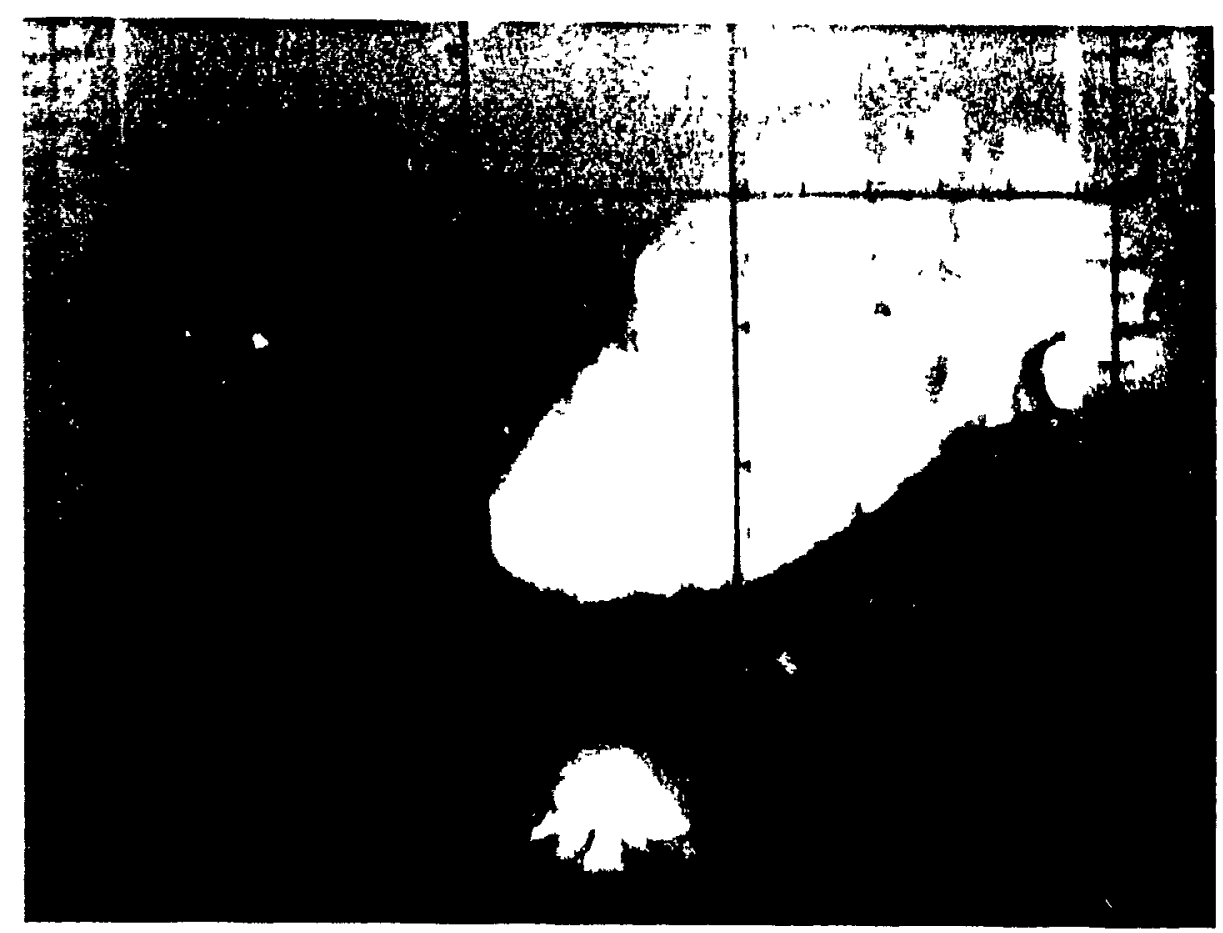

Figure 5.12 The shape of a bubble at resonance in an aerated vibrated beds of $100-\mu \mathrm{m}$ alumina particles with a single hole in bottom plate. $\mathrm{f}=24 \mathrm{~Hz}, \mathrm{~A}=2 \mathrm{~mm}, \mathrm{H}_{\mathrm{v}}=112 \mathrm{~mm}, \mathrm{U} / \mathrm{U}_{\mathrm{mf}}=0.65 \mathrm{:}$ 
For $100-\mu \mathrm{m}$ alumina particles at higher air flow rates such as $\mathrm{U} / \mathrm{U}_{\mathrm{mt}}=2.9$, the vertical dimension of the bubble was greater than the horizontal dimension for all $\mathrm{H}_{0}$. When the bed was first brought to $U_{m r}$ and bubble air was forced in through a central hole in the bottom plate, the bubble cross-section was circular at all elevations. It may be recalled that, compared to resonating beds, $f$ has a much reduced effect on bubble size and shape in vibrated beds aerated through a perforated bottom plate as compared to beds aerated through a single hole only.

Kunii and Levenspiel (1984) have described bubbles in fluidized beds as being close to spherical when small and flattened and distorted when larger. This is also the case for bubbles in aerated vibrated beds. Under resonant conditions, bubbles are very tlat particularly at lower bed heights $\left(\mathrm{H}_{0}<140 \mathrm{~mm}\right)$. At lower bed heights where the resonant condition is most intense $\left(\mathrm{H}_{0}<140 \mathrm{~mm}\right)$, the bubbles are very flat with a width to height ratio of about 6 . It is worth noting that negative pressures of the greatest magnitude $(-4 \mathrm{kPa})$ exist below the bed in these cases. The thattened shape is agan believed to be due to the upper and lower bubble surfaces being forced together due to the reduction of pressure. The horizontal dimension increases to maintain mass conservation of air if air flow out of the bubble is negligible.

For $360-\mu \mathrm{m}$ glass beads at low air flow rates e.g. $U / U_{m t}=0.60$, the bubbles were of circular cross-section. Even when the bubbles increased in size by up to $80 \%$, they were still of circular cross-section. At higher air flow rates e.g. $U / U_{m}=2.6$ and all frequencies of vibration, the bubbles were slightly elongated in the vertical direction. It seems that bubble shapes in large-particle beds are like those in non-vibrated fluidized beds. This is due to the absence of significant pressure fluctuations induced 
by vibration.

Kunii et al. (1967) detected the presence of solids within the core portion of rising gas bubbles in fluidized beds. Bubbles in aerated vibrated beds have streams of particles continually passing through the bubble zone particularly at resonance (Figures 5.1 and 5.12). This is probably due to the negative pressure in the bubbles not being able to prevent particles from falling in. The fraction of the bubble that contains particles could not be accurately measured but it is roughly estimated to be close to $25 \%$ at resonance.

\subsubsection{Some General Bubble Characteristics}

While bubbling generally begins once minimum fluidizing conditions have been exceeded for fluidized beds, this is not the case for aerated vibrated beds. For a bed with a perforated bottom plate with $\mathrm{U}<\mathrm{U}_{\mathrm{mt}}$ (which would not exhibit bubbling), the application of mechanical vibration permits the transition to a bubbling bed. The degree of bubbling is minimal at low frequencies but is vigorous at higher trequencies. Additionally, the bubbles are quite small $\left(d_{b}<15 \mathrm{~mm}\right)$ and numerous. This is expected to be desirable for mixing and is further discussed in Section 5.4 and in Chapter 6.

\subsubsection{Effect of Immersed Surfaces on Bubbling}

Botterill (1975) has stated that general bubbling behaviour in gas-fluidized beds is much affected by the presence of immersed horizontal surfaces. However, at velocities close to $U_{m}$, bubbles are formed at the immersed surfaces. Bubbles tend to break at these surfaces. 
As in the case of fluidized beds, bubbles form at immersed horizontal surfaces in aerated vibrated beds. At low aeration rates, bubbles that rise up to meet the immersed surface divide into two smaller bubbles which rise up either side of the surface. The formation of bubbles at the horizontal immersed surfaces is again believed to be due to the formation of cavities resulting from the disruption of joint oscillations close to the immersed suriace. Bubbles also spend a disproportionate amount of time close to immersed surfaces perhaps due to higher porosity in their vicinity. This is discussed in Chapter 7.

Small bubbles in small-scale fluidized beds operating close to the minımum thuidizıng condition tend to rise close to the wall. At higher gas velocities, the bubbles travel through the centre of the bed. Similarly, in aerated vibrated beds, small bubbles in small-scale fluidized beds operated close to the minimum fluidizing condition tend to rise close to the wall at low vibration frequencies. On the other hand, at higher frequencies they travel throughout the whole bed. This is probably due to a stabilizing effect of vibration.

\subsubsection{Bubble Splitting and Coalescence}

Coalescence in a resonating bed is a slow process. Bubbles coalesce when a rising bubble enters into the region close to a leading bubble. Splitting occurs due to the presence of an immersed surface or the presence of a large stream of particles falling through the bubble. In either case, the bubble is split and smaller bubbles are formed. Yet, it must be noted that bubbles in aerated vibrated bed are stable i.e. they are very resistant to splitting even when particles descend through them. 


\subsubsection{Correlation of Data using Dimensionless Groups}

Erdesz (1990) attempted to obtain dimensionless groups to correlate the effect of vibration on bubble phenomena. He defined bubble Strouhal numbers, $\mathrm{St}_{\mathrm{w}}$, in the gas-fluidized beds based on the bubble sizes and frequencies predicted by Kunı et al. (1967) and the bubble velocity reported by Harrison and Leung (1962):

$$
S t_{b}-\frac{f_{b} d_{b}}{U_{b r}} .
$$

Note that the Strouhal number gives the ratio of oscillation to velocity. Erdesz (1990) calculated Strouhal numbers of the gas in gas-fludized beds using the frequency of self-oscillation in gas-flurdized beds predicted by Hiby (1967):

$$
s t_{g}=\frac{f d_{h}}{U} .
$$

Erdesz (1990) also attempted to show that the bubble Strouhal number decreases with an increase ir. gas Strouhal number in gas-fluidized beds. Using the results of this study, he calculated bubble and gas Strouhal numbers for aerated vibrated bech. He claimed that the bubble Strouhal number remained invariant with gas Strouhal numbers except at resonance where a maximum in bubble Strouhal number wais obtained. Based on this result, Erdesz (1990) concluded that vibrition stabilizes initial disturbances in aerated vibrated beds.

However, the validity of Erdesz's calculation of gas Strouhal number is dubious tor both gas-fluidized beds and aerated vibrated beds. The velocittes and trequencies he used in his calculations have little effect on gas behaviour. It maly be more appropriate to use the settling velocity of the particles rather than the gas velocity in 
the definition of gas Strouhal number.

\subsection{IMPLICATIONS FOR DESIGN}

Aerated vibrated beds operated under resonant or near-resonant conditions offer a viable design alternative for gas-solid contactors. Compared to fluidized beds, bubbles in aerated beds operating at or close to the resonant point spend a longer time in the bed allowing increased contact time for heat and mass transfer. The bubbles form at a reduced frequency which limits the rate of gas by-passing. A great percentage of the bubble volume is occupied by particles and this increases the surface area for mass transfer. Contrary to what was previously thought for large particle beds (Gupta and Mujumdar (1980)), in the small-particle beds, bubble sıze increases and this larger bubble size presents the gas with a larger by-pass volume. However, this is partially offset by a lower frequency of bubble formation and reduced bubble rise velocity. The shape of the bubbles and the great percentage (estimated at $25 \%$ ) of its volume occupied by particles lead to increased gas-solid contacting. Small bubbles may be created in small-particle vibrated fluidized beds at velocities below $\mathrm{U}_{\mathrm{mr}}$. This offers improved mixing for non-resonant beds at low aeration rates without allowing as much gas by-passing as obtained in gas-fluidized beds.

\section{$5.4 \quad$ CLOSURE}

Resonance has a strong effect on bubbling in aerated vibrated beds. At the resonant point the bubble size reaches a maximum, while bubble rise velocity and frequency reach minima. At the resonant point, bubble sizes are up to $215 \%$ the value in the absence of vibration. On the other hand, bubble frequencies and bubble rise 
velocities are up to $75 \%$ lower than their values in the absence of vibration. When there is no resonance for vibrated beds aerated through one hole in the bottom plitte. the bubble size increases slightly to a maximum while both the bubhle ise velucit! and frequency decrease sightly. For beds operated at $U_{m}$, both bubble size and rise velocity remain invariant with vibration frequency, but the bubble frequency increases slightly with increasing $\mathrm{f}$. The application of mechanical vibration results in the stabilization of bubbles in beds (the bubbles are very resistant to splitting or breikup). Vibration offers a better control parameter than air flow in beds of partcles in it does not automatically result in increased bubble size which would leald in il decrease in transport processes in gas-fluidızed beds. 


\section{CHAPTER 6. FLOW CHARACTERISTICS - MIXING AND PARTICLE FLOW PATTERNS}

\section{$6.1 \quad$ INTRODUCTION}

Observed particle circulation and mixing patterns are described and an attempt is made to correlate the experimental findings with bed dynamics including resonance and bubble phenomena. Overall particle mixing studies are presented and discussed. Ditierences in particle circulation in small- and large-particle beds including the effects of aeration are highlighted. The relationship between particle circulation and the shape of bed surfaces including resonant and non-resonant behaviour in vibrated beds will be discussed as well as particle circulation patterns around immersed surfaces. The implications of these operations on the design of vibrated beds will also be discussed.

Particle circulation patterns within the bed are presented schematically. The total mixing time is defined as the time taken for a bed of particles to become completely homogeneous i.e. uniformity of composition (Uhl and Gray (1967)) from an originally layered state. Partıcle circulation is represented by the velocity (approxımate velocity measured as the ratio of a specific distance travelled to the time taken to do so). Unless otherwise stated, experiments were conducted at a half-amplitude of vibration of $2 \mathrm{~mm}$ in a $20-\mathrm{mm}$ thick rectangular bed of $100-\mu \mathrm{m}$ alumina particles (Geldart group B) aerated through a single hole in the bottom plate. Prior published work is confined mainly to beds of large particles. 


\subsection{FLOW CHARACTERISTICS IN BEDS WITHOUT INTERNALS}

\subsubsection{Flow Characteristics for Small-Particle Beds (Aluminil)}

Air Flow through a Single-Aperture Bottom Plate

Schematic flow patterns for an $A V B$ of $100-\mu \mathrm{m}$ alumına with $U / \mathrm{U}_{\mathrm{m}}=0.65$ for varying values of $\mathrm{H}_{0}$ are shown in Figures $6.1-6.4$. Figure 6.1 shows tlow palterns for $\mathrm{H}_{0}=110 \mathrm{~mm}$ and $\mathrm{A}=2 \mathrm{~mm}$. This figure clearly shows that at low $t$ values and hence low intensities of vibration, there is negligble particle motion: particle motion was confined to the core region of the bed by the bubble-induced circulation. At f $\sim 5 \mathrm{~Hz}$, the region of the bed where particle circulation was visually discermble increased. This region is referred to as the region of influence. Even at $t=10 \mathrm{~Hz}$ $(\mathrm{K}=0.8)$ particulate motion was still confined to the central bubble-aftected section It is believed that the region of influence is enlargened by an increase in bubble size with increase in $\mathrm{f}$.

Bulk particle motion becomes quite evident at $\mathrm{f}=15 \mathrm{~Hz}(\mathrm{~K}=1.8)$. The surfice of the bed is concave upwards at this point. Particle motion at the top of the bed is along the top layers towards the trough created by the concalve shape of the surfice. In the bed, the general particle motion was down the middle and upwards along the side walls. This is against the direction of motion of the bubbles and the direction of particle flow in fluidized beds. Mixing in the bed was minimal. The net region of upward flow was about $30 \%$ greater than the net region of downward flow inclicatung that the particles were moving downward at a taster speed than that at which they were moving up. In fact, particle circulation velocity down the middle wiss about 10 $\mathrm{mms}^{-1}$ while upwards along the side walls it was about $2.5 \mathrm{mms}$. These values may be compared with values of $11 \mathrm{mms}^{1}$ and $8 \mathrm{mms}^{-1}$ reported by Sprung (1987) and 
Thomas (1988) respectively. However, their direction of particlulate flow is in the opposite direction to that stated above. There was uniform mixing of particles throughout the bed. At $\mathrm{f}=20 \mathrm{~Hz}(\mathrm{~K}=3.2)$, the motion was similar to that at $\mathrm{f}=15 \mathrm{~Hz}$. However, particle motion was now faster and mixing was more intense. Particle circulation velocity close to the wall had increased to $5 \mathrm{mms}^{-1}$ and remained at $10 \mathrm{mms}^{1}$ down the central core. The top of the bed was almost flat; it had only a slight curvature downwards at the centre. Particle motion at the surface was then slower than at $\mathrm{f}=15 \mathrm{~Hz}$. Bubbles were now larger and more stable and the bed started to exhibit resonant behaviour. There was good mixing in the bed.

At $\mathrm{f}=24 \mathrm{~Hz}(\mathrm{~K}=4.6)$, the bed displayed fully-developed resonance. Elongated, flat bubbles were evenly distributed throughout the vessel (they were not confined to the centre as at lower $f$ values). The consequence was more random motion of particles. No regular flow patterns could be observed and hence particle circulation velocities could not be determined. The randomness of the motion produced more rapid and intense mixing. At $\mathrm{f}=24 \mathrm{~Hz}$ i.e. the resonant frequency, mixing in the bed was the most intense (it took 13 seconds for the bed to become homogeneous from an initial layered state).

Flow patterns for a similar experiment with $\mathrm{H}_{0}=160 \mathrm{~mm}$ are sketched in Figure 6.2. The flow patterns are similar to those displayed in Figure 6.1 except that similar flow patterns now occur at lower $\mathrm{f}$ values. For example, at $\mathrm{f}=12 \mathrm{~Hz}(\mathrm{~K}=1.2)$ the particles could be seen travelling up the central core of the bed and onto the top of the bed and travelling downward just away from the middle. It then seems that there was generally some motion up the central axis due to the bubbles, but most of the 
particle flow along the central core was downwards. Resonant behaviour begins around $f=15 \mathrm{~Hz}$ and larger, more stable bubbles form. At $\mathrm{f}=17 \mathrm{~Hz}$, bed resonance is fully developed accompanied by large, flat, stable bubbles. At this frequency, the most vigorous particle motion and most intense mixing was observed. In fact, the particles were moving down the middle at $12 \mathrm{mms}^{1}$ and up the sides at $10 \mathrm{mms}^{-1}$ compared to $10 \mathrm{mms}^{-1}$ and $2 \mathrm{mms}^{-1}$ respectively at $\mathrm{f}=14 \mathrm{~Hz}$. However, it took 50 seconds for the particles to become randomly mixed compared to 13 seconds for $\mathrm{H}_{0}=110 \mathrm{~mm}$. This indicates that not only is particle motion most vigorous at the resonant point but it also decreases with an increase in bed height. As expected, similar behaviour had been noted in Chapter 4 for the resonance intensity.

Figure 6.3 shows schematic flow patterns for $\mathrm{H}_{0}=260 \mathrm{~mm}$. Increased particle circulation again started at lower frequencies as compared to that for $\mathrm{H}_{0}=110 \mathrm{~mm}$ or $160 \mathrm{~mm}$. In fact, at $\mathrm{f}=10 \mathrm{~Hz}(\mathrm{~K}=0.8)$, well-developed circulation patterns were already set up. Particle circulatory patterns varied with elevation in the bed. Towards the top of the bed, the particles moved up the middle and down the sides. Towards the bottom of the bed, the particles moved down the middle and up the sides. Thus an upper and a lower circulatory loop were set up. Where the two loops met, particle flow was directed horizontally towards the centre of the bed. This can be clearly seen at $\mathrm{f}=12 \mathrm{~Hz}(\mathrm{~K}=1.2)$. This type of circulatory pattern contınued into resonance which was well-developed at $12 \mathrm{~Hz}(\mathrm{~K}=1.2)$. At $\mathrm{f}=16 \mathrm{~Hz}$, the circulatory patterns were similar. However, stagnant zones were present on both sides between the walls and the centre of the bed. Mixing times were now in excess of three minutes. 


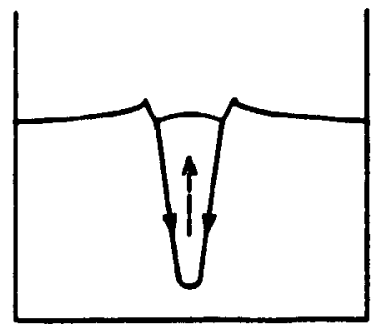

(a) $f=0 \mathrm{~Hz}$

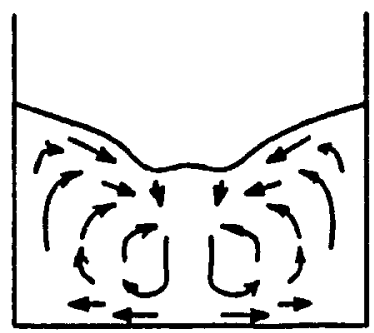

(d) $f=15 \mathrm{~Hz}$

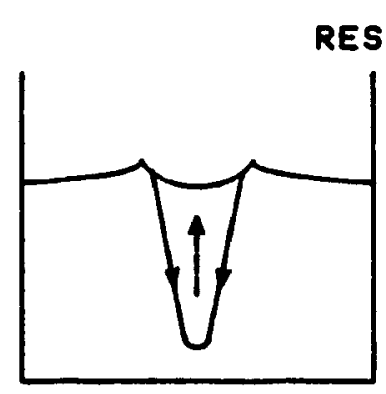

(b) $f=5 \mathrm{~Hz}$

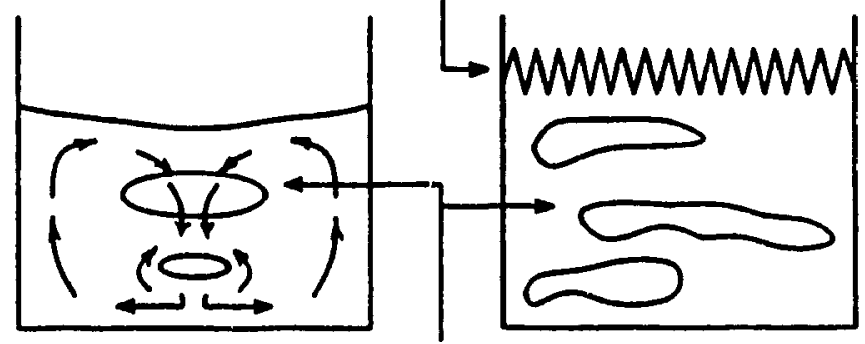

(.) $f=20 \mathrm{~Hz}$ BUBBLES (f) $f=24 \mathrm{~Hz}$

Figure 6.1 Schematic flow patterns for AVB's of $100-\mu \mathrm{m}$ alumina particles with a single aperture-bottom plate, $\mathrm{U} / \mathrm{U}_{\mathrm{mc}}=0.65$ and $\mathrm{H}_{0}=110 \mathrm{~mm}$.

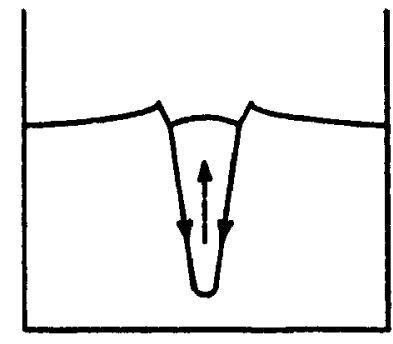

(0) $\mathrm{F}=\mathrm{O} \mathrm{Hz}$

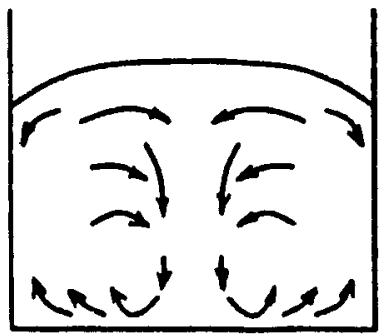

(d) $f=14 \mathrm{~Hz}$

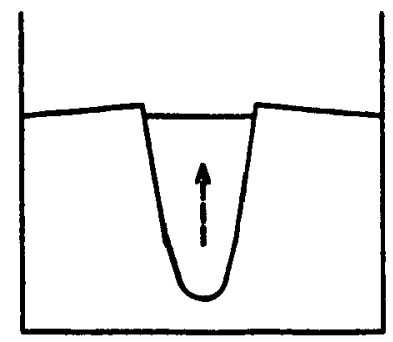

(b) $f=5 \mathrm{~Hz}$

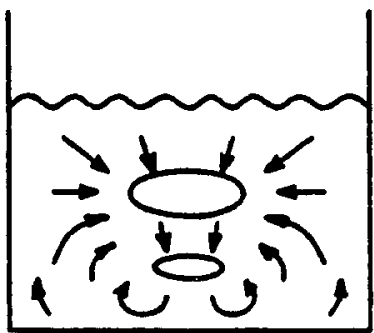

(.) $P=15 \mathrm{~Hz}$

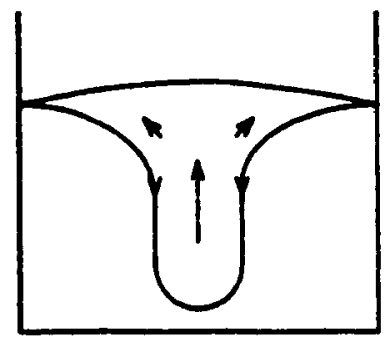

(c) $1212 \mathrm{~Hz}$

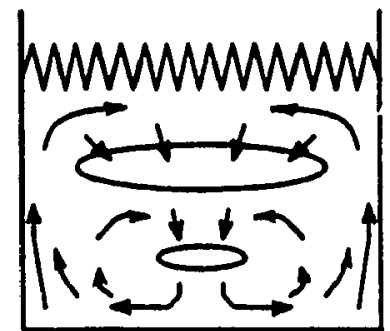

(f) $f=17 \mathrm{~Hz}$

Figure 6.2 Schematic flow patterns for AVB's of $100-\mu$ m alumina particles with a single-aperture bottom plate, $\mathrm{U} / \mathrm{U}_{\mathrm{mf}}=0.65$ and $\mathrm{H}_{0}=160 \mathrm{~mm}$. 
In all the experiments depicted in Figures 6.1 to 6.3, particle flow velocities increalsed with increasing frequency as the resonance condition was approached. Schematic particle circulatory patterns at the resonant point are shown in Figure 6.4. Flow patterns were similar and the circulation velocittes were the highest at the resonant point. Particle flow velocities show the same relation with frequency as bed height and bubble size discussed in Chapters 4 and 5 . The frequency of vibration then has a controlling effect on the flow patterns, bubble size and the shape of the bed surface. The intensity of particle motion increased with increasing $f$ and $A$ but decreased with increasing $\mathrm{H}_{\text {u. }}$. For example, at resonance, particle circulation velocities which averaged about $11 \mathrm{mms}^{-1}$ at $H_{n}=110 \mathrm{~mm}$ averaged $+\mathrm{mm} \mathrm{s}^{1}$ at $\mathrm{H}_{0}=160 \mathrm{~mm}$.

Thomas (1988), Sprung (1987) and Suzuki et al. (1980) have reported that circulation rates for a given particle size increase with increase in $\mathrm{K}$. While this is true it does not show the whole picture. More correctly, for beds of small particles, circulation rates of the particles increase with frequency to a maximum at the resonant point. This is obvious in Figures 6.1 to 6.4. The increase with $\mathrm{K}$ is in so tar as the trequency is increased. For $f>f_{r}$, particle curculation rates decrease as seen in Figure 6.3. The frequency of vibration is a better parameter than $K$ for characterizing particle circulation in aerated vibrated beds small particles.

\subsubsection{Flow Characteristics for Beds of Glass Bealds}

Air Flow through a Single-Aperture Bottom Plate

Flow patterns for beds of $360-\mu \mathrm{m}$ glass beads with the single-aperture bottom plate are depicted in Figure 6.5. For $\mathrm{H}_{\mathrm{n}}=115 \mathrm{~mm}, \mathrm{f}=16 \mathrm{~Hz}(\mathrm{~K}=2.1)$ and $\mathrm{U} / \mathrm{U}_{\mathrm{mt}}=0$, 


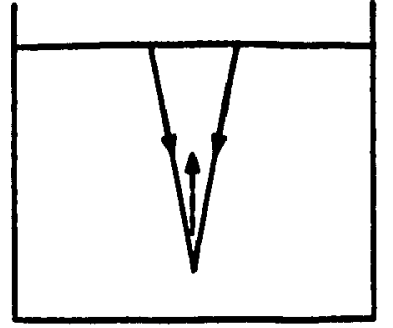

(-) $1: 0 \mathrm{~Hz}$

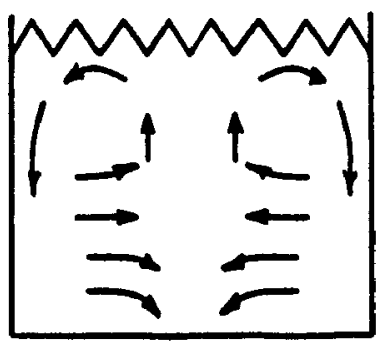

(d) $1=11 \mathrm{~Hz}$

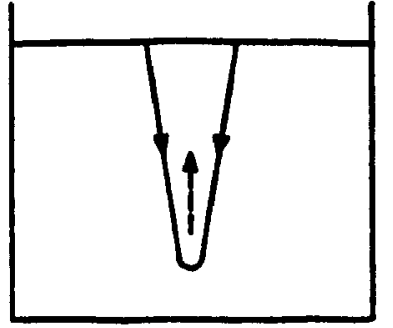

(b) $f=5 \mathrm{~Hz}$

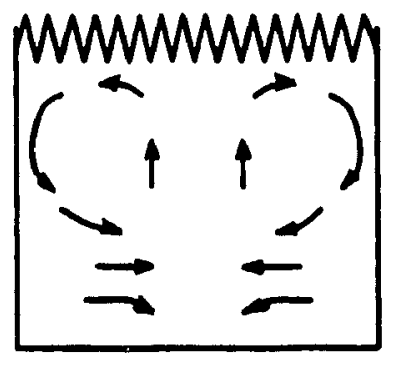

(.) $1=12 \mathrm{~Hz}$

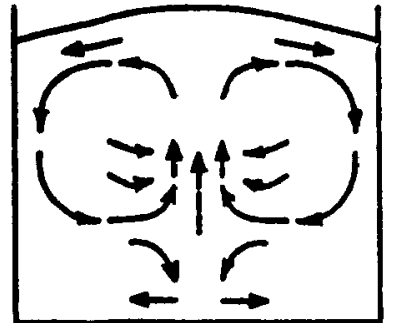

(e) $1210 \mathrm{~Hz}$

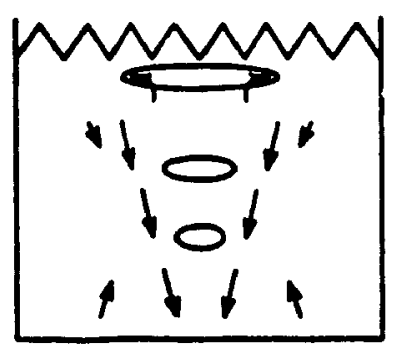

(f) $=16 \mathrm{~Hz}$

Figure 6.3 Schematic flow patterns for AVB's of $100-\mu \mathrm{m}$ alumina particles with a single-aperture bottom plate, $\mathrm{U} / \mathrm{U}_{\mathrm{m} t}=0.65$ and $\mathrm{H}_{0}=260 \mathrm{~mm}$.

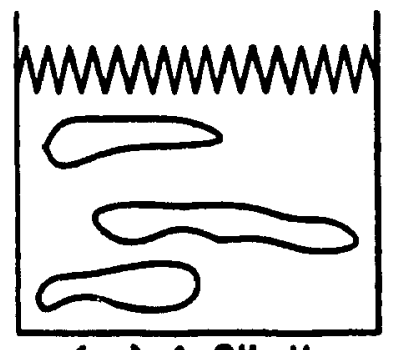

(0) $1.24 \mathrm{~Hz}$ $H_{0}=110 \mathrm{~mm}, K=4.6$ MUWWWWW

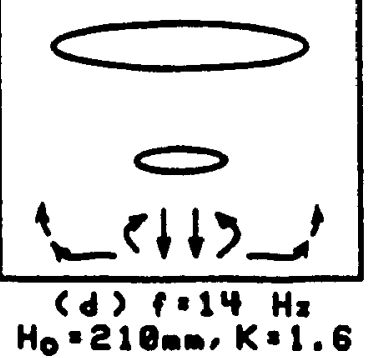

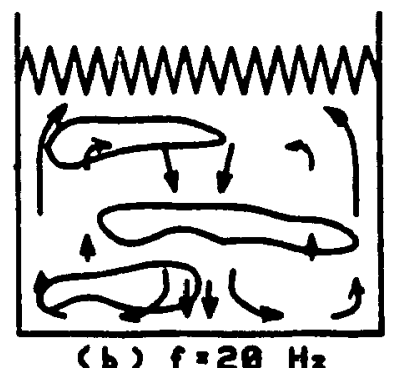

(b) $f=20 \mathrm{~Hz}$ $H_{0}=148 \mathrm{~mm}, K=3.2$

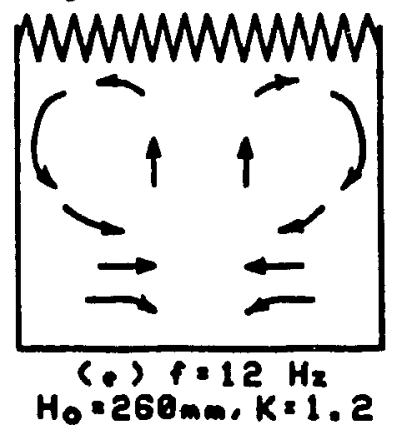

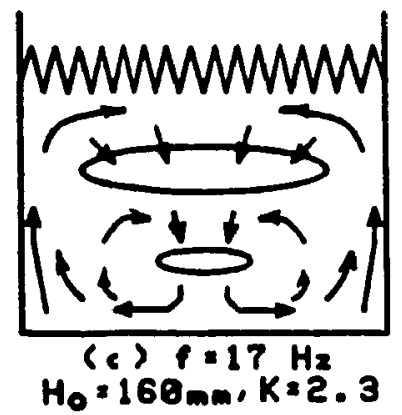

$H_{0}=168$ mm, $K=2.3$

Figure 6.4 Schematic flow patterns for AVB's of $100-\mu \mathrm{m}$ alumina particles at resonance with a single-aperture bottom plate for different $\mathrm{H}_{0}$ values and $\mathrm{U} / \mathrm{U}_{\mathrm{m}}=0.65$. 
particles piled up on one side to give the surface of the bed an oblique shape. There was slight vertical diffusion of particles particularly in the top layer. Figure $6.5 \mathrm{~b}$ shows data at the same frequency but with $\mathrm{H}_{0}=110 \mathrm{~mm}$ and the aeration rate set at $\mathrm{U}_{\mathrm{m} \text { - }}$ The particles were well-mixed in 25 seconds. The particle motion was generally down the middle and up the sides of the bed. Aeration thus has a strong influence on particle flow behaviour. As shown in Figures 6.5c through 6.5e, when $\mathrm{H}_{0}$ is increased to 200 or $300 \mathrm{~mm}$, bubbles form and the particles continue to move down the middle and up the sides as they do in shallower beds. When $f$ was reduced to zero, there was no longer bulk particle motion. The particles merely moved up and down in a small central region. At a frequency of $16 \mathrm{~Hz}$, the mixing time was 35 seconds for $\mathrm{H}_{0}=200 \mathrm{~mm}$ and 100 seconds for $\mathrm{H}_{0}=300 \mathrm{~mm}$.

As was the case with bubble and resonance phenomena, beds of large particles behave differently from beds of small particles. For both medium-size and small particles $\left(d_{p}<400 \mathrm{~mm}\right)$ the direction of particle motion is the same and aeration has a strong infll ence on particle flow behaviour. Particle circulation rates are higher in beds of small particles than those for beds of larger particles at comparable operating parameters. This will be further discussed in Sections 6.2.4 and 6.2.8.

\subsubsection{Flow Characteristics for Mixtures: Beds of Glass Beads and Alumina} Mixing patterns for a bed of 2:1 mixture (by volume) of $100-\mu \mathrm{m}$ alumina and $360-\mu \mathrm{m}$ glass beads are shown in Figure 6.6. Glass beads were first added to the bed to a height of $100 \mathrm{~mm}$. Alumina particles were then added to make $H_{0}=150 \mathrm{~mm}$. The air flow rate was $U / U_{m f}=0.65$ for alumina and $A$ was $2 \mathrm{~mm}$. $U p$ to $f=8 \mathrm{~Hz}$. $(\mathrm{K}=0.5)$, no particle motion was observed. At $\mathrm{f}=10 \mathrm{~Hz}(\mathrm{~K}=0.8)$, particles 
started to move slowly downward in the middle of the bed. At $\mathrm{f}=12 \mathrm{~Hz}(\mathrm{~K}=1.2)$, air started to bubble through the central core of the bed. Alumina particles started to flow down this central bubble-affected area. This area had grown to occupy the central portion of the bed confining the glass beads to the sides of the vessel at $f=15 \mathrm{~Hz}$. At $\mathrm{f}=16 \mathrm{~Hz}$, the bed displayed resonant behaviour and the particles were well-mixed and did not segregate. As indicated in Chapter 4, vibrated beds of mixtures of small, and to a lesser extent medium-size particles, do display resonant behaviour. Resonant behaviour results in enhanced particle motion and hence mixing.

\subsubsection{Mechanism of Solids Circulation in Small-Particle Beds}

Thomas (1988) has alluded to the differences between the flow behaviour of largeand small-particle vibrated beds. However, as seen in Chapter 4 they behave differently depending on whether or not they are aerated. Only aerated beds are discussed in this section. It will be seen in Section 6.2.6 that in non-aerated vibrated beds, particles tend to pile preferentially in different sections of the bed. This has been referred to by Thomas (1988) as bunkering. He suggested that overall particle circulation in small-particle beds is due to bunkering. However, Thomas' (1988) investigation was restricted to shallow non-aerated vibrated beds. In aerated vibrated beds, bunkering was non-existent. Particle circulation was nevertheless intense at the resonant point. The phenomenon that determines particle circulation is related, like the case for bunkering described by Thomas (1988) to the gas flows in the bed caused by pressure gradients. Time-dependent pressure gradients are initiated by compression waves created by vibration of the particulate mass during lift-off. 

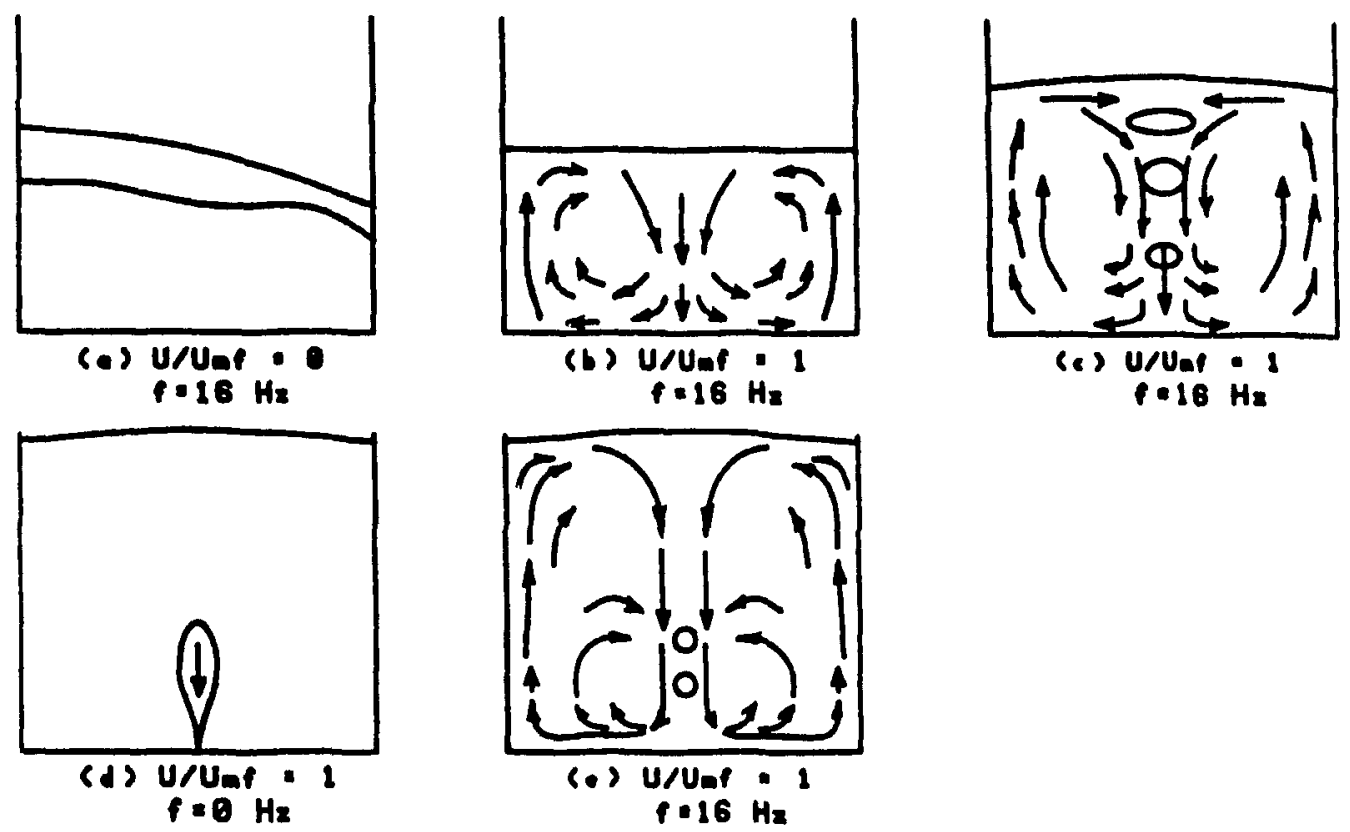

Figure 6.5 Schematic flow patterns for AVB's of $360-\mu \mathrm{m}$ glass beads at resonance with a single-aperture bottom plate for different $\mathrm{H}_{0}$ and $\mathrm{U} / \mathrm{U}_{\mathrm{m}}$ values: (a), (b) $\mathrm{H}_{0}=110 \mathrm{~mm}$; (c) $\mathrm{H}_{0}=200 \mathrm{~mm}$; (d) and (e) $\mathrm{H}_{0}=300 \mathrm{~mm}$.

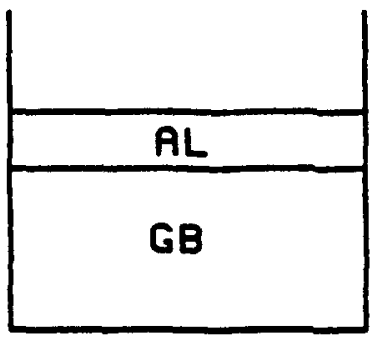

(a) $1.5 \mathrm{~Hz}$

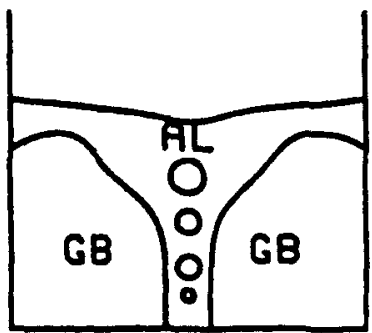

(d) $f=12 \mathrm{~Hz}$

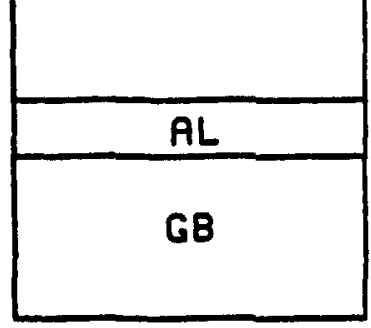

(b) $f=8 \mathrm{~Hz}$

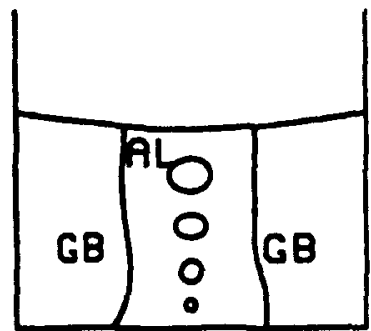

(.) $1814 \mathrm{~Hz}$

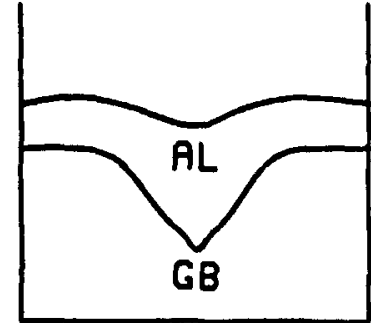

(e) $1210 \mathrm{~Hz}$

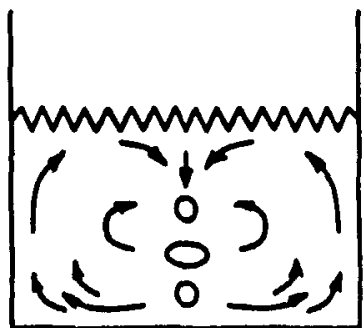

(f) $1216 \mathrm{~Hz}$

Figure 6.6 Mixing of $100-\mu \mathrm{m}$ alumina particles and $360-\mu \mathrm{m}$ glass beads in an AVB with a single-aperture bottom plate, $\mathrm{U} / \mathrm{U}_{\mathrm{m}}=0.65$ and $\mathrm{H}_{0}=150 \mathrm{~mm}$ ( $50 \mathrm{~mm}$ alumina on top of $100 \mathrm{~mm}$ glass beads). 
Particle circulation regimes may be divided into pre-resonance, resonance and postresonance regions. In aerated beds with a single orifice in the bottom plate gas bubbles are formed. Bubble sizes are largest at the resonant point. Particle circulation is also related to the formation of gas bubbles.

In the pre-resonance regime, gas flow is for the most part confined to the central core where the bubbles rise. There is mixing and particle circulation caused by the bubhles only in the central core. The bubbles are essentially spherical during the preresonance regime. It is expected that mixing and particle circulation is due to the bubble wake (Rowe (1971) and Kunii and Levenspiel (1984)). With an increase in the frequency, the increased force, of vibration is able to expand the central core. The bulbles begin to have a significant effect on the shape of the bed surface. In addition, as bubbles are formed at the base of the bed and start to rise, particles rush down around them before the next bubble forms. This is because the pressure at the central hole is greater than at the sides of the vessel. The resulting horizontal pressure gradients are symmetrical on either side of the vertical axis and they cause particles to move towards the sides at the bottom of the bed. For continuity, particles fall down the beds vertical axis and rise up by the side walls. This occurs despite particle movement due to bubble wake as expected from fluidized bed theory. This indicates that, since air is not spread out through the bed but is instead confined to the central core, vibration forces have a stronger influence on particle motion than does the bubble wake. The contribution of the bubble wake to particle motion decreases with increasing vibration frequency. Furthermore, particles move faster down the middle and slower up the side walls (where drag is greater). The consequence is the creation of a convex-shaped bed surface. While the bed surface 
shape gets increasingly convex with increasing frequency, there is a limit to this due to the differences in circulation rates at the walls and at the central axis of the bed being not that great. In addition, when bubbles collapse at the surface, particles fall into the "sink" thus created. This increases particle flow downwards and increases the horizontal pressure gradients at the bottom of the bed. Surface shape thus affects particle flow. This will be seen to be much more predominant in non-aerated vibrated beds discussed in Section 6.2.6.

As discussed in Chapter 5, in the resonance-affected region, bubbles get longer and flatter but larger and slower moving and have a lower frequency of formation at the base of the bed as compared to those in the pre-resonance regime. It may be recalled from Chapter 4 that the: pressure at the bottom of the bed decreases to below atmospheric in many cases. Since the pressure at the central hole where the bubbles are formed will not fall, the horizontal pressure gradients increase appreciably. The particle flows described for the pre-resonance regime are ail greatly augmented in the resonance regime. Therefore, particles move down the middle and up the sides at much faster velocities despite the slower rise velocities of the bubbles. The contribution of bubble wake to particle motion becomes almost insignificant due to the overwhelming effect of vibration forces and the pressure gradients they create and because bubble wakes are much smaller for the flatter bubbles. As the bubbles collapse at the surface, the rapid agitation of the particles there results in a greater rate of fall of the particles into the "sink" thus created and an increase in particle circulation rates.

At lower bed heights $\left(\mathrm{H}_{0}<100 \mathrm{~mm}\right)$ where the resonant frequency is of the order 
of $25 \mathrm{~Hz}$, the pressure at the base of the bed is so low that it is extended upwards along the bed height. This causes the formation of horizontal pressure gradients throughout the bed and hence particles can move horizontally and vertically throughout. This leads to random particle circulation and mixing.

As $\mathrm{H}_{0}$ increases, the resonance intensity factor decreases and the pressure at the bottom of the bed increases. This leads to a reduction in the horizontal pressure gradients and consequently to a decrease in particle circulation rates with increasing bed height. This causes poorer mixing. In addition, at greater bed heights, horizontal pressure gradients are not confined to the base of the bed, but are present at some distance (about $40 \mathrm{~mm}$ ) above the bottom plate. The reason for this is not known. However, the consequence is the creation of a double circulation pattern as seen in Figure 6.3.

In the post-resonance regime, the dynamics of the bed has features common to the pre-resonance and resonance regimes. Not unexpectedly, particle circulation rates are much lower than during the resonance regime but higher than those during the pre-resonance regime.

For beds of alumina/glass beads mixtures, there is no discernible particle motion at lower frequencies ( $\mathrm{f}<10 \mathrm{~Hz}$ ) as the air flow is insufficient to develop pressure gradients or bubbles to affect the larger glass beads. At lower frequencies, air is basically distributed by the glass beads through the alumina that is at the top.

At higher frequencies compaction caused by vibration leads to changes in the surface 
shape as the particles in the central core are compacted while those towards the side walls experience drag and hence are not as free to move. The change in shape sets up a slow movement of particles down the central core of the bed. At even higher frequencies, this motion leads to some mixing of the two types of particles. This in turn leads to the presence of alumina between the glass beads and hence to resonance as seen before in Chapter 4. Pressure gradients and bubbling associated with resonance leads to the previously described resonance flow patterns.

In summary, particle flow patterns, mixing, bubbling and surface shapes are all interrelated. Together with the frequency and amplitude of vibration they determine particle flow rates in aerated vibrated beds. As shown in Chapter 5, higher frequencies lead to increased bubbling and hence increased particle flow particularly at resonance. Furthermore, higher frequencies lead to higher pressure gradients in the bed and consequently increased particle motion. Frequency, rather than vibration parameter, is a better parameter for characterizing particle circulation and mixing $\mathrm{n}$ aerated vibrated beds of small particles.

\subsubsection{Flow Characteristics in Non-Aerated Beds}

Flow patterns for a bed of $100-\mu \mathrm{m}$ alumina particles for $\mathrm{H}_{0}=110 \mathrm{~mm}$ incl $\mathrm{A}=2 \mathrm{~mm}$ in a non-aerated bed are shown in Figure 6.7. For $\mathrm{f}<10 \mathrm{~Hz}$ no motion was observed. At $\mathrm{f}=15 \mathrm{~Hz}(\mathrm{~K}=1.8)$, there was merely diffusion of partucles in the vertical direction in the uppermost layers. Around $\mathfrak{f}=15 \sim 20 \mathrm{~Hz}(\mathrm{~K}=1.8-3.2)$, the top surface of the bed had a distorted asymmetric convex shape. Particles flowed from the higher side across the top of the bed and in the opposite direction across the centre. At $\mathrm{f}=20$ and $22 \mathrm{~Hz}$, the particles bunkered to one side. They flowed 
downwards at the top layers, downwards along the shorter side, horizontally across the bottom and up the deeper side. Similar circulatory patterns were set up in the centre of the bed. At $\mathrm{f}=24 \mathrm{~Hz}(\mathrm{~K}=4.6)$, the bed displayed fully-developed resonance as the bed pumped in air to sustain itself. The particles flowed down the middle and at the side walls. There was a much slower upflow between these two regions.

Flow patterns for $100-\mu \mathrm{m}$ particles in a $210-\mathrm{mm}$ high non-aerated bed are shown in Figure 6.8. Circulatory patterns were basically similar to those for $H_{n}=110 \mathrm{~mm}$ depicted in Figure 6.7. However, particle circulation rates were lower at this greater bed height. At $\mathrm{f}=23$ and $24 \mathrm{~Hz}(\mathrm{~K}=4.3$ and 4.6$)$, resonance was just beginning to develop in the bed. Resonance was not fully-developed as the bed could not sustain a resonant state without air injection at this bed height. A circulatory pattern was set up with particles moving down the middle and up the sides. At $f=24 \mathrm{~Hz}$, there was greater motion throughout the bed and the resonance at the top was not fully-developed but was more pronounced than at $\mathrm{f}=23 \mathrm{~Hz}$.

For $\mathrm{H}_{0}=260 \mathrm{~mm}$ at $\mathrm{f}=20 \mathrm{~Hz}(\mathrm{~K}=3.2)$, the shape of the top surface of the bed was such that there was a peak close to one side and a "valley" close to the other side. As usual, particles flow at the top from peak to valley. They moved down the lower side, horizontally across the bottom of the bed, up the higher side and downwards along the inclined top.

For beds of fine particle, surface shapes with particles piling up preferentially on one side of non-aerated vibrated beds have also been reported by Pakowski et al. (1984), 
Sprung (1987) and Thomas (1988). Thomas (1988) reported that only three shapes were possible: centre-high, centre-shallow and wall-high. He reported that surface shapes with the simultaneous presence of a hill and a valley other than at the side walls was impossible to obtain. These surface shapes were observed in this study. It has been seen that particle flow patterns depend strongly on the combination of f, $\mathrm{G}$ and $\mathrm{H}_{0}$.

\subsubsection{Mechanism of Solid Circulation in Non-Aerated Vibrated Beds}

It was seen in Section 6.2.1 that particle circulation and surface shapes are interrelated. Thomas (1988) believed that the flow of gas within the bed caused by pressure gradients is responsible for particle motion and he proposed a mechanısm for bunkered configurations and the associated flow patterns for vibrated beds. His theory is adopted in this study for beds that bunker. It considers particle circulatton and bunkering as being interdependent. Bunkering is responsible for horizontil pressures that cause particle motion. Particle motion in turn sustains the bunkered structure. The pressure gradients proposed are due to the behaviour of the bed is a vibrating porous piston as described in Chapter 4.

The absence of bubbles in non-aerated vibrated beds also causes a substantlal decrease in particle motion. In fact, in aerated vibrated beds, the intense mixing zones are partially due to the bubble motion. At the frequency corresponding (t) resonance in aerated beds, the non-aerated vibrated bed has the greatest cilpacity (o) pump air. The pressure giadients are then the highest. Particle flow is then at its greatest and the bed surface at its flattest but as mentioned in Chapter 4 no resonant behaviour is observed. 


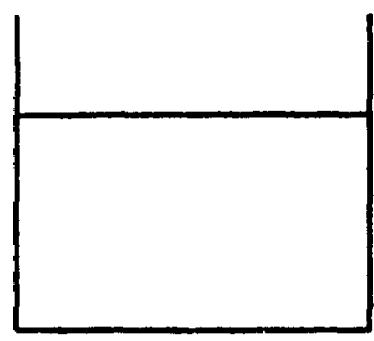

(a) $1=0-10 \mathrm{~Hz}$

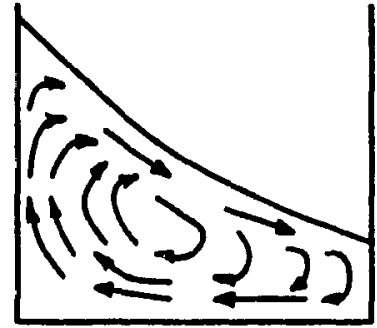

(d) $f=20 \mathrm{~Hz}$

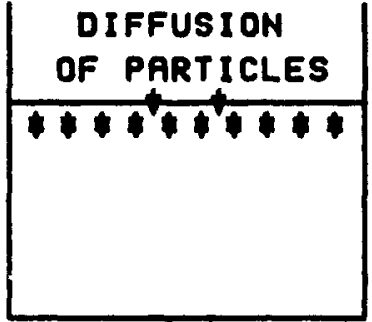

(b) $1: 15 \mathrm{~Hz}$

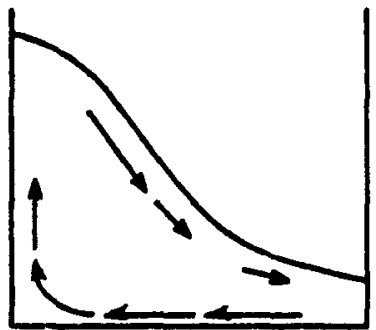

(.) $1.22 \mathrm{~Hz}$

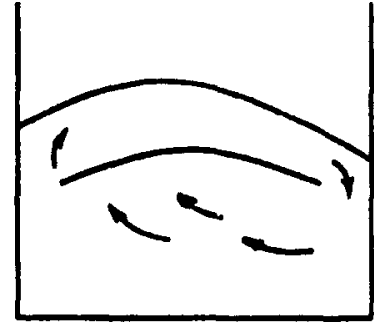

(c) $1=15-20 \mathrm{~Hz}$

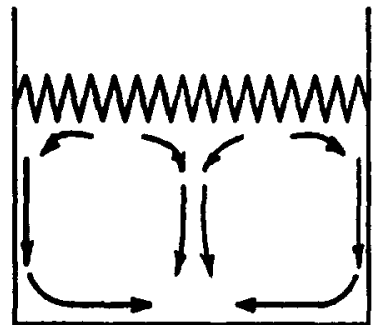

(f) $1224 \mathrm{~Hz}$

Figure 6.7 Schematic flow patterns for non-aerated vibrated beds of $100-\mu \mathrm{m}$ alumina particles for $\mathrm{H}_{0}=110 \mathrm{~mm}$.

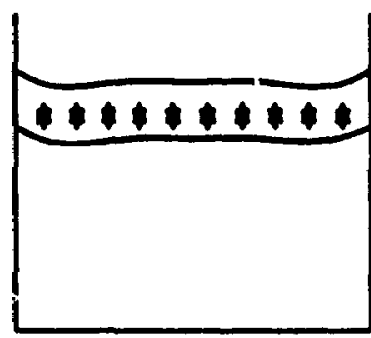

(0) $f=15 \mathrm{~Hz}$

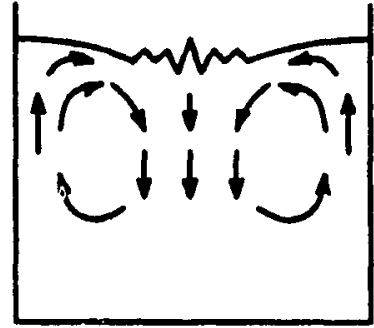

(d) $\mathrm{f}=23 \mathrm{~Hz}$

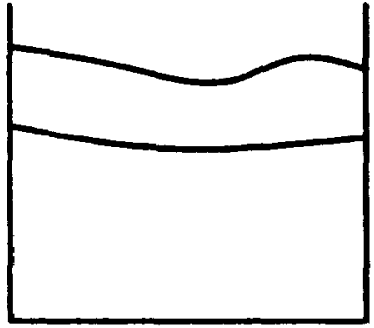

(b) $1217 \mathrm{~Hz}$

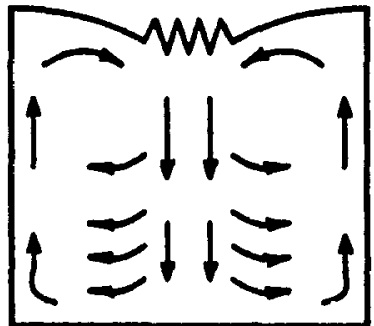

(.) $1224 \mathrm{~Hz}$

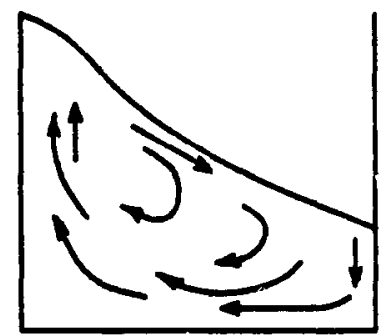

(c) $1=20 \mathrm{~Hz}$

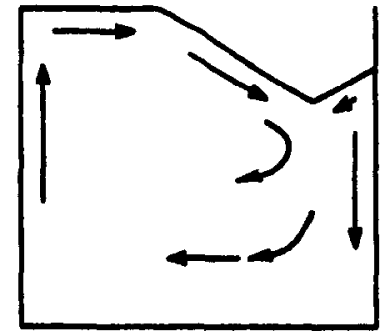

(f) $f=20 \mathrm{~Hz}$

Figure 6.8 Schematic flow patterns for non-aerated vibrated beds of $100-\mu \mathrm{m}$ alumina particles for $\mathrm{H}_{0}=210 \mathrm{~mm}$. 
To highlight some of the differences in aerated versus non-aerated vibrated beds a comparison was made between an aerated and a non-aerated bed of $100-\mu \mathrm{m}$ alumina particles vibrated at a frequency of $24 \mathrm{~Hz}$ and with $\mathrm{H}_{0}=110 \mathrm{~mm}$. Not unexpectedly, the mixing time is 47 seconds for the non-aerated bed as compared to 18 seconds for the aerated bed.

In vibrated beds that bunker, there was significant motion at the surface of the bed. This is where the bed has the highest porosity. Due to the significant particle motuon, the particles were best mixed at the surface. When bunkers were less pronounced. mixing in the bed was mostly convective. Bunkering then results in improved mixıng in vibrated beds albeit of the surface mixing type.

\subsubsection{Flow Characteristics for Molecular Sieve Particles}

\section{Air Flow through a Single-Aperture Plate}

Flow patterns in beds of $1.4-\mathrm{mm}$ molecular sieve particles with the single-aperture bottom plate are shown in Figures 6.9 and 6.10. The results are for $A=2 \mathrm{~mm}$, $\mathrm{U} / \mathrm{U}_{\mathrm{mf}}=0.5$ and $\mathrm{H}_{0}=135$ and $200 \mathrm{~mm}$ respectively. $\mathrm{Up}$ to $\mathrm{f}=10 \mathrm{~Hz}(\mathrm{~K}=0.8)$ the surface of the bed was slightly concave. There was no discernable motion of the particles except in a spherical region close to the aperture. Here the particles moved upwards along the central axis and downwards at the periphery in a spouting motion. At $\mathrm{f}=12 \mathrm{~Hz}(\mathrm{~K}=1.2)$, the spherical affected region expands by about $30 \%$. The particles in the rest of the bed particularly close to the top became more mobile. moving down the middle and up the side. This motion intensitied at $t=14 \mathrm{~Hz}$ ( $K=1.6$ ) and had extended to the whole bed for $\mathrm{H}_{0}=135 \mathrm{~mm}$. Towards the centre of the bed the particles move outwards to the sides. At $\mathrm{f}=16 \mathrm{~Hz}(\mathrm{~K}=2.1)$ the 
particles circulated throughout the bed and the flow patterns were otherwise similar to those at $\mathrm{f}=14 \mathrm{~Hz}$. Circulation rates were never as high as for the smaller 100$\mu \mathrm{m}$ particles.

\section{Perforated Bottom Plate}

Figure 6.11 shows flow patterns for $1.4-\mathrm{mm}$ molecular sieve particles in an aerated bed vibrated at $\mathrm{f}=16 \mathrm{~Hz}(\mathrm{~K}=2.1)$ with a perforated bottom plate and with $H_{0}=120 \mathrm{~mm}$. When the air velocity corresponded to $U_{m f}$, the particles move up the middle and down the sides. When the air velocity was less than $U_{m}$, particles move In the opposite direction, i.e. down the middle and up the sides. When the air flow rate was much greater than $U_{m}$, the particle flow was again up the middle and down the sides. This implies that the direction of particle circulation depends on the aeration rate with respect to $U_{m}$.

\subsubsection{Mechanism of Solids Circulation in Large-Particle Beds}

Thomas (1988) reported that beds of large particles which are more permeable to gas flows have little horizontal pressure gradients and hence bunkering is absent. In this study also, bunkering does not occur in large-particle beds and the latter is symmetrical about the vertical axis. Particles in each half of the bed divided by the central vertical plane do not mix.

It is believed that, unlike the case of small-particle beds, particle motion in largeparticle beds is not due to horizontal pressure gradients. In fact, particle motion is now due to the direct effect of vibration on the particles rather than indirectly through pressure gradients. Particle motion near the air inlet is due to spouting at 


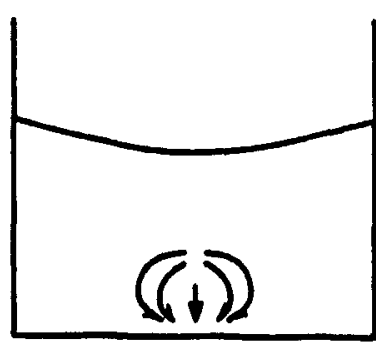

(a) $f=0 \mathrm{~Hz}$

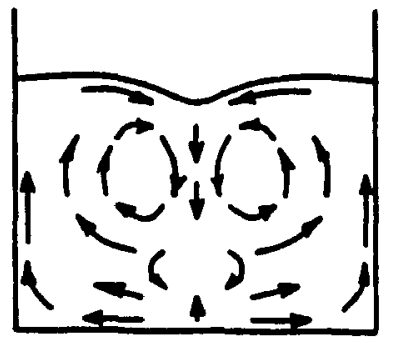

(d) $1: 14 \mathrm{~Hz}$

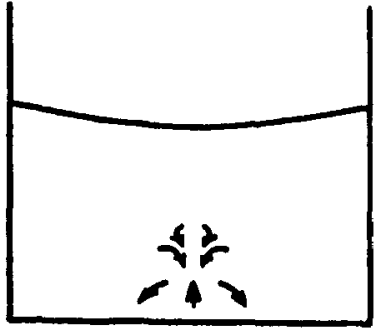

(b) $1=18 \mathrm{~Hz}$

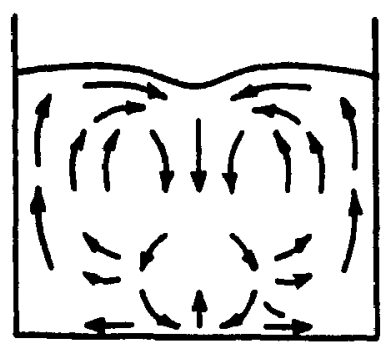

(e) $f=16 \mathrm{~Hz}$

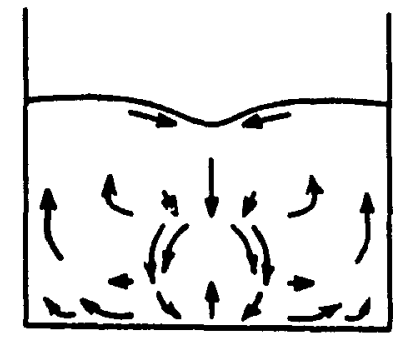

(c) $f: 12 \mathrm{~Hz}$

Figure 6.9 Schematic flow patterns for AVB's of 1.4-mm molecular sieve particles with a single aperture botttom plate, $U / \mathrm{U}_{\mathrm{mt}}=0.5$ and $\mathrm{H}_{0}=135 \mathrm{~mm}$.
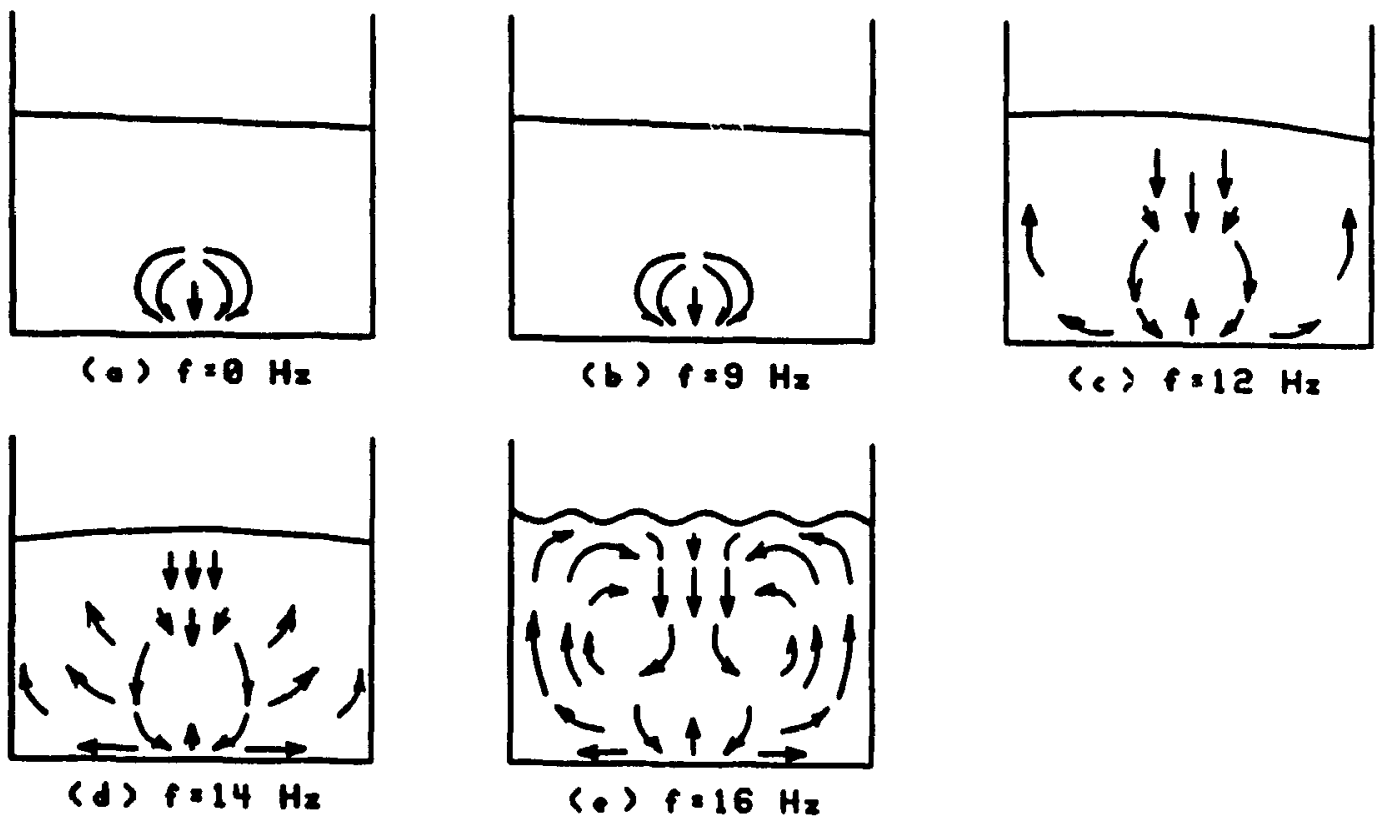

Figure 6.10 Schematic flow patterns for AVB's of 1.4-mm molecular sieve particles with a single aperture botttom plate, $U / U_{m t}=0.5$ and $H_{4}=2000 \mathrm{~mm}$. 
low frequencies. This spout acts along with vibration to set up the numerous circulation loops.

At higher frequencies air gaps begin to form below the bed. This causes an uptlow of gas and pressure gradients directed similarly upwards. Horizontal pressure gradients are less pronounced because the bed is permeable to gas flow. Particles move up in the direction of the vertical pressure gradients and continue to move down in a spherical region close to the aperture. The air gap between the bed and the bottom plate expands at higher frequencies and since the frequency of the compression wave (described in Chapter 4) Increases, the pressure gradients increase causing an increase in particle flow with frequency. Recall that pressure gradients are created by compression waves. Particle circulation rates are never as high as they are in small-particle beds due to the lower pressure gradients in large-particle beds.

When the perforated plate is used at air flows above $U_{m}$, particle flow is similar to that described for fluidized beds even when vibration is applied. It had already been seen in Chapters 4 and 5 and reported by Pakowskı and Mujumdar (1982) and Malhotra and Mujumdar (1985a) that the effects of aeration are much stronger than the effects of vibration at aeration rates above $U_{m}$.

When a perforated plate is used at air flows below $U_{m}$, vibration has a stronger intluence on the flow characteristics. Hence particle flow is similar to that observed for vibrated beds or aerated vibrated beds with a single orifice. The inability to trap air in large-particle beds results in particle motion much reduced from that in smallparticle beds. 


\subsection{FLOW CHARACTERISTICS OF ALUMINA IN BEDS WITH INTERNALS}

\subsubsection{Effect of a 20-mm Diameter Circular Cylinder}

Flow patterns for $100-\mu \mathrm{m}$ alumina particles in a $210-\mathrm{mm}$ high aerated bed vibrated at $\mathrm{f}=16 \mathrm{~Hz}(\mathrm{~K}=2.1)$ containing a rigidly fixed $20-\mathrm{mm}$ dameter circular cylinder are shown in Figure 6.12. The cylinder was fixed $100 \mathrm{~mm}$ trom the sides and $100 \mathrm{~mm}$ from the bottom plate which contained a single aperture. When the aur inlet to the bed was sealed and the air flow totally cut off, a resonant condition wils attianed and the particles moved down the middle and up the sides. At the elevatton of the cylinder, the particles moved inwards towards the cylinder from the walls and llowed obliquely downwards past the cylinder. When the aperture at the bottom of the led was left open without air being forced in the flow patterns were basically sumbir 10 those described above. However, the particles at and below the elevation of the cylinder were much more mobile. More vigorous resonance wals acheved and the particle motion intensified when the aeration rate was increased to $U U_{\mathrm{m} t}=0105$ However, the particles moved upwards close to the walls and down the mudlle Again, at the elevation of the cylinder, there was movement of particles inwarch towards it. At the base of the bed there was movement of particles outwirch trom the centre. Yet, there was a thin layer of particles moving downwards at the wall near the top of the bed. This would imply that a plane of slip existed ne:ir the wall.

Experiments similar to those described above were conducted except with at perforated plate instead of a single orifice plate with $\mathrm{H}_{n}=110 \mathrm{~mm}$ and aleritunn rate corresponding to $\mathrm{U} / \mathrm{U}_{\mathrm{m}}=1$. The flow patterns are shown in Figure 6.13. Wulhout vibration, no particle flow was discernible. At $\mathrm{t}=5 \mathrm{~Hz}(\mathrm{~K}=0.2)$, there wis some diffusion of particles across horizontal layers in the bed. At $t=10 \mathrm{~Hz}(\mathrm{~K}=0) 8$, the 


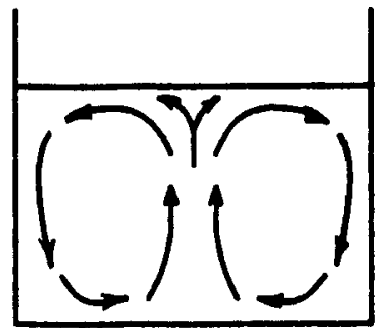

(a) $1316 \mathrm{~Hz}$ U/Umf:0.6

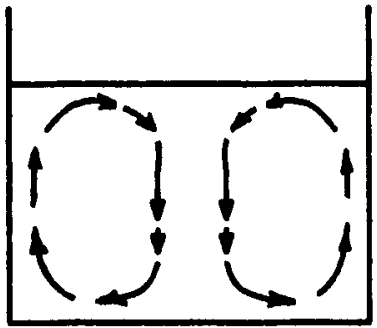

(b) $f: 16 \mathrm{~Hz}$ U/Umf $=1.0$

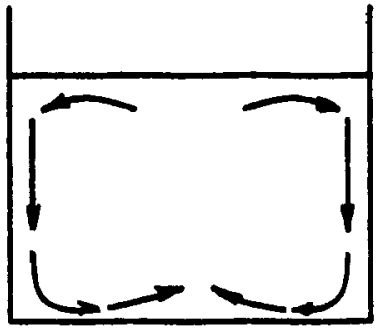

(c) $1: 16 \mathrm{~Hz}$ U/Umf $: 2.0$

Figure 6.11 Schematic flow patterns for AVB's of 1.4-mm molecular sieve particles with a perforated botttom plate, (a) $U / U_{m t}=0.6$; (b) $U / U_{m t}=1$;

(c) $\mathrm{U} / \mathrm{U}_{\mathrm{mr}}=2$.

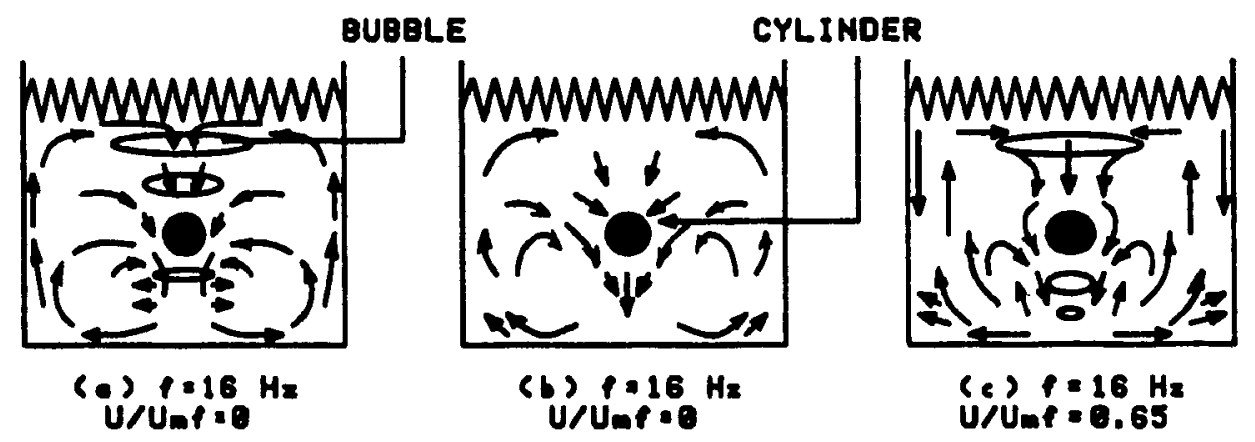

Figure 6.12 Schematic flow patterns at resonance for 210-mm high AVB's of 100$\mu \mathrm{m}$ alumina particles with a $20-\mathrm{mm}$ circular cylinder located $100 \mathrm{~mm}$ from the sides and above the bottom plate with a single aperture, (a) and (b) $\mathrm{U} / \mathrm{U}_{\mathrm{mt}}=0$ and (c) $\mathrm{U} / \mathrm{U}_{\mathrm{mf}}=0.65$. 
bed bunkered on one side resulting in an inclined surface. The particles flowed down the other side and across the bottom. At $\mathrm{f}=15 \mathrm{~Hz}(\mathrm{~K}=1.8)$, the bed surface was again nearly horizontal. As discussed in Chapter 5, bubbles were formed and the particles moved downward in the middle of the bed (hence downward by the cylinder) and up the sides of the containing vessel and the region in between the side walls and the cylinder. At $\mathrm{f}=20$ and $24 \mathrm{~Hz}(\mathrm{~K}=3.2$ and 4.6$)$, the bed behaviour was similar but the region of downflow had expanded.

For $100-\mu \mathrm{m}$ alumina particles in a $220-\mathrm{mm}$ deep bed containing a tixed $20-\mathrm{mm}$ diameter cylinder, the observed particle circulation patterns are shown in Figure 6.14. A perforated bottom plate was used and $G$ was set at $U / U_{m}=1$. Without vibration, there was no particle flow. At $\mathrm{f}=5 \mathrm{~Hz}(\mathrm{~K}=0.2)$, bubbles were formed on one side of the bed. The particles moved up this side and down the other side. At $f=10 \mathrm{~Hz}$ ( $\mathrm{K}=0.8$ ), bubbles were formed on the other side of the bed. At the wall, the particles moved up this side but downwards to both sides of the cylinder. For $f>15$ $\mathrm{Hz}(\mathrm{K}=1.8)$, there was an increase in the number of bubbles present in the bed with an increase in frequency and the particle flow was mainly confined in a downward direction by the cylinder.

Particles present on top of the cylinder were always stationary or slow moving. This was particularly pronounced at higher bed heights and at lower frequencies when particle circulation in the bed was minimal. The affected region started from the cylinder's upper surface and extended triangularly upwards to form a peak about 1.5 cylinder diameters above the cylinder. Like the cases without the cylinder, particles in the corners of the vessel were not mobile and hence not well-mixed. 


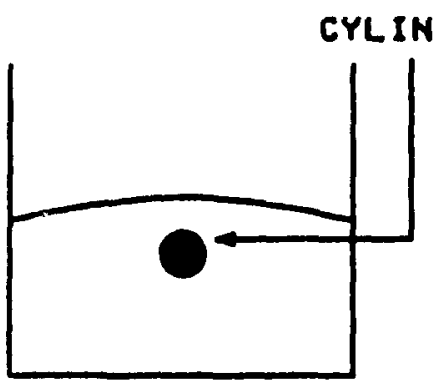

(a) $f=0 \mathrm{~Hz}$

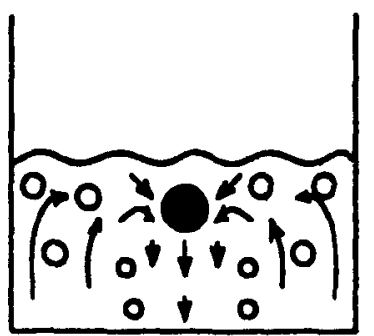

(d) $\mathrm{f}=15 \mathrm{~Hz}$
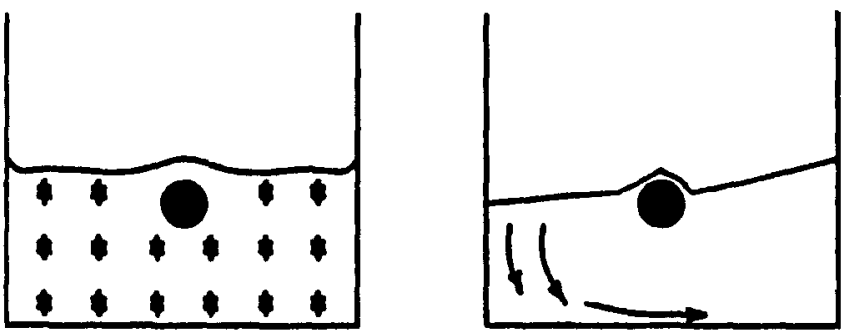

$(b) f=5 \mathrm{~Hz}$ BUBBLES

(c) $f=10 \mathrm{~Hz}$

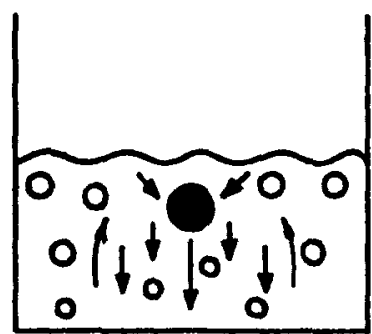

(f) $\mathrm{f} \cdot 24 \mathrm{~Hz}$

Figure 6.13 Schematic flow patterns for 110-mm high AVB's of $100-\mu \mathrm{m}$ alumina particles with a $20-\mathrm{mm}$ circular cylinder located $100 \mathrm{~mm}$ from the sides above a perforated bottom plate with $\mathrm{U} / \mathrm{U}_{\mathrm{m} t}=1$.
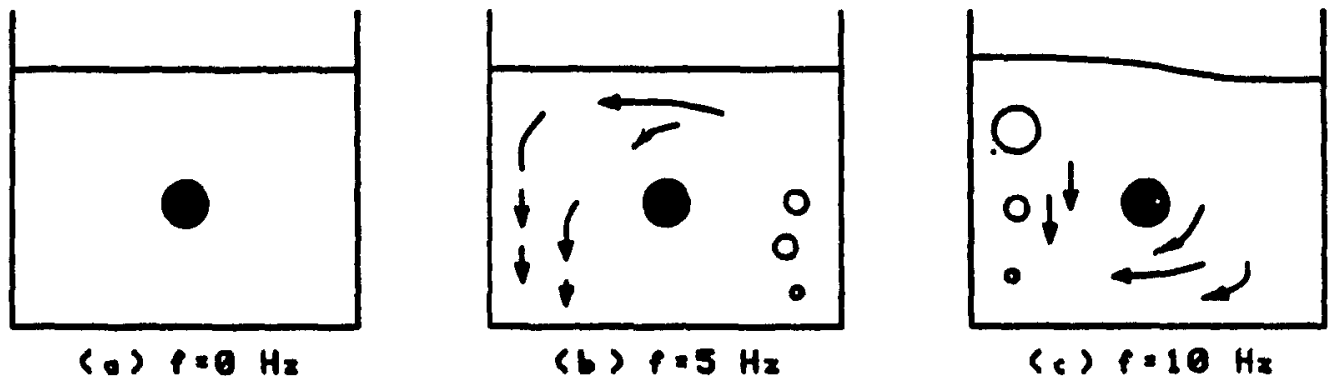

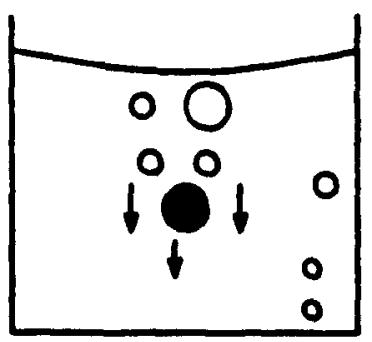

(d) $1215 \mathrm{~Hz}$

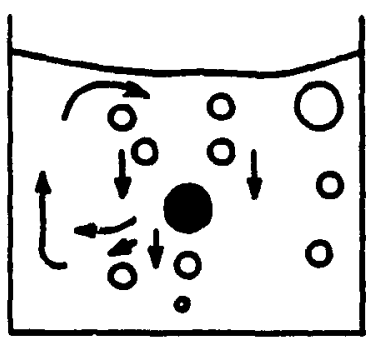

(.) $1220 \mathrm{~Hz}$

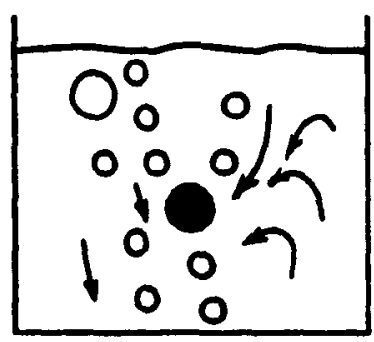

(f) $f=24 \mathrm{~Hz}$

Figure 6.14 Schematic flow patterns for 220-mm high AVB's of $100-\mu \mathrm{m}$ alumina particles with a $20-\mathrm{mm}$ circular cylinder located $100 \mathrm{~mm}$ from the sides above a perforated bottom plate with $\mathrm{U} / \mathrm{U}_{\mathrm{m} r}=1$. (A solid circle represents the cylinder). 


\subsubsection{Effect of a 40-mm Diameter Circular Cylinder}

Flow patterns for $100-\mu \mathrm{m}$ alumina particles in a $185-\mathrm{mm}$ high aerated vibrated bed with a $40-\mathrm{mm}$ diameter circular cylirder fixed $100 \mathrm{~mm}$ from the sides and $100 \mathrm{~mm}$ from the bottom plate are shown in Figure 6.15. The bottom plate wals pertorated and the air flow rate was maintained at $U_{m r}$. Flow patterns are similar to those for the 20-mm diameter cylinder. Significant particle motion occurred only for $f>10 \mathrm{~Hz}$ $(\mathrm{K}=0.8)$ where bubbling was apparent and the particles moved down one sule and up the other. A continual increase in the number of bubbles accurred at $f=15.20$ $\mathrm{Hz}(\mathrm{K}=1.8-3.2)$ and the particles moved down the central core close to the cylinder. At $\mathrm{f}=24 \mathrm{~Hz}$, bubbling intenstfied and the particles moved down the middle close to the cylinder and upwards in the region between the middle and the sides.

\subsubsection{Mechanism of Solids Circulation in Beds with Internils}

The presence of a fixed horizontal circular cylinder in the bed results in distontioms of the normal particle flow. For small-particle aerated vibrated beds with a ungle orifice, the general particle flow patterns remain the same: down the middle core and up along the side walls. However, the particles move relattvely tast in the vicunty of the lower half of the cylinder. The presence of the cylinder does not appear w alfect the overall particle circulation rates.

Bubbles move up the centre of the bed and split into two upon impact with the cylinder's lower surface. The bubbles do not scour the top surface of the cylindier at low air flow rates $\left(U / U_{m t} \sim 1\right)$, and hence there is little particle mixing directly above the cylinder. The particles moving down are diverted to the side of the cylinder The 


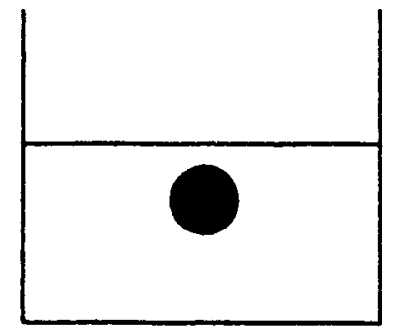

(a) $f=0 \mathrm{~Hz}$

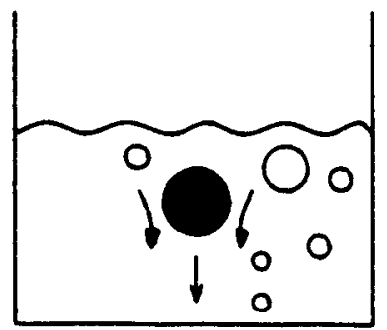

(d) $f=15 \mathrm{~Hz}$

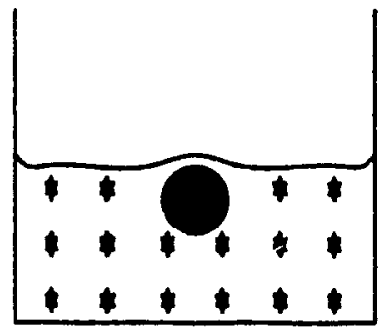

(b) $f=5 \mathrm{~Hz}$

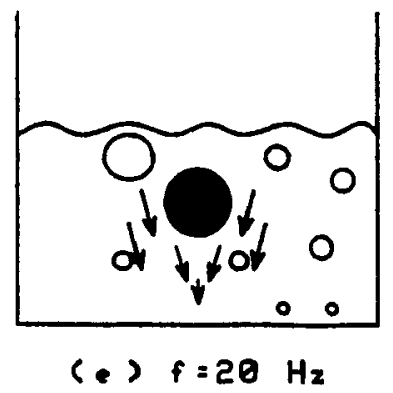

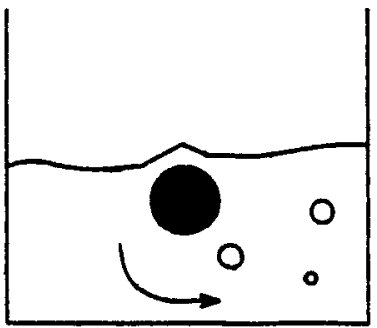

(c) $f=10 \mathrm{~Hz}$

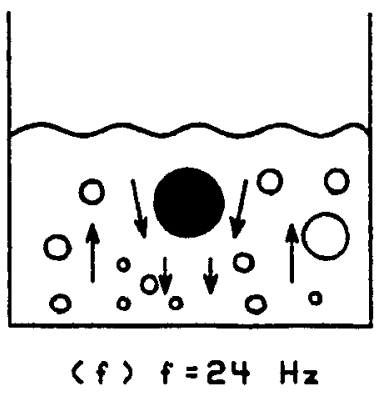

Figure 6.15 Schematic flow patterns for 185-mm high AVB's of $100-\mu \mathrm{m}$ alumina particles with a $40-\mathrm{mm}$ circular cylinder located $100 \mathrm{~mm}$ from the sicles above a perforated bottom plate with $U / U_{m}=1$. 
particles on top of the cylinder then remain motionless.

At higher air flow rates the bubbles are large enough to engulf the whole cylinde surface periodically i.e. $d_{b}$ is greater than $d_{c}$. The immobile layer on the upper surface of the cylinder is then disturbed periodically at the bubble passage trequency. Large bubbles also $\mathrm{r}$ sult in increased distortions to the particle flow and result in increased gas-shrouding of the cylinder which has important implications tor heilt transfer from a cylinder immersed in vibrated beds.

\subsection{IMPLICATIONS FOR DESIGN}

Aeration of vibiated beds results in increased particle motion of small-particle beds. Such beds should be aerated and operated at or close to the resonant point. This is where particle motion is most intense while the bed pressure drop is minimal. Since particle circulation rates decrease with increasing bed height, a bed height of $\mathrm{H}=120-200 \mathrm{~mm}$ is recommended.

Beds of particles that do not exhibit resonant behaviour (such as large-particle beds) should be operated at the highest frequency that the equipment allows as particle motion is determined by the intensity of the applied vibration. Such beds maly be operated with minimal or without aeration as it has only marginal effects on particle circulation in large-particle beds. Therefore, aeration rates may be chosen according to the requirements of the process.

Vibrated fluidized beds should be operated at aeration rates not exceeding $0.8 \mathrm{U}_{\mathrm{mr}}$ unless higher rates are needed for other reasons. This range of aeration leads to 
formation of small bubbles which enhances particle circulation and mixing. Further implications of particle mobility will be considered in Chapter 7.

\subsection{CLOSURE}

The flow patterns developed in vibrated beds depend on the method and rate of aeration, bed height, frequency of vibration, the presence of internals and particle size. Mixing rates and particle circulation rates are higher in aerated vibrated beds of small particles. These beds yield flow patterns with particles moving down the middle and up the sides. The particle flow rate is negligible at low frequencies but increases with frequency to reach a maximum at resonance for small-particle beds. Vibration frequency rather than the vibration parameter is a better characterizing parameter for particle circulation and mixing in vibrated beds. Particle flow is due to the presence of horizontal and vertical pressure gradients and bubble passage. In the absence of air flow, small-particle beds tend to bunker. Bunkering is due to the presence of horizontal pressure gradients. Again, particle flow rates increalse with frequency. Large-particle beds $\left(d_{p}>1 \mathrm{~mm}\right)$ have particle tlow down the middle and up the sides at low air flow rates $\left(U / U_{m f} \sim 0.6\right)$. However, they have lower circulatory rates due to reduced pressure gradients and bubbling. In fact, particle circulation is due for the most part to the direct application of vibration. In beds aerated with perforated bottom plates, the flow patterns are similar once the air flow rate is less than or equal to $U_{m}$. At air flow rates above $U_{m}$, the particle flow is like that in flurdized beds being up the middle and down the sides. The presence of internals distorts the regular circulation patterns. However, the basic particle flow patterns remain the same. A stationary region is generally present on the upper surface of the cylinder. The mechanism of particle flow in beds with internals is 
basically the same as in beds without internals except that the former creates increased horizontal pressure gradients. The presence of a cylinder leads to bubble splitting and increased mixing to its sides. 


\section{CHAPTER 7. SURFACE-TO-BED HEAT TRANSFER}

\section{$7.1 \quad$ INTRODUCTION}

Immersed surface heat transfer in beds of medium-size and large particles $\left(d_{p}>250 \mu \mathrm{m}\right)$ has been studied by Pakowski ind Mujumdar (1982), Ringer and Mujumdar (1982), and Malhotra and Mujumdar (1985b, 1987). This chapter discusses cylindrical surface-to-bed heat transfer characteristics of aerated vibrated beds of small particles. These particles display resonant behaviour as described in Chapter 4. Experimental data are presented and an attempt is made to relate heat transfer results to bubble phenomena, particle flow patterns and to air gaps around the cylinder in both aerated and non-aerated vibrated beds. A simple semi-empırical correlation based on the bed aerodynamics is proposed to relate the measured heat transfer results to observed flow patterns.

\subsection{EXPERIMENTAL RESULTS}

Particle surface coverage results are presented. These experiments were conducted in the 20-mm thick rectangular vessel (See Chapter 3). To permit visual observation of the air gaps and hence estimation of surface coverage, the test cylinders were attached to the sides of the vessel unlike the case for the heat transfer experiments where they were externally suspended.

All heat transfer data were obtained in the rectangular bed at a bed thickness of 60 $\mathrm{mm}$. Two suspended cylindrical heating probes, one $20 \mathrm{~mm}$ and the other $40 \mathrm{~mm}$ in diameter, consisting of cartridge heaters embedded in copper tubes insulated at both ends were used. The surface temperature distribution of the probe immersed in the 
bed was measured at seven peripheral locations and averaged to give an anerage surface temperature, $T$. Heat supplied to the probe $(Q)$ was determined usmg a $D C$ wattmeter. Assuming no heat loss from the probe ends, the surface-to-bed heat transfer coefficient was defined as:

$$
h-\frac{Q}{A_{c} \Delta T}
$$

where

$$
\text { - } \Delta T-T_{s}-T_{b} \text {. }
$$

\subsubsection{Particle Surface Coverage}

The behaviour of a vibrated bed in the vicinity of an immersed horizontal cylmuricill heater is important as it influences heat transfer between the heater and the bed (Pakowski and Mujumdar (1982), Malhotra and Mujumdar (1985a), Malhotra and Mujurndar (1987), Thomas et al. (1987), and Pakowskı and Gora (1989)). There is formation of particle-free air gaps around the immersed surfice. In additun, there is coverage of the top surface of the cylinder by slow-moving or almost stagnamt particles which limits the particle-surface contact.

The extent of time-averaged surface coverage of the cylinder by particles was tound, following Malhotra and Mujumdar (1987), by defining the tume-averaged traction of the cylinder surface covered by particles, w (i.e. in contact with the bed) in 
where $\theta$ is the angle measured from the centre of the circular dummy probe as shown in Figure 7.1. The particle coverage is found for each still photograph (1 still $=1 / 60$ second). Fifteen (15) stills were used to obtain the average fractional surface coverage. The average coverage over a cycle can be found from the period of vibration.

For $100-\mu \mathrm{m}$ alumina particles, air gaps form around the cylinder for $f>0.8 \mathrm{t}_{\mathrm{r}}$. In the absence of air flow, on average $50 \%$ of the cylinder surface is in continuous contact with particles. The alr gap is larger and deeper at the lower surface of the cylinder as seen in Figure $7.2 \mathrm{a}$ for $\mathrm{H}_{0}=215 \mathrm{~mm}, \mathrm{U} / \mathrm{U}_{\mathrm{m}}=0$ and $\mathrm{f}=16 \mathrm{~Hz}$. The cylinder creates a region of high bed porosity i.e. a region of lower aerodynamic resistance in its vicinity. The air therefore flows preferentially around the cylinder. Moreover, oscillatory voids remain close to the cylinder's upper surface to form a butterfly-like shape. These voids keep expanding and contracting and are shed from time to time at frequencies about 4 times lower than the vibration frequency. In the presence of air flow, the air gaps become larger, and on average less than $30 \%$ of the cylinder is covered by particles. For $\mathrm{H}_{0}=200 \mathrm{~mm}, \mathrm{U} / \mathrm{U}_{\mathrm{m} t}=0.65$ at $\mathrm{f}=\mathrm{f}_{\mathrm{r}}=15 \mathrm{~Hz}$, large bubbles occupy the bed as was observed in Chapter 5. When the bubbles pass the cylinder the air gaps are disturbed. As shown in Figure 7.2b, during bubble passage the cylinder is totally engulfed by the bubble. The bubble size increases with increasing values of $U / U_{m}$. Consequently, $w$ decreases with increasing $U / U_{m c}$ values during bubble passage and at times may fall to as low as zero. Note that though the gaps are described as particle-free, they are not necessarily devoıd of particles. In fact, they are regions of very high porosity (estimated at $98 \%$ or more). 
For $f>f_{r}$, the bubble size decreases to about $30 \%$ of the size at the resoniant frequency of $15 \mathrm{~Hz}$ as was seen in Chapter 6. Bubbles still engulf the cylinder most of the time. Their smaller size and the size of the cylinder limit the arr gap coverage. The average particle surface coverage increases to about $10 \%$. The top surtace, however, remains essentially devoid of particles and only the lower surfiace of the cylinder maintains contact with the bed.

For $1.4-\mathrm{mm}$ molecular sieve particles, the particle coverage at three ditterent frequencies are shown in Table 7.1. As shown in Figure 7.3, the shapes of the :ur gaps are different from those for the smaller alumina partıcles. The average fractional coverage at $f=10 \mathrm{~Hz}$ is 0.72 . At $\mathrm{f}=13 \mathrm{~Hz}$ the coverage decreases $\mathrm{t}$ 0.59 . However, as was also the case at $\mathrm{f}=10 \mathrm{~Hz}$, the arr gap was formed only att the bottom of the cylinder. At $\mathrm{f}=16 \mathrm{~Hz}$, air gaps appeared on the top surtace of the cylinder while the coverage decreased to an average of 0.22 comprising of 11.118 . 1long the bottom and 0.35 along the top surfaces. This implies that particle surtace coverage decreases with increasing $\mathrm{K}$ as other researchers (Pakowskı and Mujumdlar (1982), Malhotra and Mujumdar (1985a), Malhotra and Mujumdar (1987), Thomas et al. (1987) and Pakowski and Gora (1989)) have found. However, this dependence is restricted to large-particle beds. In small-particle beds the particle surfice coverage is a function of $f$ rather than $K$.

\subsubsection{Heat Transfer}

Figure 7.4 shows the variation of $\mathrm{h}$ with $\mathrm{f}$ for a bed of $100-\mu \mathrm{m}$ alumina particles ill different $A$ values while Figure 7.5 shows the same results except that $h$ is plotted against $\mathrm{K}$. The heat transfer coefficients were obtained at $\mathrm{H}_{0}=155 \mathrm{~mm}$ and 


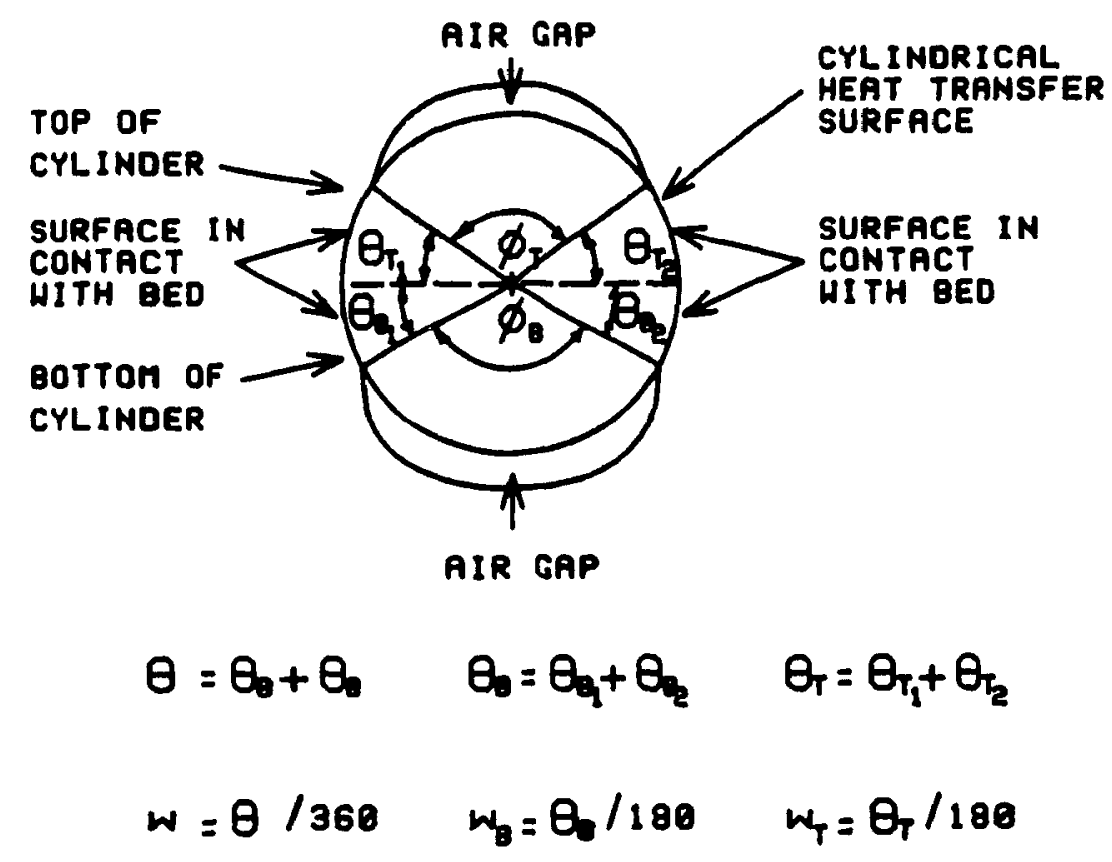

Figure 7.1 Schematic representation of particle surface coverage of heat transfer tube. 


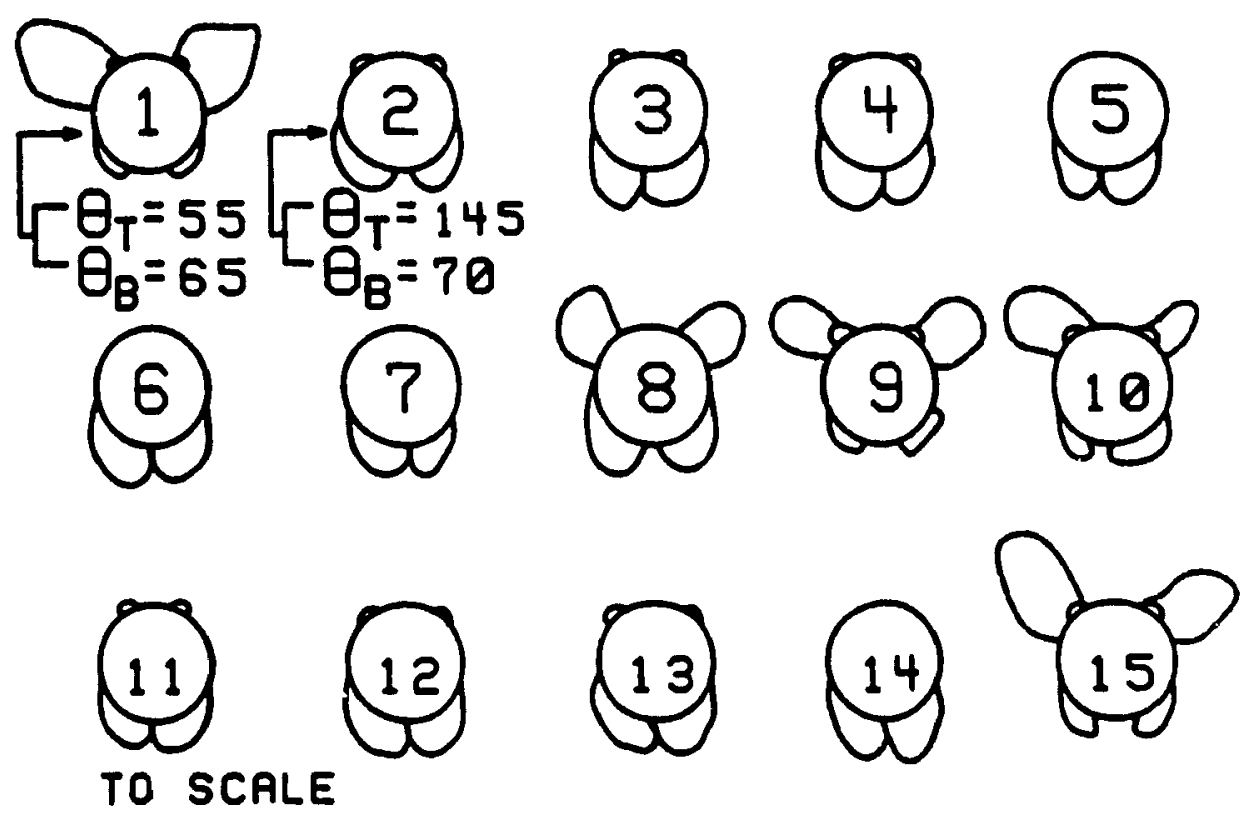

(a)
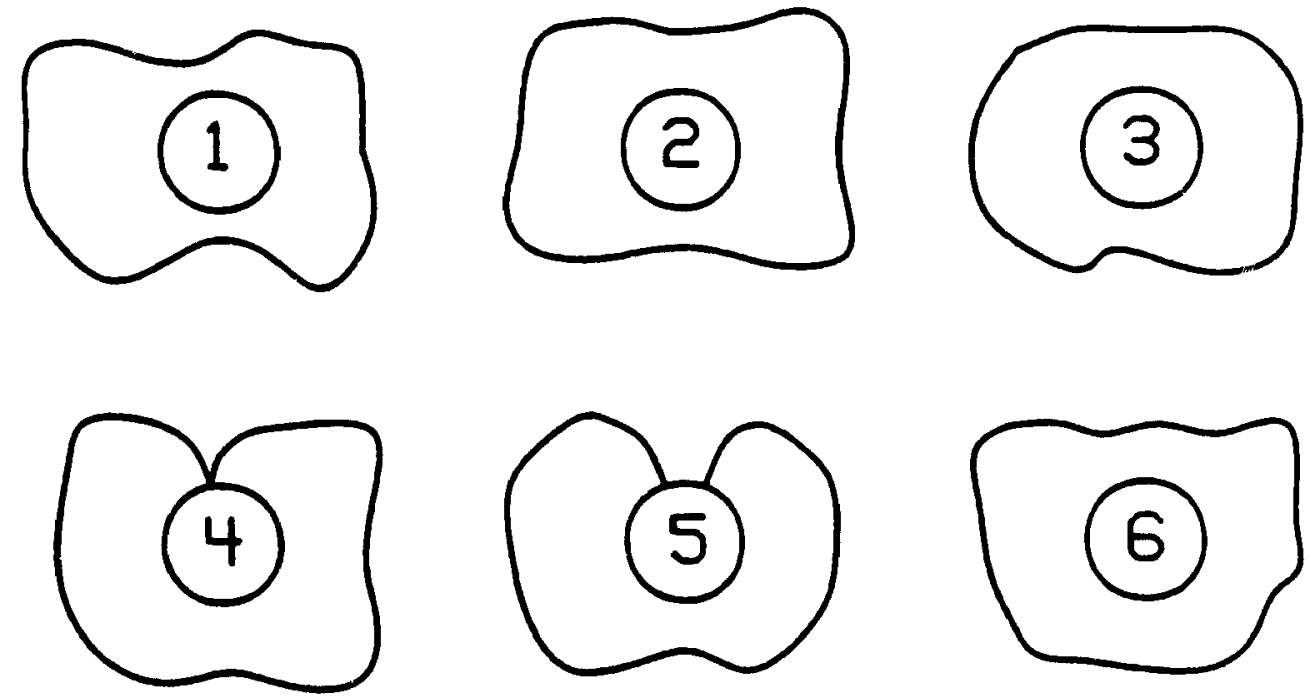

(b)

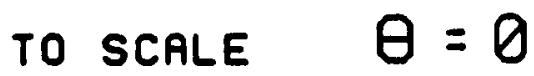

Figure 7.2 Schematic time-averaged air gaps around a 20 -mm circular cylinder in a bed of $100-\mu \mathrm{m}$ alumina particles as a function of time (eilch step $=0.0167 \mathrm{~s}$ ): (a) $\mathrm{H}_{0}=215 \mathrm{~mm}, \mathrm{U} / \mathrm{U}_{\mathrm{mt}}=0, \mathrm{t}=16 \mathrm{~Hz}, \mathrm{~A}=2 \mathrm{~mm}:$ (b) $\mathrm{H}_{0}=215 \mathrm{~mm}, \mathrm{U} / \mathrm{U}_{\mathrm{mt}}=0.65, \mathrm{f}=15 \mathrm{~Hz}, \mathrm{~A}=2 \mathrm{~mm}$. 
Table 7.1 Fractional particle coverage of cylinder surface with air flow through a bottom plate with one central hole.

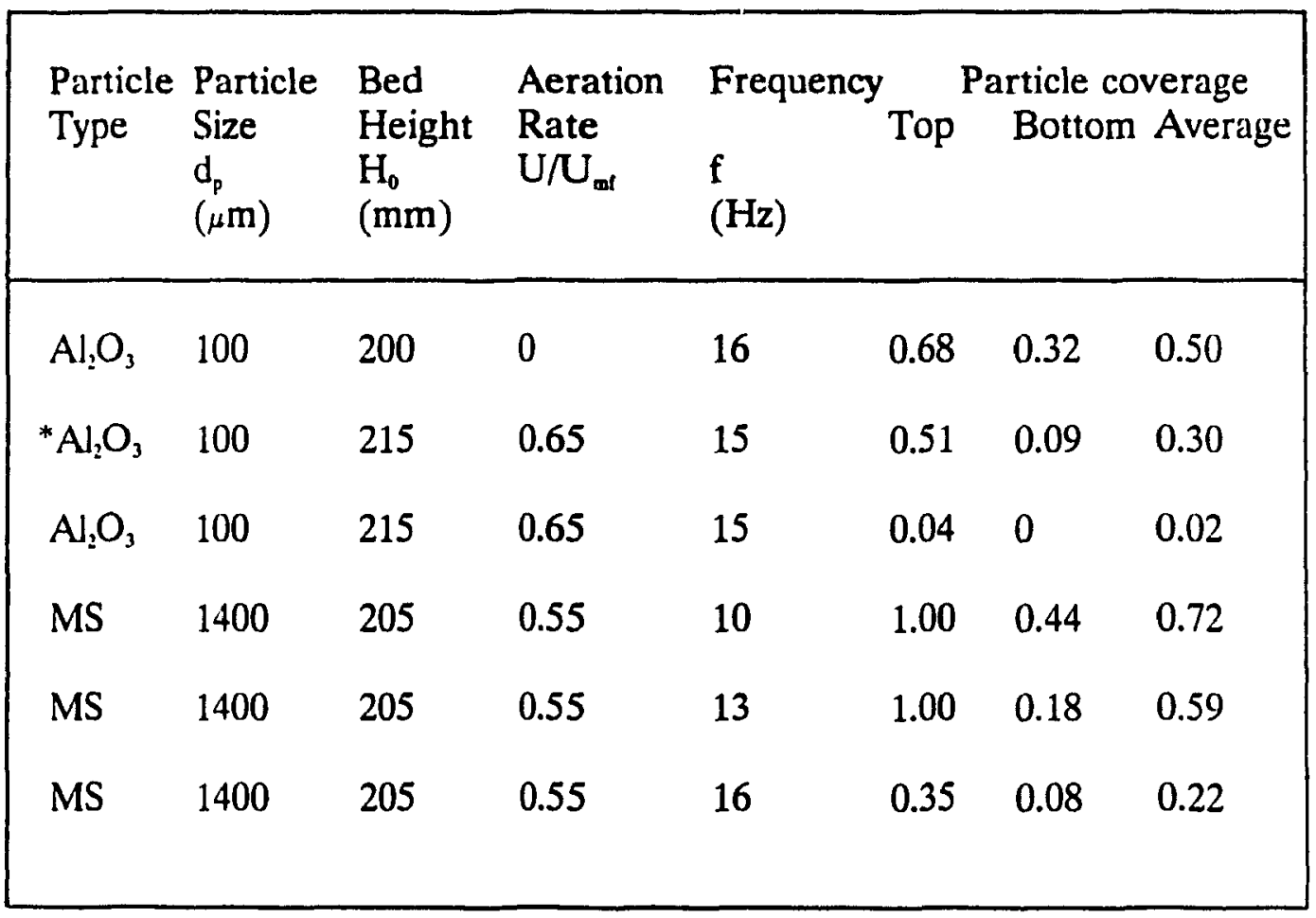

* - during bubble passage 

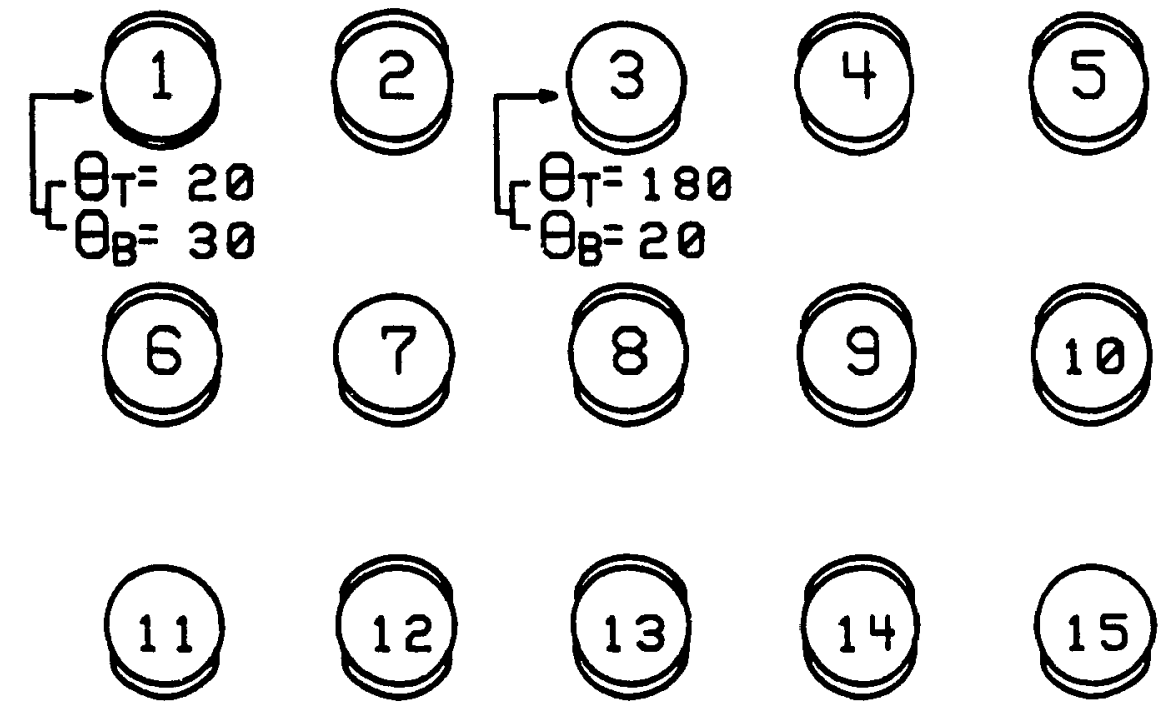

\section{TO SCALE}

Figure 7.3 Schematic time averaged air gaps around a $20-\mathrm{mm}$ circular cylınder in a bed of 1.4-mm molecular sieve particles as a function of time (each step $=0.0167 \mathrm{~s}): \mathrm{H}_{0}=205 \mathrm{~mm}, \mathrm{U} / \mathrm{U}_{\mathrm{mt}}=0.55, \mathrm{f}=16 \mathrm{~Hz}, \mathrm{~A}=2 \mathrm{~mm}$. 
$\mathrm{U} / \mathrm{U}_{\mathrm{m} t}=0$. Most heat transfer results for vibrated bed studies have been presented as plots of $h$ vs $\mathrm{K}$ or Nu vs $\mathrm{K}$ (Mujumdar and Pakowski (1984), Malhotra and Mujumdar (1987), Thomas (1988), Pakowski and Gora (1989), etc.) It is expected that the use of $\mathrm{K}$ would appear preferable to $\mathrm{f}$ as a parameter since it is dimensionless and it offers one parameter instead of two ( $f$ and $A$ ) for data representation. This method of representation is suitable for large-particle beds where heat transfer rates and particle motion have been found to be directly related to the vibrational intensity and hence $\mathrm{K}$. However, it has been shown in Chapters 4,5 and 6 that $f$ rather than $K$ is a better parameter for characterizing particle motion in vibrated beds of small particles. Comparing Figures 7.4 and 7.5 , it is seen that no additional information is contained in the $\mathrm{h}$ vs $\mathrm{K}$ plot.

Furthermore, a misleading conclusion may be derived from $\mathrm{h}$ vs $\mathrm{K}$ plots that it is the direct effect of vibration which governs heat transfer rates which is not the case for vibrated beds of small-particles. It will be seen later in this chapter that for beds of particles that exhibit resonant behaviour, heat transfer rates can be used to predict $\mathrm{f}_{\mathrm{r}}$ and vice-versa. In addition, a new dimensionless parameter - the frequency factor, $\mathrm{F}=\mathrm{f} / \mathrm{f}_{\mathrm{r}}$ - may be defined to characterize heat transfer rates. Clearly, use of this parameter is restricted to beds of particles that display resonant behaviour. It will not be used as the base parameter in this study as beds which do not resonate are studied for comparison with beds that do.

Nusselt numbers could be used to represent heat transfer rates in a non-dimensional form. The Nusselt is defined as: 


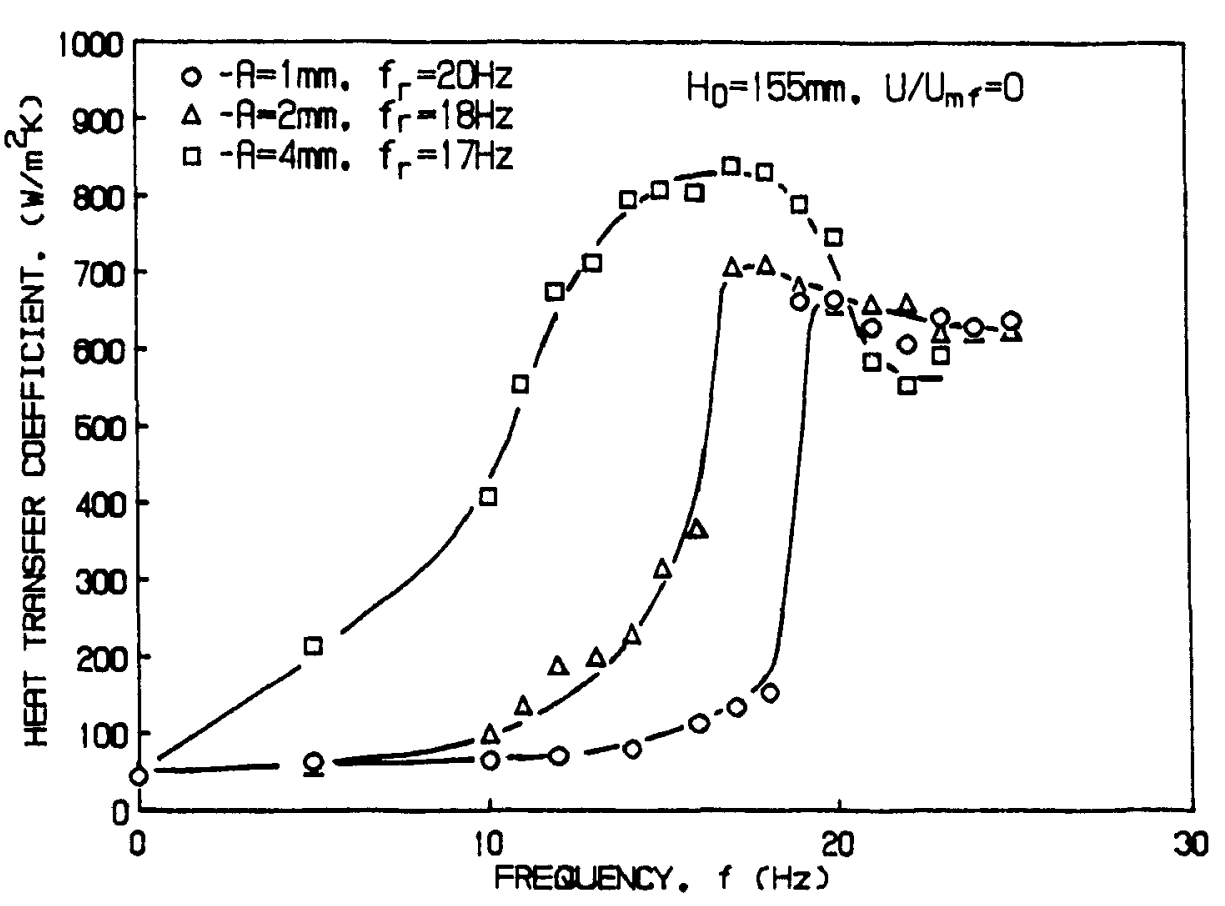

Figure 7.4 Effect of $f$ on $h$ for $100-\mu \mathrm{m}$ alumina particles in a vibrated bed with a bottom plate with one hole for different $A$ values.

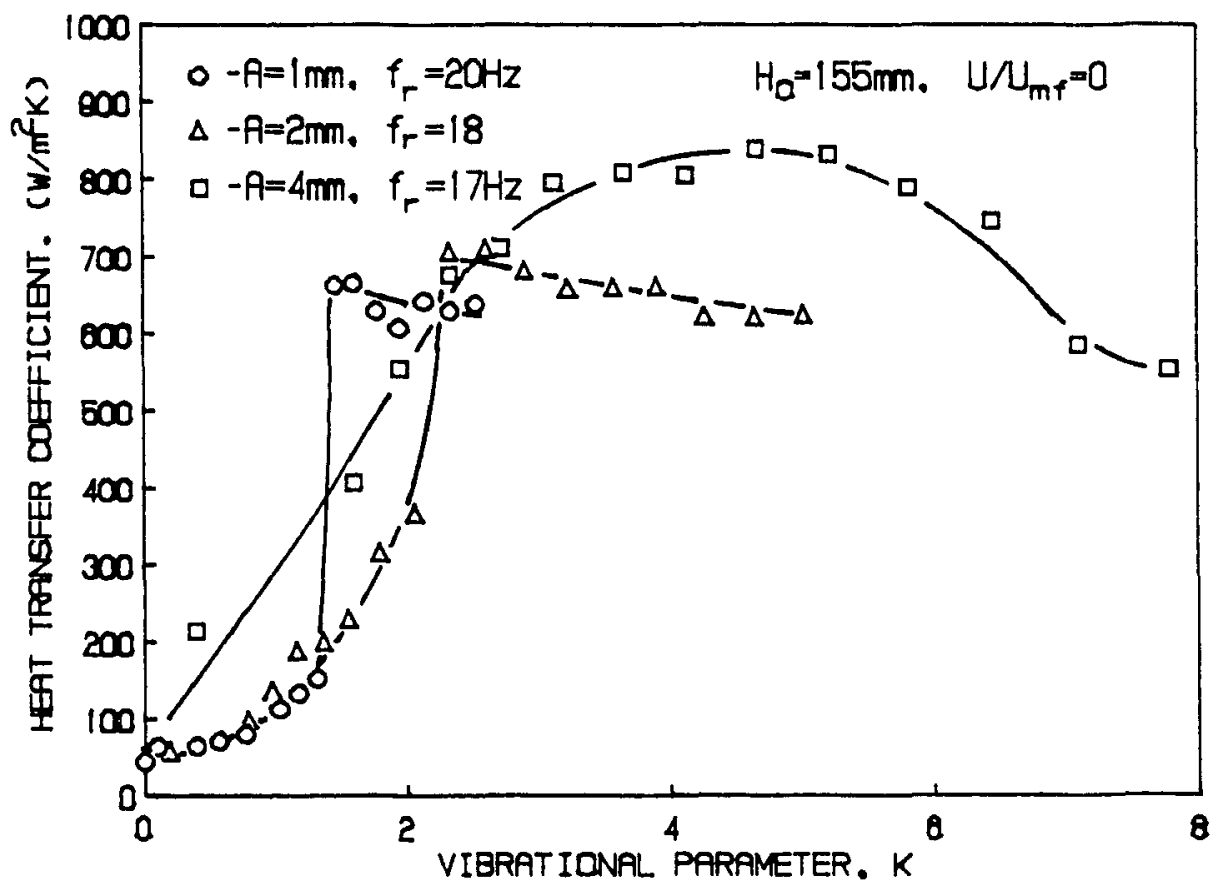

Figure 7.5 Effect ot $\mathrm{K}$ on $\mathrm{h}$ for $100-\mu \mathrm{m}$ alumina particles in a vibrated bed with a bottom plate with one hole for different $A$ values. 
where $k_{e}$ is the effective thermal conductivity of the medium surrounding the surface. For estimation of $k_{e}$, the correlation of Yagi and Kunii (1957) for an incipiently fluidized bed and the correlation of Kobayashi (1969) for packed beds are used. Figure 7.6 shows the data of Figure 7.4 plotted as Nu vs $\mathrm{F}$ while Figure 7.7 shows the same data plotted as Nu vs K. However, this offers a non-dimensiona! representation of heat transfer rates rather than additional information for the range of parameters used in this study. Furthermore, there is need for a proper correlation for estımating the effective thermal conductivity of vibrated beds and hence Nusselt number representation is then an approximation. In this study, most heat transfer results will be presented primarily in the $h$ vs $f$ form and sometimes $h$ vs $F$ and $h$ vs $K$ forms.

\section{Typical Heat Transfer Results}

Figure 7.8 shows the effect of frequency of vibration on the heat transfer coefficient for beds of $100-\mu \mathrm{m}$ alumina particles. The heat transfer coefficients were obtained at $H_{0}=155 \mathrm{~mm}, A=2 \mathrm{~mm}$ and $\mathrm{U} / \mathrm{U}_{\mathrm{m}}=0$, i.e. no forced air flow. The heat transfer coefiicients were determined by starting at the highest frequency i.e. $25 \mathrm{~Hz}$ and ending with a non-vibrated bed. In this way, the air which becomes trapped in the bed initially allows it to exhibit resonant behaviour without supplemental air flow.

As seen in Figure 7.8, the heat transfer rate remains close to its packed bed value of $44 \mathrm{Wm}^{2} \mathrm{~K}^{1}$ at low frequencies (in this case $\mathrm{f}<10 \mathrm{~Hz}$ ). This is because, as seen in Chapter 6 , the bed is compacted at these frequencies and particle motion is almost 


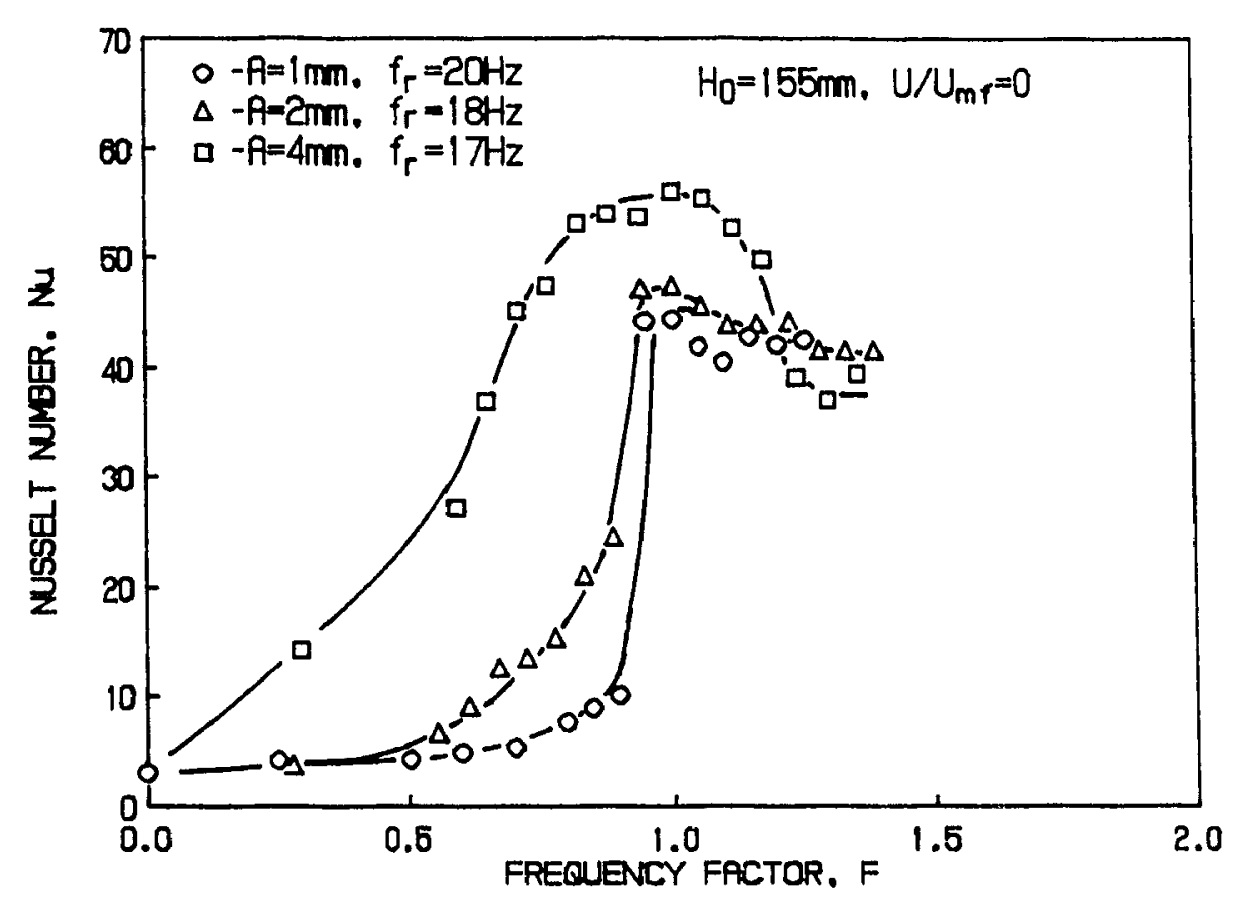

Figure 7.6 Effect of $\mathrm{F}$ on $\mathrm{Nu}$ for $100-\mu \mathrm{m}$ alumina particles in a vibrated bed with a bottom plate with one hole for different $A$ values.

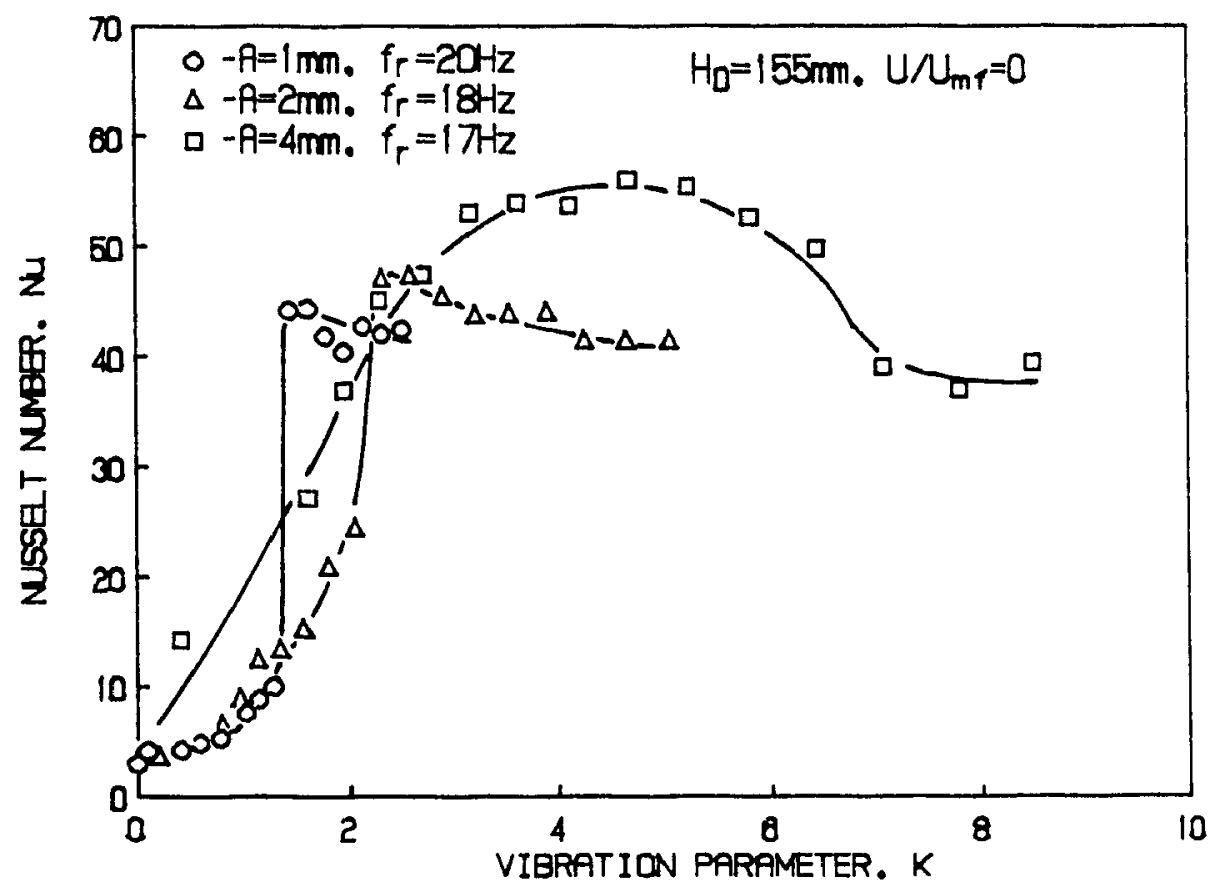

Figure 7.7 Effect of $\mathrm{K}$ on $\mathrm{Nu}$ for $100-\mu \mathrm{m}$ alumina particles in a vibrated bed with a bottom plate with one hole for different $\mathrm{A}$ values. 
nonexistent. At $\mathrm{f}=11 \mathrm{~Hz}$, which corresponds to a value of $\mathrm{K}=1$, particle motion just begins. Note that in this thesis, the intensity of particle motion is referred to as particle mobility.

Particle mobility increases dramatically as $f$ approaches $f_{r}$. The heat transfer coefficient increases with increasing particle motion to reach a maximum at the resonant point where particle motion is most intense. However, the resonant point Is also the point where the bed porosity is maximal and the cylinder surface coverage by particles is minimal. These parameters decrease the heat transfer rate. Since heat transfer coefficients are nevertheless the highest when the cylinder surface coverage is minimal, it is inferred that decreased cylinder surface coverage by particles is offset by the enhanced intensity of particle circulation in the bed i e. particle renewal rate along the cylinder surface and mixing. Particle mobility is then the more significant of the two parameters (particle mobility and surface coverage).

It was seen in Chapter 6 that for $f>f_{r}$ the bed has some of the resonant and preresonant characteristics. Particle circulation is then less intense than at the resonant point and diminishes slightly witi increase of $\mathrm{f}$ as explained in Chapter 6. The heat transfer coefficient also decreases correspondingly.

\section{Effect of Bed Height}

Figure 7.9 shows the effect of $\mathrm{f}$ on $\mathrm{h}$ for beds of $100-\mu \mathrm{m}$ alumina particles at different bed heights. The heat transfer coefficients were obtained with $A=2 \mathrm{~mm}$ and $\mathrm{U} / \mathrm{U}_{\mathrm{mf}}=0$. For each bed height, the heat transfer rate remains close to the packed bed value of $44 \mathrm{Wm}^{2} \mathrm{~K}^{1}$ ai low frequencies. Particle motion and consequently heat 


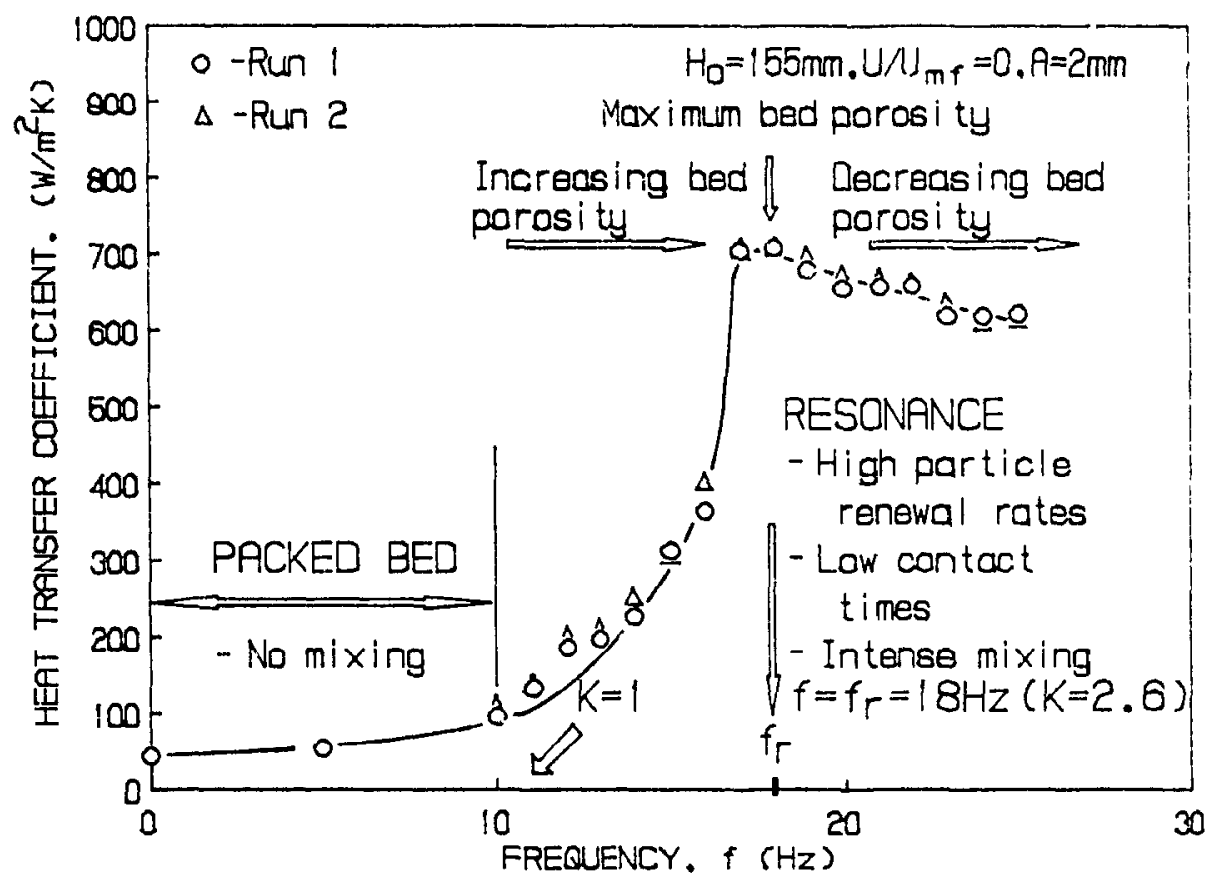

Figure 7.8 Typical effect of $\mathrm{f}$ on $\mathrm{h}$ for $100-\mu \mathrm{m}$ alumina particles in al vibrated bed with a bottom plate with one hole. 
transfer ratus are enhanced with increasing $f$ to reach a maximum at $f=f_{r}$. Figure 7.10 shows the same data as those in Figure 7.9 but with the heat transfer enhancement factor, $E=h / h_{0}$, plotted as the ordinate against the frequency factor, $F$ plotted as abscissa. The maximum enhancement in heat transfer is clearly seen at $\mathrm{f}=\mathrm{f}_{\mathrm{r}} \quad$ The maximum heat transfer coefficients for the different bed heights are shown in Tabie 7.2. Of course, the variation of $h_{\max }$ with $\mathrm{H}_{0}$ reflects the variation of $f_{r}$ with $H_{b}$ as discussed in Chapter 4, i.e. $h_{\text {max }}$ decreases with increase in $H_{0}$. Particle mobility at resonance decreases with increasing bed height (Chapter 6 ). As expected, $E_{\max }$ decreases from a value of 19 at $\mathrm{H}_{0}=135 \mathrm{~mm}$ and this corresponds to $\mathrm{h}_{\max }=826 \mathrm{Wm}^{2} \mathrm{~K}^{-1}$ to 12 at $\mathrm{H}_{0}=205 \mathrm{~mm}$ corresponding to $\mathrm{h}_{\max }=547 \mathrm{Wm}^{2} \mathrm{~K}^{\prime}$.

Resonance in a bed as high as $350 \mathrm{~mm}$ is not very pronounced. Not unexpectedly, similar trends are not observed at this bed height. Particle circulation at this bed height is much reduced and hence $h$ is lower. In fact, for this bed height $h_{\max }$ is 195 $\mathrm{Wm}^{-2} \mathrm{~K}^{1}$ which is only $28 \%$ of the value of $708 \mathrm{Wm}^{-2} \mathrm{~K}^{1}$ at $\mathrm{H}_{0}=155 \mathrm{~mm}$. The attenuation of vibration-induced particulate motion is quite significant beyond a bed height of about $200 \mathrm{~mm}$ over the parameter ranges covered in this study.

\section{Effect of Amplitude of Vibration}

The effect of $f$ on $h$ for a $155-\mathrm{mm}$ deep bed of $100-\mu \mathrm{m}$ alumina particles vibrated at various amplitudes is shown in Figure 7.4. The shapes of the curves are similar to those in Figure 7.6. However, for $f<f_{r}$, the heat transfer coefficient increases with amplitude of vibration at any $f$ i.e. the curves are increasingly displaced to the left. Local sharp variations of bed porosity act as disturbances which amplify leading to resonance. Pressure gradients developed in the bed amplify and particle motion 


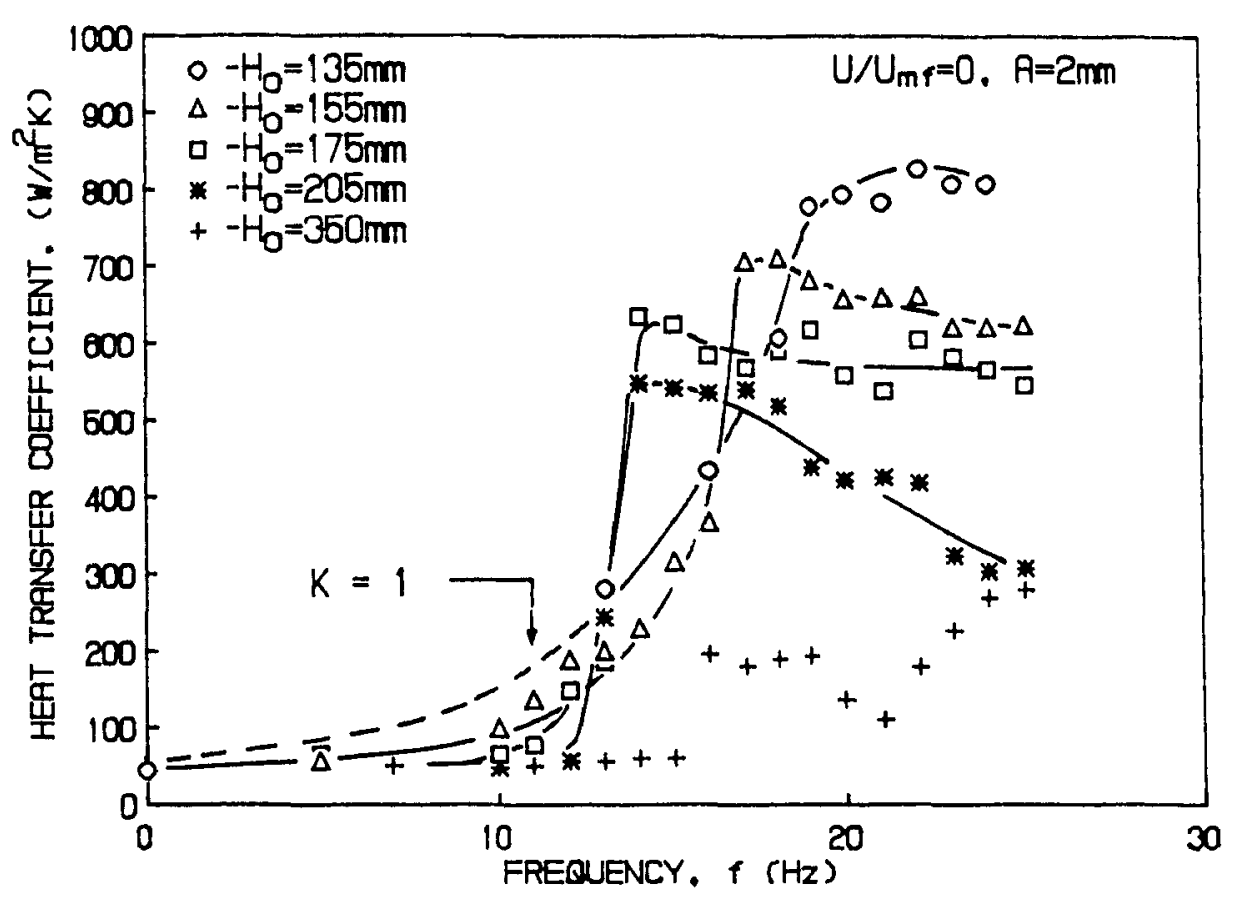

1.58

Figure 7.9 Effect of $f$ on $h$ for $100-\mu \mathrm{m}$ alumina particles in a vibrated bed with , bottom plate with one hole for different $\mathrm{H}_{1}$ values.

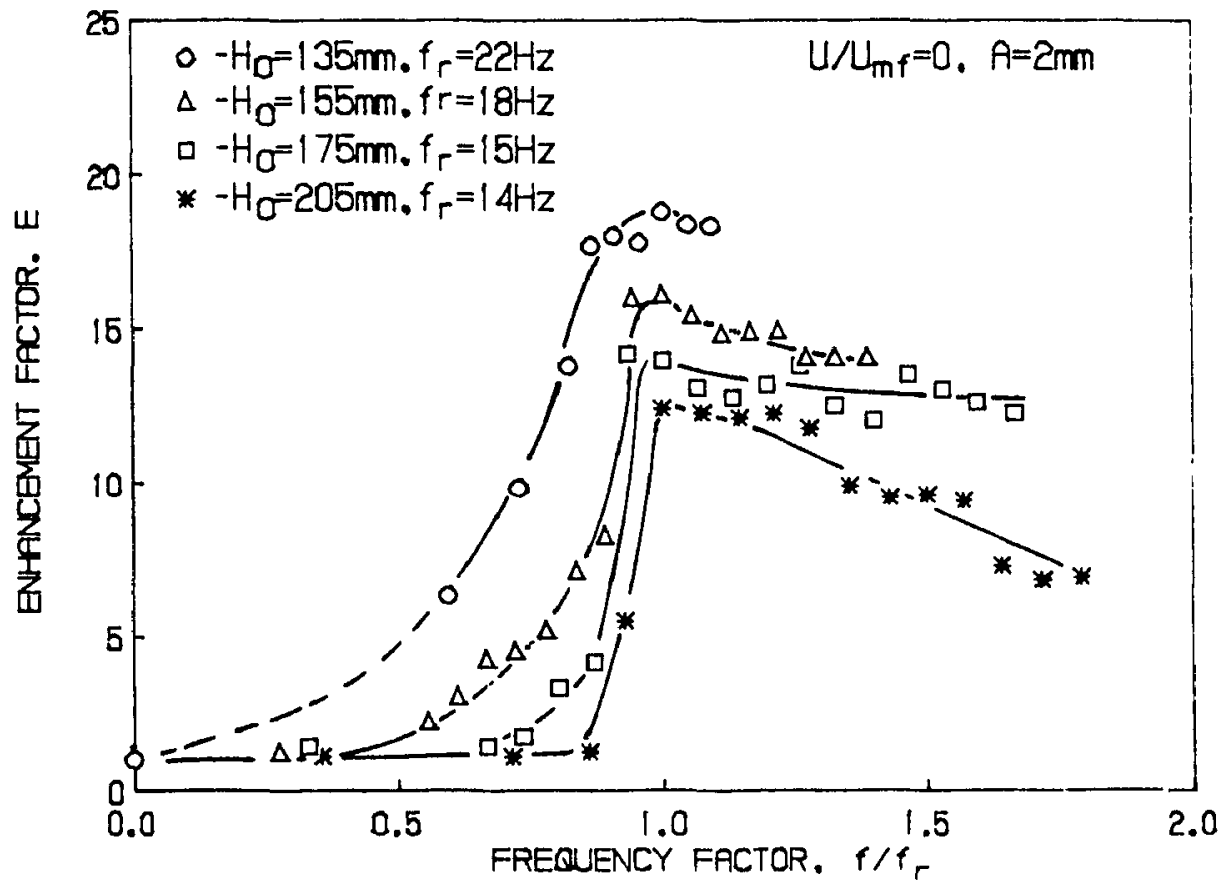

Figure 7.10 Variation of $\mathrm{E}$ with $\mathrm{F}$ for $100-\mu \mathrm{m}$ alumina particles in a viblated beil with a bottom plate with one hole for ditterent $\mathrm{H}_{1}$ values 
Table 7.2 Maximum heat transfer coefficients in aerated vibrated beds.

\begin{tabular}{|c|c|c|c|c|c|c|c|}
\hline $\begin{array}{l}\text { Particle } \\
\text { Type }\end{array}$ & $\begin{array}{l}d_{p} \\
(\mu \mathrm{m})\end{array}$ & $\begin{array}{l}\mathrm{H}_{0} \\
(\mathrm{~mm})\end{array}$ & $\begin{array}{l}\text { A } \\
(\mathrm{mm})\end{array}$ & $\mathrm{U} / \mathrm{U}_{\mathrm{mt}}$ & $\begin{array}{l}f_{r} \\
(H z)\end{array}$ & $\begin{array}{l}h_{\max } \\
\left(W^{-2} K^{-1}\right)\end{array}$ & $\begin{array}{l}\mathrm{Nu}_{\max } \\
\mathrm{h}_{\max } \mathrm{d}_{\mathrm{c}} / \mathrm{k}_{\mathrm{e}}\end{array}$ \\
\hline $\mathrm{Al}_{2} \mathrm{O}_{3}$ & 100 & 135 & 2 & 0 & 22 & 830 & 55.3 \\
\hline $\mathrm{Al}_{2} \mathrm{O}_{3}$ & 100 & 155 & 2 & 0 & 18 & 710 & 47.3 \\
\hline $\mathrm{Al}, \mathrm{O}, \#$ & 100 & 155 & 2 & 0 & 18 & 705 & 94.0 \\
\hline $\mathrm{Al}_{2} \mathrm{O}$ & 100 & 175 & 2 & 0 & 15 & 635 & 42.3 \\
\hline $\mathrm{Al}_{2} \mathrm{O}$ & 100 & 205 & 2 & 0 & 14 & 550 & 36.7 \\
\hline $\mathrm{Al}_{2} \mathrm{O}_{3}$ & 100 & 350 & 2 & 0 & $16+$ & 195 & 13.0 \\
\hline $\mathrm{Al}_{2} \mathrm{O}$ & 100 & 155 & 1 & 0 & 20 & 665 & 44.3 \\
\hline $\mathrm{Al}_{2} \mathrm{O}_{3}$ & 100 & 155 & 4 & 0 & 17 & 840 & 56.0 \\
\hline $\mathrm{Al}_{2} \mathrm{O}$ & 100 & 155 & 2 & 0 & 18 & 750 & 50.0 \\
\hline GB & 360 & 155 & 2 & 0 & 14 & 405 & 60.0 \\
\hline MS & 1400 & 155 & 2 & 0 & 13 & 185 & 18.0 \\
\hline $\mathrm{Al}_{2} \mathrm{O}_{3}$ & 100 & 155 & 2 & 1 & 18 & 690 & 46.0 \\
\hline $\mathrm{Al}_{2} \mathrm{O}_{3}$ & 100 & 155 & 2 & $1^{*}$ & 14 & 600 & 40.0 \\
\hline $\mathrm{Al}: \mathrm{O}_{3}$ & 100 & 155 & 2 & $1^{*}$ & 14 & 540 & 36.0 \\
\hline $\mathrm{Al}_{2} \mathrm{O}_{1}$ & 100 & 155 & 2 & $1^{*}$ & 14 & 590 & 39.3 \\
\hline
\end{tabular}

+ - estimated, * - perforated bottom plate, \# - for 40-mm diameter cylinder 
increases. Correspondingly, $h$ increases. Compared to the case for $A=1 \mathrm{~mm}, h_{m n}$ is increased by $7 \%$ by increasing $A$ to $2 \mathrm{~mm}$ and by $27 \%$ by increasing $A$ to $4 \mathrm{~mm}$ i.e. $h_{\max }$ is 830,710 and $665 \mathrm{Wm}^{-2} \mathrm{~K}^{-1}$ at $\mathrm{A}=4(\mathrm{~K}=7.8), 2(\mathrm{~K}=2.6)$ and $1(\mathrm{~K}=1.6)$ respectively.

The bed expansion increases with $A$ and so does $d_{b}$ as well as the extent of aur gilps that surround the cylinder. However, the heat transfer coefficient still increases. This again indicates the greatly offsetting effect of particle circulation on cylinder-to-bed heat transfer. The augmented particle movement with increasing $A$ values results in larger values of $h_{\max }$. These maximum values of $h$ are shown in Table 7.2.

While resonance is amplified by increasing $\mathrm{A}$ and particle motion intensities, for $f>f_{r}$, particle circulation rate decreases and hence $h$ decreases with increasing $t$. At higher A values however, the sharp variations of local bed porosity which may he amplified into a state of resonance are no longer present and particle motion subsides. The bed mobility outside the resonance-affected area is similar at all three half-amplitudes of vibration, viz., $A=1,2$ or $4 \mathrm{~mm}$. This is reflected in the h values in that they all tend to a value of about $600 \mathrm{Wm}^{\prime} \mathrm{K}^{1}$ for $\mathrm{f}>20 \mathrm{~Hz}$.

\section{Effect of Air Flow Rate}

Figure 7.11 shows the effect of $f$ on $h$ for a $155-\mathrm{mm}$ high bed of $100-\mu \mathrm{m}$ alumina particles vibrated at $A=2 \mathrm{~mm}$. Air was introduced through a single, central $2-\mathrm{mm}$ hole in the bottom plate. The air flow rate equivalent to the flow required to fluidize the bed using a porous plate distributor with no vibration is referred to as $U / U_{m}=1$. The air flow rates used were $0,0.7 \mathrm{U}_{\mathrm{m}}$ and $\mathrm{U}_{\mathrm{m}}$. Firstly, aeration must exceed $\mathrm{U}_{\mathrm{m}}$ 
to effect a change in the variation of $h$ with $\mathrm{f}$. An increase in $U / U_{m f}$ results in only a small (up to $10 \%$ ) escalation in particle mobility and hence increase in $h$ for $f<f_{r}$. An increase in aeration rate to $U_{m t}$ also results in a more fully developed resonant condition and hence increased particle mobility and $h$. Above the resonance point the bed is fully aerated and hence further aeration has negligible effect. Secondly, Just below $f=f_{r}$, since the bed can now retain increased particle mobility, the heat transfer coefficient displays a much less drastic change in slope at $f=f_{r}$, unlıke the calse tor $\mathrm{U} / \mathrm{U}_{\mathrm{m}}<1$.

For $175-\mathrm{mm}$ and $205-\mathrm{mm}$ high beds of $100-\mu \mathrm{m}$ alumina particles, Figure 7.12 shows the effect of $f$ on $h$. The results show that aeration rates below $U_{m}$ have negligible effect on $\mathrm{h}$ for $\mathrm{H}_{0}>175 \mathrm{~mm}$. This is because at these higher bed heights bed porosity and particle mobility are not sensitive to low aeration rates once the resonant condition can be attained. It may be concluded that once the bed resonates, low aeration rates give $h$ values about equal to those for no aeration. The heat transfer coefficient values in the absence of aeration may be used to represent those for the aerated case if the aeration rates are relatively low $\left(<U_{m}\right)$.

Figure 7.13 shows the effect of $\mathrm{f}$ and $\mathrm{A}$ on $\mathrm{h}$ for a $155-\mathrm{mm}$ high bed of $100-\mu \mathrm{m}$ alumina particles and $\mathrm{U} / \mathrm{U}_{\mathrm{m} t}=1$. As before, an increase in $\mathrm{A}$ resulted in an increase in $h$ particularly before and up to the resonant point. An increase in A causes enhancement in heat transfer rates as larger amplitudes permit easier amplification of variations in bed porosity which leads to the onset of resonance. However, as also seen in Figure 7.4, the increase in $\mathrm{h}$ is not directly proportional to $\mathrm{A}$ for a fixed frequency as a plot of $h$ vs $K$ would suggest. Increasing A from 1 to $2 \mathrm{~mm}$ resulted 


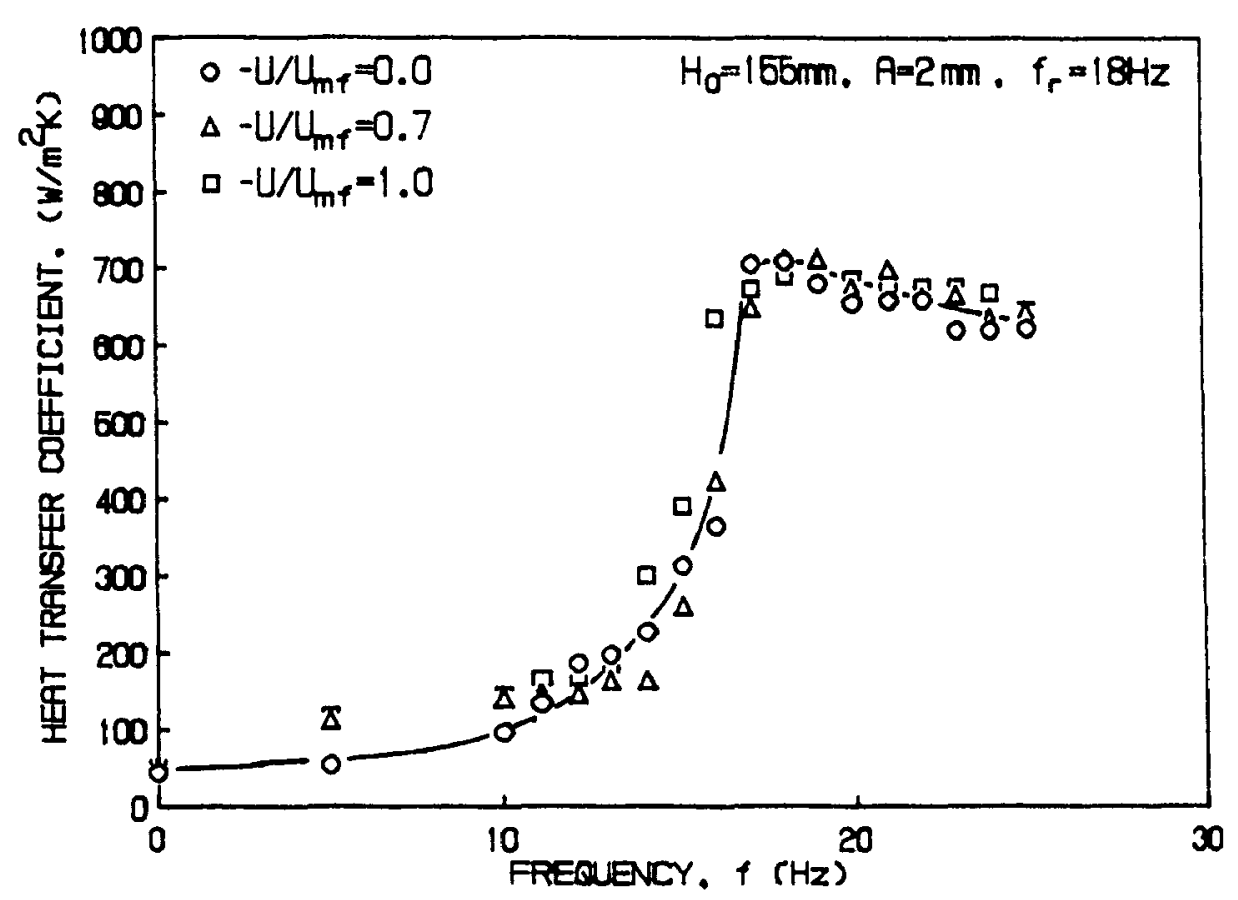

Figure 7.11 Variation of $\mathrm{h}$ with $\mathrm{f}$ for $100-\mu \mathrm{m}$ alumina particles in a vibrated bed with a bottom plate with one hole at different aeration rates.

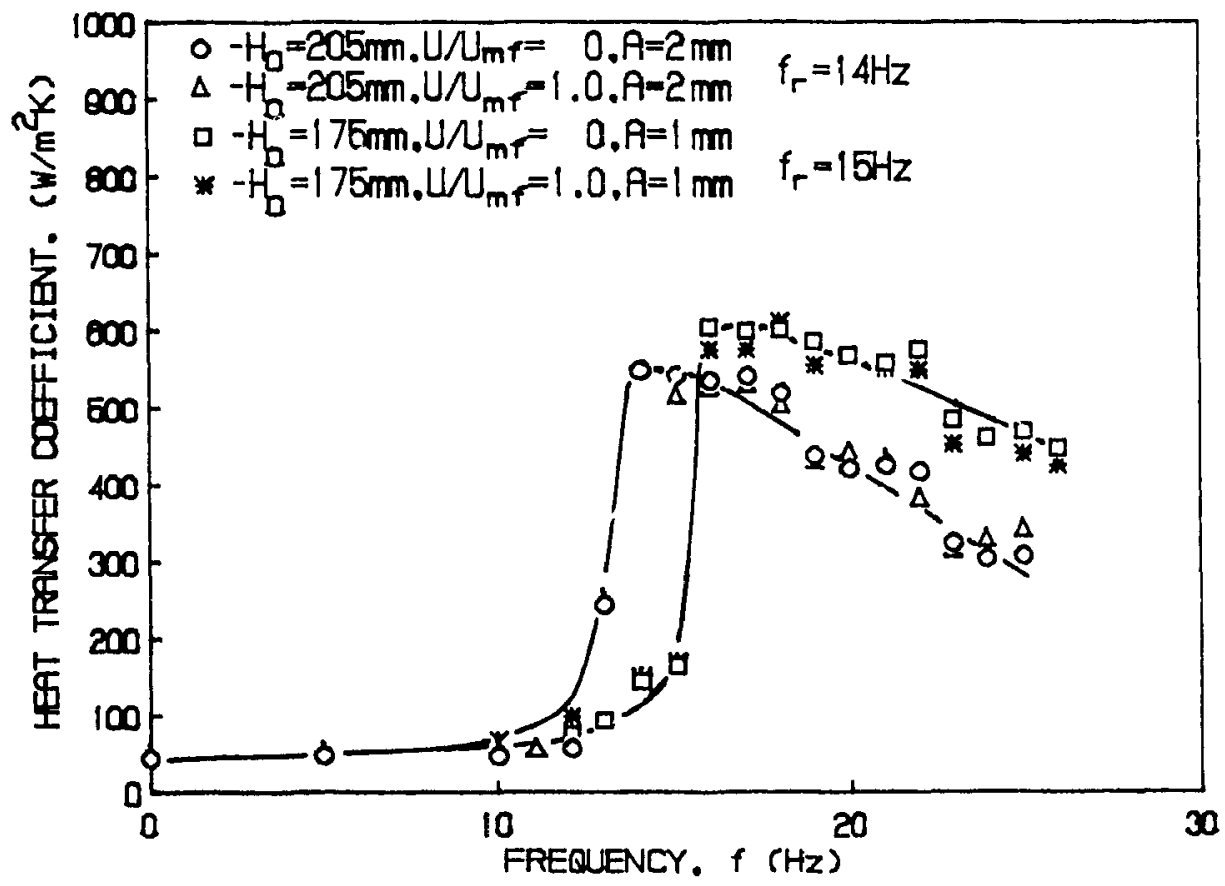

Figure 7.12 Variation of $\mathrm{h}$ with $\mathrm{f}$ for $100-\mu \mathrm{m}$ alumina particles in a vibrated bed with a bottom plate with one hole at different aeration rates and $H_{\text {" }}$ values. 
in a negligible augmentation in $\mathrm{h}_{\max }$ of $4 \%$ i.e. from 664 to $690 \mathrm{Wm}^{-2} \mathrm{~K}^{-1}$.

For $155-\mathrm{mm}$ deep beds of $100-\mu \mathrm{m}$ alumina particles, Figure 7.14 shows the effect of $\mathrm{f}$ on $\mathrm{h}$ for two different heater probe locations. One location was $100 \mathrm{~mm}$ above the bottom plate and $100 \mathrm{~mm}$ from the sides as used in all the other experiments. The other location was $100 \mathrm{~mm}$ above the bottom plate and $50 \mathrm{~mm}$ from one side. The results show that the locations used have no noticeable effect on the heat transfer rate.

\section{Effect of Heater Probe Diameter}

Figure 7.15 shows the effect of $\mathrm{f}$ on $\mathrm{h}$ for $20-\mathrm{mm}$ and $40-\mathrm{mm}$ diameter cylinders $\mathrm{in}$ a $155-\mathrm{mm}$ high bed of $100-\mu \mathrm{rn}$ alumina particles. The probe size has negligible effect except at the points of lower particle mobility. Decreased coverage of the heat transfer surface by the particles would have a greater effect on the heat transfer rate under conditions of reduced particle mobility. The heater size does not appear to be a major factor in affecting the heat transfer rates for the cylinder sizes used.

\section{Effect of Particle Size}

Figure 7.16 shows the effect of $f$ on $h$ for beds of alumina particles, glass beads, and molecular sieve particles of different sizes. The amplitude of vibration was $2 \mathrm{~mm}$, $\mathrm{U} / \mathrm{U}_{\mathrm{mt}}=0$ and $\mathrm{H}_{0}=155 \mathrm{~mm}$. Beds of smaller particles e.g. $27-\mu \mathrm{m}$ and $100-\mu \mathrm{m}$ alumina which can resonate resulted in higher surface-to-bed heat transfer rates. For example, $h_{\max }$ is $753 \mathrm{Wm}^{2} \mathrm{~K}^{1}$ for $d_{p}=27 \mu \mathrm{m}$ and $708 \mathrm{Wm}^{2} \mathrm{~K}^{1}$ for $\mathrm{d}_{\mathrm{p}}=100 \mu \mathrm{m}$ while it is $403 \mathrm{Wm}^{2} \mathrm{~K}^{\prime}$ for $d_{p}=360 \mu \mathrm{m}$ and for $d_{p}=1.4 \mathrm{~mm}$ it was $185 \mathrm{Wm}^{2} \mathrm{~K}^{\prime}$. As expected, higher $h$ values were obtained with $27-\mu \mathrm{m}$ particles than with the larger 


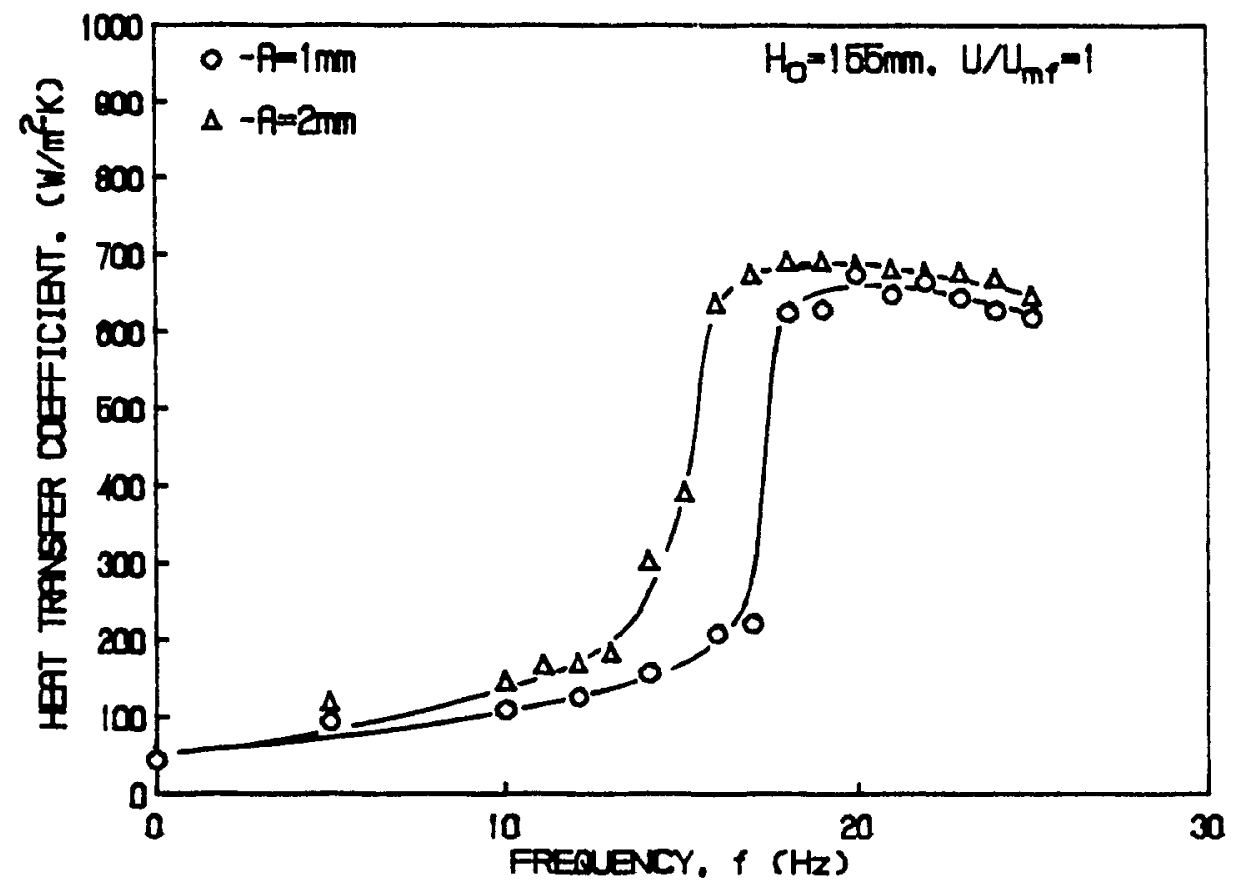

Figure 7.13 Effect of $f$ on $h$ for $100-\mu \mathrm{m}$ alumina particles in a vibrated bed with a bottom plate with one hole for $\mathrm{H}_{0}=155 \mathrm{~mm}$ and different $\mathrm{U} / \mathrm{U}_{\mathrm{mr}}$ and A values. 


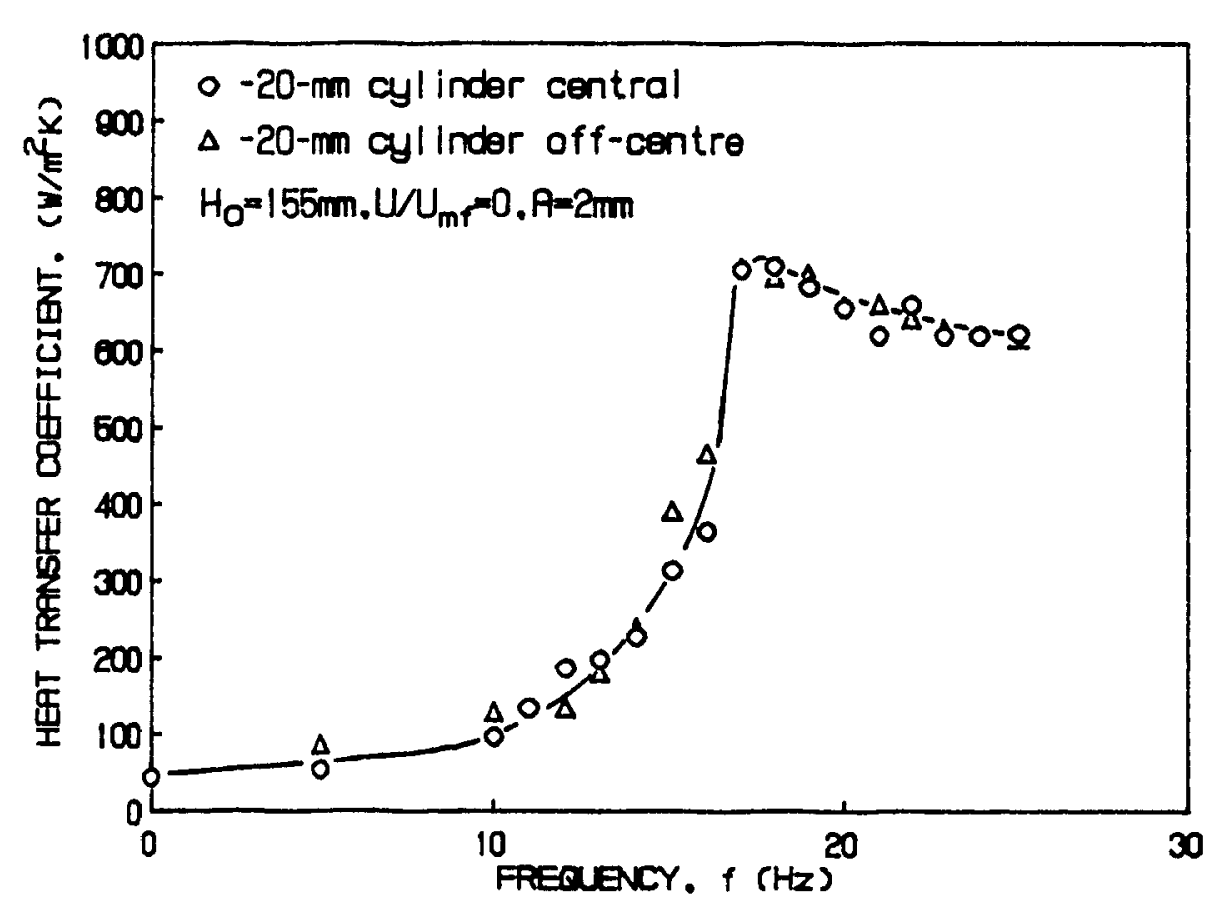

Figure 7.14 Effect of $\mathrm{f}$ on $\mathrm{h}$ for $100-\mu \mathrm{m}$ alumina particles in a vibrated bed with a bottom plate with one hole for different probe locations and $\mathrm{H}_{0}=155 \mathrm{~mm}$.

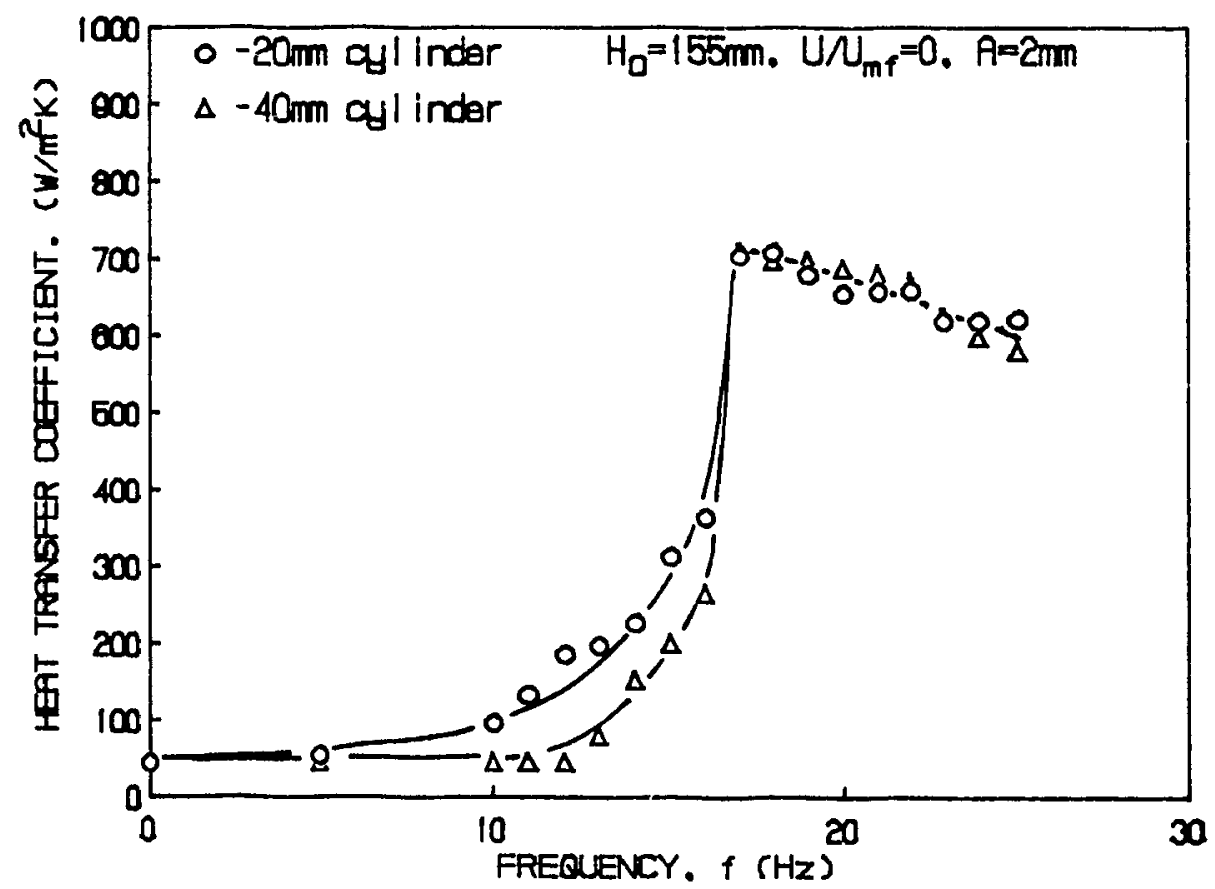

Figure 7.15 Effect of $\mathrm{f}$ on $\mathrm{h}$ for $100-\mu \mathrm{m}$ alumina particles in a vibrated bed with a bottom plate with one hole for different cylindrical probe sizes and $\mathrm{H}_{0}=155 \mathrm{~mm}$. 
$100-\mu \mathrm{m}$ particles. As seen in Figure 7.17 where the data of Figure 7.16 are re-plotted as $\mathrm{E}$ vs $\mathrm{f}$, there is greater enhancement of heat transfer (up to 16 times) tor smaller particles as compared to the 9-fold enhancement for $360-\mu \mathrm{m}$ glass beads and 5-fold enhancement for $1.4-\mathrm{mm}$ molecular sieve. This is in accordance with the normally observed increase in heat transfer with decreasing particle size (Pakowski and Mujumdar (1982), Malhotra and Mujumdar (1985b), Thomas (1988), etc.).

Beds of $360-\mu \mathrm{m}$ glass beads and $1.4-\mathrm{mm}$ molecular sieve particles do not resonate as noted in Chapter 4. Particle circulation is thus much less intense as compared to that in resonating beds of small particles under similar conditions (Chapter 6). However, these larger particles do display increased mobility with increasing $f$. As for smallparticle beds, $\mathrm{h}$ reaches a maximum at a particular frequency for large-particle beds as well. No theory has been developed to predict these trequencies. The maximi in heat transfer rates occur above $\mathrm{f}=11 \mathrm{~Hz}$ particularly for $360-\mu \mathrm{m}$ glass beads.

Figure 7.18 shows the effect of $\mathrm{f}$ on $\mathrm{h}$ for a $155-\mathrm{mm}$ high bed of $1.4-\mathrm{mm}$ molecular sieve particles. Increasing $\mathrm{A}$ has little effect on $\mathrm{h}$ for the molecular sieve particles. This is expected as for these larger particles amplitude has little effect on particle mobility.

\section{Vibrated Fluidized Bed (VFB) Heat Transfer}

All the previously reported results were for a bottom plate with a single orifice. One such result and others with a perforated bottom plate are shown in Figure 7.19. The perforated plate had 2-mm holes on a square pitch to give an open area of $6 \%$. The particles were $100-\mu \mathrm{m}$ alumina in a $155-\mathrm{mm}$ deep bed vibrated at $A=2 \mathrm{~mm}$. For 


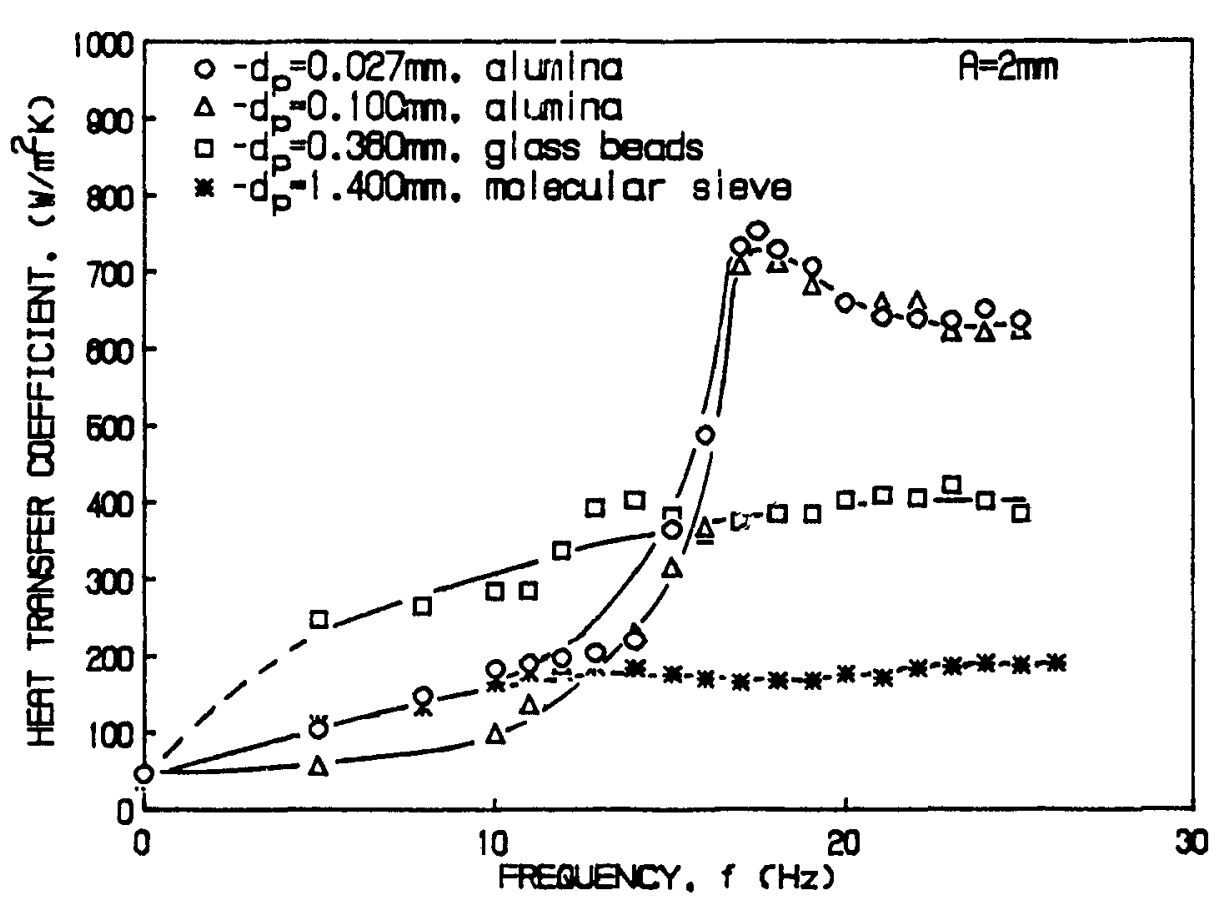

Figure 7.16 Effect of $\mathrm{f}$ on $\mathrm{h}$ for particles of different sizes in a vibrated bed with a bottom plate with one hole for $\mathrm{H}_{0}=155 \mathrm{~mm}$.

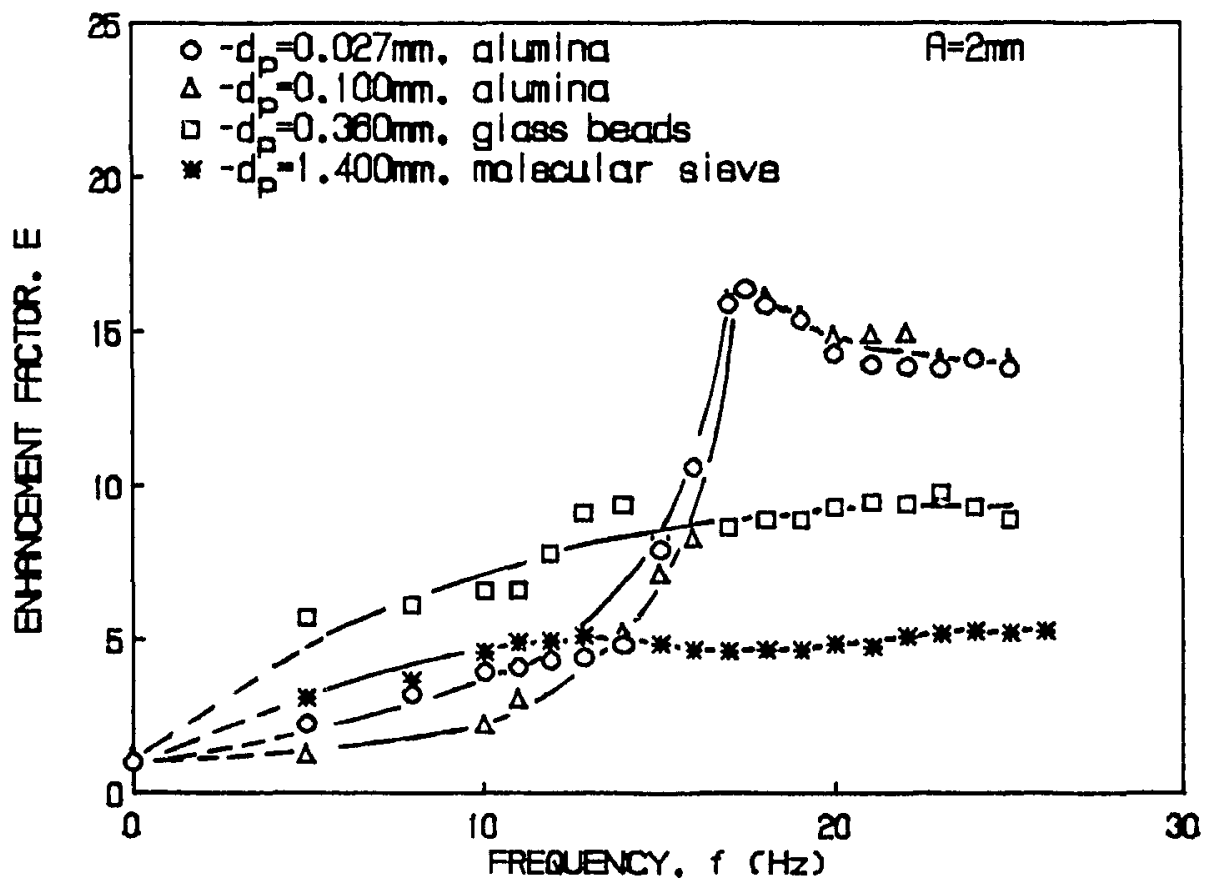

Figure 7.17 Variation of $\mathrm{E}$ with $\mathrm{f}$ for particles of different sizes in a vibrated bed with a bottom plate with one hole for $\mathrm{H}_{0}=155 \mathrm{~mm}$. 


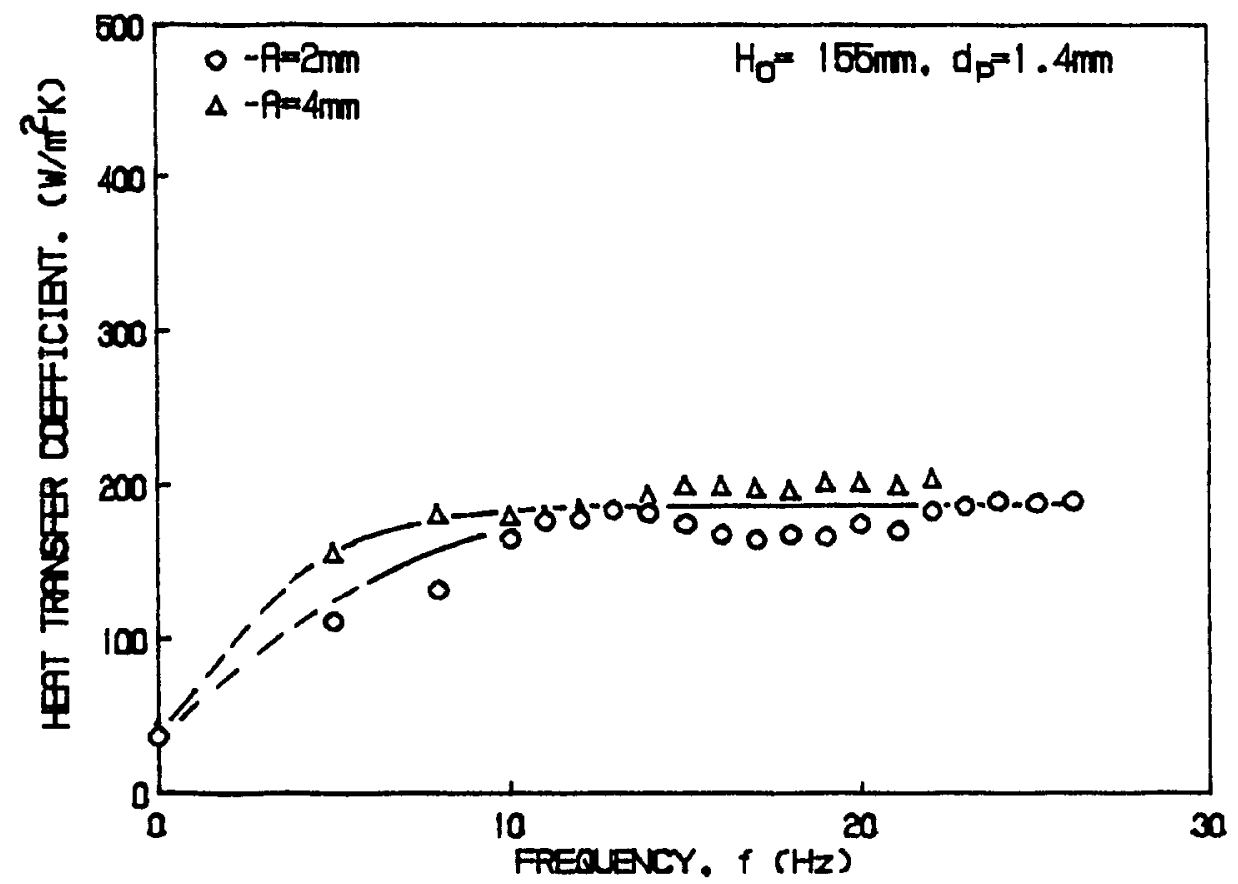

Figure 7.18 Effect of $\mathrm{f}$ on $\mathrm{h}$ for 1.4-mm molecular sieve particles in a vibrated bed with a bottom plate with one hole for different $A$ values and $\mathrm{H}_{0}=155 \mathrm{~mm}$. 
an air flow rate of $\mathrm{U}_{\mathrm{m} t}$ the bed with the perforated plate is a vibrated fluidized bed (VFB).

The curve obtained for the VFB at an aeration rate of $U_{m i}$ had a maximum but the shape of the curve was different. The heat transfer coefficient in the initially quiescent bed ( $\mathrm{f}=0 \mathrm{~Hz}$ ) was $130 \mathrm{Wm}^{-2} \mathrm{~K}^{-1}$. The heat transfer coefficient increased almosi linearly with $f$ to reach a maximum of $600 \mathrm{Wm}^{2} \mathrm{~K}^{-1}$ at $\mathrm{f}=14 \mathrm{~Hz}$. This maximum value is lower than the maximum in the resonating bed of $690 \mathrm{Wm}$ ' $\mathrm{K}$ ' also at $f=14 \mathrm{~Hz}$ ( $\mathrm{h}_{\max }$ for the resonating bed is $15 \%$ greater than for the VFB). Particle mobility is increased in the VFB not only because of pressure gradients but also because of bubbles. It may be recalled from Chapter 5 that the application of vibration to a lluidized bed or to a vibrated one with a perforated bottom plate results in bubbling which increases with increasing $f$.

The VFB displayed some of the surface and resonant characteristics but these were not allowed to grow because of the limited ability of the bed to trap air due to the high open area of the bottom plate. Muchowski and Mannchen (1980) apparently observed resonant behaviour in their bed of $100-\mu \mathrm{m}$ glass beads at 1 bar. However, they did not characterize the phenomenon as such. The heat transfer coefficient was higher than they expected. However, it can be exprained based on the results of this study and it was possibly due to increased particle cirsulation and resonance.

Other VFB results for a $155-\mathrm{mm}$ high bed of $100-\mu \mathrm{m}$ alumina particles are also shown in Figure 7.19. The air flow rates were $0.5 \mathrm{U}_{\mathrm{mr}}$ and $2 \mathrm{U}_{\mathrm{mr}}$. At an air flow rate of $2 \mathrm{U}_{\mathrm{m}}$, there is no observed difference in $\mathrm{h}$ at the lower frequencies as compared 
to the bed aerated at $U_{m e}$. This indicates that the effect of vibration is greater than that of aeration under these conditions. The maximum $h$ value is higher for higher $\mathrm{U} / \mathrm{U}_{\mathrm{m} t}$ values. At frequencies above those at which the maxima occur, li is higher than that for the case with the air flow rate of $U_{m}$. This results from the increalsed mixing caused by the bubbles when the bed is not in resonance.

The data in Figure 7.19 are replotted as $E$ vs $f$ plots in Figure 7.20. E is as high as 15 for the bed aerated through one hole as compared to 12 for the same bed arated through a perforated bottom plate at $0.5 \mathrm{U}_{\mathrm{m}}$, and 3.4 and 4.6 respectively for VFB's at $U_{m f}$ and $2 U_{m c}$. Also, the maximum heat transfer coetficient in the resonating bed is 5.3 times that obtained in a non-vibrated gas-fluidized bed with $\mathrm{U} / \mathrm{U}_{\mathrm{m}}=1$.

At low air flow rates $\left(0.5 \mathrm{U}_{\mathrm{m}}\right)$ the shape of the curves $h$ vs $f$ or $E$ vs $F$ is different. The curve then has a shape like those for the VFB and the single-orifice aerated vibrated bed put together. This could be so because the bed can assume a state of limited resonance due to lower aeration rates as obsered by Muchowski and Mannchen (1980). It may be recalled that higher aeration rates tend to dampen the resonant behaviour of aerated vibrated beds (Chapter 4).

\section{Comparison of Expermmental Results with Prior Works.}

Figure 7.21 shows the variation of $\mathrm{h}$ with $\mathrm{K}$ obtained by various researchers. Except for Thomas (1988) all prior researchers worked with large-particle beds. As expected, the heat transfer coefficients they obtained were lower than those obtanned with the small particles used in this study. Table 7.3 compares $h_{\max }$ data of the various studies. Except for the results of Thomas (1983) the curves have the same 


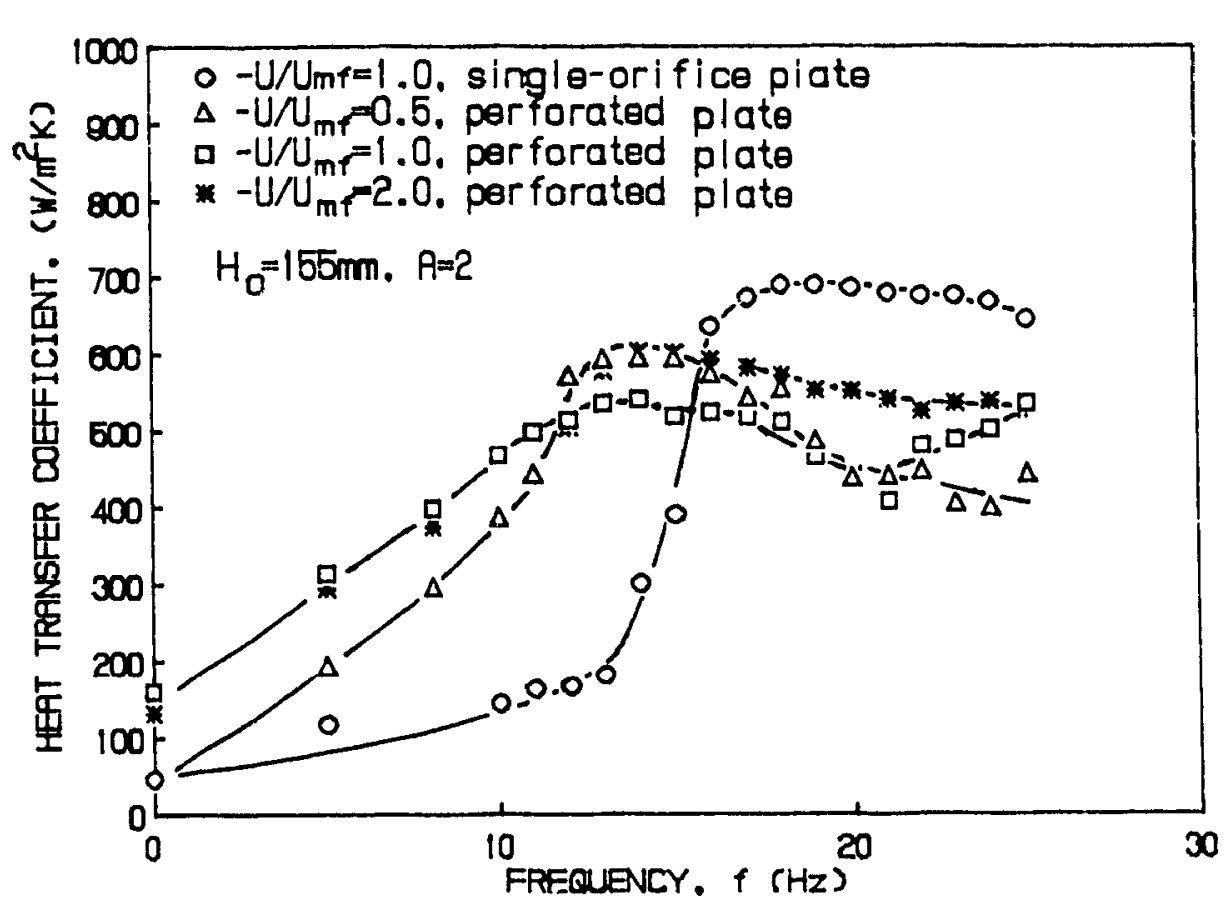

Figure 7.19 Effect of $\mathrm{f}$ on $\mathrm{h}$ for $100-\mu \mathrm{m}$ alumina particles in vibrated beds alt different aeration rates and $\mathrm{H}_{0}=155 \mathrm{~mm}$.

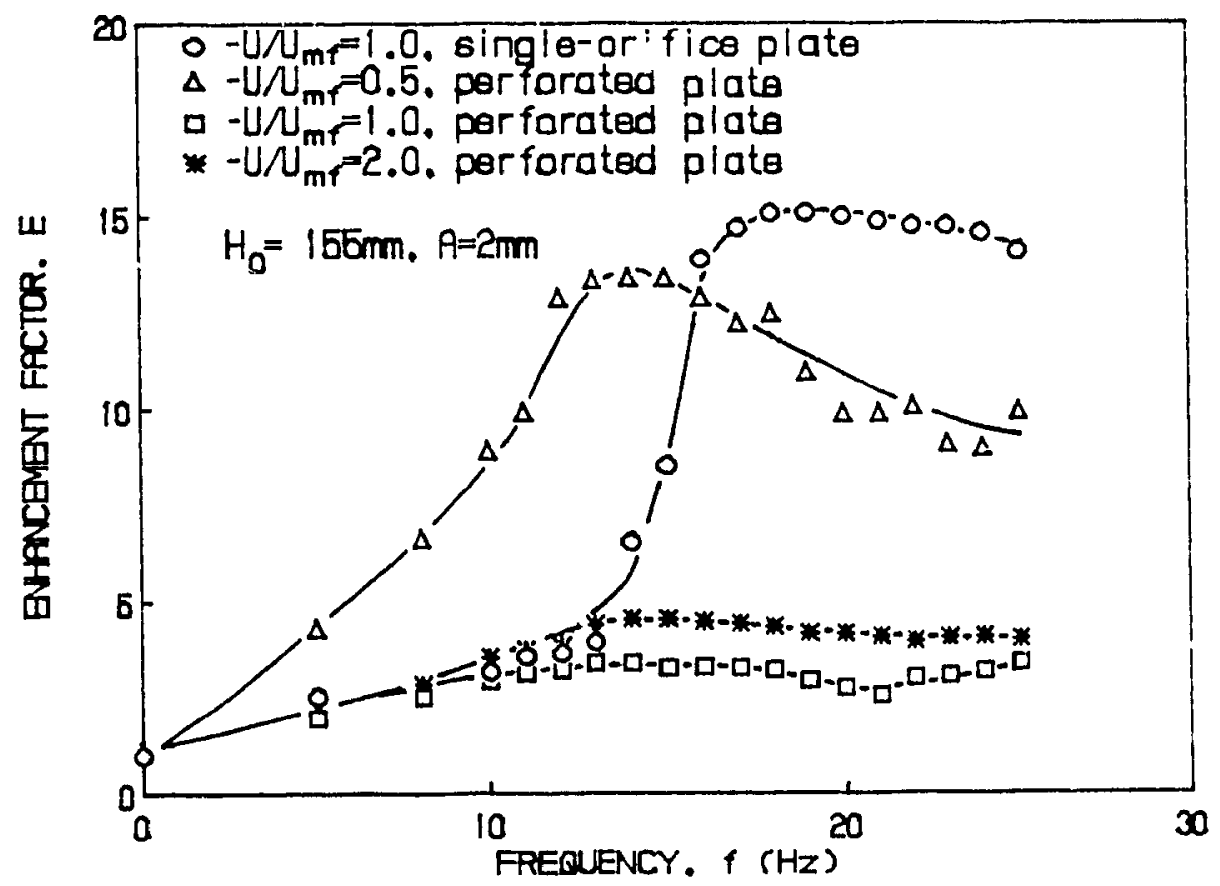

Figure 7.20 Variation of $\mathrm{E}$ with $\mathrm{f}$ for $100-\mu \mathrm{m}$ alumina particles in vibratted heds at different aeration rates and $\mathrm{H}_{0}=155 \mathrm{~mm}$. 
Table 7.3 Maximum heat transfer coefficients in vibrated beds in this and other studies.

\begin{tabular}{|c|c|c|c|c|c|c|c|c|}
\hline Researcher & $\begin{array}{l}\mathrm{d}_{\mathrm{p}} \\
(\mu \mathrm{m})\end{array}$ & $\begin{array}{l}A \\
(m n\end{array}$ & & $\begin{array}{l}\mathrm{f} \\
(\mathrm{Hz})\end{array}$ & K & $\begin{array}{c}\mathrm{h}_{\max } \\
\left(\mathrm{Wm}^{\cdot} \cdot \mathrm{K}^{\cdot 1}\right)\end{array}$ & $\begin{array}{c}k_{p} \\
\left(W m^{\prime} K^{\prime}\right)\end{array}$ & $\begin{array}{l}\alpha_{p} \\
\left(x 1^{s}\right) \\
\left(m^{2} s^{\prime}\right)\end{array}$ \\
\hline This study & 100 & 2 & 0 & 22 & 3.9 & 830 & 36 & 1.20 \\
\hline $\begin{array}{l}\text { Zabrodskii } \\
\text { et al. (1968) }\end{array}$ & 68 & 2 & 0 & 19 & 2.9 & 800 & - & - \\
\hline Thomas (1988) & 125 & $0.8-2.2$ & 0 & 25 & 5.4 & $300^{*}$ & 36 & 1.31 \\
\hline $\begin{array}{l}\text { Malhotra and } \\
\text { Mujumdar (1985b) }\end{array}$ & 1400 & 2.8 & 0 & 13 & 2.0 & 181 & 0.589 & 0.05 \\
\hline This study & 1400 & 2 & 0 & 16 & 2.0 & 185 & 0.589 & 0.05 \\
\hline $\begin{array}{l}\text { Malhotra and } \\
\text { Mujumdar (1987) }\end{array}$ & 325 & 4.3 & 0 & 11 & 2.0 & 462 & 0.837 & 0.05 \\
\hline $\begin{array}{l}\text { Pakowski and } \\
\text { Gora (1989) }\end{array}$ & 228 & 4.3 & 0 & 11 & 2.0 & 527 & 0.864 & 0.05 \\
\hline
\end{tabular}

* - highest value obtained 
basic shape. The shape of the $\mathrm{h}$ vs $\mathrm{K}$ curve has been attributed by the different researchers to the competing effects of particle motion and air gap formation around horizontal heating surfaces used in these studies. Similar processes occur with the beds of large particles used in this study. In fact, Figure 7.22 shows the dependence of $\mathrm{h}$ on $\mathrm{K}$ for $1.4-\mathrm{mm}$ molecular sieve particles used in this study and the work of Malhotra and Mujumdar (1985b). It is easily seen that except for $\mathrm{K}<1.5$, the experimental $\mathrm{h}$ values found were identical despite the differences in bed heights used. The parameter $\mathrm{K}$ appears to be an appropriate parameter to characterize the heat transfer behaviour for beds of large particles.

For small-particle beds that exhibit resonant behaviour the mechanisms are different. Figure 7.23 shows a plot of $h$ vs $K$ for beds of $68-\mu \mathrm{m}$ corundum particles obtained by Zabrodskii et al. (1968) and for the $100-\mu \mathrm{m}$ alumina particles used in this study. Not only are the shapes of the curves similar but for any $\mathrm{K}$ the actual values of $\mathrm{h}$ is of comparable magnitude. Note that the amplitude is the same in both calies and hence the variation in $\mathrm{K}$ is due solely to variation in f. Zabrodskii et al. (1968) did not mention resonant behaviour but it is expected that the particles they used exhibited resonance. In fact, for the bed height they used $\left(H_{0}=75 \mathrm{~mm}\right)$, h reached maximum values at $\mathrm{f}=20 \mathrm{~Hz}$ for $\mathrm{A}=1,2$ and $4 \mathrm{~mm}$ showing that there was a dependence on $f$ rather than on $K$. A comparison of this work with that of Zabrodskii et al. (1968) for beds of small particles shows that the results of this study are in accordance with those of other works. The $h$ vs $\mathrm{K}$ curve of Thomas (1988) was obtained by keeping $\mathrm{f}$ constant at $25 \mathrm{~Hz}$ and varying $\mathrm{A}$. This implies that the results are for $h$ as a function of $A$. Despite the fact that $h$ is a much stronger function of $f$ than of $A$ for small particles, the $h$ values Thomas (1988) obtained were 


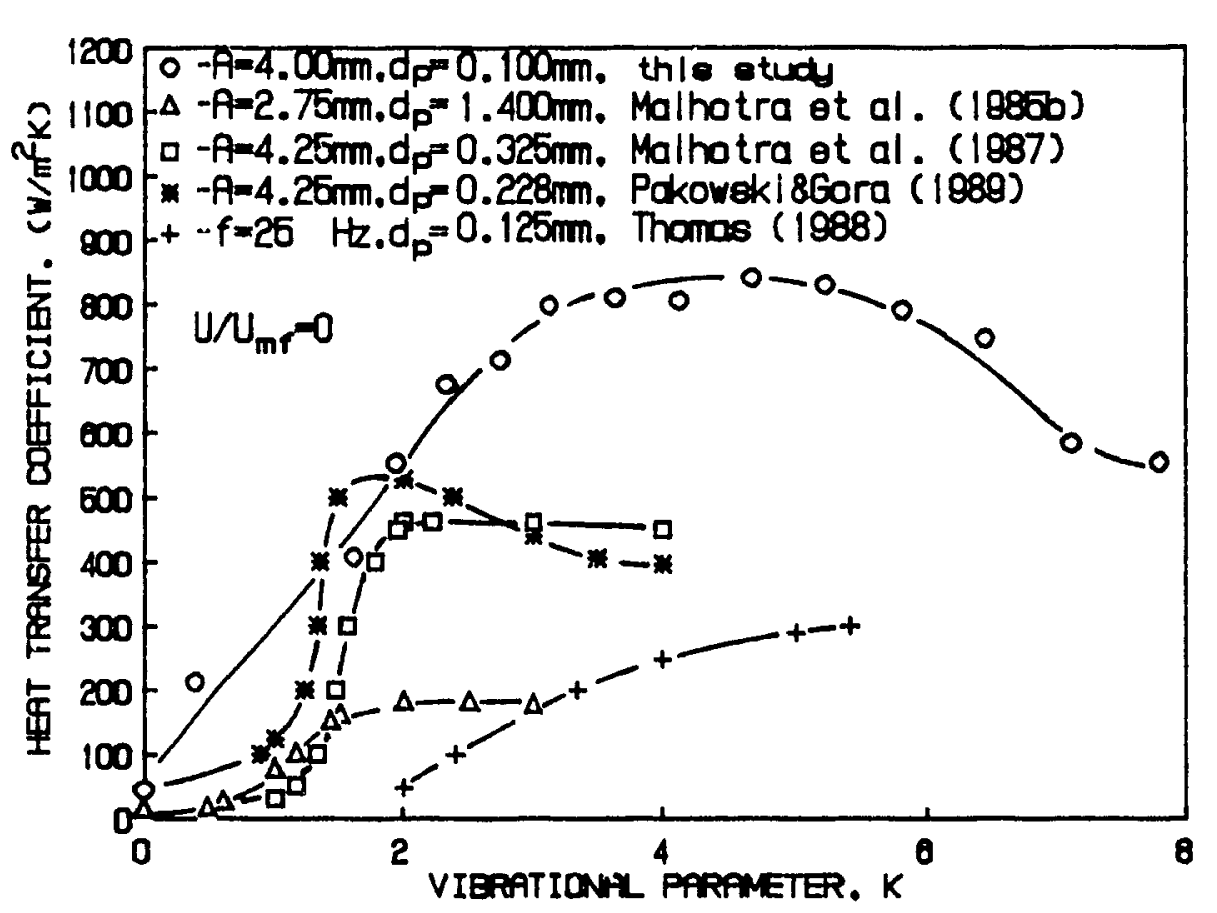

Figure 7.21 Variation of $\mathrm{h}$ with $\mathrm{K}$ reported by various researchers.

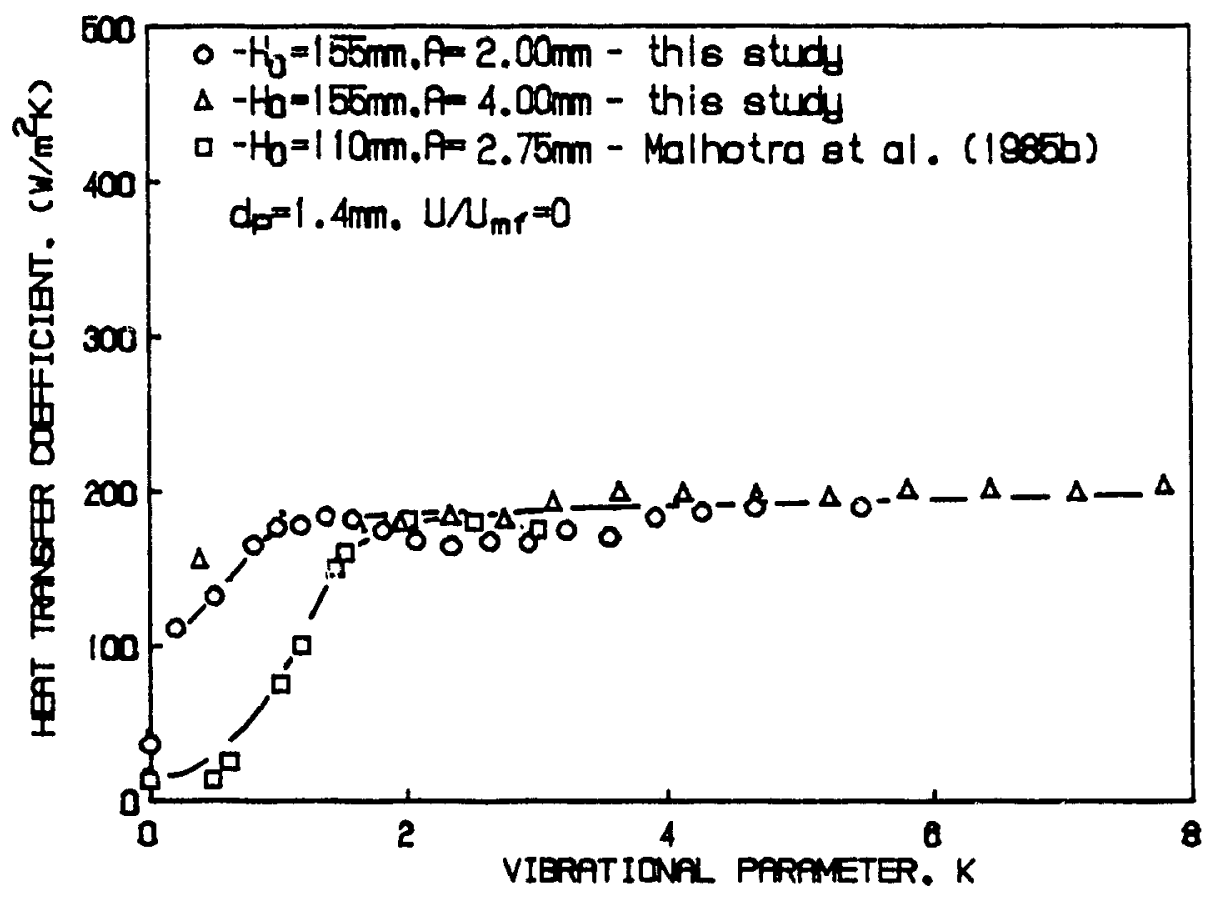

Figure 7.22 Comparison of the variation of $\mathrm{h}$ with $\mathrm{K}$ for $1.4-\mathrm{mm}$ molecular sieve particles for this study and previous work. 
much lower than expected. From the results of this study it is expected that, had he kept $A$ constant and varied $f$, he might have obtained higher heat transfer rates. Also, though $\mathrm{f}=25 \mathrm{~Hz}$ was the resonant frequency for the lower bed heights used in this study $\left(\mathrm{H}_{0} \sim 100 \mathrm{~mm}\right)$, it is expected that it was still below the resonant frequency for the shallow bed heights he used $\left(\mathrm{H}_{0}-40 \mathrm{~mm}\right)$. This supports the results of this study that $\mathrm{K}$ is an inapproprate parameter for characterizing contact heat transfer in beds of small particles.

\subsection{DATA CORRELATION}

It had been shown in previous chapters that small-particle beds behave differently from beds of large particles. In this study, a simplified theoretical formulation is presented to semi-quantitatively predict observed trends in heat transfer. The correlation of the data, including the theoretical formulation, is limited to heat transfer in small-particle beds and limited to operating conditions where resonant behaviour is displayed. Conclusions and contributions from this work are thus lımited to the parameter ranges stated here.

\subsubsection{Heat Transfer Mechanism: General Features}

Surface-to-bed heat transfer consists of three additive components: particle convective, particle conductive, and radiative heat transfer (Botterill (1975) and Muchowski (1983)). Radiative heat transfer is limited to high temperatures and hence is not applicable to this study. Higher rates of heat transfer between a bed and a surface are achieved when there is rapid exchange of material between the region directly adjacent to the heat transfer surface and the rest of the bed i.e. when the particle residence times close to the heat transfer surface are very short (Botterill 


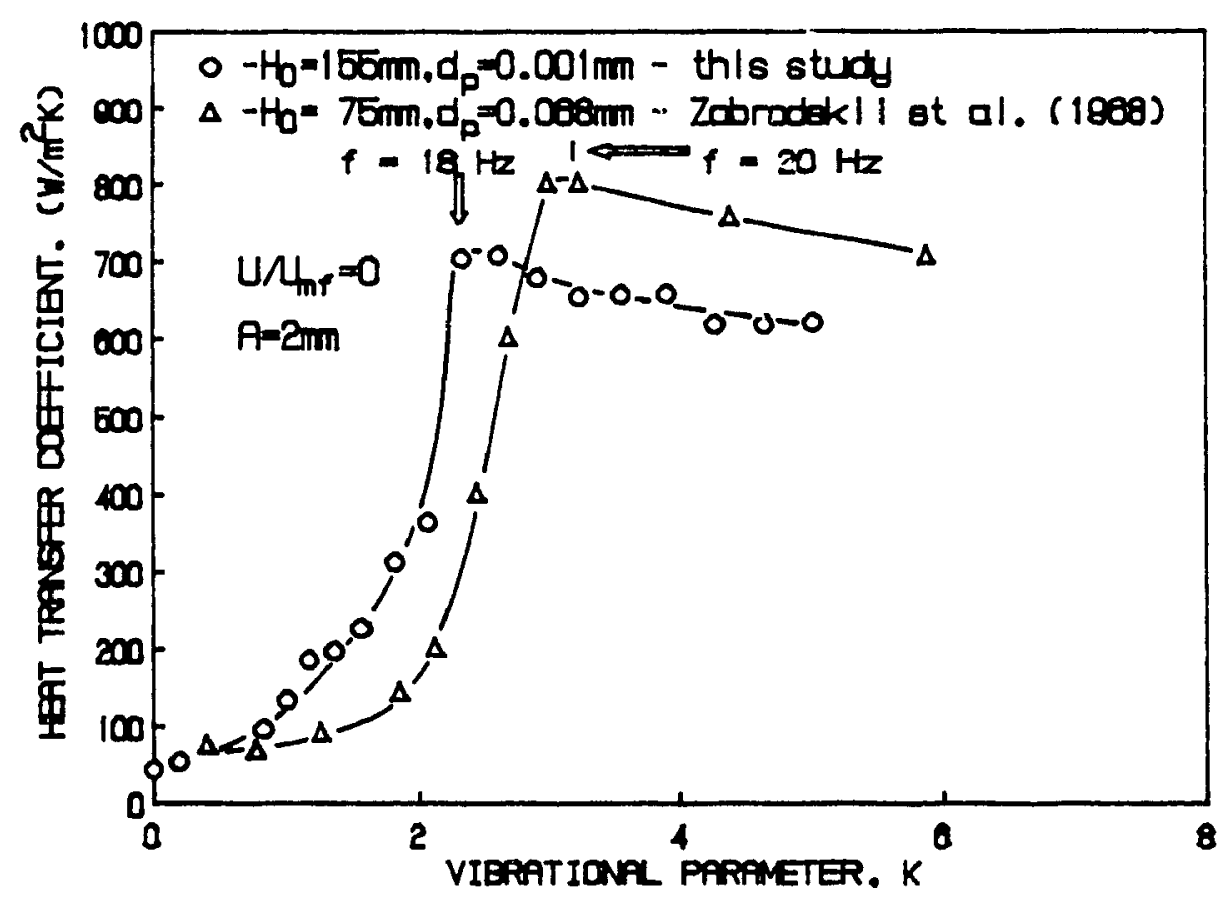

Figure 7.23 Comparison of the variation of $\mathrm{h}$ with $\mathrm{K}$ for small particles tor this study and previous work. 
(1975)). The high heat capacity of the particles and their mobility through the bed lead to enhanced heat transfer rates. Particle convective heat transfer consists of two basic mechanisms: (1) surface-to-particle heat transfer whereby heat is transferred to or from a surface and (2) heat convection by particle motion whereby the transterred heat is dissipated in the bed. These mechanisms have been discussed in detall by Gloski et al. (1984).

\subsubsection{Formulation of Problem}

\section{Assumptions}

The following are the assumptions of this analysis:

(a) parricle sizes are small $\left(\mathrm{d}_{\mathrm{p}}<250 \mu \mathrm{m}\right)$ and the bed exhibits distinct resonant behaviour.

(b) aeration rates dre low $\left(<2 \mathrm{U}_{\mathrm{m}}\right)$.

(c) gas convective heat transfer is negligible.

(d) the direct effect of surface coverage is neglected.

Because of the particle size and aeration rates to which the model is limited, the contribution of gas convective heat transfer should be negligible. In fact, it had been shown earlier in the chapter that contact heat transfer coefficients in aerated and non-aerated vibrated beds whıch exhibit resonant behaviour are almost identical. This implies that the contribution of gas convective heat transfer to the overall heal transfer may be neglected. Heat transfer rates will be assumed to be due to particle convection only. The neglect of surface coverage from the correlation may not at first sight appear to be a good assumption. It would be expected that very low particle surface coverages would greatly limit the heat transfer rate. This has not been found to be the case, however. Both air gap coverage and particle circulation 
increase with increasing $f$ to reach a maximum at $f=f_{r}$. This implies that the particle circulation rate is the rate controlling process in this case. Gas thermal conductivity does not seem to be a significant factor (Mujumdar and Pakowski (1984), Malhotra and Mujumdar (1987) and Pakowski and Gora (1989)).

\section{Development of the Correlation}

The heat transfer rate may be expressed as a function of the main variables that affect it:

$$
q=f_{1}\left[\rho_{p}, k_{p}, c_{p}, d_{p}, d_{c}, \Delta T, H_{0}, A, f, f_{r}\right] .
$$

A dimensional analysis with these variables leads to:

$$
\frac{h d_{p}}{k_{p}}-f_{1}\left[\left(\frac{f}{f_{r}}\right)\left(\frac{H_{0}}{d_{p}}\right),\left(\frac{A}{d_{p}}\right),\left(\frac{d_{c}}{d_{p}}\right),\left(\frac{\rho_{p} c_{p} d_{p}{ }^{2} f}{k_{p}}\right)\right] .
$$

Equation 7.6 may be rewritten as

$$
h-N f_{2}\left[\frac{f}{f_{r}}\right] f_{3}\left[\left(\frac{H_{0}}{d_{p}}\right)\left(\frac{A}{d_{p}}\right)\left(\frac{d_{c}}{d_{p}}\right)\right] f_{4}\left[\frac{k_{p}}{d_{p}} \frac{d_{p}{ }^{2} f}{\alpha_{p}}\right]
$$

where

$$
\alpha_{p}-\frac{k_{p}}{\rho_{p} c_{p}}
$$


is the particle thermal diffusivity and $\mathrm{N}$ is a constant.

Note that

$$
N u_{m}-\frac{h d_{p}}{k_{p}}
$$

is a modified Nusselt number, and

$$
F O_{m}=\left(\frac{\rho_{p} c_{p} d_{p}{ }^{2} f}{k_{p}}\right)-\left(\frac{d_{p}{ }^{2} f}{\alpha_{p}}\right)
$$

is a modified Fourier number representing the dimensionless frequency. Physically, the latter represents the ratio of heat transfer by particle convection to heat transport by conduction. The dimensional analysis shows that, as noted by Schlünder (1981), the rate of heat transfer in beds of mobile particles depends on the thermal characteristics of the bed as well as the intensity of particle motion which depencis on $F=f / f_{r}$. The heat transfer rate additionally depends on $A, d_{p}, H_{0}$, and $d_{l}$.

\section{Particle Mobility Theory}

The intensity of particle motion is referred to in this study as particle mobility Leading up to the resonant frequency $\left(f \leq f_{r}\right.$ ), particle mobllity increases due $\mathrm{t}$ ) resonant effects. Past the resonant frequency, particle mobility is due to bed dynamics having similar features to those at resonance and pre-resonance regıme. As the results have shown, the intensity of particle motion decreases gradually with increasing frequency beyond the resonant point. In describing surface-t()-bed healt transfer pre- and post-resonant behaviour must be described separately. 


\section{Pre-resonant Regime}

The function $\mathrm{f}_{2}$ represents particle mobility. Particle motion and the ability of the particles to transfer heat at the heat transfer surface is directly related to the resonance of the bed. Therefore, it is expected that a relation describing resonance will also describe particle mobility. Consequently, a theoretical expression describing resonance developed by Kreyszig (1979) to represent the response (including resonance) of a body to an applied sinusoidal forcing function is briefly prest nted. A modified expression is then used to represent particle mobility in a prelımınary fashion.

It may be assumed that the body responds to a forcing function described by:

$$
f(t)=F_{0} \cos (\omega t)
$$

The differential equation describing the system is given by Kreysig (1979) and Newland (1984) as:

$$
m y+c y+k y-F_{0} \cos (\omega t) .
$$

Since there is damping, the damping factor $c$ is greater than zero. From the theory of free oscillations it is known that the resonant frequency is given by (Kreyszig (1979)):

$$
\omega_{0}-\sqrt{k / m}
$$


The response to $f(t)$ may be represented by:

$$
Y(t)=C^{*} \cos (\omega t-\phi) .
$$

where $C^{*}$ is the amplitude of the response function and is represented by kievszig (1979) as:

$$
C^{*}(\omega)-\frac{F_{0}}{\sqrt{m^{2}\left(\omega_{0}^{2}-\omega^{2}\right)^{2}+\omega^{2} c^{2}}} .
$$

The maximum of $\mathrm{C}^{\circ}(\omega)$ can be determined by setting $d C^{*} / \mathrm{d} \omega$ to zero which gives:

$$
c^{2}=2 m^{2}\left(\omega_{0}^{2}-\omega^{2}\right) .
$$

For $c^{2}>2 m^{2} \omega_{n}{ }^{2}=2 m k$, this equation has no real solution (Krevszig (1979)) However, for $c^{2} \leq 2 \mathrm{mk}, C^{*}(\omega)$ has a maxımum at $\omega=\omega_{m \text { n }}$ which mcicises is decreases and approaches $\omega_{11}$ as $c$ approaches zero. Note that $C^{*} / F_{n}$ is the amplification (ratio of the amplitudes of outpla and input).

It is expected that particle mobility will have a similar dependence on trejuence as the dependence of the amplitude of the response of the bociy to which vibrallum in imparted. Equation 7.15 is therefore modified to represent partch: mobility tor th: aerated vibrated bed as a function of frequency by defimng an amplitucatum licton. $\mathrm{M}$, similar to that mentioned above.

$$
f_{2}-M-\frac{1}{\sqrt{\left(1-\left(f / f_{F}\right)^{2}\right)^{2}+c_{x}{ }^{2}\left(f / f_{f}\right)^{2}}} .
$$


The parameter $c_{x}=c / f_{r}$ is the damping factor. The mobility of the particles will depend on $\mathrm{c}_{\mathrm{x}}$. Determınation of damping was not attempted as it was considered beyond the scope of this work. However, from discussions in Chapter 4 , it is expected that the damping factor will depend on the amplitude of vibration, bed height and particle size. The damping factor may be used as an adjustable parameter in the correlation. The amplitication increases as $c_{x}$ approaches zero. The damping factor, $c_{y}$, will have to be titted empirically. Extensive experımental data are needed to determıne $c_{x}$ in a mort reliable manrer.

\section{Elfect of Amplitude. Bed Height Particle Size and Cylınder Diameter}

The function $f_{1}$ allows tor the adjustment of heat transter rates for $H_{11}, d_{1}, d_{l}$ and $A$. As the present results show, an increase in A results in augmentation of healt transter

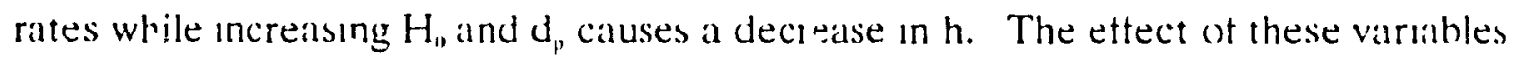
on the heat transter coetficient may be estimated from a qualitatıve and quantitative representation of the observed bed behaviour to tit the heat transfer data. In pievious works on heat transter in gas-flundized beds (Zabrodskii (1966)), the dependence of $h$ on $d_{p}$ gives an inverse relationship. However, for aerated vibrated beds, once the bed displays resonant behaviour, the parucle size is no longer a critical parameter. A small dependence of heat transter rates on particle size is then

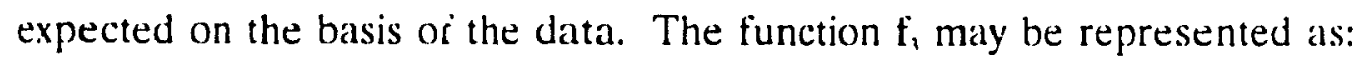

$$
f_{3}=\left[\left(\frac{H_{0}}{d_{p}}\right)^{a}\left(\frac{A}{d_{p}}\right)^{b}\left(\frac{d_{c}}{d_{p}}\right)^{d}\right] .
$$




\section{Heat Transfer Potential}

The function $f_{1}$ gives an expression referred to in this study as the heat trimsled potential. This is a function of the thermal properties of the particles in the hed and the applied frequency. A heat transfer mechanism involving unsteady-state conduction similar to that of Mickley and Fairbanks (1955) is believed to kepesent the heat transfer process. Supporting theory is available from the book of Carriliw and Jaegar (1959).

$$
f_{4}=\left(\frac{k_{p}}{d_{p}}\right]\left[\frac{\rho_{p} c_{p} d_{p}{ }^{2} f}{k_{p}}\right]^{e} \text {. }
$$

\section{$\underline{\text { Representation of Surface-to-Bed Heal Transter }}$}

For $\mathrm{f} \leq \mathrm{f}_{\mathrm{r}}$, surface-to-bed heat transfer in aerated vibrated beds of small pallukes $\left(\mathrm{d}_{\mathrm{p}}<250 \mu \mathrm{m}\right)$ may be represented by:

$$
h=\frac{\mathrm{Nf}_{3} f_{4}}{\sqrt{\left(1-\left(f / f_{r}\right)^{2}\right)^{2}+c_{x}{ }^{2}\left(f / f_{r}\right)^{2}}}
$$

The parameters $\mathrm{a}, \mathrm{b}, \mathrm{d}$ and $\mathrm{e}$ are obtained by a non-linear regresson analysis of the data at $h=h_{m x}$. The heat transfer coefficient is expected to be proportonal to the square root of $k_{p}, \rho_{p}$ and $c_{p}$ as proposed by Mickley and Farbanks (1955) tor their packet model. Based on this, the parameter $\mathrm{e}$ is taken to be 0.5 . The proposed equation for the heat transfer potential is:

$$
f_{4}=\left(\frac{k_{p}}{d_{p}}\right]\left[\frac{\rho_{p} c_{p} d_{p}^{2} f}{k_{p}}\right]^{1 / 2}=\left(k_{p} \rho_{p} c_{p}\right)^{1 / 2} f^{1 / 2}
$$


For alumina particles (Perry et al. (1984)),

$\mathrm{k}_{\mathrm{p}}=36 \mathrm{Wm}^{-1} \mathrm{~K}^{1}$

$\rho_{\mathrm{p}}=3840 \mathrm{kgm}^{3}$

$\mathrm{C}_{\mathrm{p}}=784 \mathrm{Jkg}^{1} \mathrm{~K}^{1}$

Then $\left(k_{p} \rho_{p} C_{p} f\right)^{12}=(36 \times 3840 \times 784 \times f)^{12}=10,409 \mathrm{f} \mathrm{Wm}^{-2} \mathrm{~K}^{-1}$.

The damping parameter $c_{x}$ is obtained from the regression as 0.15 to fit the data of this study. The exponents $\mathrm{a}, \mathrm{b}$ and $\mathrm{d}$ are found to be $-0.5,0.2$, and 0.4 respectively to fit the data while the constant $\mathrm{N}$ is found to be $6.3 \times 10^{\text {? }}$.

\section{Post-resonant Regime}

Based on the data, the variation of $h$ with frequency in the post-resonant regime is not a complicated function. Since the behaviour of the bed in this regime has features of resonance behaviour, a simple equation contaning an inverse square root relationship for $F$ and based on the maximum heat transter coetficient (at resonance). is used to represent heat transfer coefficients in the post-resonant regime.

$$
h=h_{\max }\left(\frac{f}{f_{r}}\right)^{-05} .
$$

The maximum heat transfer coefficient $h_{\max }$ is obtained from Equation 7.20 at $t=\mathrm{f}_{r}$.

\subsubsection{The Fit of the Correlation}

For $100-\mu \mathrm{m}$ alumina particles a comparison of the heat transfer coefficient dependence on $\mathrm{f} / \mathrm{f}_{r}$ obtaned experimentally and predicted by the correlation is shown in Figures 7.24 and 7.25. Figure 7.24 shows results for different $H_{0}$ values. The correlation is seen as fitting the data quite closely $( \pm 15 \%)$. Figure 7.25 shows 


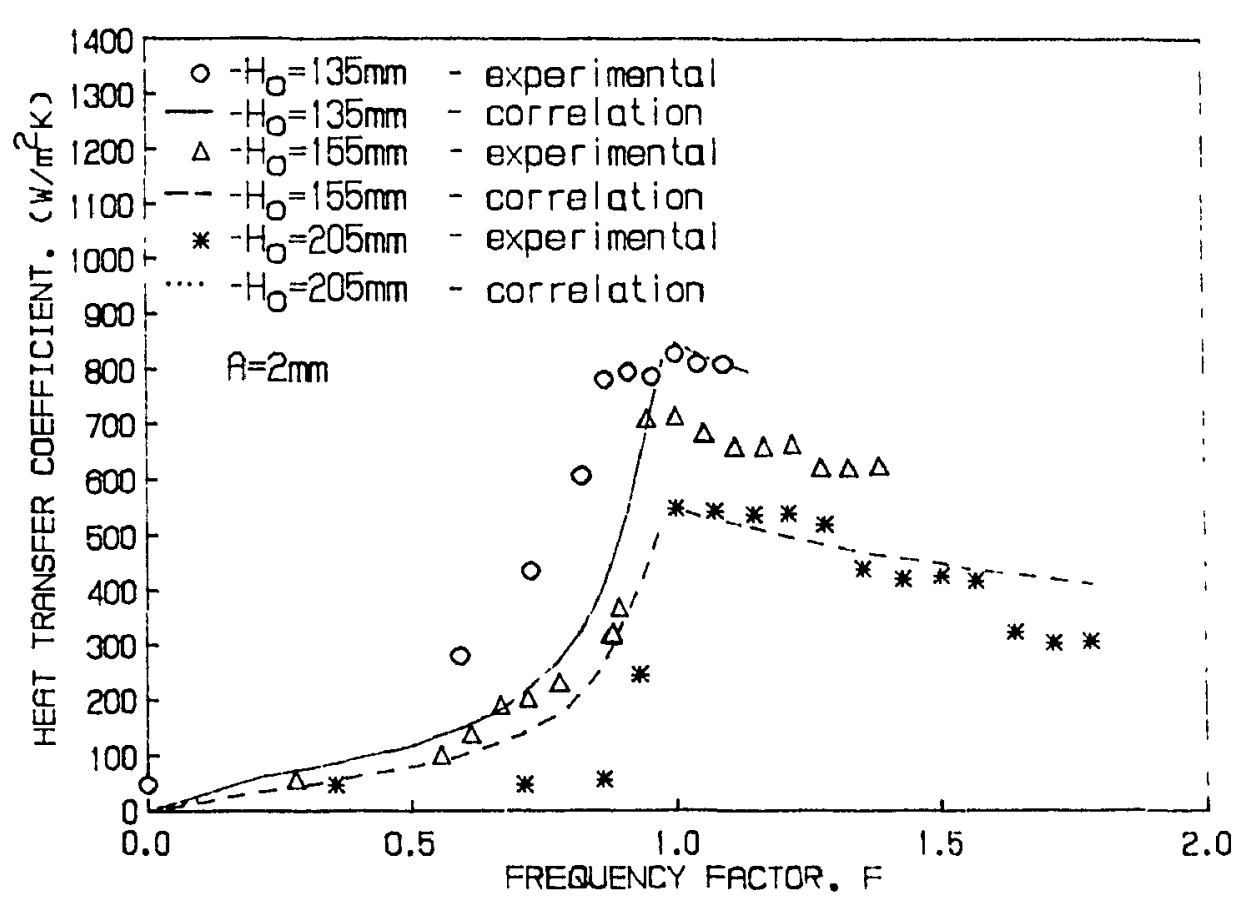

Figure 7.24 Comparison of experimental results with correlation predictions (1) $100-\mu \mathrm{m}$ alumina for different $\mathrm{H}_{0}$ values.

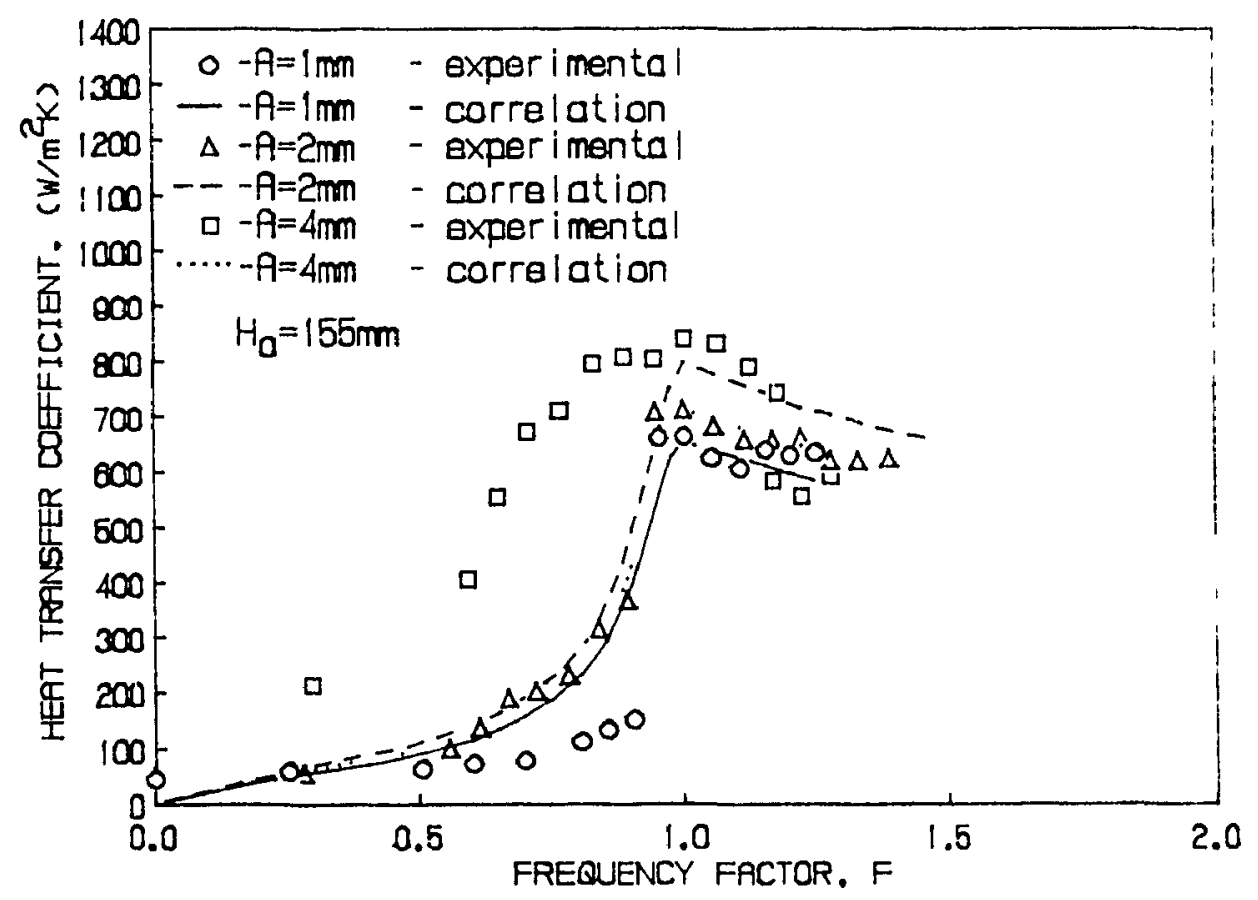

Figure 7.25 Comparison of experimental results with correlation predictions for $100-\mu \mathrm{m}$ alumina for different $\mathrm{A}$ values. 
results for different $A$ values. Again, reasonable fitting of the data is obtained. However, for $\mathrm{A}=4$ and $\mathrm{f}<\mathrm{f}_{\mathrm{r}}$, the prediction of the correlation is up to $200 \%$ oft the experimental value. Figure 7.26 shows the effect of particle size on the predictions of the correlation. Fair agreement with the experimental data is seen.

\subsubsection{Limitations of the Correlation}

The correlation is limited to beds of small particles that exhibit resonant behaviour. Since the correlation is based on $h_{\max }$, the fit of the data is very good at $f=t$. However, there is appreciable deviation of the predictions of the correlation from experımental data at lower $f / t_{r}$ values particularly for lower $H_{n}$ and higher $A$ values. This is because the damping factor $c_{x}$ changes under these conditions. The damping factor $c_{x}$, was kept constant in the correlation. The correlation may thus be improved by incorporating a dependence of $\mathrm{c}_{\mathrm{x}}$ on $\mathrm{A}$ and $\mathrm{H}_{0}$ into the correlation. This is beyond the scope of this work. Additionally, below $\mathrm{f}=\mathrm{f}_{\mathrm{r}}$, the heat transter coetticients in aerated vibrated beds is close (or relatively close) to the packed bed value and hence this area of operation is of no practical importance in the operations of vibrated beds. The correlation need not be compared to those for large particle beds due to the differences in heat transfer mechanisms discussed in Section 7.2.2.

\subsection{IMPLICATIONS FOR DESIGN}

The operation of vibrated beds under conditions of low aeration at or just above the resonant point $\left(1.1-1.4 \mathrm{f}_{\mathrm{r}}\right)$ otfers an attractive design alternative from the point of heat transfer. This type of operation is limited to beds of small particles. Particle mobility is most intense in the resonance-affected area. Resonant frequencies may be predicted from the bed helght using Equation 4.25. Particle mobility can be 


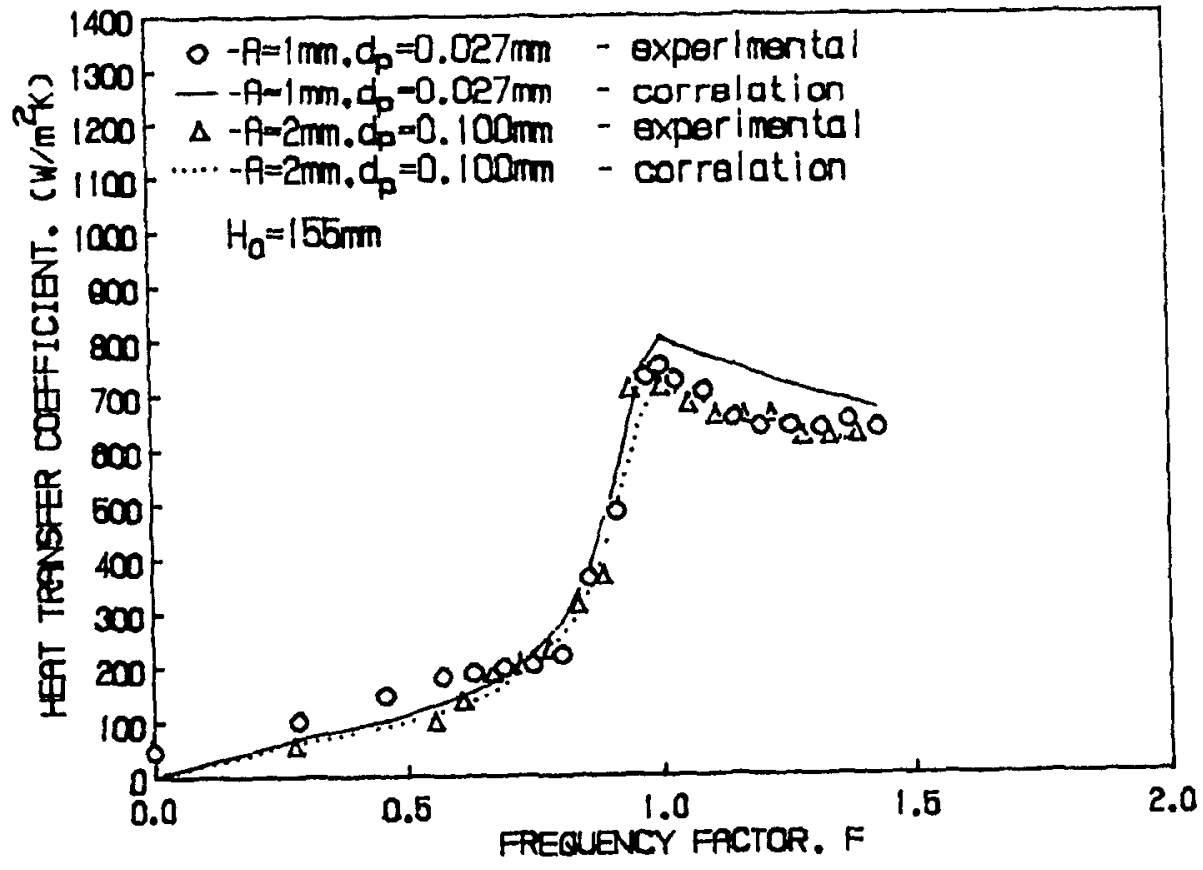

Figure 7.26 Comparison of experimental results with correlation predictions for different $d_{p}$ values. 
predicted from this resonant frequency. Heat transfer coefficients may then be predicted using the simple semi-empirical correlation developed in this study.

Beds of small particles which do not display resonant behaviour (possibly due to equipment design) may be operated at frequencies close to those for a resonating bed

of equal height. Maximum heat transfer rates may be determined as a fraction of that for the resonating bed. Large-particle beds may be designed on the basș of models and correlations existing in the literature (Malhotra and Mujumdar (1987), Pakowski and Gora (1989), etc.).

\subsection{CLOSURE}

Contact heat transfer coefficients show similar variation with frequency as particle mobility and hence circulation rates. For small-particle beds having bottom plates with low open areas, the contact heat transfer coefficient remans close to the packed bed value as the frequency is increased. Close to the resonant frequency, it increases rapidly to reach a maximum at the resonant frequency. Thereafter, $h$ decreases only gradually with further increase of frequency. The contact heat transter coefticients at resonance are much higher than those in packed beds (up to 19 times) and higher than those in vibrated fluidized beds (up to 1.2 times). In addition, heat transter coefficients increase with amplitude and decrease with increasing bed neight and particle size. Furthermore, they are also independent of the heater size and lateral position and only slightly dependent on the aeration rates within the parameter ranges used in these experiments. The high heat transfer rates are due to particle mobility which reaches a maximum at the resonant point. Surface coverage is greatly affected by both the resonant frequency and aeration rates. It affects the heat 
transfer rate but is not rate limiting even at low bed bulk densittes and surtalce particle coverage. A simple semi-empirical correlation is developed for comtact heilt transfer which is based on particle mobility on the basis of resonance predicted theoretically. It is found to correlate the data reasonably well over the range of parameters studied. 


\section{CHAPTER 8. CONCLUSIONS AND \\ CONTRIBUTIONS TO KNOWLEDGE}

\section{$8.1 \quad$ CONCLUSIONS}

This study is concerned with aerodynamics (including bed resonance), particle flow, bubble phenomena and cylinder-to-bed heat transfer in aerated vibrated beds of small particles $\left(d_{p}<250 \mu \mathrm{m}\right)$. Studies of aerated vibrated beds of large particles were conducted as needed to highlight the similarities and particularly the differences between these beds and those of small particles.

The following are the main conclusions of this thesis.

1 A resonant condition occurs in aerated beds of small particles $\left(d_{p}<250 \mu \mathrm{m}\right.$, but not larger particles) vibrated in vessels having a bottom plate of low open area. It is due to the propagation of pressure waves through compressibility of the bed and may be described by Equation 4.25.

2 With increasing vibration frequency, bubble size reaches a maximum, and bubble rise velocity and frequency reach minima at the resonant point. At resonance, bubble size is up to 200 times the size without vibration but bubble rise velocity and frequency are only about $30 \%$ of their value in the absence of vibration. For beds operated at $U_{m \text { ro }}$ the bubble frequency increases slightly but both bubble size and rise velocity remain invariant with increase in vibration frequency. 
3 In aerated vibrated beds of small particles, both the intensity of particle motion and the contact heat transfer coefficient increase with increasing frequency to reach a maximum at the resonant frequency. The intensity of particle motion may be semi-quantitatively predicted by a theoretical formulation of a bed at resonance and used to correlate cylinder-to-bed healt transfer coefficients. The latter increase with amplitude and decrease with increasing bed height and particle size and is only slighily dependent on aeration rates within the ranges used in these experiments. In resonatıng beds, these coefficients are much higher than those in packed beds (up to 19 tımes).

4 Vibration frequency rather than the vibration parameter is better for characterizing particle circulation and mixing as well as heat transter in aerated vibrated beds of small particles.

\subsection{CONTRIBUTIONS TO KNOWLEDGE}

1 A resonant condition occurring in small-particle aerated vibrated beds hals been studied for the first time and is shown to offer a viable design alternative for gas-solid contactors. A model is developed to predict the dependence of the resonant frequency on bed height.

2 Bubble phenomena in aerated beds have been studied for the first time. It is found that bubble size reaches a maximum while bubble rise velocity and bubble frequency reach minima at the resonant point. 
3 Particle motion in small-particle aerated vibrated beds has been studied and found to be most intense at or close to the resonant point.

4 Cylinder-to-bed heat transfer in resonating beds has been studied for the first time and a semi-empirical correlation is presented to predict surface-to-bed heat transfer coefficients.

5 Frequency rather than vibrational parameter, $\mathrm{K}$, has been found to be a better parameter for characterizing flow and heat transfer phenomena in smallparticle aerated vibrated beds. 


\section{REFERENCES}

1 Akiyama, T. and Naito, T., "Vibrated Beds of Powders: A New Mathematicill Formulation", Chem Eng. Sci., Vol. 42, No. 6, 1305-1311 (1987).

2 Akiyama, T., Naito, T. and Kann, T., "Vibrated Beds of Wet Particles", Powder Technology, Vol. 45, 215-222 (1986).

3 Arai, N. and Sugiyama, S., "Studies of Fluidization of Moist Parucles", J. Chem. Eng. of Japan, Vol. 7, No. 4, 247-251 (1974).

4 Bachmann, D., Verfahrenstechnik Z. Ver. dtsch. Ing. Beihett, No. 2, +3 (194(1).

5 Barry, B. A., "Errors in Practical Measurement in Science, Engineermb. and Technology", John Wiley and Sons, Inc., New York, (1978).

6 Botterill, J. S. M., "Flund Bed Heat Transter", Academic Press, Londun ( (975)

7 Botterill, J. S. M. and Willams, J. R., "Mechanısn of Healt Tramsted in (i.lsFluidized Beds", Trans. Inst. Chem. Engrs., Vol. 41, 217-231) (1963.3).

8 Bragg, G. M., "Principles of Experımentation and Measurement". PrenticeHall, Inc., New Jersey (1974).

9 Bretsznajder, S., Jaszczak, M. and Pasiuk, W., "Increasing the Ritte of Certiun Industrial Chemical Processes by the Use of Vibration", Int. Chem. Eng . V(ul 30, 496-502 (1963).

10 Buevich, Yu. A. and Galontsev, V. L., "Vibrational Fluidizatıon of a Shaillow Granular Bed", Inzh.-Fiz. Zh., Vol. 34, No. 3, 394-4(13 (1978).

11 Buevich, Yu. A., Ryzhkov, A. F. and Kharisova, N. M., "Imbtibutity of it Vibrational Fluidized Bed", Inzh.-Fiz. Zh., Vol. 37, No. 4. 626-63.34(1979)

12 Bukareva, M. F., Chlenov, V. A. and Mikhailov, N. V., "Investıgithen of Heall Transfer Between Heatıng Surtaces and a Vibrofluidized Bed", Int. ("hem. Eng., Vol. 9, No. 1 119-121 (1969).

13 Bukareva, M. F., Tatevosyan, D. A., Chlenov, V. A. and Mlikhallov, X. V.. Teoret. Osn Khım. Teknol., 1 (1974).

14 Carslaw, H. and Jaegar, J., "Heat Conduction in Solıds", $2{ }^{\text {nd }}$ Editıon. Clarendon Press, Oxford (1959). 
15 Cheremissinoff, N. P. and Cheremissinoff, P. N., "Hydrodynamics of Gas-Solid Fluidization", Gulf Publ. Co., Houston, London, Paris, Tokyo (1984).

16 Chlenov, V. A. and Mikhailov, N. V., "Some Properties of a Vibrating Fluidized Bed", J. of Eng. Phys., Vol. 9, 137-139 (1965).

17 Chlenov, V. A. and Mikhailov, N. V., "Vibrokypiaschy Sloi (Vibrofluidized Beds)", Nauka, Moscow, (1972).

18 Davidson, J. F. and Harrison, D., "Fluidized Particles", Cambridge University Press, London (1963).

19 De Martin, M., Paquette, F. and Spinelli, A., "Free Surface Dynamıcs of Longitudinally Excited Liquid Columns", Mechanical Engıneering Laboratory II, McGill University, Montreal, December (1988).

20 Dodge, F. T., Kana, D. D. and Abramson, H. N., "Liquid Surface Oscillations in Longitudinally Excited Rigid Cylindrical Containers", AIAA Journal, Vol. 3, No. 4, 685-695 (1965).

21 Eccles, E. R. A., Erdesz, K. and Mujumdar, A. S., "Resonance Phenomena in Aerated Vibrated Beds", in "Fluidization VI" - Proceedings of the Sixth Engineering Conference on Fluidization, Eds., Grace, J. R., ن̉ergougnou, M. and Shemilt, L. W., Engineering Foundation, New York, USA 219- 228 (1989).

22 Erdesz, K., Personal Communication (1990).

23 Erdesz, K. and Halasz, G., "Hydrodynamic Studies of Fluidized Beds IX. The Mechanically Analogous Model of Vibrofluidized Bed", Hung. J. Ind. Chem., Vol. 12, 441-450 (1984).

24 Erdesz, K. and Mujumdar, A. S., "Classification Method for Vibrated Fluidized Equipment for the Processing of Particulate Materials", Proceedings of Powder and Bulk Sclids Conference, Rosemount, IL, USA, May 11-14 (1987).

25 Erdesz, K. and Mujumdar, A. S., "Numerical Investigation of a Phenomenological Model for Vibrated Fluidized Beds", Drying Technology An International Journal, Vol. 7, No. 3, 487-502 (1989).

26 Erdesz, K. and Mujumdar, A. S., "Application of Vibration Techniques for Drying and Agglomeration in Food Processing", Drying Technology - An International Journal, Vol. 6, No. 2, 255-274 (1988).

27 Garrett, C. J. R.,"On Cross-Waves", J. Fluid Mech., Vol.41, Part 4, 837 (1970). 
28 Geldart, D., "Types of Gas Fluidization", Powder Technol., Vol. 7. 285-292 (1973).

29 Gelperin, N. I., Ainstein, V. G. and Kava, V. B., "Osznovileklinik1 psevdoozhizheniya (Fundamentals of Fluidizatıon Techniques)", in Russi:n. h. himia, Moscow (1967).

30 Gloski, D., Glicksman, L. and Decker, N., "Thermal Ressstance at a Surtace in Contact with Fludized Bed of Particles", Int. J. Heall Mass Transter, Vol. 27, No. 4, 599- 610 (1984).

31 Gray, W. A. and Rhodes, G: T., "Energy Transter during Vibuatory Compaction of Powders", Powder Technol., Vol. 6. 271 -281 (1972).

32 Gupta, R., "Aerodynamics and Drying Characteristics of a Vibrated Fludired Bed", M.Eng. Thesis, Dept. of Chem. Eng., McGill University, Montreil. Canada, (1979).

33 Gupta, R. and Mujumdar, A.S., "Aerodynamics of a Vibrated Fluid Bed". C.ın. J. of Chem. Eng., Vol. 58, 332-338 (1980).

34 Gutman, R. G. "Vibrated Beds of Powders". Ph.D. Dissertituon, Unversty of Cambridge, England (1974).

35 Gutman, R. G., "Vibrated Beds of Powders Part I: A Theoretical Model tor the Vibrated Bed", Trans. Inst. Chem. Engrs., Vol. 54. 174-185 (1976il).

36 Gutman, R. G., "Vibrated Beds of Powders: Part Il- Heat Transter in and Energy Dissipation of a Vibrated Bed". Trans. Inst. Chem. Engrs., Vol 54. 251-257 (1976b).

37 Harrison, D. and Leung, L. S., "Bubble Formation at an Oritice in a Fluklized Bed", Trans. Inst. Chem. Engrs., Vol. 39, 4199-41+(1961).

38 Harrison, D. and Leung, L. S., "The Rate of Rise of Bubbles in Fludized Beds", Trans. Inst. Chem. Engrs., Vol. 40, 146 (1962).

39 Hashimoto, H. and Sudo, S. "Dynamic Behaviour of a Liquid Free Surtace in a Cylindrical Contaner Subject to Vertical Vibratoon". JS.ME Int. Journil. Vol. 27, No. 227, 923-930 (1984).

Hashimoto, H. and Sudo, S., "Frequency Characteristacs of a Bubble Clustel in a Vibrated Liquad Column", J. Spacecraft and Rockets, Vol. 22. No o. 649-655 (1985). 
41 Hashimoto, H. and Sudo, S., "Drop Formation Mechanism in a Vertically Vibrated Liquid Column", AIAA Journal, Vol. 25, No. 5, 727-732 (1987).

42 Hashimoto, H. and Sudo, S., "Violent Liquid Sloshing Vertically Excited Cylindrical Containers", Expt. Th. and Fluid Sci., Vol. 1, 159-169 (1988).

43 Hiby, J. W., "Periodic Phenomena Connected with Gas-Solid Fluidization", Proceedings of the International Symposium on Fluidization, Ed., Drinkenburg, A. A. H., Netherlands University Press - Amsterdam, 99-110 (1967).

44 Jackson, R., "The Mechanics of Fluidized Beds. Part 1. The Stability of the State of Uniform Fluidization ", Trans. inst. Chem. Engrs. Vol. 41, 13-21 (1963a).

45 Jackson, R., "The Mechanics of Fluidized Beds. Part 2. The Motion of Fully Developed Bubbles", Trans. Inst. Chem. Engrs. Vol. 41, 22-28 (1963b).

46 Kal'tman, I. I. and Tamarin, A. I., "Investigating the Transfer of Heat between a Vibration-Fluidized Bed of Disperse Material and a Body that is Beın's Cooled within this Material", Inzh. Fiz. Zh., Vol. 16, No. 4, 630-638 (1969).

47 Kapustin, E. A., Prosvimin, V. I. and Butorina, I. V. Teor. Osmy. Khim. Tekh., Vol. 14, 720 (1980).

48 Kavetskii, G. D. Nikonov, L. V., Kartechin, N. G., Krohlin, N. G. and Kosheleva, M. K., "Aerodynamics of Flow in Vibro-Aero Fluıdized Bed", Chem. Tech. of Fuel and Oils, Vol. 11, 717-721 (1975).

49 Klıne, S. J. and McClintock, F. A. "Describing Uncertainties in Single Sample Experıments", Mechanical Engineering, 75 (1953).

50 Kobayashi, M., Ph.D Thesis, Northwestern University, Evanston, Illinois (1969).

51 Kossenko, G. D., Reshetnikov, E. G., Syromyatnikov, N. I. and Sapozhnikov, B. G., "Model Studies of Tube-to-Bed Heat Transfer in Vibro-fluidized Bed", Inst. Fuel Symp. Series No. 1: Fluidized Combustion, Vol. 1, B 4-1 (1975).

52 Kreyszig, E. "Advanced Engineering Mathematics", $4^{\text {th }}$ Edition, John Wiley and Sons, New York, (1979). 
53 Kröll, W., "Uber das Verhalten von Schuilgut in lotretch schwingenden Gefassen", Forsh. auf. dem. Gebiate des Ingenieur, Vol. 20. No. 1. 2-10 (195.t).

54 Kröll, W., "Flıesserscheınungen an Haufwerken in Schwingenden Gattassen". Chernie-Ing-Techn., Vol 27, No. 1, 33-38 (1955).

55 Kuni, D. and Levenspiel, O., "Fluidization Engineerıng", Wıley, (198-1).

56 Kunii, D. Yoshida, K, and Hiraki, I., "The Behaviour of Freely Bubllung Fluidized Beds", Proceedings of the International Symposium on Flukdzittun. Ed., Drinkenburg, A. A. H., Netherlands University Press - Amsterdim. 24.3254 (1967).

57 Kwamya, J. M. Eng. B. Report, McGill University, Montreal, Canadlal (19St)

58 Levenspiel, O. and Walton, J. S.. "Bed-Wall Heat Transter in Flundized Systems", Chem. Eng. Prog. Symp. Series, Vol. 50, No. 9. 1-13 (1954).

59 Lozada, R., M.Eng. B. Report, McGill University, Montreal, Canada (1985).

60 Malhotra, K., Law, R. L. K. C. and Mujumdar, A. S., "Picssule [D!op" Characteristics tor Vibrated Beds of Dry and Sticky Particles". Powidel Technology, Vol. 39, 101-104 (1984).

61 Malhotra, K. and Mujumdar, A. S., "Immersed-Surtace Heat Tiamster in ، Vibrated Fluıdized Bed", Ind. Eng. Chem. Res., Vol. 26. No. 1(1, 1983-194)? (1987).

62 Malhotra, K. and Mujumdar, A.S., "Flow Patterns for Cylinders Immersed in an Aerated Vibrated Bed", Can. J. Chem. Eng., Vol. 63. 22-28 (1985i1).

63 Malhotra, K. and Mujumdar, A.S., "Single Tube Heilt Transter in Aerilted Vibrated Beds", in "Drying '85", Ed., Mujumdar, A. S.. Hemosphese Publismg Corporation 186-194 (1985b).

64 Meirovitch, L., "Elements of Vibrational Analysis", McGraw Hill, New York (1975).

65 Mickley, H. S. and Farbanks, D. F., "Mechanısm of Healt Tramstet to Fluidized Beds", AIChE J., Vol. 1, 374 (1955).

66 Mickley, H. S. and Trillıng, C. A., "Heat Transfer Charactersstıcs of Fludized Beds", Ind. Eng. Chem., Vol. 41, No.6, 1135-1147 (1949). 
67 Miksis, M. J. and Ting, L., "Wave Propagation in a Bubbly Liquid with FiniteAmplitude Asymetric Bubble Oscillations", Phys. Fluids, Vol. 29, No. 3, 603618 (1986).

68 Miksis, M. J. and Ting, L., "Viscous Effects on Wave Propagation in a Bubbly Liquid", Phys. Fluids, Vol. 30, No. 6, 1683-1689 (1987).

69 Molerus, O., "Hydrodynamic Stability and Stabilization of the Fluidized Bed by Means of Forced Vibrations of the Flsid", Proceedings of the International Symposium on Fluidization, Ed., Drinkenburg, A. A. H., Netherlands University Press - Amsterdam, 144-153 (1967).

70) Muchowski, E., "Heat Transfer from Heated Surtaces to Spherical Packings of Spheres at Atmospheric Pressure and under Vacuurn", Int. Chem. Eng.. Vol. 20, No. 4, 564-576 (1980).

71 Muchowski, E. and Mannchen, E., "Heat Transfer from the Bottoms of Vibrated Vessels to Stirred Packings of Spheres at Atmospheric Pressure and Under Vacuum", Int. Chem. Eng., Vol. 20, No. 4, 577-582 (1980).

72 Mujumdar, A. S., "Aerodynamics, Heat Transfer and Dryıng in Vibrated Flud Beds", Rev. Latinoam Transt. Cal. Mat., Lat. Am. J. Heat Mass T ranster, No. 7, 99-110 (1983).

73 Mujumdar, A. S., "Vibrated Fluidized Beds as Chemical Reactors", in "Frontiers of Chemical Reaction Engineering", Vol. 2, Eds., L. K. Doraiswamy and R. A. Mashelkar, Wiley, New Delhi/New York, (1984).

74 Mujumdar, A. S. and Erdesz, K., "Application of Vibration Techniques for Drying and Agglomeration in Food Processing", Drying Technology - An International Journal, Vol. 6, No. 2, 255-274 (1988).

75 Mujumdar, A. S., and Pakowskı, Z., "Heat Transter in Vibrated Fludd Beds Basic Principles and Design Considerations", Multi-Phase Flow and Heat Transfer III. Part B: Applications, Eds., Veziroglu, T. N. and Bergles, A. E., Elsevier, Amsterdam, 441-452 (1984).

76 Murray, J. D., "On Mathematics of Fluidization. Part I. Fundamental Equations and Wave Propagation", J. Fluid Mech., Vol. 21, 465 (1965).

77 Myklestad. N. O., "Fundamentals of Vibration Analysis". McGraw Hill, New York, Toronto (1956). 
78 Newland, D. E., "An Introduction to Random Vibration and Spectral Analysis", $2^{\text {nd }}$ Ed., Longman, London (1984).

79 Nguyen, X. T. and Leung, L. S., "A Note on Bubble Formation at an Orifice in a Fluidized Bed", Chem. Engng. Sci, Vol. 27, 1748-1750 (1972).

80 Ockendon, J. R. and Ockendon, H., "Resonant Surface Waves", J. Fluid Mech., Vol. 59, Part 2, 397-413 (1973).

81 Osinskii, V. P., Sazhin, B. S. and Chuvpilo, E. A., "Results of Tests on a Dryer with a Vibrated Fluidized Bed", Chem. and Petrol. Engg., Vol. 11, 866-869 (1969).

82 Perry, R. H., Green, D. W. and Maloney, J. O., "Perry's Chemical Engineers' Handbook", Sixth Edition, McGraw Hill, New York (1984).

83 Pakowski, Z. and Gora, L., "The Mechanism of Heat Transter between Vibrofluidized Bed and Immersed Horizontal Heater", Proceedings of the $5^{\text {th }}$ CAC, Vol. 1, 353-358 (1989).

84 Pakowski, Z. and Mujumdar, A.S., "Heat Transfer From a Horizontal Cylinder to a Vibrated Bed of Wet Particles", Presented at the Third Drying Symposium, Birmingham, (1982).

85 Pakowski, Z., Mujumdar, A. S. and Strumillo, C., "Theory and Application of Vibrated Bed and Vibrated Fluid Bed for Drying Process", in "Advances in Drying", Ed., Mujumdar, A. S., Vol. 3, Hemisphere/Springer-Verlag, 245-306 (1984).

86 Pavlichenko, A. V., Ryzhkov, A. F., Putrik, B. A., Moiseyeva, T. A., "Vytor rezhima vibrobunkerovki melkodispernikh othodov AES (Selecticn of Vibroregimes for Discharge of Particles from Bins on NPS (Nuclear Power Stations)", in Tepchofizika yadernikh energeticheskikh ustanovok, Ukrahsky Polytechnical Institute (UPI) Sverdlovsk, 68-75 (1984).

87 Ringer, D. U., "Calculation of Heat Transfer in Vibrating Conveyors", in "Drying '80", Vol. 2: Proceedings of the Second International Symposium, Ed., Mujumdar, A. S., Hemisphere Publishing Corp, Washington, 144-151 (1980).

88 Ringer, D. U. and Mujumdar, A. S., "Flow and Immersed Surface Heat Transfer in a Vibro-fluidized Bed", in "Drying '82", Ed., Mujumdar, A. S., Hemisphere/McGraw Hill, New York, 67.73 (1982). 
89 Ringer, D. U. and Mujumdar, A. S., "Analysis of Aerodynamics and Heat Transfer in Vibrofluidized Beds", Drying Technology-An International Journal, Vol. 2, No. 4, 449-470 (1984).

90 Rowe, P. N., "Experimental Properties of Bubbles", in "Fluidization", Eds., Davidson, J. F. and Harrison, D., Academic Press, London 121-191 (1971).

91 Ryzhkov, A. F., and Baskakov, A. P., "Equations of Motion of the Material in a Shaker", Inzh. Fiz. Zhurnal, Vol. 27, No. 1, 15 (1974).

92 Ryzhkov, A. F., Baskakov, A. P. and Munts, V. A., "Heat Transfer from a Hot Surface to a Vibrated Fluidized Bed", Heat Transfer - Soviet Research, Vol. 8 , No. 5, 136 (1976).

93 Ryzhkov, A. F. and Putric, B. A., "Dynamitcheskiye svoitva ryhlovo zermistovo sloya (Dynamic Features of a Loose Bed of Particles)", Inzh. Fiz. Zhurnal, Vol. 52, 795-802 (1987).

94 Ryzhkov, A. F. and Tolmachov, E. M., "o vybore optimalnoy visoty vibrozhizhennovo sloya (Selection of Optimal Height of a Vibrofluidized Bed)", Theo. Osn. Fizh. Khim., Vol. 17, No. 2, 206-213 (1983).

95 Schlünder, E. U., "Heat Transfer Between Packed, Agitated and Fluidized Beds and Submerged Surfaces", Chem. Eng. Commun., Vol. 9, 273-302 (1981).

96 Sprung, R., "Studies in Vibrofluidized Beds and Synthesis of Silica Catalysts", Ph.D. Dissertation, Virginia Polytechnic Institute and State University, Blacksburg, Virginia, USA (1987).

97 Strumillo, C. and Pakowski, Z., "Drying of Granular Products in Vibrofluidized Beds", in "Drying '80", Vol. I, Ed., Mujumdar, A. S., Hemisphere Publishing Corporation, New York, 211-226 (1980).

98 Sudo, S. and Hashimoto, H., "Unsteady Pressure Response of a Liquid in a Cylindrical Container Subject to Vertical Vibration", JSME Int. Journal, Series II, Vol. 31, No. 2, 227-233 (1988).

99 Suzuki, K., Hosaka, H., Yamazaki, R. and Jimbro, G., "Drying Characteristics of Particles in a Constant Rate Drying Period in Vibrofluidized Bed", J. Chem. Eng. of Japan, Vol. 13, No. 2, 117-122 (1980a).

100 Takahashi, H., Suzuki, A, and Tanaka, T., "Behaviour of a Particulate Bed in the Field of Vibration I. Analysis of particle motion in a vibrated vessel" Powder Technol., Vol. 2, 65-71 (1968-69). 
101 Tamarin, A. I. and Kal'tman, I. I., "The Effective Thermal Diffusivity of a Bed Fluidized by Vibration", J. Eng. Physics, Vol. 20, 197-201 (1971).

102 Thomas, B., "Shallow Vibrated Particulate Beds - Bed Dynamics and Heilt Transfer", Ph.D. Dissertation, Virginia Polytechnic Institute and State University, Blacksburg, Virginia, USA (1988).

103 Thomas, B. Liu., Y. A., Chan, R. and Squires, A. M., "A Method of Observating Phase Dependent Phenomena in Cyclic Systems: Application to Study of Dynamics of Vibrated Beds of Granular Solids", Powder Technol., Vol. 52, 77-92 (1987b).

104 Thomas, B., Mason, M. O., Liu., Y. A., and Squires, A. M., "Mapping the 'States' of a Vibrated Bed", AIChE Annual Meeting: Symposium on Fundamentals of Fluidization and Fluid-Particle Systems, New York, New York, USA November 15- 20 (1987a).

105 Thomas, B., Sprung, R., Liu., Y. A., and Squires, A. M., "Heat Transfer from a Heated Tube in Shallow Vibrated Beds", Manuscript No. 4497, AIChE National Meeting, Miami, Florida November 1986.

106 Thomas, B. and Squires, A. M., "Vibrated-Bed Microreactors Simulating Catalytic Fluid Beds: A Feasibility Study", in "Fluidization VI" - Proceedings of the Sixth Engineering Conference on Fluidization, Eds., Grace, J. R., Bergougnou, M. and Shemilt, L. W., Engineering Foundation, New York, USA 375-382 (1989).

107 Uhl, V. W. and Gray, J. B., "Mixing: Theory and Practice", Volume 2, Academic Press, New York (1967).

108 Ur'ev, N. B., Kolloid. Zh., Vol. 40, 915 (1978).

109 Ursell, F., "Edge Waves on a Sloping Beach", Proc. R. Soc. Lond. Vol. 214A, 79-97 (1952).

110 van Deemter, J. J., "Instabilities", Proceedings of the International Symposium on Fluidization, Ed., Drinkenburg, A. A. H., Netherlands University Press Amsterdam, 91-98 (1967).

111 Vernon, J. B., "Linear Vibration Theory", John Wiley and Sons, Inc., New York (1967).

112 Vinogradov, E. L., Makar'ev, M. A., Ur'ev, N. B. and Yamschikov, V. M., Kolloid. Kh., Vol. 42, 1170 (1980). 
113 Wallis, G. B., "A Simplified One-Dimensional Representation of TwoComponent Vertical Flow and its Application to Batch Sedimentation", in Symposium on the Interaction between Fluids and Particles, Ed., Rottenburg, Institution of Chemical Engineers, London, 9 (1962).

114 Wallis, G. B., "One-Dimensional Two-Phase Flow", McGraw Hill, Inc., New York (1969).

115 Yagi, S., and Kunii, D., "Studies of Effective Thermal Conductivities in Packed Beds", AIChE J., Vol. 3, No. 3, 373-381 (1957).

116 Yamazaki, R., Kanagawa, Y., and Jimbo, G., "Heat Transfer in Vibrofluidized Bed - Effect of Pulsated Gas Flow", J. Chem. Eng. of Japan, Vol. 7, No. 5, 373-378 (1974).

117 Yoshida, T. and Kousaka, Y., "Flow of Granular Solids through a Vibrating Orifice", Int. Chem. Eng., Vol. 9, No. 1, 177-180 (1969).

118 Yoshida, K., Kunii, D. and Levenspiel, O., "Heat Transfer Mechanism Between Wall Surface and Fluidized Bed", Int. J. Heat and Mass Transfer, Vol. 12, 529-536 (1969).

119 Zabrodskii, S. S., "Hydrodynamics and Heat Transfer in Fluidized Beds", M.I.T. Press, Cambridge, Massachusetts. (1966).

120 Zabrodskii, S. S., Zamnius, I. L., Malyukovich, S. A. and Tamarin, A. I., "The Transfer of Heat from a Finely Dispersed Material Fluidized by a Stream of Gas or Through Application of Vibrations", J. Eng. Physics, Vol. 14, 235-238 (1968).

121 Zaitsev, E. D., Redekop, V. V. and Sheustov, Pharm. Chem. Journal, Vol. 11, 35 (1976).

122 Zenz, F. A., "Fluidization Phenomena and Fluidized Bed Technology", in "Handbook of Powder Science and Technology", Eds., Fayed, M. E. and Otten, L., Van Reinhold Co., New York, 464-506 (1983).

123 Zhang, X.-R., Homsy, G. M. and Ropchan, W. T., "Bubble Formation in a Single-Jet Gas-Solid Fluidized Bed", Int. J. Multiphase Flow, Vol. 13, No. 5, 649-660 (1987). 